\title{
SPENT FUEL RECEIPT SCENARIOS STUDY
}

\author{
L. B. Ballou \\ D.N. Montan (Consultant) \\ M. A. Revelli
}

September 1990

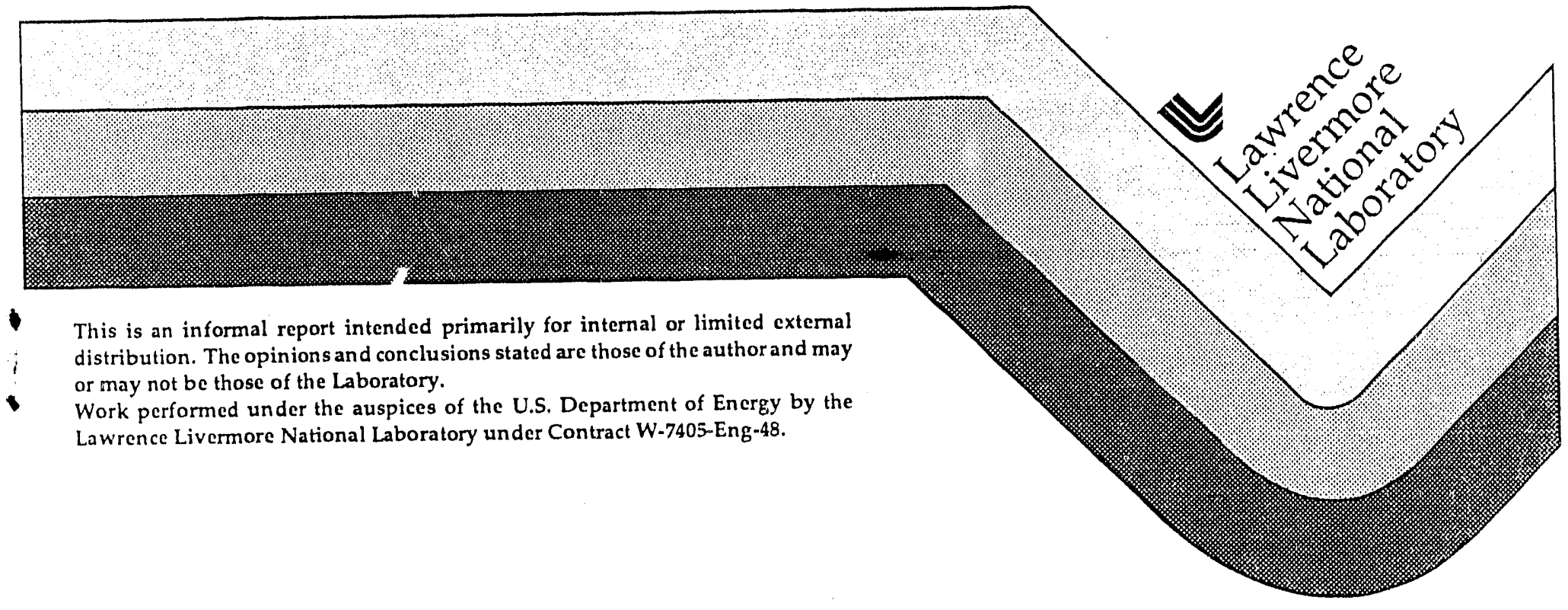


This document was prepared as an account of work sponsored by an agency of the United States Government. Neither the United States Government nor the University of California nor any of their employees, makes any warranty, express or implied, or assumes any legal liability or responsibility for the accuracy, completeness, or usefulness of any information, apparatus, product, or process disclosed, or represents that its use would not infringe privately owned rights. Reference herein to any specific commercial products, process, or service by trade name, trademark, manufacturer, or otherwise, does not necessarily constitute or imply its endorsement, recommenidation, or favoring by the United States Government or the University of Callfornia. The views and opinions of authors expressed herein do not necessarily state or reflect those of the United States Government or the University of California, and shall not be used for advertising or product endorsement purposes.

This report has been reproduced ditectly form the best avallable copy.

Available to DOE and DOE contractors from the Office of brientific and Technical Information P.O. Box 62. Gak Ridge, TN 37831

Prices available from 1615157608401 , FTS b26-8401.

Avallable to the public from the National Technical information Service U.S. Department of Commerce 5285 l'ort Royal Rd., Springfield, VA 22161

Price

Code

A01

\section{Papercopy Prices}

A02

$\mathrm{A03}$

A04

A05

A06

A07

A08

A09

A10

A11

A 12

A13

A. 14

A15

A16

A17

A18

A 19

A 20

A21

A 22

A23

A 24

A 25

A99
Page

Range

Microfiche
1- 10
11- 50
51- 75
76-100
101-125
126-150
151-175
176-200
201-225
226-250
251-275
276-300
301-325
326-350
351-375
376-400
401-425
426-450
451-475
476-500
501-525
526-550
551-575
576-600

601 \& UP

Prepared by Yucca Mountain Project (YMP) participants as part of the Civilian Radioactive Waste Management Program. The Yucca Mountain Project is managed by the Yucca Mountain Project Office of the U.S. Department of Energy, Las Vegas, Nevada. 


\section{SUMMARY}

This study supports an OCRWM investigation of the options available to the DOE and the nuclear utilities for selection of spent fuel for accertance into the Federal Waste Management System for disposal. It identifies several possible spent fuel receipt scenarios and analyzes the nearfield thermal effects in a simulated Yucca Mt. repository that would result from emplacement of spent fuel and DHLW on schedules that are determined by the scenarios.

Three receipt scenarios are developed. They are designed to accept different portions of the spent fuel inventory, consistent with the acceptance schedule in the 1988 Mission Plan Amendment (DOE, 1988a). They specify the spent fuel discharge year (age) and burnup (GWD/MTU) characteristics by reactor type (BWR and PWR) as a function of receipt year. The first scenario implements the Oldest Fuel First concept that is the primary basis for allocation of acceptance priority in the standard contracts between DOE and the spert fuel generators (10 CFR 961, 1983). The other two scenarios employ a strategy that results in receipts with the characteristic of uniform integrated energy deposition of the spent fuel and co-emplaced DHLW over the repository operational period.

The siudy is constrained by a specific set of assumplions, including disposal of intact fuel assemblies, emplaced in vertical holes, in a repository moxleled after the hasic design and operating concept als detailed in the SCP-CDR. It focuses on the near-field thermal effects during the first 30) years following repository closure, the minimum period during which the NRC requires that the wasie packages provide "substantially complete containment." The study evaluates the potential for enhancing performance during this period, by maintaining the emplacement hole wall temperatures above the boiling point of water, thus minimizing the effects of aqueous corrosion by liquid water contacting the waste package containers. The study does NOT purport to optimize any of the other elements of the DOE Waste Management System, or even all elements of the reposicory subsystem.

In general, the effect of emplacing spent fuel and DHLW as scheduled by the receipt scenarios falls short of fulfilling the objective of maintaining all emplacement holes above the unconfinea boiling point of water for at least 300 yrs after repository closure. However, when combined with one or both of the other possible "heat-tailoring" options, i.e., package-scale adjustment of the spent fuel characteristics and/or geometric modifications to the repository disposal panels, this objective appears to be achievable when the levelized energy receipt scenarios are employed.

The study recommends additional analyses and sensitivity studies to evaluate further these basic concepts. Continuing interaction with other system elements is also recommended, with the objective of developing a receipt scenario that is optimized over all elements of the DOE system and that can be accepted by the nuclear utilities.

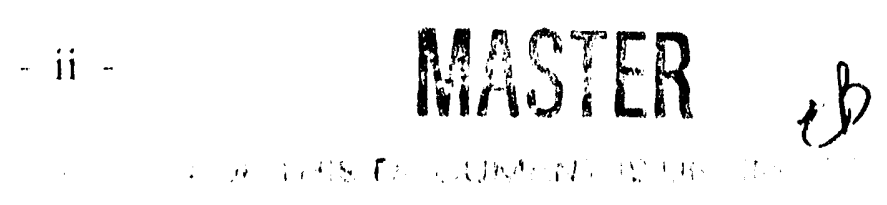




\section{CONTENTS}

SUMMARY.

KEY TO ACRONYMS. . . . . . . . . . . . . . . . iv

1.() INTRODUCTION. . . . 1

1.1 OBJECTIVE OF THE STUDY. . . . . . . . . . . . 1

1.2 SUMMARY OF ASSUMPTIONS. . . . . . . . . 2

1.2.1 Acceptance Rate and Inventory Assumptions

1.2.2 Waste Package Configuration Assumptions

1.2.3 Repository Assumptions

1.3 QUALIFICATIONS. . . . . . . . . . . . 5

2.0 DISCUSSION. . . . . . . . . . . . . . . 6

2.1 SCOPE OF THE STUDY. . . . . . . . . . . 6

2.1.1 Inventory Considerations

2.1.2 Scenarios Investigated

2.2 SELECTION METHODOLOGY. . . . . . . . . 7

2.2.1 "Optimization Parameter"

2.2.2 Development of the Selection Algorithm

2.2.3 Output Description

2.3 THERMAL ANALYSIS PARAMETERS AND METHODOLOGY. . 10

2.3.1 Repository and Panel Geometry

2.3.2 Waste Package Distributions

2.3.3 Waste Characteristics

2.3.4 Analysis Methodology

2.3.5 Limitations of the Analyses

3.0 RESULTS AND CONCLUSIONS. . . . . . . . . . . 15

3.1 RESULTS OF THE STUDY. . . . . . . . . . . 15

3.1.1 Oldest Fuel First Scenario

3.1.2 Levelized Energy Scenarios

3.1.3 Thermal Analyses of the Scenarios

3.2 CONCLUSIONS.
3.2.1 Conclusions on Receipt Scenarios

3.2.2 Conclusions on Thermal Analyses

3.3 RECOMMENDATIONS. . . . . . . . . . . 23

$4 .()$ REFERENCES. . . . . . . . . . . . . . . 25

FIGURES

APPENDICES

A - Waste Acceptance Schedule

B - Historical and Projected Inventory Tables

C - Flowchart and Listing of Scheduling Program

D - Oldest Fuel First Receipt Schedule from Oldest Fuel Inventory

F - Levelized Energy Receipt Schedule from Oldest Fuel Inventory

F - Levelized Encrgy Receipt Schedule from "Hi-Graded" Inventory

G - Reference Information/Technical Data Base Summary 


\section{KEY TO ACRONYMS}

ASG

BWR

CDC

CFR

CPU

DHLW

DOE

DOE-HQ

DWPF

EIA

FIFO

GWD

HLW

HWVP

INEI.

LIFO

LLNL

MRS

MTU

NRC

NTS

OCRWM

OFF

ORNL:

PNL

PRS

PWR

QAL.

SCP.CDR

WBS

WVIJP

YMP

YMIO
Automated Sciences Group, Inc. (ORNL. contractor)

boiling water reactor (type of nuclear power plant)

Control Dala Corporation

Code of Federal Regulations

central processing unit

defense high level waste (DOE Defense Program HLW)

'Department of Energy

Department of Energy - Headquarters (Washington, DC.)

Defense Waste Processing Facility (Savannah River, GA)

Energy Information Administration (DOE)

first in-first out (an inventory management strategy)

gigawall-days (a unit of energy - spont fued burmup)

high level waste (often solidified reprocessing wastes)

Hanford Waste Vitrification Plant (at the Hanford site)

Idaho National Engineering Laboratory (Westinghouse)

last in first out (an inventory management strategy)

Lawrence Livermore National Laboratory (Univ. of Calif.)

Monitored Retrievable Storage

inetric tons of uranium (mass of $11 \mathrm{O}_{2}$ in reactor fuel)

Nuclear Regulatory Commissio , (Washington, DC)

Nevada T'est Site (DOE facilit in southern Nevada)

Office of Civilian Radionctive Waste Management (DOFi)

Oldest fuel first (a spent fucl allocaltion scenario)

Oak Ridge National Laboratory (Martin-Marietla)

Pacific Northwest Laboratories (Battelle)

Preferred Receipt Scheduler (compuler program)

pressurized water reactor (type of nuclear power plant)

Quality issurance tevel (establishes QA recpuirements)

Site Characterization Plan - Conceptual Design Report

Work Breakdown Struclure (a program activity hierarchy)

West Valley (New York) Demonstration Project

Yucca Mountain Projecl

Yucea Mountain (Nevadda) I'rojuct ()flice (I)( )I: 


\section{0-INTRODUCTION}

This study reports on the results of an assignment from the DOE Office of Civilian Radioactive Waste Management to evaluate of the effects of different scenarios for receipt of spent fuel on the potential performance of the waste packages in the proposed Yucca Mountain high-level waste repository. The initial evaluations were performed and an interim letter report was prepared during the fall of 1988. Subsequently, the scope of work was expanded and additional analyses were conducted in 1989. This report combines the results of the two phases of the activity.

This study is a part of a broader effort to investigate the options available to the DOE and the nuclear utilities for selection of spent fuel for acceptance into the Federal Waste Management System for disposal. Each major element of the system has evaluated the effects of various options on its own operations, with the objective of providing the basis for performing system-wide tradeoffs and determining an optimum acceptance scenario.

Therefore, this study considers different scenarios for receipt of spent fuel by the repository only from the narrow perspective of their effect on the very near-field temperalures in the repository following permanent closure. The study disregards impacts on other elements of the DOE Waste Management System. Even the local impacts on other aspects of the repository are not considered, although some comments on possible implications are contained in the conclusions.

This report is organized into three main sections. The balance of this section is devoted to a statement of the study objective, a summary of the assumptions used to guide and define the study, and some qualifications that address the sources of information and quality assurance issues.

The second section of the report contains a discussion of the major elements of the study, including the scope of the study, a description of the methodology that was developed and used to select the receipt schedules, and a discussion of the parameters and analyses that were used to evaluate the thermal effects in the repository.

The third section summarizes the results of the study and draws some conclusions from them. It also recommends some specific additional work, primarily sensitivity studies, that would complement the study and provide added insight to guide future activities related to this topic.

The appendices include copies of the waste acceptance schedule and the existing and projected spent fuel inventory that were used in the study, a flowshart and source listing of the sofiware that was developed and used to generate the receipt scemarios, and the anmual receipt schedules for the scenarios that were analyzed.

\section{1- OBIECTIVE OF THE STUDY}

The objective of the Spent Fuel Receipt Scenarios Study is 10 coviluate several scenarios for receipt of spent fuel at the proposed Yucca Mountain high-level waste repository and to select one or more preferred receipt schedules that would, if implemented, enhance the postclosure performance of the waste packages and the engineered barrier system. This enhancement is derived from the judgment that the assurance of integrity of the waste packages can be substantially improved if the emplacement borehole walls can be mantained at a temperature in excess of the local uncontined boiling point, calculated 10 be $97^{\circ} \mathrm{C}$ at the repository elevation, for the minimum containment period of $3(0)$ years following closure. In the unsalurated zone of Yucea Mountain, 
this condition is expected to prevent liquid water from contacting the container surfaces and thus prechude aqueous corrosion processes.

Implicit in this objective are two separate but closely interactive elements:

- Scenario evaluation and selection of receipt schedules for use in the the rmal analyses, and

- Analysis of the effects on the waste package themal enviromunem in the repository that would result from emplacement of spent fuel on these schedules.

It is important to emphasize that the objective of the study does nol consider optimization of any other elements of the DOF Waste Management System or even any other aspects of the repositcry element.

\section{2- SUMMARY OF ASSUMPTIONS}

A series of assumptions were needed in order to establish a basis for procecding with the development of receipt scenarios and analysis of the thermal effects in the repository. These assumptions have been used in all aspects of the study with no significint de viation. They fall into three broad categories:

- Spent fuel acceptance rates and inventory information.

- Waste package contents and configurations.

- Repository design concepts and rock properties.

\subsection{1- Acceptance Ratte and Inventory Assumptions}

Three assumptions were made relating to spent fucl acceptance rates and inventory. First, it was assumed that the waste acceptance schedule is as labulated in the 1988 OCRWM I raft Mission Plan Amendment, Table 2-2 (DOE, 1988a). That schedule specifies acceptance in the first repository of a total of $70,()(0)$ MTU (metric tons of uranium), of which $6.3,020$ MTU is spent fuel and $6980 \mathrm{MTU}$ is high-level waste. Waste is to be accepted at the repository over a 25 -year period from 2003 through 2027. During the first five years, only spent fuel is accepted at rates from 400 to $1800 \mathrm{MTU} / \mathrm{yr}$. During the following 17 years, the acceptance rate is a "steady-state" $3000 \mathrm{MTU}$ spent fuel and 40)() MTU (equivalent) high-level waste. During the final three years, the acceptance rate declines. The Mission Plan waste acceptance schedule is reproduced in Appendix A. This assumption was adequate to allow the spent fuel receipt schedules to be developed, but we found it necessary to make some additional assumptions about the receipt sequencing for high-level waste in order to perform the repository thermal analysus. These are discussed in Section 2.3.3.

Second, it was necessary to assume a spent fuel inventory, including historical data and annual projections, for use in the study. This information is in the form of tables, arranged by year, containing each year's discharges identified by reactor lype and segregated into burnup ranges of $5 \mathrm{GWD} / \mathrm{MTU}$ for each type. The tables typically are expressed in units of both MTU and intact assemblies. 
During the study, DOE-HQ determined that the inventory information to be released in the OCRWM database managed by Oak Ridge National Laboratory should be used. 'Two sets of information were provided to us from different DOE contractors. One came from Andress \& Associates, who maintain the Energy Information Administration database and make the long-term projections. The other came from ASG, who maintain the OCRWM database for ORNL. Slight differences were found between the two in the historical data; however, these differences are not significant at the level of detail of this study. We elected to use the Andress tibles (Andress, 1988); they are the basis of the receipt schedules and analyses in this report and are reproduced in Appendix B. Both sets of inventory information represent the EIA historical data through 1987 and the "No New Orders - Extended Burnup" projection case.

The third acceptance assumption is that all fuel will have a minimum age of five years after discharge at the time of acceptance. We have interpreted this assumption to mean that the minimum age constraint applies to the time of receipt at the repository. This difference would be significant only late in the operational period if there is a substantial delay between acceptance into the DOE system and receipt at the repository.

\section{$1,2,2$ - Waste Package Configuration Assumptions}

This category of assumptions relates to the design concepts for, and constraints on, the waste packages. Again, there are three hasic assumptions. The first of these addresses the physical form of the spent fuel as installed in waste packages for disposial in the repository. We assume the form to be intact fuel assemblies for two reasons. First, this form results in less energy available for release as heat following emplacement on a per-package hasis than consolidated fuel; this assumption is conservative with respect to the study objectives. The second reason is that inventory allocation is simplified because the inventory is expressed in terms of intact assemblies, without regard to any modification made to the physical form by the owners prior to acceptance into the DOE system or modifications by the DOE system prior to emplacement.

The second assumption in this category is that the fuel assemblies will be packaged for emplacement in the "hybrid" waste package configuration. This configuration concept (DOE, $1988 \mathrm{~b}$ ) is designed to provide an efficient packing of intact fuel assemblies in a circular envelope with a $271 / 4$. inch inside diameter. This configuration, shown in Figure 1 , is designed to accommodate three PWR assemblies spaced 120 degrees apart on the outside perimeter, with three BWR assemblies similarly positioned. An additional BWR assembly fits in the center of the package. This 3 PWR - 4 BWR configuration is in almost exactly the same ratio as the aggregate ratio of the inventory on an assembly basis. Therefore, all spent-fuel packages will be assumed to have this internal configuration. Given the average weights, in MTV, of the fuel assemblies, all spent-fuel packages are assumed to contain 2.015 MTU. For example, during the "steady-state" receipt years $2(0) 8-2(24$, the repository will emplace $3(0)(0) / 2.015$, or 1489 spent-fuel packages per year.

The third waste-package assumption is that the peak cladding temperature in all spent-fuel packages will be limited to $350^{\circ} \mathrm{C}$ in an inert gas environment. This constraint is recjuired to ensure that gas pressure in the fuel rods will not cause stress rupture failure of the fuel cladding, which could result in rapid release of the radionuclides that would he available for transport in the event of container breach. Cladding failure exposes the $\mathrm{UO}_{2}$ fuel pellets for oxidation by repository air in a breached container, from which the inert cover gas has escaped. This assumption leads to a maximum emplacement hole wall temperature design limit of $275^{\circ} \mathrm{C}$ for spent-fuel packages. 


\section{$1.2 .3-$ Repository Assumpunes.}

The last caltegory of asmumprons is related to atipeces of the reposilory design and the hydrologic and themal properties of the rock in the repository horizon. These assimmptions provide a basis for analyzing the thermal response of the waste-patekage emplacement holes on omplacing spent fuel that is received on the selected schedules.

The repository design and operating concepts established in the SCY. CDR (Sandia, 1987) have been assumed. The hasic design concept is that the repository layout will consist of a set of excavated pancls comprised of access drifts and cmplacement drifts. These palleds will be served by a set of eentrally localted main drifis that will provide hallinge roules for excavalted rock, waste package transporters, and other service functions. The emplatement pands will he developed sequentially, with their excavation, emplacement hole construction, and outfilling proseceding in parallel with waste emplacement operations in previously conslruled panels. For this study we assumed that, during the "steidy-state" operational period, all waste ieceipts for a given year will be emplaced in a single panel. We recognized that this is a simplification of the conceptual design, in which the panels are of irregular size; but a felt that our assumptions were consistent with the design concepts, and that the level of detail of the study did not warrant any more detuiled treatment of the design. For our analysis, we modeled a set of emplacement panels that are sized and arranged in a lay ut that approximates the conceptual design. The details of this simulated repository layout are described in Section 2.3.1. The limitations of these analyses, in terms of the physical repository parimeters, are discussed in Section 2.3 .5 .

The SCP-CDR describes two alternatives for waste package emplacement oricntation. The first is emplacement of a single waste package vertically in a hole in the floor of the emplacement drift. Each emplacement drifi contains a single row of emplacement holes. The second altermative is emplacement of multiple waste packinges placed end to end in long neal horizontal holes drilled in the ribs of the drifts. It is acknowledged that this concept is beyond presently avaliable technology and would require some development. The YMP is presently evaluating these concepts, together with a third concept that involves a variant of the SCP.CDR horizonal scheme, in which one to three packages are placed in short horizontal holes. A decision on the emplacement orientation will be made prior to initiating the next design phase.

For this study, we assumed that the waste packages are emplaced vertically, with a spacing between holes of $7.5 \mathrm{ft}$, the minimum separation that is operationally feasible. Section 2.3 .1 discusses the details of the assumed panel geometry. The SCP-CDR design specifies an emplacement hole diameter of $29 \mathrm{in}$. for a 26 -in. diancter container. However, we have assumed a hole diameter of $31 \mathrm{in} .10$ be consislent with a 28 -in. diameter thin walled container containing the hybrid spentefuel configuration described in Section 1.2.2.

The final assumptions we made are values for tost rock parameters that are needed for the thermal analyses. These physical properties of the rock are used in the calculations and are limited to the thermal diffusivity, conductivity, and ambient comperature. The thermal diffusivity has not been reported explicilly, and is therefore computed 10 be: $31.34 \mathrm{~m}^{2} / \mathrm{yr}$ using reported values for conductivily, density, and heat catpacity. The mean values for density and heal calpacity from the Yuecal Mountain Project Reference Information Base (1)OR, 1987b) were used. The conductivity used in these analyses $\quad 2.1 .5 \mathrm{~W} / 111$ - K) was determined by linear interpolation at a salturation of $6.5 \%$ between the meatl values for "(ry" and fully salluralled conditions, also taken from the Reference Information Base fon the 'lopopah Spring weleled toff ('S'S2) repository host rock. The analyses

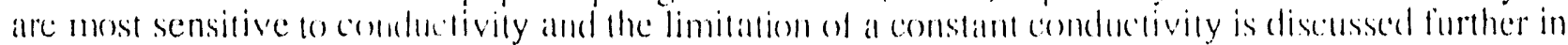
Section 2.3.5. The ambiem rex.temperature was assumed lo be: $25^{\prime \prime}$ '. 


\section{3- OUALIFICATIONS}

'Two topics must be addressed under the general heading of cualifying statements or conditions with respect to this study. The first involves the information that was provided to us by others for which we have no formal mechanism for independent validation. If it contains errors, those errors will be propagated in the results of this study. As indicated in the summary of assumptions, this information includes the fuel acceptance schedule, the inventory history and projections, the high-level waste production schedules, the waste-form thermal characteristics, the repository design concepts, and the rock properties. This information has been compiled from several sources, as referenced throughout this document.

The second qualifier relates to the formal establishment of the scope and direction of the study. This study was initiated at the direction of the Yucca Mountain Project Cffice by letter to LLNL (Skousen, 1988) as an assigned Action Item under WBS 1.2.2. The initial work that was done in 1988 was performed under WBS 1.2.1.2 as a Systems Engineering activity. The additional analyses that were done in 1989 were performed under WBS 1.2.2.4 as a Waste Package Design activity. These activities were not assigned a formal Quality Assurance Level (QAL), but were conducted under the principle of "good scientific and engineering practice." Periodic reviews of the progress of the study have been performed by LLNL, YMPO, and DOE-HQ. The study is QAL III. 


\section{0-DISCUSSION}

This section discusses the scope of the study, the development and application of the fuel selection scheduling algorithm, and the parameters and melhodology employed in the repository thermal analyses.

\subsection{SCOPE OF THE STUDY}

Adequate information was not avalable to us at the initiation of the study to provide even conjectural guidance as to the constraints, preferences, or latitude that could be expected from other elements of the overall spent-fuel management system. In retrospect, that is probably just as well; we were neither influenced nor constrained in the study by these factors and have therefore developed our "preferred" scenarios from only the perspective of the repository engineered barrier system.

We clearly recognize that there are many, often conflicting, agendas that will need to be considered in deciding the ultimate approach to be taken to schedule spent-fuel acceptance into the DOE disposal system. Our scope is therefore confined to expressing a preliminary preference, and assessing the effect on the near field repository temperatures that would result from the emplacement of the selected spent fuel receipts.

\subsection{1- Inventory Considerations}

At the outset of the study, we were faced with an immediate question of what part of the inventory we should consider for acceptance in the repository. While the DOE has contracted ultimately to accept all commercially generated spent fuel into the system, the acceptance schedule for the first repository is limited to 63,(20) MTU over a 25-yr period ending in 2027. The projected discharges through that year total $85,500 \mathrm{MTU}$. Considering that, in general, only fuel that is five or more years old will be accepted into the DOE system, we were still faced with an eligible inventory of 80,300 MTU discharged through 2022. Several approaches were considered for allocating the inventory to be accepted. For example, one could decide to accept $79 \%(63 / 80)$ of each year's discharge. Lacking any firm guidance or other basis for this allocation, we have considered two cases that, from our viewpoint, seem reasonable.

The first case assumes that the first 63,020 MTU discharged will be accepted. This approach results in acceptance of all fuel discharged through 2011 and one-third of the discharge from 2012. In this case, the only age constratint is the five-year minimum, so it would be allowable, for example, to accept $20(0) 5$ discharges in any year after 2010 .

The second case we considered takes a different approach. Remembering that our overall objective is to limit liquid water contacting waste packages in the repository, we decided to consider an inventory allocation consistent with that objective. It assumes that we are free to select the portion of the inventory with the highest decay energy content that is otherwise eligible for acceptance. This is achieved with the tuel that has the highest burnup in each discharge year. We are further constrained by the assumptions of the study to maintain a $4: 3$ ratio of BWR to PWR fuel, on an assembly count basis, in each year, to fill the "intact hybrid" container configuration. This would, for example, result in acceptance of all BWR fuel discharged through 2022 with burnups in excess of $25 \mathrm{GWD} / \mathrm{MTU}$, and all PWR fuel through the same time with burnups in excess of $30 \mathrm{GWD} / \mathrm{MTU}$. In effect, this approach amounts to "hi-grading" the inventory to further our objective. In the scenario we used, some variations were incorporated in the receipt schedules, but the approach was maintained. 


\subsection{2- Scenarios Investigated}

To select our receipt schedules, a total of about 100 possible schedule cases were generated and evaluated. Most of these were variations on only two basic scenarios, including various combinations of the two.

The first basic scenario that was considered was a simple "oldest fuel first" approach. In inventory management terms, this strategy is also known as "First In - First Out," or simply "FIFO." Based on previous work, we expected that the result would not be very satisfactory, and it is not. In this scenario, the resulting waste stream exhibits the characteristic of monotonically decrcasing age at emplacement and a corresponding increase of the average burnup of the fuel received, due to the historical pattern of discharges and the increasing burnup levels projected by the nuclear utilities. The net effect of these two factors is a very non-uniform integrated energy content in the annual receipts, which translates to a very unbalanced temperature distribution in the repository. The average age and burnup as a function of receipt year for this scenario are shown in Figure 2 as solid lines. The "+" marks in Figures 2, 3, and 4 indicate the ages of the fuel that are present in the stream in the year of receipt.

The other basic scenario we investigated was the "Last In - First Out," or "LIFO," approach, subject only to the five-year minimum time since discharge limitation. As expected, this results in a waste stream that is effectively the inverse of the FIFO approach. The average age slowly increases from 5 to about 10 years during the first 17 operating years, then rapidly increases to almost 25 years in the final years of operation. The average burnup declines over time as the older, low-burnup fuel is phased into the receipt stream. Figure 3 shows the average age and burnup for the LIFO scenario, with a five-year minimum age. This scenario results in a waste stream with two age components, as shown by the "+" marks; one is the fuel that becomes eligible for acceptance by reaching the five-year minimum age, and the other is a progressively older component that is needed to fill the acceptance quota for a given year.

Several other LIFO scenarios were considered, with different fixed or time-varied minimum ages. An example of this approach, using a fixed minimum age of 16 years, is shown in Figure 4. Note that the oldest fuel, when finally accepted into the system, wals discharged more than 55 years prior to receipt. The acceptability of this situation to the other elements of the waste management system remains to be determined.

As we considered the implications of these simple scenarios, it hecame obvious that an approach that would most likely result in a preferred receipt schedule would be a combination of the two basic scenarios, FIFO and LIFO, with the option to adjust the fraction from each that is accepted in each year. At this point, we recognized the need for incorporating additional capabilities into the selection algorithm to allow for this option and the need for an optimization parameter. These aspects are discussed in more detail in the next section.

\section{2- SELECTION METHODOIOGY}

This section is devoted to a discussion of the approach and methodology that have been used in the study. We describe the basis for the approach used. the "optimization parameter" employed, the development and implementation of the selection algorithm (including its variables), and the format and content of the output of the selection program.

\subsection{1 - "Optimization Parameter"}

Early in the planning of this study, we found that, with several different receipt scenarios to examine and emplacement schemes to analyze, we would need a single "(optimization parameter" that could be employed to judge the relative merits of different approaches. 
In the context of this linited study, the term "optimization" is used advisedly; i.e., it does not imply anything about the efficiency of the o'verall nuclear waste system, the DOE-OCRWM Waste Management Program, or the Yucca Mountain Project. It is used only in the very narrow sense of a relative standard for evaluating the effectiveness of different receipt scenario options at controlling the thermal response of the engineered barrier system during the period 300 to 1000 years following repository closure. It is during this period that the NRC regulations establish a performance objective of "substantially complete containment." In the unsaturated zone of Yucca Mountain, we believe the case can be made that liquid water cannot contact the container surfaces, and aqueous corrosion modes will not be operable, if the walls of the emplacement boreholes can be maintained at a temperature in excess of the local unconfined boiling point.

Several possible parameters were considered as the measure of effectiveness for the various spent-fuel selection scenarios, Among those parameters considered were waste age at emplacement, burnup (GWD/MTU), initial power (decay heal) generation rates, and integrated energy deposition. Recognizing that the long-term effectiveness is most closely related to the energy deposited in the host rock per unit area, we decided to use the integrated energy contained in each year's fuel receipts as the "optimization parameter" for this study. Fuel receipt scenarios were then developed, by fuel type, age and burnup rancre, to achieve a uniform integrated energy content in the fuel received during each year. The method for calculating this parameter is described in Section 2.2.2. We recognize that these receipt schedules are by no means unique solutions. With over 200,000 fuel assemblies from which to select, a nearly infinite number of possible combinations will satisfy the criteria. We further acknowledge that some modification to these "optimized" schedules may be needed to compensate for repository geometry and waste package distribution effects, as discussed later in this report. The limitations on this study did not allow for detailed evaluation of these aspects.

\subsection{2-Development of the Selection Algorithm}

The initial assessment of the scope of this study revealed that no computer program was readily available that was suitable for the task at hand; i.e., sufficiently flexible to allow investigation of alternative strategies for selection of fuel from the projected inventory and compatible with the available LLNL computer resources. Therefore, we decided to develop a new program, incorporating as much flexibility as possible to allow changes as the study developed.

This computer program, written in FOR'TRAN, is very flexible and allows selection from the spent fuel inventory to meet the objectives of the study. It is named "Preferred Receipt Scheduler" or "PRS." It reads a fuel inventory file developed from the OCRWM database and a set of user-supplied parameters for the allocation algorithms. The inventory input file contains the actual and projected numbers of fuel assemblies discharged annually, by reactor type, subdivided into twelve burnup ranges of 5-GWD/MTU for each type. PRS then generates an allocation using these parameters and algorith ns; and outputs a summary of the allocation results, individual annual acceptance tables, and a listing of the original and unallocated inventory.

PRS is sequenced to accept a set of user-supplied parameters and option selections which are read from an input file. The program then executes a series of nested "do loops" in which all of the allocations are made, with periodic calls to a subroutine that generates the output files for plotting or listing. The sequence of instructions is specifically tailored to this study; i.e., it considers a 60-yr period from 1968 (the date of the earliest discharges in the inventory) to 2027 (the last year of waste acceptance to the first repository). With minor revisions, the program could be modified to evaluate other time periods. 
The sequence of instructions includes an exterior loop that is indexed over the 60-yr period. This loop performs a series of initialization steps prior to invoking the two principal "do loops." These principal loops, each of which is itself a nested loop that is indexed over both time and burnup range, have time-dependent variables that are supplied in the input file that is read at the beginning of the program. The major difference between these two loops is that they are designed to allocate the available inventory according to two opposing straiegies. The first sequence to be invoked is the LIFO (Last In-First Out) loop that has several user-selected parameters including minimum age, number of years to be considered, and fraction of available inventory of a particular discharge year that may be accepted. The second sequence is the FIFO (First In-First Out) loop that also has a user-selected rarameter of the fraction of the tolal fuel required for a receipt year that is to be allocated from the inventory on an "oldest first" basis. The allocations to a receipt year from these two algorithms are compared with the total fuel required, by fuel type, for that year. The available inventory is then appropriately decremented, and the number of assemblies allocated from the inventory, by discharge year, burnup range, and fuel type, are written to an output file. In both of the allocation loops, the allocation from a particular discharge year's avaiable inventory is made by decrementing from the highest burnup range first and proceeding to lower burnup ranges as necessary to fill the allocation.

To evaluate the effectiveness of selected variables in each run, it is necessary to compute the contribution of each allocation of fucl assemblies from each burnup range from each discharge year to the integrated energy that will be deposited in the repository. This calculation is made within the allocation loops at each index and accumulated for the total allocation for each receipt year. The calculation is made by reference to two three-dimensional arrays that contain the integrated energy for each fuel type by burnup range for each discharge year and receipt year. These arrays are loaded at run time from an auxiliary file. That file was generated using the thermal power values from the ORNL database of ORIGEN2 calculations, integrated appropriately from the year of receipt to year 2353 , or approximately $300 \mathrm{yr}$ following repository closure.

The software described here was developed on an "ad hoc" basis for this study. It does not conform to formal quality assurance requirements, other than "good scientific practice," and must therefore be considered as a Quality Assurance Level III item. It has not been verified or validated by any formal and documented protocol; however, we have carefully examined the results for consistency. The initial and final inventory printouts have been compared to ensure that all of the inventory has either been allocated or remains for future allocation. This is more an accountability check than a verification of the software, but is a valid check that the program is performing as designed.

A total of 13 versions of this program evolved during the study, all of which have been archived for future reference. All of the calculations that support the conclusions of this report were made with the last version of the program. A listing of the source code for that version, with a list of the key variables and their functions, is included as Appendix $\mathrm{C}$. This source code is configured to run on th. L Livermore Computer Center Cray 1 system, but could be easily modified for other computers, including a personal computer with sufficient memory and a FORTRAN compiler. Typically, the time required for execution on the Cray system is about 3 seconds per run.

\section{$\underline{2.2 .3-\text { Otitput Description }}$}

As briefly mentioned in Section 2.2.2. each run of the selection program produces several different types of output. This section describes these output products, including the format of those for which only brief headers or labels are supplied. These outputs, for the receipt scenarios that have been used in the thermal effects analyses, are included in Section 3.1, and Appendices D, $E$, and $F$. 
The first table in the output is a summary, by emplacement year, of the user-supplied input parameters; quantities and average age, burnup and energy characteristics, by individual reactor type and the combined averages, of the fuel selected for each year; followed by the overall totals or averages, as appropriate, for the 25 -yr operating period.

This summary is followed by 25 pages that detail the fuel assembly receipl schedule for each repository operating year from 2003 to 2027. Each page identifies the emplacement year, the discharge years from which the allocation has been drawn, the age at emplacement, and the number of assemblies, by reactor type, in each of the 12 burnup ranges, reading left to right from low to high burnup. This array is also totaled both down and across.

After the annual receipt schedules, the initial inventory and the remaining unallocated inventory are listed. These pages are labeled with only a first-page header for each listing, but the columns follow the same format as the annual receipt schedules.

In addition to the tabular information, the program also generates files for use in graphically plotting the results. Each run's output contains a single plot, on which four sets of information appear. Three of these, shown as connected points labeled "A","B", and "E", are the average age at acceptance, average burnup, and integrated energy per MTU, respectively, for each repository acceptance year. The fourth set of infurmation, shown as " + " signs on the plot, are the ages at receipt of the fuel from the specific discharge years that contribute to that year's allocation.

\section{3 - THERMAL ANALYSIS PARAMETERS AND METHODOLOGYY}

Repository panel-scale thermal analyses were performed to assess the effectiveness of the waste receipt scenarios in terms of establishing and maintaining a temperature distribution that will enhance the performance of the engineered barrier system. These analyses, while subject to several limitations, provide a basis for comparing the thermal effects resulting from the emplacement of the waste, as received in the various scenarios, in selected repository panels. These effects were investigated in four panels within the repository, and two different emplacement schemes for distribution of the waste forms within the panels were compared. The interactive effects of all waste packages in these panels, as well as the effects from packages emplaced in adjacent panels, were included. A discussion of the analytical technique and its limitations concludes this section.

\subsection{1-Repository and Panel Geometry}

In order to perform these thermal analyses, a simplified repository layout that is consistent with the study assumption of using the SCP-CDR design and operating concepts has been developed. It consists of a total of 20 panels, 10 on each side of a central area that would contain the main access drifts. The total area occupied by this repository simulation is about 1270 acres. This layout is shown in Figure 5. The panels selected for detailed analyses are identified in the figure as Panels "A","H","J", and "T".

Eighteen of the panels are identical and are sized to accommodatc the "steady-state" receipt of 3000 MTU of spent fuel and 400) MTU equivalent DHLW during the years 20(5)8-2025. This simulation panel geometry has been developed to approximate the configuration in the conceptual design. These panels are rectangular, with an active emplacernent area that consists of 17 emplacement drifts spaced $125 \mathrm{ft}$ on centers. Each drift is $10(0) \mathrm{ft}$ long, and accommodates 135 vertical emplacement holes spaced $7.5 \mathrm{ft}$ on centers. Thus each panel contains a total of 2295 holes. This is essentially the number of packages (2289) to be emplaced in each of the "steady-state" years of repository operation. The closest emplacement drift is located 25() $\mathrm{ft}$ from the center of the main access drifts, and the end emplacement hole in each drift is located $12.5 \mathrm{ft}$ from the center of the barrier pillar that separates adjacent panels. Thus, the overall area that is associated with each panel 
is a rectangle $1255 \mathrm{ft}$ by $2250 \mathrm{ft}$ and comprises 64.8 acres. This panel is shown in both Figures 6 and 7; they differ only in the arrangement of waste-form types, as discussed in Section 2.3.2.

The remaining two panels, designated as Panels "A" and "T", are configured to emplace the spent fuel that is scheduled for receipt during the startup operations in the years 2003-2007 and the final operations in 2026-2027, respectively. The deial's of Panel "A" are shown in Figure 8; Panel " $T$ " is very similar. With the exception of these two panels, it is assumed that the repository operating concept is emplacement of each year's receipts into a single panel, with development of panels for future years' receipts proceeding in parallel with emplacement operations. As a further indication of consistency with the SCP-CDR, a comparison was made of the areal power ciensity in a "typical" panel with the conceptual design. The average spent-fuel package in the oldest inventory scenarios has a thermal output of $1765 \mathrm{~W}$ and an average age of about $21 \mathrm{yr}$ at emplacement. The DHLW, assuming it is from the Savannah River DWPF in the midrange of the vitrification campaign, has a thermal output of $440 \mathrm{~W}$ per package and an age of gbout $12 \mathrm{yr}$ at emplacement (DOE, 1987a). The total initial thermal output of the packages to be emplaced in the panel is $2.98 \mathrm{MW}$, or $46.0 \mathrm{~kW} / \mathrm{acre}$. This is consistent with the allowable initial power density guideline from Appendix G of the SCP-CDR, which indicates a value of about $45 \mathrm{~kW} / \mathrm{acre}$ for waste in this age range.

\subsection{2 - Waste Package Distributions}

A wide variety of possibilities exists for ways to distribute the waste packages within a panel. As indicated in Section 2.3.1, we have elected to analyze the first and last panels, which contain only spent fuel, with the packages distributed within those panels such that each year's receipts are grouped together and emplaced sequentially from the outer rows toward the center of the repository.

For the remaining panels, which contain both waste forms, we have selected for our analyses two of the simpler schemes that could be easily realized in actual repository operations. These two schemes implement two quite different approaches to the treatment of the waste forms with respect to the resulting temperature distributions and possible radionuclide release consequences resulting from breached containers.

The first package-distribution scheme we analyzed assumes that, for the purpose of enhancing the integrity of the containment barrier during the 3()()-yr period following repository closure, the consequence of a container breach is the same, regardless of the waste form within it. This leads to a goal of the emplacement scheme to maintain the temperatures of all emplacement boreholes above the local unconfined boiling point for as long as possible, without regard for the type of waste package emplaced. Recognizing that those packages that contain DHLW will contribute only a fraction as much energy to this goal as spent-fuel packages, it follows that the package distribution should involve combining the two types to take advantage of the higher energy output of the spent-fuel packages to raise the temperature of the adjacent DHLW packages.

Recalling that our typical panel is dimensioned to accommodate 2295 packages in 17 rows of 135 packages each, we compensated for the "edge effects" on all four sides of the panel by filling the outermost two rows on each end of the panel and the outermost six holes on each end of the other 13 rows with spent-fuel packages. The remainder of the 13 inner rows are commingled, with each row containing 62 DHLW packages alternated with 61 spent-fuel packages. This distribution, show'n schematically in Figure 6, accommodates a total of 1489 spent-fuel and 806 DHLW pack, tges within the panel.

The second package-distribution scheme we analyzed takes the approach that the consequences, in terms of radionuclide release from a breached contaner, ane less significant in the case of a DHLW package. Because the waste form is enclosed by a stainkess stecl pour canister 
within the disposal container, additional resistance 10 direct contact of the glass waste form by liquid water is provided. Furthermore, there is little or no concern for releases of gaseous radionuclides directly from the glass matrix. Therefore, it may be less important to maintain the temperature of the emplacement holes containing DHLW packages above boiling, so the packages could be emplaced in a configuration where they are used as "guard heaters" around the perimeter of the panel. The spent-fuel packages could then be clustered in the central region of the panel so that, by virtue of their higher energy content, they will remain at temperatures above boiling for a substantially longer period than in the commingled arrangement.

Our implementation of this concept, for the purpose of these analyses, is to fill the outermost two rows of the panel and the outermost 10 holes on each end of the remaining 13 rows with DHLW packages. The remaining 115 holes in these 13 rows all contain spent fuel packages. This arrangement accommodates a total of 1495 spent-fuel packages and 800 DHLW packages in the panel and is shown schematically in Figure 7.

\section{$2,3,3$ - Waste Characteristics}

We did not consider "tailoring" of the contents of the individual spent-fuel packages within a panel, although the analytical method is specifically designed to allow this, down to the level of specifying the contents of each package in terms of the age and burnup of its contents. This is a very time-consuming process, and, in our judgencent, this level of detail was not warranted for the purpose of the preliminary assessments in this study.

We have, however, examined the characteristics and guantities of fuel in the annual receipt schedules that are designed to "level" the integrated energy. We are convinced that a sufficient spectrum of ages and burnups is available to allow additional tailoring of annual receipts to improve further the temperature distributions. Additional specification of the order of receipt, or sufficient lag storage capacity, at the repository or elsewhere in the system, would be needed to allow more detailed selection at the time of filling each package.

The analyses presented are for panels representing the receipts for the years 20)3-2007, 2014, 2016, and 2026-2(127. These are designated as Pancls "A","H","J" and "T", respectively. Panels " $\mathrm{H}$ " and "J" are representative of the middle of the projected repository operating period and are well into the "steady-state" operations, with annual receipts of $3(0)(0)$ MTU spent fuel and 400 "M'TU equivalent" of DHLW. We have altributed to each spent-fuel package the massweighted average age and burnup characteristics of the fuel scheduled to be emplaced in the panel selected for analysis. The characteristics of the waste forms in adjicent panels in the simulation are representative of the receipts in prior and subsequent years.

To arrive at a suitable set of characteristics for the DHLW on use in the analyses, we have made some assumptions about the sequencing of this waste form into the disposal system. While the analysis is not highly sensitive to these characteristics, the assumptions are stated here. We assumed that the "MTU equivalence" for the glass (or other) wastes is 2 MTU/canister for the WVDP waste and $0.5 \mathrm{MTU} /$ canister for the Savannah River DWPF product. Further, we assume that the initial HLW accepted at the repository in the years $20(0) 8-2()(9)$ will consist of $3(0)$ MTU (150) canisters) of WVDP and 10) MTU (20) canisters) of DWPF waste each year. This will be followed by 400 MTU $(80)$ canisters) per year of DWPF glass for the next several years, with a phase-in of HWVP and INEL product as the hacklog of DWPF waste is accepted and the DWPF production rate is reduced. Assuming disposal of the oldest production first, the DWPF product to be received in 2014 would be the 440() th to 52()$($ )h canisters produced. These canisters represent production during the years 20() $1-2(0)(5$, with an average "age" following vitrification of $12 \mathrm{yr}$. This or a similar set of assumptions is needed in order to use the ORNI, database information, as tabulated in DOE/RW-0184, for establishing the decaly energy following emplacement. Lacking 
any other basis or guidance for the analyses, we used this set of chamateristics for DH.W in all of the panels that contain both waste forms.

\section{3,4-Thermal Analysis Methodology}

The analyses for this study were made with an LLNL. implementation of the temporal and spatial superposition of the analytic solution of the diffusion equation for conductive dissipation of thermal energy from a point source. This implementation is more fully described and documented elsewhere (Montan, 1986). This software was originally written to support the design and analysis of an in-situ heater test in the Climax granite at NTS in 1977. These programs have evolved and been used extensively in a variety of applications, including most recently a preliminary thermal analysis of the SCP-CDR design in 1987. Various specialized post-processors have heen developed and employed to plot temperature vs time for selected points within an array of thermal soures; to display temperatures in very large spatial arrays, such as those reported here; and to count the number of points in such arrays that are at a given temperature at a particular time. The number of individual thermal sources and the heat-generation characteristics and geometries that can be simulated in these codes is limited only by the core memory of the computing hardware and the patience and ingenuity of the individual preparing the input. The innermost iteration loop in the calculation, which consumes the majority of the computing time, performs multiple evaluations of the complementary error function. A typical analysis of the type reported here involves about 90) million evaluations of this function. This software was originally written to run on CDC 76(0) machines, but has since been modified for the Cray 1 computers in the Livermore Computer Center, where a typical analysis requires about 12 minutes of CPU time.

The arrays of sources used in these analyses have been configured to represent spatially the simulation panels. Depending on the location within the repository simulation, i.e., a corner or interior panel being analyzed, a total of six to ten pancls are included in the source array. This is an adequate number to introduce negligible error $\left(<<() .1^{\prime C} \mathrm{C}\right)$ over simulation times up to $1000 \mathrm{yr}$. These arrays, shown schematically in Figures 9, 10, and 11, represent the equivalent of about $14,(0)(0)$ to $23,0(0)$ waste packages, or about one third to one half of the lotal in the repository.

In the array for the panel being analyzed, each waste package is individually represented by a row of equally spaced point sources along a vertical line whose length corresponds to a fuel assembly or HLW canister, with the appropriate decay energy distribuled among the points. The number of points on this line is sufficient to result in a negligible error in the calculated temperature. In these analyses, for example, 39 points are used to represent a spent fuel waste package.

The other panels in the array are the two panels (if present) on cach side of the panel to be analyzed and the pariels opposite them on the other side of the main access drifis. In each of these panels, each emplacement row is simulated by point sources along a horizontal line whose length corresponds to the length of the emplacement drift, with distributed thermal energy exuivalent to the row of waste packages they represent.

The thermal output of each of these sources is computed from a decay curve that is based on the ORNL ORIGEN2 calculations for the appropriate waste forms (Johnson and Montan, 1990). To simulate the repository operation in the calculation, each panel is assigned the appropriate source characteristics of the waste forms (MTU/package, age at emplacement, average burnup, and emplacement year). Fach panel array is activated during the calculation at the lime that the panel is loaded during the simulated repository operation.

The simulation calculates the temperature of the wall of each borehole in the panel to be analyzed at the prescribed time, superposing the contribution of each source to the temperature at each point of interest, subject to a threshold based on the fourier number to minimize the number of evaluations of the error function without degrading the result. 


\subsection{5- Limitations of the Anulyses}

In exchange for using the method of superposition of the analytic solution to the diffusion equation to simulate very large themal source arruys, we had to aceept several limitations implicit in the method. These limitations: affect two significant aspects of the repository thermal analyses.

Potentially the most severe limitation is that the only heat transpont mechanism simulated is conduction. Thus, no other mechanisms that we expect to be operative in the repository (i.e., vaporization, vapor flow in fractures and subsequent condensation of pore water, radiative and convective transport in mined openings, and heat removal by the ventilation system prior to closure) are modeled. We do not yet have good comparisons with the more sophisticated hydrothermal codes that are being developed to simulate complex heat transfer and fluid flow in fractured and partially saturated rock.

The other acknowledged limitation of this analysis method is the implicit assumption of heat dissipation in an infinite homogeneous medium whose physical properties - including density, heat capacity, and thermal conductivity - are constant. No mined openings exist in the simulation. In partially saturated rock at temperatures above the unconfined boiling point, the limitation of a constant conductivity is a source of error because the conductivity decreases as the rock is dehydrated at elevated temperatures. Also, the differing physical properties of the underlying and overburden rock units are not taken into account.

It should be noted that if the thermal conductiviry value we used is too high for the dehydrated portion of the repository, then the emplacement-hole wall temperatures predicted by these analyses will be correspondingly too low. Conversely, if the effect of the other heat transfer mechanisms that are neglected in these analyses are significant, the temperatures that are predicted at the borehole walls will be 100 high. There are some preliminary indications, based on finite difference calculations that include other heat transfer mechanisms and situration-dependent thermal conductivity, that the effects are offsetting and of similar mangiturle. 


\section{0-RESULTS AND CONCLUSIONS}

This section is a summary of the results of the study and the conclusions we have drawn based on those results. In addition, we make some recommendations for activities that we believe would be useful in providing further insight into this subject.

\subsection{RESULTS OF THE STUDY}

The results of the study are divided into two calcgories. 'The lirst contains a description of the three spent-fuel receipt scenarios that were selected for analysis and a summary of the process for arriving at the selected scenarios that invoke the "levelized" integrated energy parameter. The second category of results contains the themal analyses that were performed utilizing the scenarios, including the clfects of using the two different schemes for arranging the waste types within a panel.

\section{$3,1,1$ - Oldest Fuel First Scenario}

As indicated in Section 2.1.2, the first receipt scenario considered is the simple "oldest fuel first" or OFF approach. This scenario parallels the primary methodology established by DOE in the standard contracts for allocition of priority for delivery of spent fuel from the utilities to the Federal Wast Management System. This scenario, by definition, selects fuel for receipt in the order in which it was permanently discharged from the power reactors, and is totally indifferent to any intrinsic characteristics of the fuel such as age at receipt or burnup. The only constraint that we have placed on the receipts is that they preserve the $4: 3$ ratio, on an assicmbly basis, between BWR and PWR fuel so that the correct number of assemblies will be accepted each year to fill the spent fuel packages consistent with the study assumptions. This constraint introduces minor deviations from an exact OFF scenario in every year. These deviations are on the order of a few percent and are not significant to the thermal analyses.

The OFfi scenario accepts the first 63,020 MTU 10 be discharged. This includes all discharges from the earliest, in 1968, through 2011, with a portion of the higher burnup fuel from 2012 included to make up the full 63,()20 MTU. The average age al emplacement of this fuel receipt stream monotonically decreases with time. The fuel received in the first year $(2(0) 3)$ includes discharges from the years $1968-1973$ and is therefore $30-35 \mathrm{yr}$ old, with an average age of $31.5 \mathrm{yr}$. At the end of the repository emplacement operations in 2(127, the average age has decreased to $15.8 \mathrm{yr}$. The average burnup increases from about 15 to 4 () GWD/MT( over the first $15 \mathrm{yr}$, and then remains nearly constant for the last $10 \mathrm{yr}$. The combination of these 1 wo characteristics results in a range of more than a factor of three for the integrated energy over the repository operating period. The average age, burnup, and energy characteristics, together with the age groupings for this scenario, are plotted in Figure 12. The annual characteristics, detailed receipt schedules, and inventories for this scenario are tabulated in Appendix D.

\subsection{2-Levelized Energy Scenarios}

Before describing the delails of the fuel receipt scemarios that we have selected lo satisfy the levelized energy characteristic, we should recall that there are a near. infinite number of possibilities from which to choose. With about $28(0,0)(0)$ fuel assemblies in the projected available inventory and possible ages at receipt ranging from 5 to 60 yr, the possible permulations for accepting about 1()$,()()$ of these in any year is mind-boggling. To make our selections both compretiensible to the other elements of the DOE sy'stem (and the utilities who will be providing the finel) and flexible (to allow for some intrapanel "fine-tuning" in the emplacement configurations), we have elected to recommend receipt scenarios that have a common characteristic. IIsing the variable parameters associated with the PII:O and LIFO loops in the scheduling algorithm, we have fored the selection process to produce receipt schedules that draw from the availahle inventory in two distinct age 
groups. The groups are tightly clustered and quite different, providing latitude for other pirts of the system to accommodate their own "optimization" factors in developing their preferences, while still allowing us to achiceve our ohjectives.

It should be emphasized that there are many instances in the anmual receipts where small numbers of assemblies are specified in a burnup range for a particular fiel type and discharge year. These numbers are artifacts of the scheduling algorithm and should not be considered significant. The approach we have used was selected to be very tolerant of variations in the reedets, within rensonable bounds.

With that preface, we will describe the chanacteristics of the two levelized energy scenarios we have selected. As ciscilssed in Section 2.1.1, we were liced with making a choice of which portion of the available: inventory would be aceepted in the first repository, because the projected inventory exceeds the design capacity of the repository. The two scenarios reported here correspond to the two inventory options we selected.

\section{Levelized Energy - Oldesi Inventory Scenario}

This scenario accepts the first 63,020 M'T to be discharged. This includes all discharges from the earliest, in 1968, through 2011, with a portion of the higher burnup fuel from $2(012$ included to make up the full 63,020 MTU. This fuel is accepted in two narrow age ranges, the younger being 15-18 yr, and the older 32-36 yr after discharge all the time of acceptance. In all but the final receipt year, fiel is accepled from both age groups, thus providing some flexibility in the arrangement within each repository panel to compensate for local geometric effects. To preserve this flexibility, we were forced to allow the annual average integrated energy to increase sonewhat in the last three receipt years, because the amount of older fuel remaining in the inventory was rapidly dwindling. In the final year, there was none left, so the entire allocation was from the younger age group. However, during the first $22 \mathrm{yr}$, the average integrated energy for the receipts for each year was held constant at $84.7 \mathrm{~kW}-\mathrm{yr} / \mathrm{MTU} \pm 3.3 \%$. The average age, burmup, and energy characteristics, together with the age groupings for this scenario, are plotted in Figure 13. The annual characteristics, detailed receipt schedules, and inventories and for this scenario are tabulated in Appendix E.

\section{Levelized Energy.. "Hi-Graded" Inventory Scenario}

This receipt scenario is very similar to the previous one, but is designed to "hi grade" the available inventory by selecting the highest burnup fuel of each type. 'To fill this set of receipt schedules, all PWR fuel with hurnups $\geq 30$ () GWI)/MTU discharged between 1972 (the first year with this burnup) and 2()17, plus a portion of the 2018 discharges, were selected for receipt. For BWR fuel, all available discharges with burnups $\geq 20$ GWD/M'TU, covering the period from 1969 to 2016 , plus a portion of the 2017 discharges, were selected. Again, the fuel is accepted in two narrow age ranges, the younger being 10-12. yr, and the older 27-32 yr after discharge at the time of acceptance. These ranges have two exceptions: the age range for the first acceplance year is wider (26-34 yr) due to the very limited number of assemblies in the higher burmup ranges during the early discharge years, and a lew nine-year-old PWR assemblies were neceded in the linal acceptance year to fill out the selection. 'I'hese deviations from the general ranges are not significant. Again, in all but the final year, fuel is aceepted from both age groups, thus retaining the flexibility to make intra-panel compensations. In the final receipt year, the older inventory was exhatusted and the average integrated energy is therefore some what higher. 'The average energy during the first $24 \mathrm{yr}$ was held constant at a value of $97.2 \mathrm{~kW}-\mathrm{yr} / \mathrm{M} T U \pm .3 .3 \%$. This increalse of $>1.5 \%$ over the culergy deposition from the previous scenario should be expected (o produce al corresponding increase in the temperature rise at the emplacement hole surfaces in the repository, everything else being egual. The characteristics for this scenario are plotted in liggure 14, and the anmmal receipt scheclule data are labulated in Appendix li. 
Selecting the levelized energy receipt schedules was straightforward once we had determined that a combined FIFO-LIFO scenario with a minimum age approseh would yield a suitable result. With a clearly defined target, lee, the realizalion of our "optimization parameter," the selection process consisted of a series of "cut and try" executions of the scheduling program. The early runs were devoted to verifying the correct operation of the variable parmmeters it the program, as they were added, and qualitatively determining the sensitivity of the resull to their tise.

The scheduling program was run and evaluated about 100 times to determine the selected receipt schedules. We established a tentative goal of achieving a $\pm 1(1 \%$ range for uniformity of the integrated energy parameter. This was so easily reached that we sel a second goal of $\pm 5 \%$. As noted above, the results we are reporting for these selected scemurios are both less than $\pm 4 \%$ for this parameter. We could further improve the results, hot the validity of the inventory projections and other variables in the system do not warrant any further refinement at this time.

We have not fully evaluated the effects of all of the options avalable for adjusting the scheduling parmmeters. We are convinced, however, that the scenarios we have selected are reasonable in terms of their implementation, and sufficiently flexible to alcommodate at least some of the preferencess and constraints of other elements of the DOE system.

\subsection{3-Thermil Anulysus of the Scenamios}

A total of 12 panel-seale thermal analysis calculations have been done to atsess the effects of the deposition of radionctive decaly conergy on the temperatures of the rmplacement borehole walls at a time that corresponds to the minimum period during which "substiuntially complete containment" is to be achieved by the waste packiges. The year 23.53 , selected for these analyses, is 350 yr after the initiation of emplacement operations, or approximalcly 3()() yr following permanent closure of the repository. The points all which the temperatures are evaluated are on the borehole walls midway between the top and bottom of the waste packigges.

As stated, in Section 2.3,3, we have attributed the mass weighted average age and burnup characteristics to each of the spent fuct or DHLW packages, as appropriate, in the modeled regions of the repository. We have not attempted any geometric or package-scale "heat-tailoring" to compensate for locally hot or cold regions in any panel.

The analyses have been performed for four different panels in the simmlated repository. The most extensively studied location is Panel "H", selected because it is representative of those panels that would receive the waste packages during the "stendy-state" operations when $3(0)()$ MTU, or 1489 packages of spent fuel and $400 \mathrm{MTU}$ equivalent, or 80)() palckages of DHLW alle to be received and emplaced each year. The characteristics of receipts for the year $2(0) 14$, near the middle of the repository emplacement operations period, are used as the thermal sources in the panel for the analyses. This panel was also chosen for its geometric position in the repository as an interior panel that has at least two adjoining panels on each side. The energy contribution from these adjoining panels is accounted for in the analyses. The properties of the receipls used in the adjacent panels were selected for the years preceding and following 2()1.4 als appropriale. The modeled region is show'n in Figure?

Six different analyses of Pand "If" are reported. There of these represent the temperature distributions resulting from the emplacement of the receipts from each of the three scenarios described in Sections 3.1.1 and 3.1.2, employing the commingled waste partatge distribution scheme. The second set of three andyses are the same als the first, cxeept thall the receipts from the three scenarios are emplaced in the alternative non-conmongled configuration described in Section 2.3 .2 
the second panel lnvestiguted, Punel "J", was selected to evalunte the geonetric effects on the etemperatures that result from the ponel loculion an the end of the repository, where there are adjacent panels on only one side. In all other respects, this pancel is the sume as Pancl "I". "The modeled region for these analyses is shown in liggure 10. The churicteristic's of the recelpts for the year 20)16 are used for Pantel "J", with the contents of the other panets in the model appropriately selected. The two annlyses done on this panel use the commingled packnge distribution, and investigate only the effects of the differences between the (oldest finel bifist and levelized binergy Oldest Inventory recelpt scenarios.

The third panel we analyzed is different from the "stendy state" panels, lt is modeled receiving only spent fuel, ats planned in the acceptunce schedule, durlng the first five years of repository operations. The panel, designaled Pancl " $\Lambda$ ", is configured with the smme mumber of emplacement drifts as the steady-state panels, hut the drifts are trincated such that the receipts for each year will be accommolated within two to seven fiull drifts. 'The dedails of this pand layout are shown in Figure 8 , and lie modeled region for the andyses is shown in figgure 11. The spent finel characteristics for the years $20(0) 3102(107$ receipts ane used in lhe andyses, with the contents of the adjucent pancls appropriately adjusted. As with Pancel "f", these amilyses investignte only the

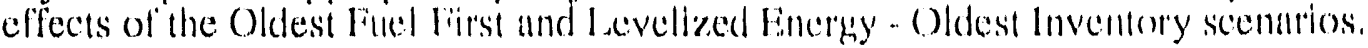

Pancl "I", the last pance we analyzed, is also different from the "steady-state" panets in our simulated repository. 'This panel, similar to Panel "A", is configured to emplace the spent fuel that is to be accepted during the last two years of repository operation, 2(126 and 2()27. "The sume modeled region was used for these analyses as for Panel "A" (Figure 11 ), and the cffects of the same two receipt scenarios were investignted.

The results of each of hese analyses are discussed briefly in the following sections and are shown graphically in the accompanying figures. These figures are of two types. The first, type A, are pseudo-isotherms of the analyzed panel. These are not true isotherms of the rock temperatures in the panel, but rather delineate regions of unilorm borehole wall temperatures, at the midpoint of the spent fuel waste packages, at 35() years following the start of emplacement, or about 30) years after repository closure. "llice interval between "isolherms" is $5 "$ "C. For reference, type $\wedge$ figures ulso contain rows of "f." murks that correspond to the lecations ol the emplaced packages.

The files from which the "isolherm" figures are made have becon processed to produce histograms. This second type of figures, type B, display the number of holes, hy waste type, thut are at a given temperature, in I" (' incements. With the aid of the "isollemens" and the histograms, one can (puickly gain considerable insight inno the results of the valrious anily'ses.

\section{Panel "H" Anulyses}

The following sectons describe briefly the results of the six different panel-scale thermal analyses that were cone for various receipt scenurios and package conligurations in Pandel "I". "The three cases that employ the SC.P.CDR emplacement scheme of commingling the spent fuel and DHLW packages are discussed first, followed by the disc ussion of the three cases that investignte the non-commingled emplicement arrangement.

\section{Qldest fuel linst-Commingled Wilste |Figures $15 \mathrm{~A}$ and $\mathrm{B} \mid$}

for this case, the borehole wall temperatures (at the midpoint of the container length,

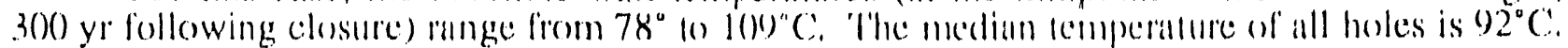

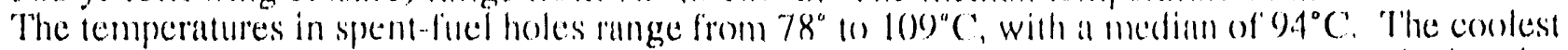
holes are along the perimeder of the panel, and the hotlest ane in the second row in firom the interion end. 'That rewe contains only spent fuel. Neurly all of the sipent livel holes in the commingled center

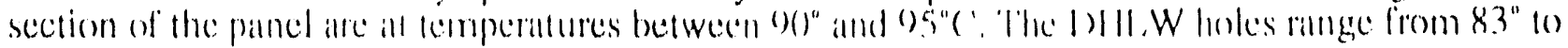


$92^{\circ} \mathrm{C}$, with a median temperature of $87^{\circ} \mathrm{C}$. These temperatures are highest in the center of the commingled region, and fall off gradually toward the outer portlons of the reglon. The large percentage of holes $(76 \%)$ that are below $95^{\circ} \mathrm{C}$ appears to preclude the possibility of local "heat talloring" to significantly increase the fraction of holes that will remain above the unconfined boiling point for the full $3(0) \mathrm{yr}$.

\section{Levelized Energy - Oldest Inventory - Commingled Waste |Figures 16A and B|}

For this case, the borehole wall temperatures range from 80$)^{\prime \prime} 10112^{\circ} \mathrm{C}$. The median temperature of all holes is $94^{\circ} \mathrm{C}$. The temperatures in spent-fuel holes range from $80^{\circ} 10112^{\circ} \mathrm{C}$, with a median temperature of $96^{\circ} \mathrm{C}$. The temperature distribution within the panel is very similar to the previous case, but slightly higher, reflecting the somewhat greater integrated energy content of the emplaced fuel. Nearly all of the spent-fuel holes in the commingled center section of the panel are at temperatures between $95^{\circ}$ and 10()$^{\circ} \mathrm{C}$. The DHLW holes range from $85^{\circ}$ to $95^{\circ} \mathrm{C}$, with a median of 9()$^{\circ} \mathrm{C}$. These temperatures are highest in the center of the commingled region, and fall off gradually toward the outer portions of the region. There appears to be a sufficient number (about 350 ) of spent-fuel holes above 10()$^{\circ} \mathrm{C}$ to allow local "heat tailoring" within the panel, by varying the age and burnup of the package contents, to bring nearly all of the spent-fuel holes up to the boiling point.

\section{Levelized Eneray - Hi-Graded Inventory-Commingled Waste |Figures 17A and B|}

The results for this case are also similar to the previous calses. This is to be expected, because the only significant difference is the higher integrated energy of the selcoted spent fuel inventory. In this case, the borehole temperatures range from $86^{\circ}$ to $121^{\circ} \mathrm{C}$, with a median temperature of $102^{\circ} \mathrm{C}$. These values are $6-8^{\circ} \mathrm{C}$ higher than the levelized energy - oldest inventory case. This is an increase of about $9 \%$ in the temperature rise above ambient, somewhat less than the approximate $15 \%$ increase in the average integrated energy obtained by "hi-grading" the inventory. This difference is explained by the constant energy contribution in the panel from the 8(0) DHLW packages (about one-third of the total number) in both cases.

For this case, the spentufuel hole temperatures range from $86^{\circ}$ to $121^{\circ} \mathrm{C}$, with a median temperature of $104^{\circ} \mathrm{C}$. Less than $2 \%$ of the spent-fuel holes are below the boiling point, so a very limited amount of package-scale heat-tailoring would be needed to reich the objective. The DHLW holes are also somewhat hotter in this case than in the previous inventory cases. They range from $92^{\circ}$ to $102^{\circ} \mathrm{C}$, with a median temperature of $97^{\circ} \mathrm{C}$. By extensive spent fuel package-tailoring to take advantage of the higher energy available, it may be possible to adjust the temperature of all holes in this panel configuration to remain above boiling for 30() $\mathrm{yr}$.

\section{Qldest Fuel First - Non-Commingled |Figures $18 \mathrm{~A}$ and $\mathrm{B}$ )}

As we expected, this configuration creates a very wide distribution of borehole wall temperatures in the panel. The borehole temperatures range from $12^{\circ} 101.34^{\circ} \mathrm{C}$, with a median temperature of $107^{\circ} \mathrm{C}$. The spent-fuel holes, which are all located in the central region of the panel, are well-guarded by the DHLW packages on the perimeter. 'The spent-fiel hole temperatures range from $81^{\circ}$ to $1.34^{\circ} \mathrm{C}$, with a median temperature of $119^{\circ} \mathrm{C}$. Aboul $9.5 \%$ of these holes are above the boiling point, so very little package-scale tailoring would be needed to bring all of their temperatures well above 10()$^{\circ} \mathrm{C}$ at 3()()$-y r$ postclosure. The DHLW holes, on the oller hand, are all below the boiling point, with temperatures ranging from $42^{\circ}$ to $95^{\circ} \mathrm{C}$, with a median temperature of only $57^{\circ} \mathrm{C}$. Recall that this effect was the intent of this emplacement schems. It is guite effective at achieving the design intent. Little variation in the energy output of the DIILW receipts in a given year is expecied, so there is no significant package-scale tailoring potential to improve the situation for the DIII.W holes in this panel configuration. 
Levalized Energy - Oldess Lnventory. Non-Commingled frigures loA and B|

The offect of changing the receiph scemario produces only minor changes in the temperature

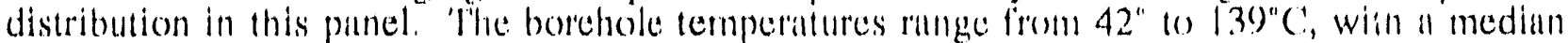
temperature of $111^{\circ} \mathrm{C}$. The spent-fluel hole temperatures range fiom $8.3^{\prime \prime} 1013$. $^{\circ} \mathrm{C}$, with 11 median temperuture of $123^{\circ} \mathrm{C}$. About $96 \%$ of the spent-fuel holes are above the boiling point, so very littl: package-scale tailoring would be needed to bring ull of their temperilures well above 10()$^{\circ} \mathrm{C}$. IIt 300-yr postelosure. The DHLW holes, on the other hand, are below the boiling point, with temperatures ranging from $42^{\circ} 1097^{\circ} \mathrm{C}$, with a median lomperature of only $59^{\circ} \mathrm{C}$. As in the previous case, there is no signficant package-siale miloring potential on improve the situation for the DHLW holes in this panel configuration.

\section{Levelized Energy - Hi-Graded Inventory - Non Commingled |l iphures $20 \mathrm{~A}$ and B}

This case is also very similar in character to the parallel case for the oldest inventory. All temperatures are slightly higher, but the overall distrihutions are nearly identical. The overall range of temperatures is somewhat wider; they range from $45^{\circ}$ to $151^{\circ} \mathrm{C}$, with a median temperature of $121^{\circ} \mathrm{C}$. The spent-fuel hole temperatures range from 9()$^{\circ}$ to $151^{\circ} \mathrm{C}$, with a median temperature of $135^{\circ} \mathrm{C}$. Less than $1 \%$ of the spent-fuel holes are culculated to be below the boiling point, and this could be easily remedled by slight package tailoring. The DHL.W holes lange fiom $45^{\circ} 10106^{\circ} \mathrm{C}^{\prime}$, with a median temperature of $63^{\circ} \mathrm{C}$. As in the other non-commingled cases, little potential exists for significant improvement in the DHI.W temperature distribution within this pand configuration.

\section{Panel "J" Analyses}

Two thermal analyses of Panel "J" were done to evaluate the geometric effects associated with its location at the end of the simulated repository. These cases were both done with the comningled waste package configuration; only the receipt scemarios were varied.

\section{Oldest Fuel First-Commingled |Figures $2 \mid A$ and $B \mid$}

The borehole temperatures in the pance are approximately the same as those seen in the interior panel, except that there is a significant asymunctry acress the width of this exterior panel. The temperatures of the spent-fuel holes on the inlerion edge of the pand are about $15^{\circ} \mathrm{C}$ higher than those on the outer edge. The temperatures range from $75^{\circ}$ I 121$)^{\circ} \mathrm{C}$, with a median temperallure of $98^{\circ} \mathrm{C}$. 'The spent-fuel holes have the wider range, varying from $75^{\prime \prime}$ to 12()$^{\prime \prime} \mathrm{C}$, with a median

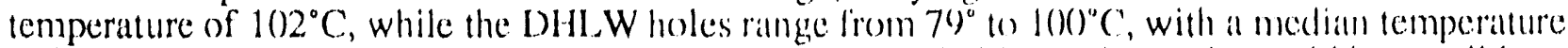
of $88^{\circ} \mathrm{C}$. About $60 \%$ of the spent-fuel holes are ahove the boiling point, so it would be possible to "tailor" the package contents to compensate for the boundary eflects and significantly increase the number of holes above boiling. However, lhis would generally lower the temperatures of the commingled DHLW holes, as they would lose some of the benefit of honter spent fuel neighbors.

\section{Levelized Energy - Oldest Inventory - Commingled |Figures 22A and B}

This case, as expected is similar to the previous one, except that the temperatures are reduced a few degrees because the integrated energy content of the fucl for the year 2016 is a little less than the oldest first scenario. The same asymmetry occurs, and it is of the same magnitude. The hole termperatures range from $70^{\circ}$ to $111^{\prime \prime} \mathrm{C}$, with a median temperulure of $92^{\circ} \mathrm{C}$. The spent-fue! holes vary from $70^{\circ}$ to $111^{\circ} \mathrm{C}$, with a median temperature of $95^{\circ} \mathrm{C}$, while the DHLW holes vary from $74^{\circ}$ to $93^{\circ} \mathrm{C}$, with a median temperature of $88^{\circ} \mathrm{C}$. . As above, package lailoring would permit some compensition for the geometric asymmetry, but with the same effect on the DHILW holes. 


\section{Panel "A" Analyses}

The most dramatic effects on the temperutures in a punel produced by the Oldest Fuel First and Levelized Energy receipt scenarios is seen in the analyses for Pancl " $A$ ". The receipts for this panel, which contains only spent fuel, exhibit the greatest difference in the integrated energy for the two scenarios. These two analyses are discussed in the following sections.

\section{Qldest Fuel First. All Spent Fuel |Figures $23 \mathrm{~A}$ and $\mathrm{B}$ |}

In this analysis, no holes remuin above the boiling point temperature at $3(0)$ yr following closure. This is the only case among those we analyzed for which that is true. The location of this panel at a comer of the simulated repository, the very low average burnup, and the advanced age of the fuel combine to produce this adverse result. The hole temperatures range from $50^{\circ} 1096^{\circ} \mathrm{C}$, with a median temperature of $83^{\circ} \mathrm{C}$. Because the receipts from this scenurio have such low energy content, there is little package tailoring that could be done to improve the situation. One other ilternative, not investigated in this study, woukd be to substantially reduce the spacing between the emplacement drifts to increase the energy density in the panel. Recall that we have already used the minimum spacing between holes that is receptable for construction and operations.

\section{Levelized Energy-Oldest Inventory. All Spent Find |Figures 24A and B|}

In contrast to the preceding case, the use ol the levelized encegy scenario receipts for the early years very significantly increases the harchole temperalures throughout this panel. The temperatures range from $73^{\circ}$ to $139^{\circ} \mathrm{C}$, but the median lemperature is $12.3^{\circ} \mathrm{C}$, and only about $5 \%$ of the holes are at less than the boiling point at 30)() yr. 'Therefore, only very minimal package tailoring would be needed to ensure that all holes would sattisfy the objective. This cure, and the preceding one, both contain the same type of asymmetry observed in Panel "J" due to the corner location of this panel. The asymmetry in Panel " $A$ " is less pronounced, due to the absence of the very low energy DHLW in this panel. It should be noted that, by continuing to use the 7.5-ft hole spacing, even though the panel contains only spent fuel, this case and the following Panel "T" cases have mised the effective areal power density (APD) in the panel well above the SCP.CDR design basis of $57 \mathrm{~kW} / a c r e$. As discussed in the following section, entitled "Other Thermal Analyses Results", these cases are very near the power density that would exceed the allowable peak temperature for" the waste form. Some further observations and inferences from this analysis are included in the conclusions in Section 3.2.

\section{Panel "T" Analyses}

T'wo analyses were performed in the other panel that contains bnly spent fuel, Panel "T". These cases parallel the Pancl "A" cases, and are included to show the effect of a significantly higher integrated energy density on the temperature distributions, irrespective of the receipt scenario that is employed.

\section{Oldest Fuel First - All Spent Fuel |rigures $25 \wedge$ and $B$ |}

This case results in the highest temperatures that were calculated for any of those analyzed. The borehole temperatures range from $83^{\circ}$ to $162^{\circ} \mathrm{C}$, with a median temperature of $143^{\circ} \mathrm{C}$. More than $99 \%$ of the holes are above boiling at $300 \mathrm{yr}$, and about half of them would be expected to still be above boiling temperature at the end of $10(0) \mathrm{yr}$. There is an asymmetry in the distributions similar to that observed in the Panels "J" and " $A$ " cases due to the geometric: location in the repository simulation. 
Levelized Energy - Oldest Inventory - All Spent Fuel |Figures 26A and B]

This case is virtually identical to the previous one and is included only to complete the study matrix. A very slight difference in the area within the 160$)^{\circ} \mathrm{C}$ "isotherm" is observed but is not significant at the resolution of the analysis. A cursory examination of the fuel receipt characteristics resulting from these two scerarios for the final two years of operations shows that this similarity was to be expected.

\section{Qther Thermal Analyses Results}

Two other aspects of the thermal effects were investigated in the course of the study. We made a calculation of the borehole wall temperature distributions at points located opposite the ends of the waste packages to see how the end effects influenced the temperatures. At 300 yr after closure, the temperature differences between the midplane of the package length and the end of the package were small. They ranged from $t$ difference of $4.4^{\circ} \mathrm{C}$ in a hole located in the extreme corrar of the panel to $5.1^{\circ} \mathrm{C}$ in the hottest hole in the center of the panel. When expressed as a fraction of the temperature increase above the pre-emplacement ambient, these differences are the same. In the actual repository situation, other local effects, such as a convective cell within the waste packageborehole annulus, will probably dominate the thermal field within the borehole, and the real distribution would be somewhat different than the one we calculated.

We also calculated a borehole-wall time history for the emplacement hole in Panel "H" with the highest 300-yr temperature to determine what the peak temperature was that it reached and when that peak occurred. This calculation was done to assure ourselves that the peak temperature was below the design limit of $275^{\circ} \mathrm{C}$ established in the SCP-CDR. The calculated peak was $242^{\circ} \mathrm{C}$ and it occurs $22 \mathrm{yr}$ after emplacement. This time history for the period from emplacement to 3()() $\mathrm{yr}$ following repository closure is shown in Figure $27 \mathrm{~A}$. This time history calculation was extended to show the rate of continued cooling out to $1000 \mathrm{yr}$; this is plotted in Figure 27B.

This peak borehole-wall temperature value was also compared with the results of packagescale finite difference and finite element calculations that have been done, using the "hybrid" package configuration, to infer a peak spent-fuel cladding temperature. From this comparison, the peak cladding temperature corresponding to this peak borehole temperature would be $335^{\circ} \mathrm{C}$. This compares with a design basis limit on the peak fuel cladding temperature of $350^{\circ} \mathrm{C}$. The peak cladding temperature would be expected to occur about 4 yr after emplacement.

\section{2 - CQNCLUSIONS}

Based on the results of the receipt scenario investigations and the thermal analyses described in the preceding sections, we conclude that it is feasible to specify age, burnup, and fuel type characteristics of the spent-fuel waste stream to be delivered to the repository for disposal, and to tailor that stream to distribute its energy output in the repository to balance the temperature distributions within the disposal panels. However, it is beyond the scope of this limited study to assess the feasibility of delivering a spent-fuel waste stream with tailored characteristics to the repository because there are many other elements of the waste management system that have constraints on, or preferences for, these characteristics.

\subsection{1 - Conclusions on Receint Scenarios}

There are a near-infinite number of possible scenarios for scheduling spent-fuel receipts. Must of them would be based on one or another of the common inventory management strategies, such as "first in-first out," "last in-first out," or some combination of these. Because the spent fuel inventory will have been discharged over a long period of time prior to the initial shipments to the repository and because the discharges will continue during the receipt period, the selection scenarios 
are complex. During the "steady-state" repository" operational pericd, the annual discharges are less than the receipt rate. This allows us to receive a blended mix of fuel ages as the older backlog is "worked off." The extreme case of this approach is shown in Figure 3, where a mix of 5-yr-old and older fuel is received. The older fuel fraction of the fuel stream gets progressively older, and flexibility to tailor the energy characteristics is lost.

We conclude, after examining a wide variety of possible scenarios, that the approach we selected using fuel in two fairly narrow age ranges to equalize the energy contained in each year's receipts is a reasonable choice. Many other scenarios using this general approach are certainly possible.

The major conclusion to be drawn from a comparison of the Oldest Fuel First and the Levelized Energy scenarios is that the principal effect occurs during the first 10-12 yr of operations. During this period the largest annual variations in the OFF integrated energy values are observed, and, therefore, the largest benefits accrue by leveling this characteristic. This, of course, is accomplished at the expense of a somewhat lower integrated energy in the levelized case in the later years. If this leveling can be achieved, other options exist for increasing the hole temperatures for extended periods, such as reducing the spacing between emplacement drifts, effectively increasing the areal energy density.

\subsection{2- Conclusions on Thermal Anailyses}

We conclude from the preliminary thermal analyses of the effectiveness of emplacing the spent fuel and high-level waste that there is a strong potential for reaching the objective of keeping a very large fraction of the emplacement holes holler than the unconfined boiling point of water for time periods in excess of $3(x)$ yr following repository closure.

Though the analyses reported here fall short of the objective of maintaining all emplacement hole temperatures above boiling for 30() $\mathrm{yr}$, they are based solely on uniform emplacement of the "as-received" waste stream. In the results section, we have alluded to some package-scale tailoring of the spent fuel to substantially improve the wall-temperature distribution. In addition, it is possible to vary the emplacement drift and hole spacings within the panels to further enhance the distributions. This "geometric heat tailoring" could be very effective, but in order for it to be viable, with the present repository construction and operating concepts, it would require fairly detailed knowledge of the characteristics of the spent fuel and high-level waste about two years in advance of receipts.

This lead time could be achieved by advance agreement with the utilities. Alternatively, a capability to modulate the character of the waste stream utilizing a lag storage facility within the control of the DOE system, such as an MRS, could serve this function.

\section{3-RECOMMENDATIONS}

As we reached the completion of the study reported here, there were several additional tasks that we realized ought to be undertaken. We therefore recommend that consideration be given to authorizing this additional effort, in the interests of bringing the study to a logical completion, for this level of detail. These tasks are almost entirely in the category of sensitivity studies, which will bring insight to the effect of varying parameters that we did not adequately investigate.

From the thermal analyses, it is clear that the effects of tailoring the contents of selected individual packages and panel-scale geometric tailoring will have significant effects on the thermal distributions. A few additional analyses will provide a basic understanding of these effects, and should be done. Coordination with the repository design team will be needed to establish the details of the parameters to be varied for these proposed analyses 
Comparative analyses of the effects of OFit and Levelized linergy scenario receipts in a few of the other panels, especially those between "A" and "H", should be performed to get a better perspective on the temperature distributions $\mathrm{i}$. that region.

Finally, we recommend a continuation, on a periodic basis, of the discussions that were initiated in conjunction with this study among the members of the OCRWM and the contractor community with a specific interest in the various aspects of spent-fuel receipt scheduling implications. Consideration should also be given to adding to this group representation from the HLW element, so that the overall scheduling of the DOE system waste stream can be discussed. 


\section{0 - PEFERENCES}

10 CFR 961, 1983. "Standard Contract For Disposal of Spent Fucl And/(or High-Level Radioactive Waste," Code of Federal Regulations, Title 10, Parr 961. NNA.87()407.0158.

Andress, D., 1988. Personal Communication, David Andress \& Associates, Inc., Kensington, MD, to L. Ballou, Lawrence Livermore National Laboratory, Livermore, CA, dated October 6, 1988. NNA.9()()43().(1)46.

DOE (U.S. Department of Energy), 1987a. Characteristics Or Spen Eucl High-Level Waste And Other Radioactive Wastes Which May Require Long.Term Lsolation, Office of Civilian Radioactive Waste Management, Washington, D.C., DOE/RW-()184 (Volume 1 of 6). HQ().88(0121.(0)()1.

DOI: (U.S. Department of Energy), 1987b. Nevada Nuclear Waste Storage Investigitions Project Reference Information Base, Nevada Operations Office, Las Vegas, NV, NNWSI/88-5 (Version ()3.()()1). NNA.88()121.(1)43.

DOE (U.S. Department of Energy), 1988a. Draft 1988 Mission Plan Amendment, Office of Civilian Radioactive Waste Management, Washington, D.C., DOE/RW-0187. HQ(0.880620.0022

DOE (U.S. Department of Energy), 1988b. Site Characterization Plan, Yuccia Mountain Site, Nevada Research and Development Area, Nevalda Office of Civilian Radioactive Waste Management, Washington, D.C., DOE/RW-(0199, (Chapter 7). HQ().881201.(00)2.

Johnson, G.L., and D. N. Montan, 199(). Thermal Calculations Perlaining To A Proposed Yucca Mountain Nuclear Waste Repository, Lawrence Livermore National Laboratory, Livermore, CA., UCRL-ID-10.3534. NNA.9(0)925.0)6().

Montan, D.N., 1986. The Plus Eamily = A Set of Compuler Programs To Evaluate Analytical Solutions of The Diffusion Equation, Lawrence Livermore National Laboratory, Livermore, CA., UCID -2068(). NNA.9)()43().(5)44.

Sandia, 1987. Nevada Nuclear Waste Storage Investigations Project Site Characierization Plan Conceptual Design Report, Sandia National Laboratories, Albuquerque, NM., SAND84-2641 (6 Volumes).NN1.880902.0014 through NN1.88(1)9(2.00)19.

Skousen, L.P., Personal Communication to T.O. Hunter, Sandia National Laboratories, and L.D. Ramspott, Lawrence Livermore National Laboratory, Request for Waste Receipt Scenarios Study, dated Sept. 1, 1988. NNA.900430.(0)(15. 


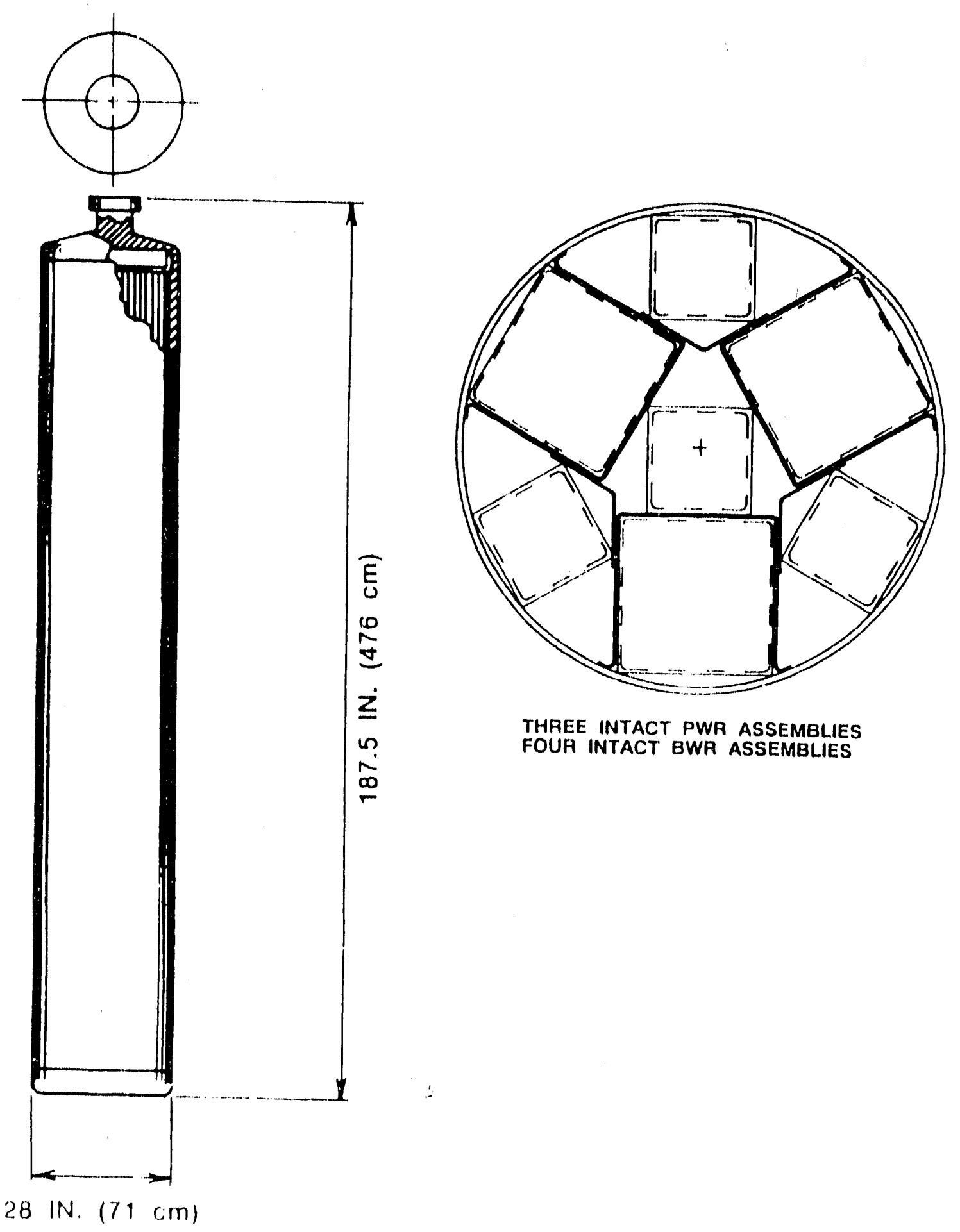

Figure 1. Hybrid spent fuel waste package configuration 


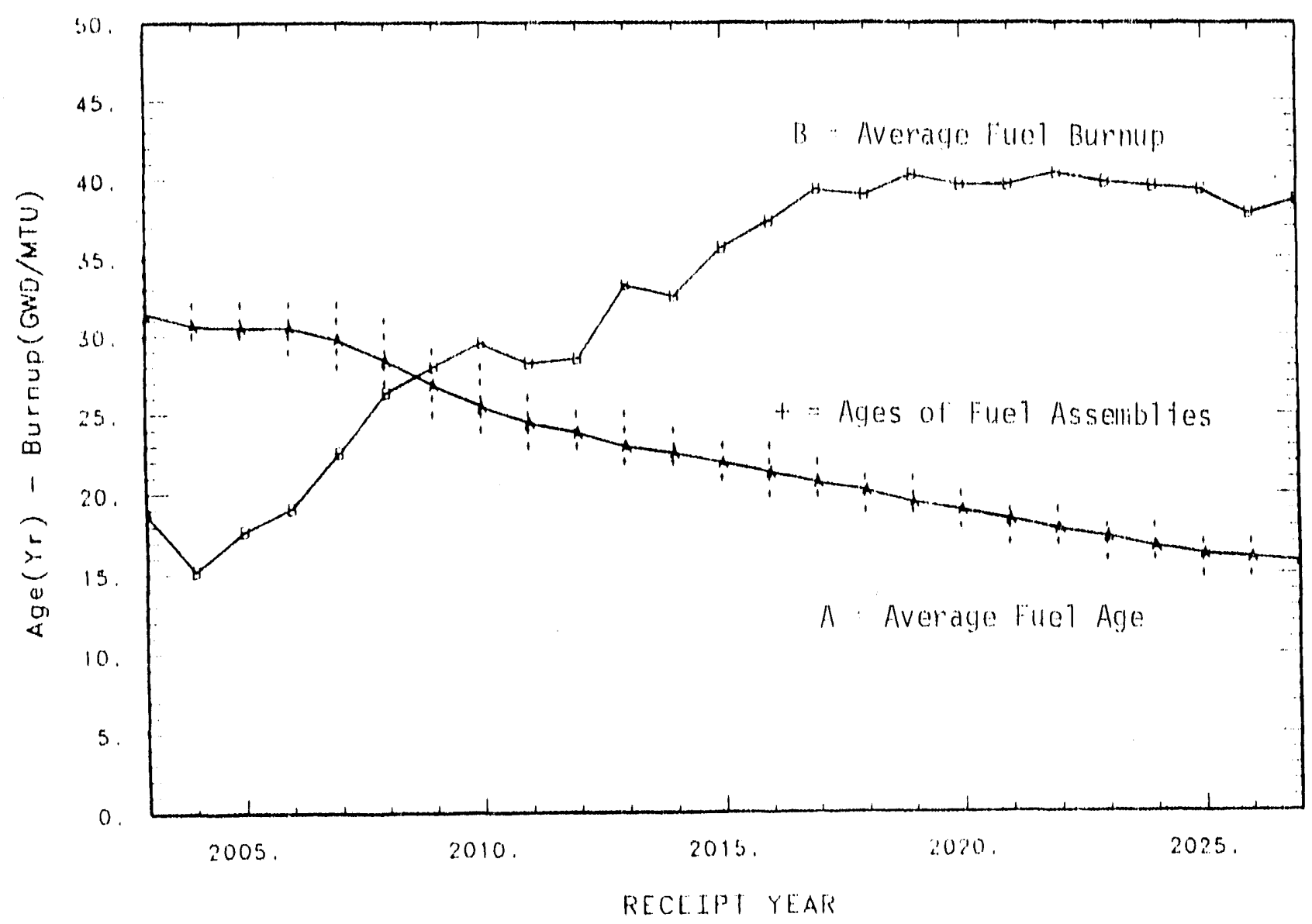

Figure 2. Age and Burnup characteristics of spent fuel received in the "First In - First Out" receipt scenario 


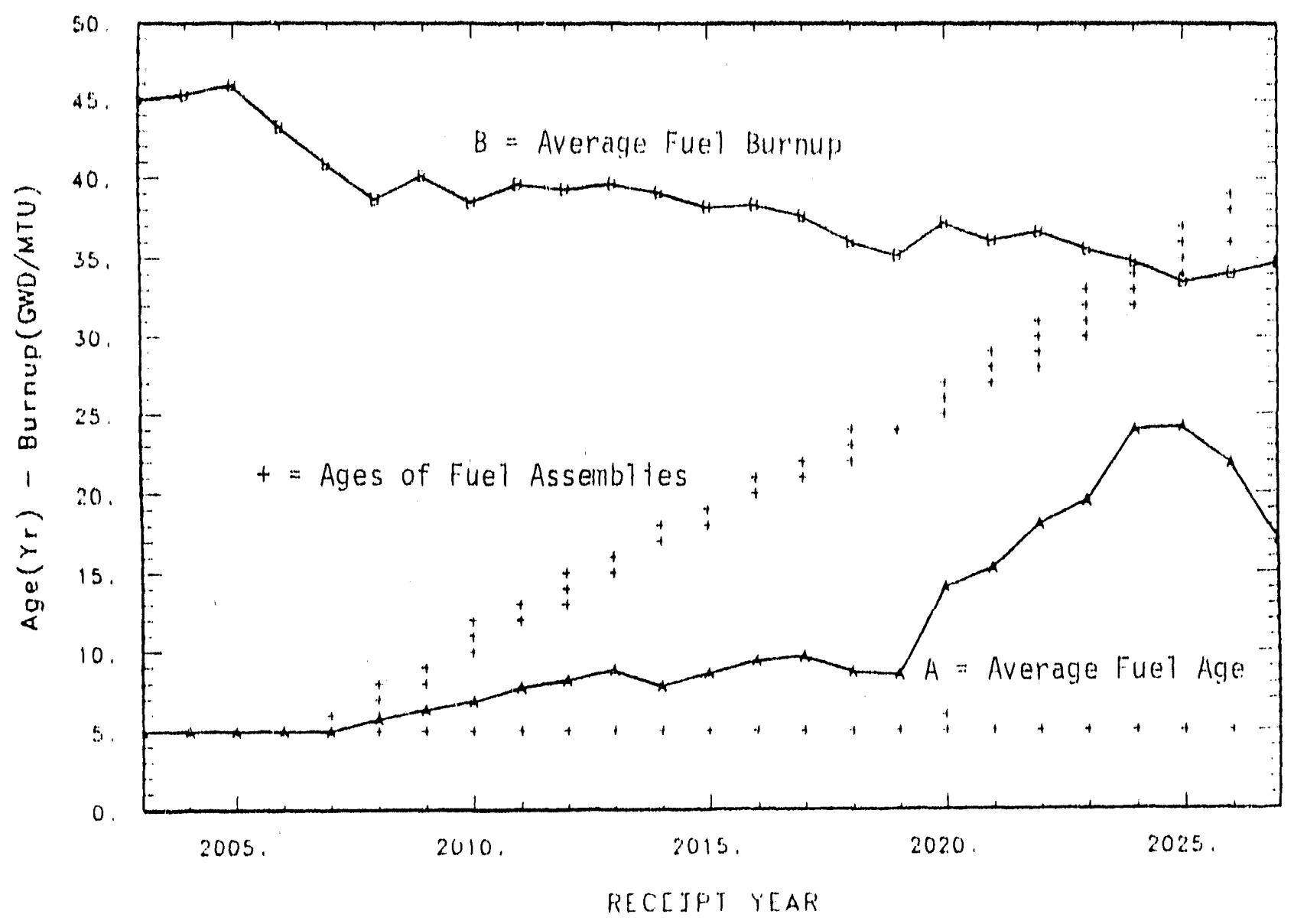

Figure 3. inge and Burnup characteristics of spent fuel received in the "Last In - First Out" receipt scenario with a 5 - year minimum age 


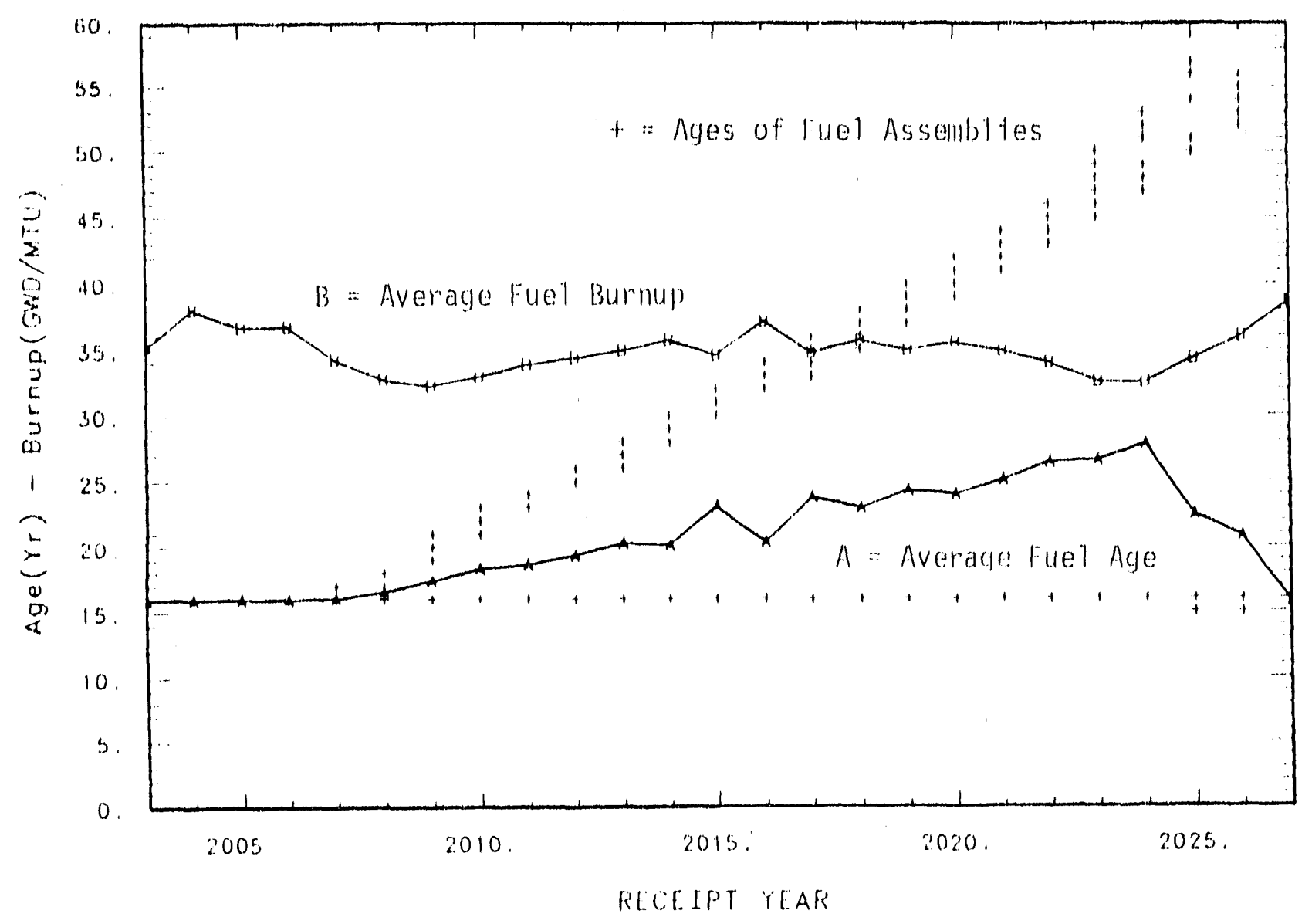

Figure 4. Age and Burnup characteristics of spent fuel received in the "Last In - First Out" receipt scenario with a 16 - year minimum age 


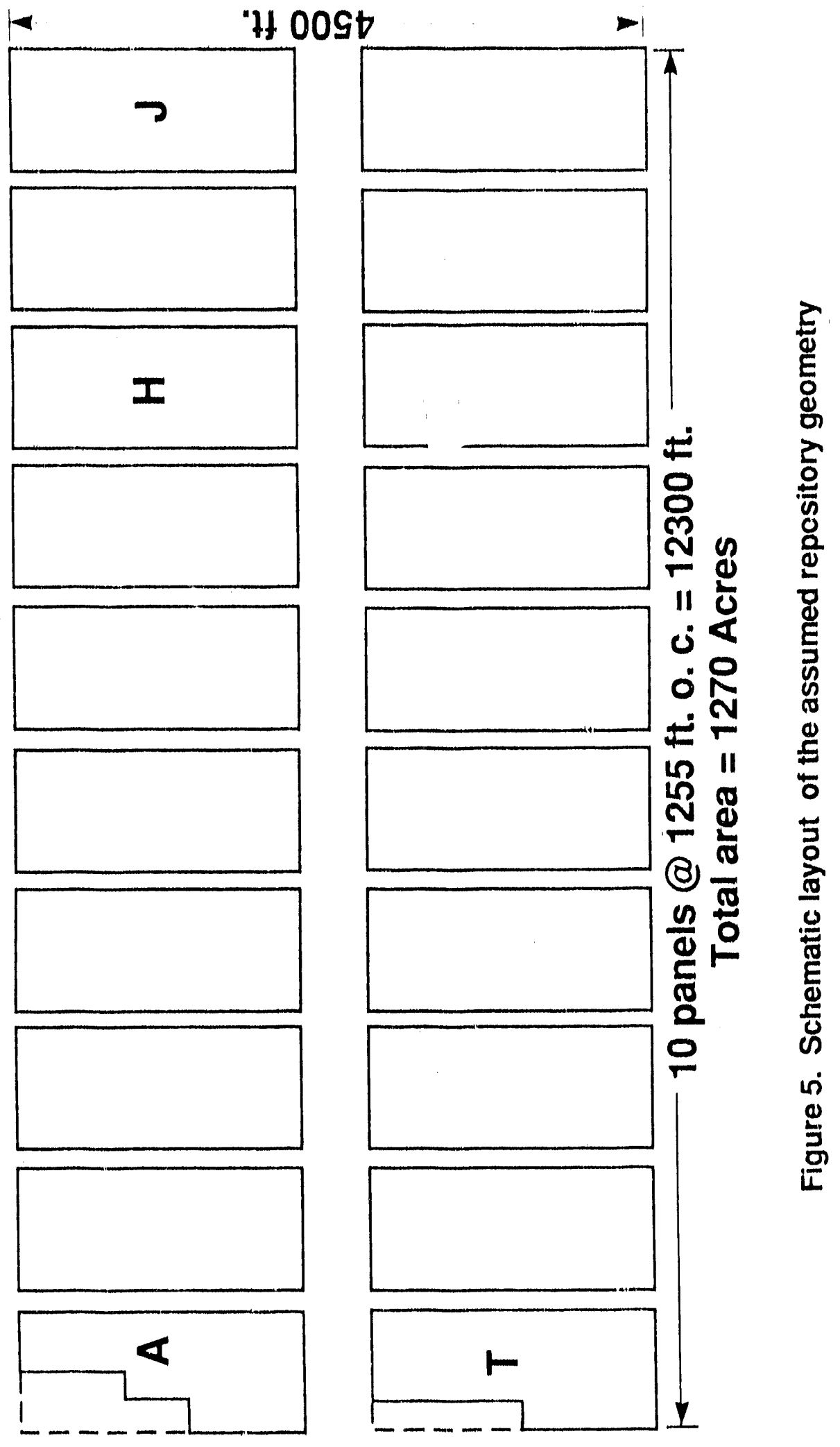




\section{(Not to scale)}

Two exterior rows, all 135 holes contain spent fuel

13 rows in middle of panel, each contains 6 SF at ends of row and 62 DHLW and $61 \mathrm{SF}$ commingled In center of row

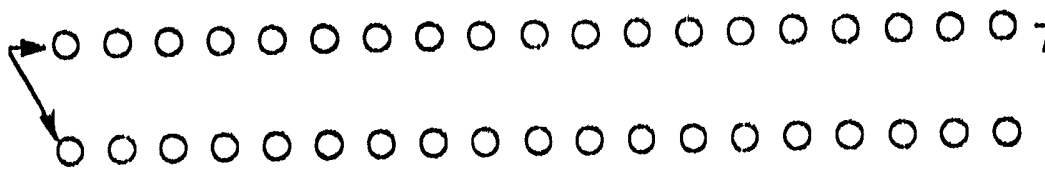
T000000・0・0・0・000000 $000000 \cdot 0 \cdot 0 \cdot 0 \cdot 000000$ 000000 000000 000000 000000 000000 000000 000000 000000 000000

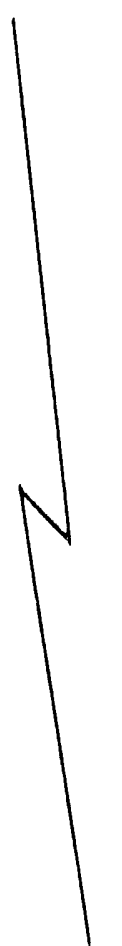
- 000000 - 000000 - 000000 - $000000 \frac{\text { N }}{\mathrm{N}}$ - 000000 - 000000 $-000000$ - 000000 - 000000 $000000 \cdot 0 \cdot 0 \cdot 0 \cdot 000000$ $1000000 \cdot 0 \cdot 0 \cdot 0 \cdot 000000$

Two interior rows, all 135 holes contain spent fuel

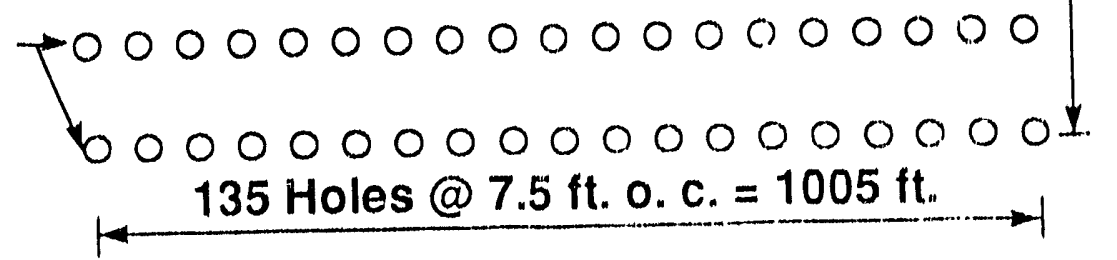

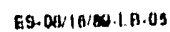

Figure 6. Commingled waste emplacement layout within a typical panel $(H, J)$ 
(Not to scale)

Two exterior rows, all 135 holes contain DHLW

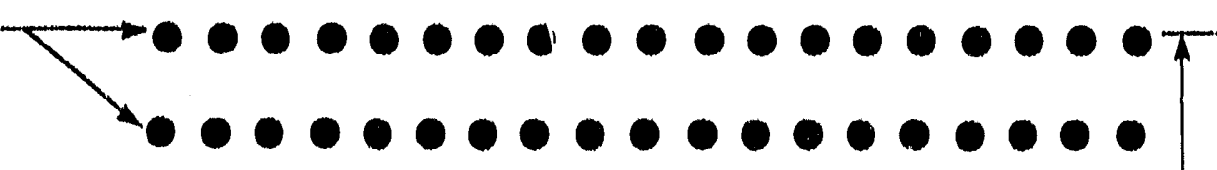

13 rows in middle of panel, each contains 10 DHLW at ends of row and $115 \mathrm{SF}$ contalners in center of row

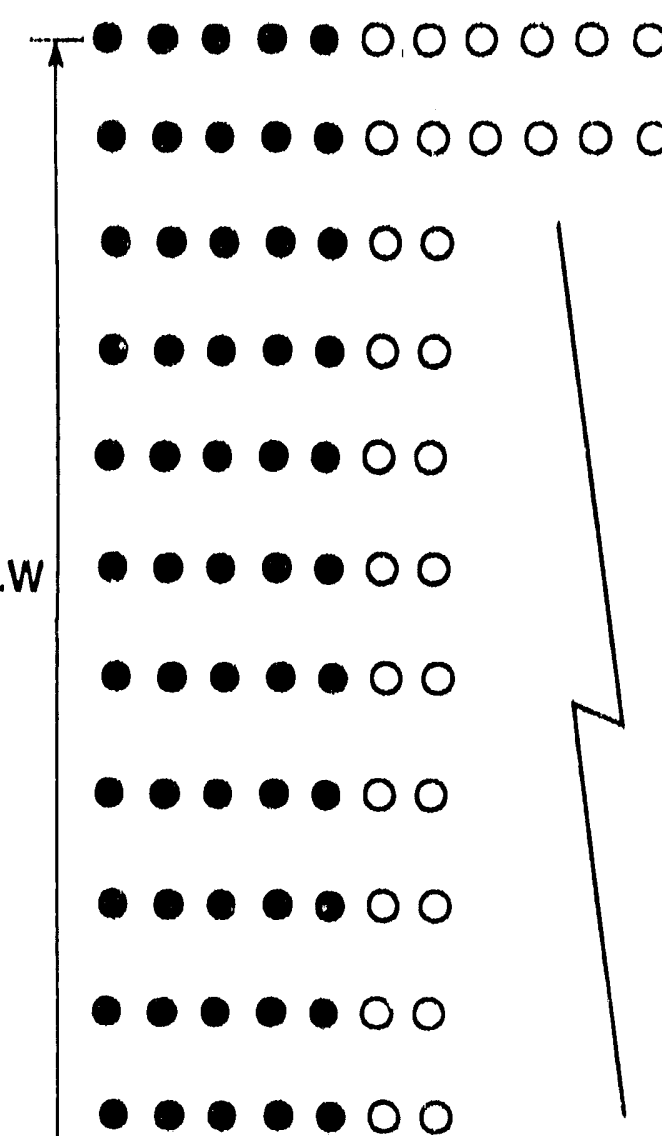

$000 \bullet \bullet \bullet \bullet$ 000000 $00 \bullet \bullet \bullet \bullet$ $00 \bullet \bullet \bullet \bullet \cdot \frac{1}{20}$

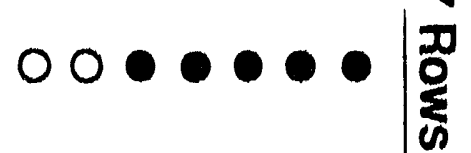
$00 \cdot 0 \cdot 0$ (2) $000.0 \cdot \frac{N}{N}$ OCl. 00.0 O 0000 $\bullet \bullet \bullet 000000000 \bullet \bullet \bullet \bullet$

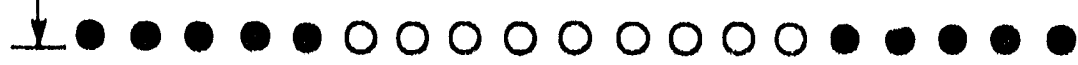

Two Interior rows, all 135 holes contain DHLW

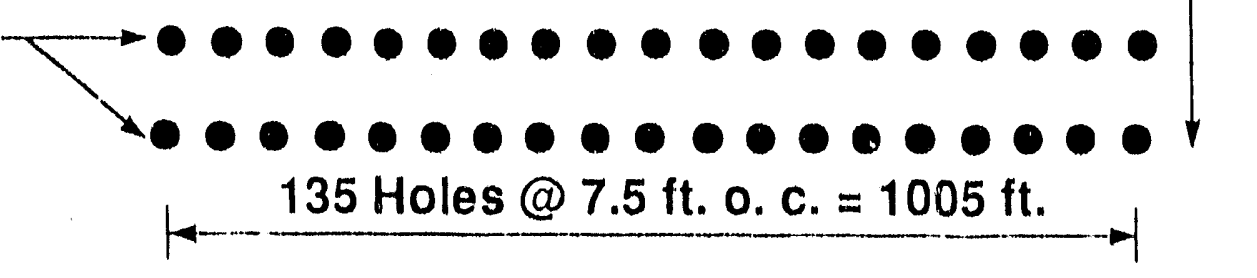

Figure 7. Non-commingled waste emplacement layout within a typical panel $(H, J)$ ES 000.04/90.M11.01 


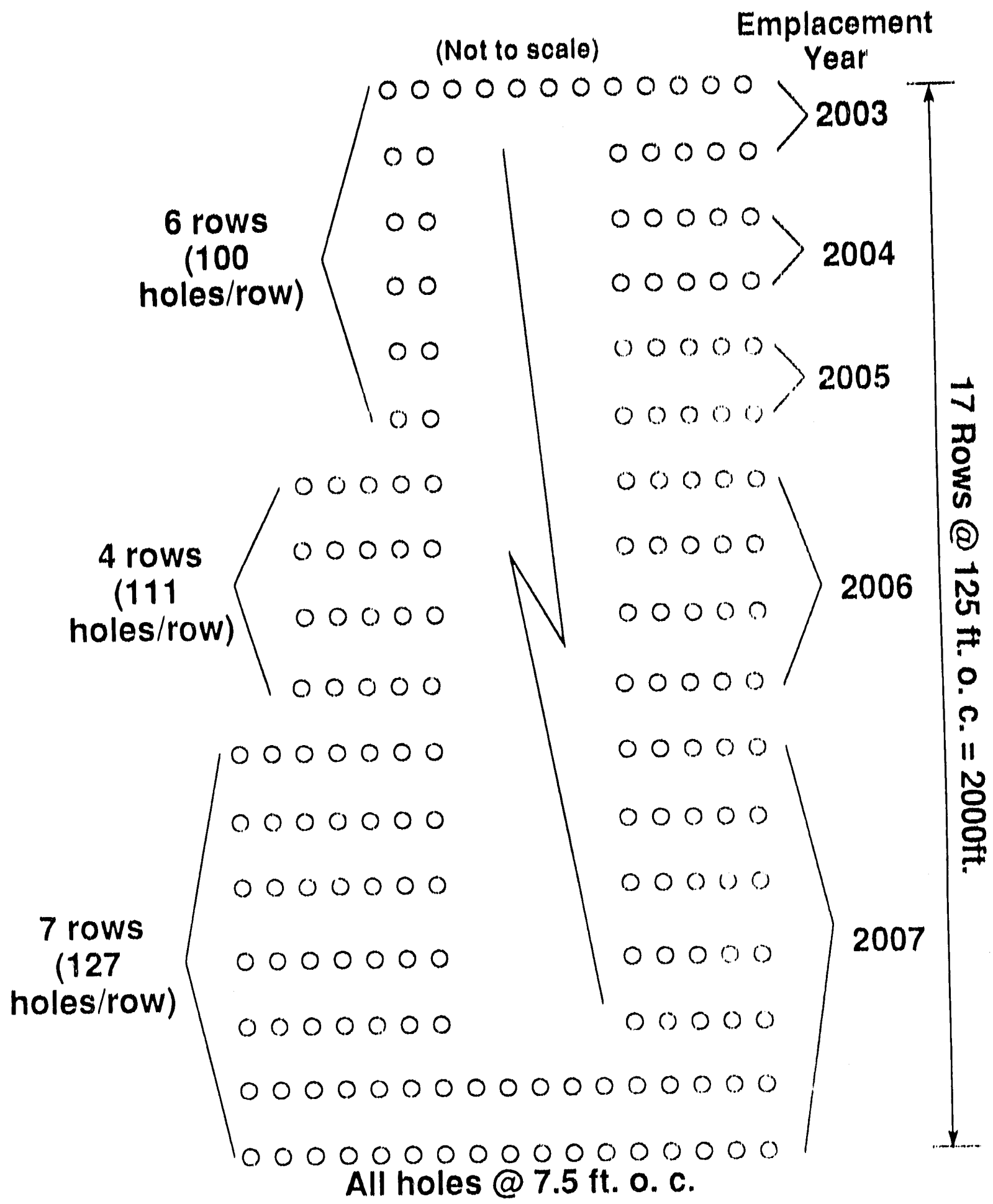

Figure 8. All Spent Fuel emplacement layout within Panel A 

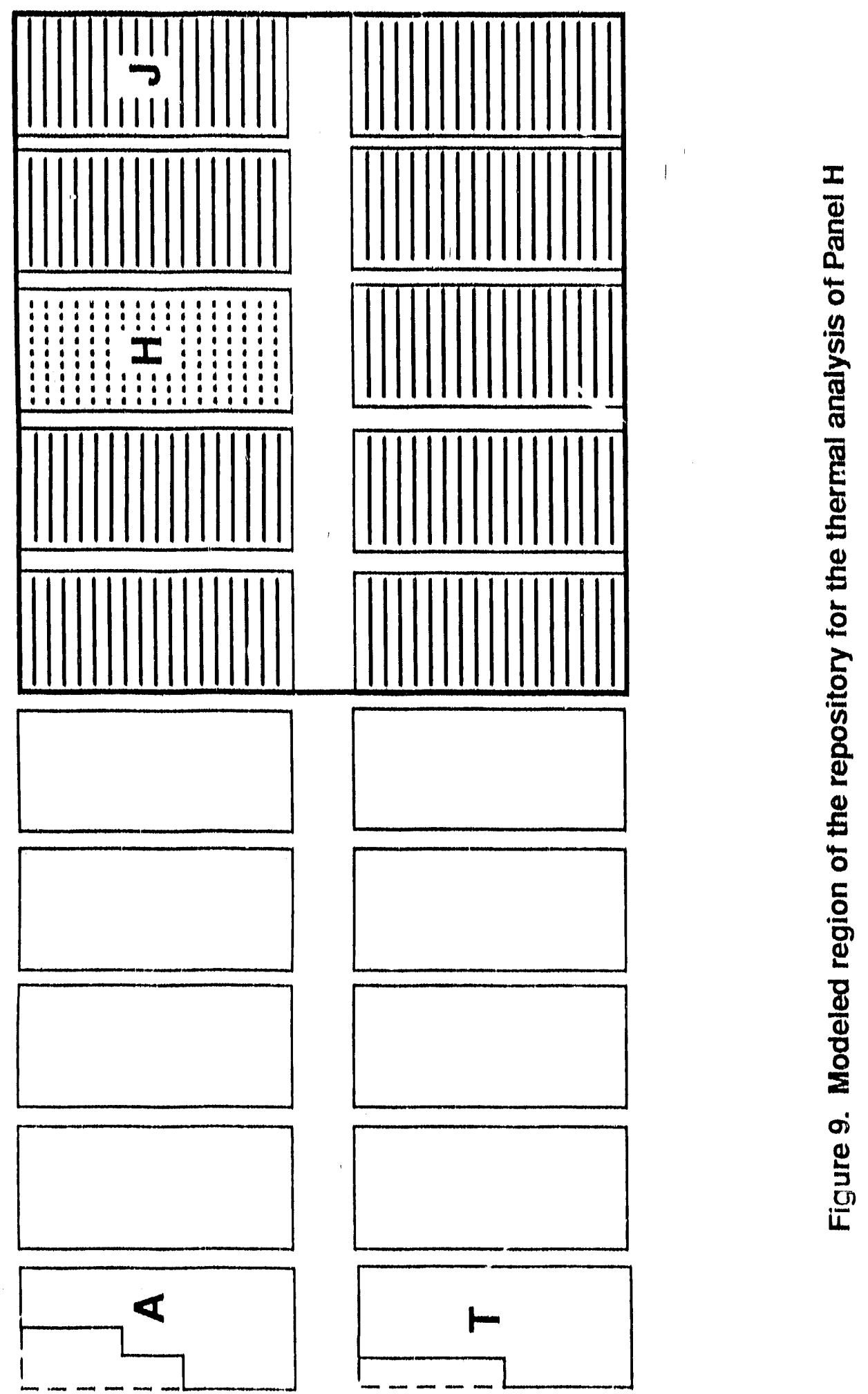


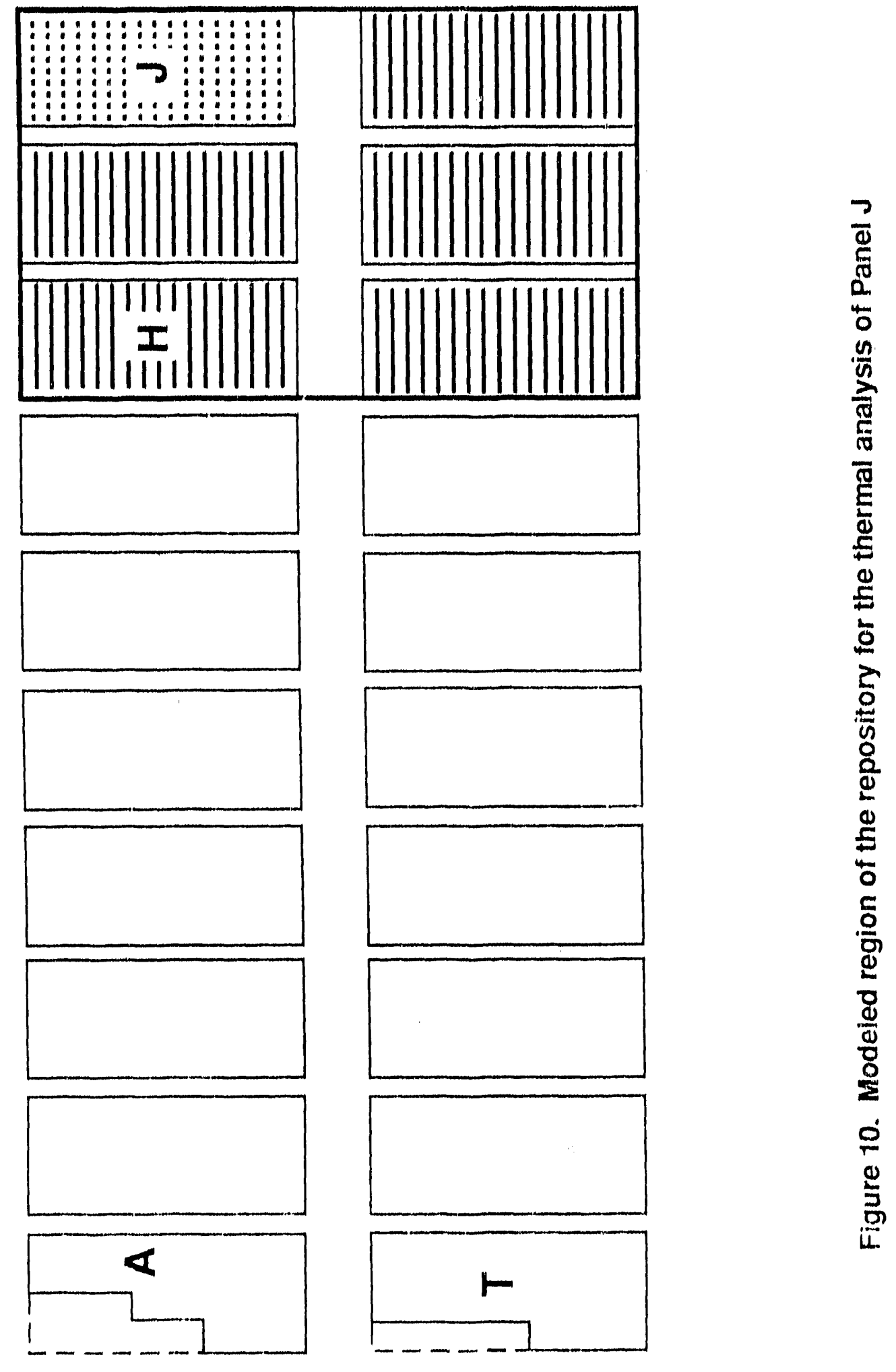




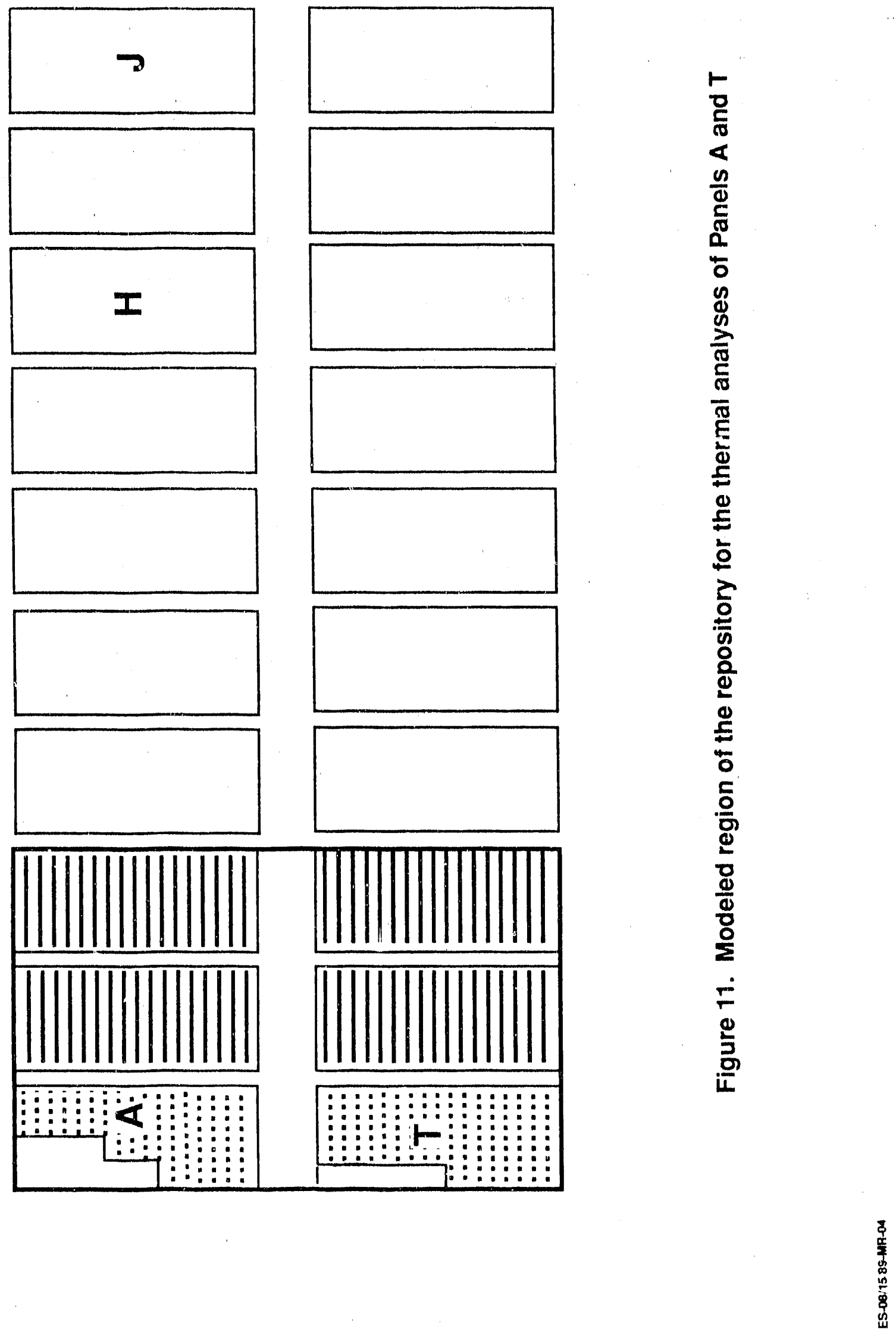




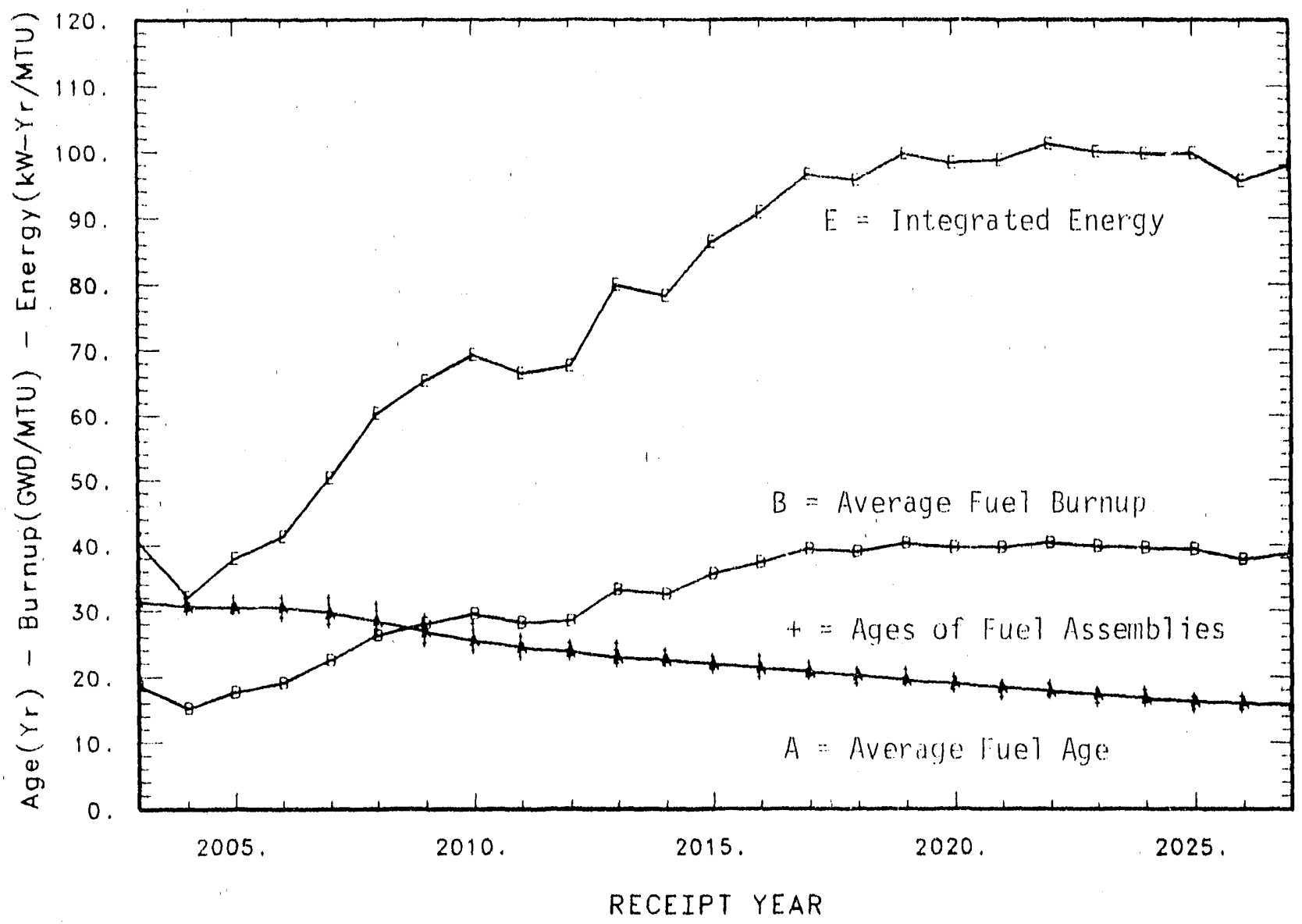

Figure 12. Age, Burnup and Integrated Energy characteristics of spent fue! received in the "Oldest Fuel First" receipt scenario 


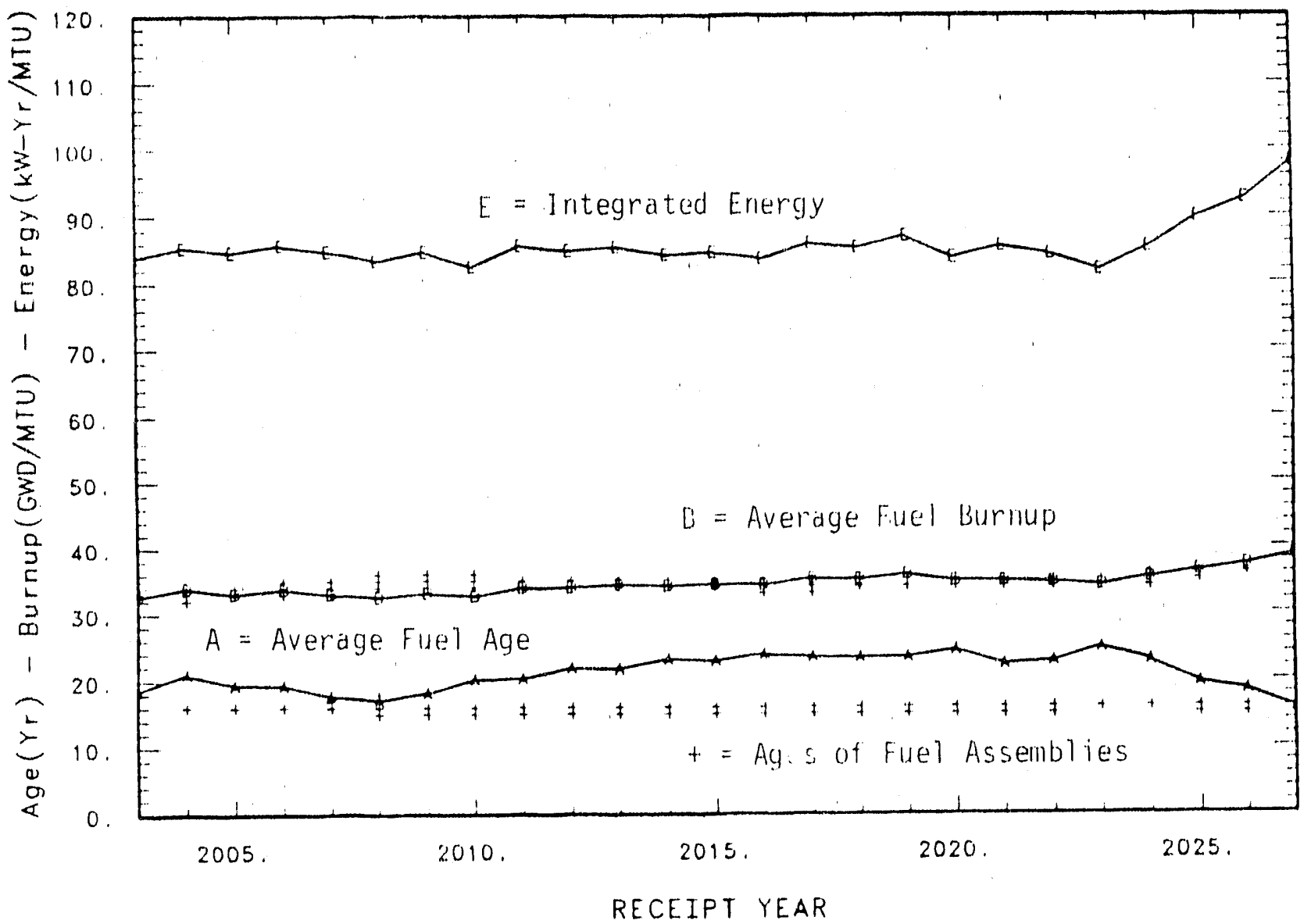

Figure 13. Age, Burnup and Integrated Energy characteristics of spent fuel received in the "Levelized" receipt scenario 


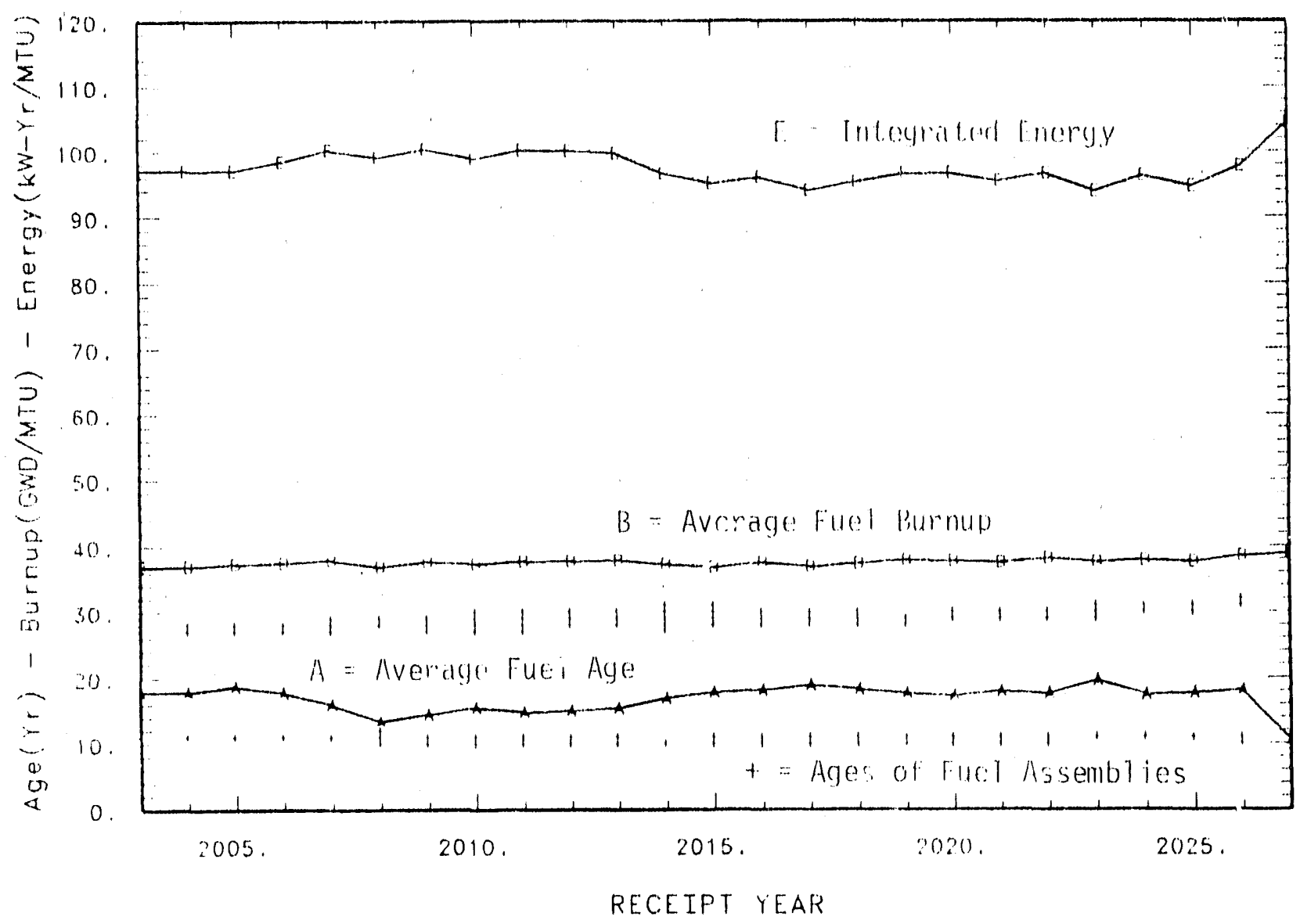

Figure 14. Age, Burnup and Integrated Energy characteristics of spent fuel received in the "Levelized Hi-Graded" receipt scenario 


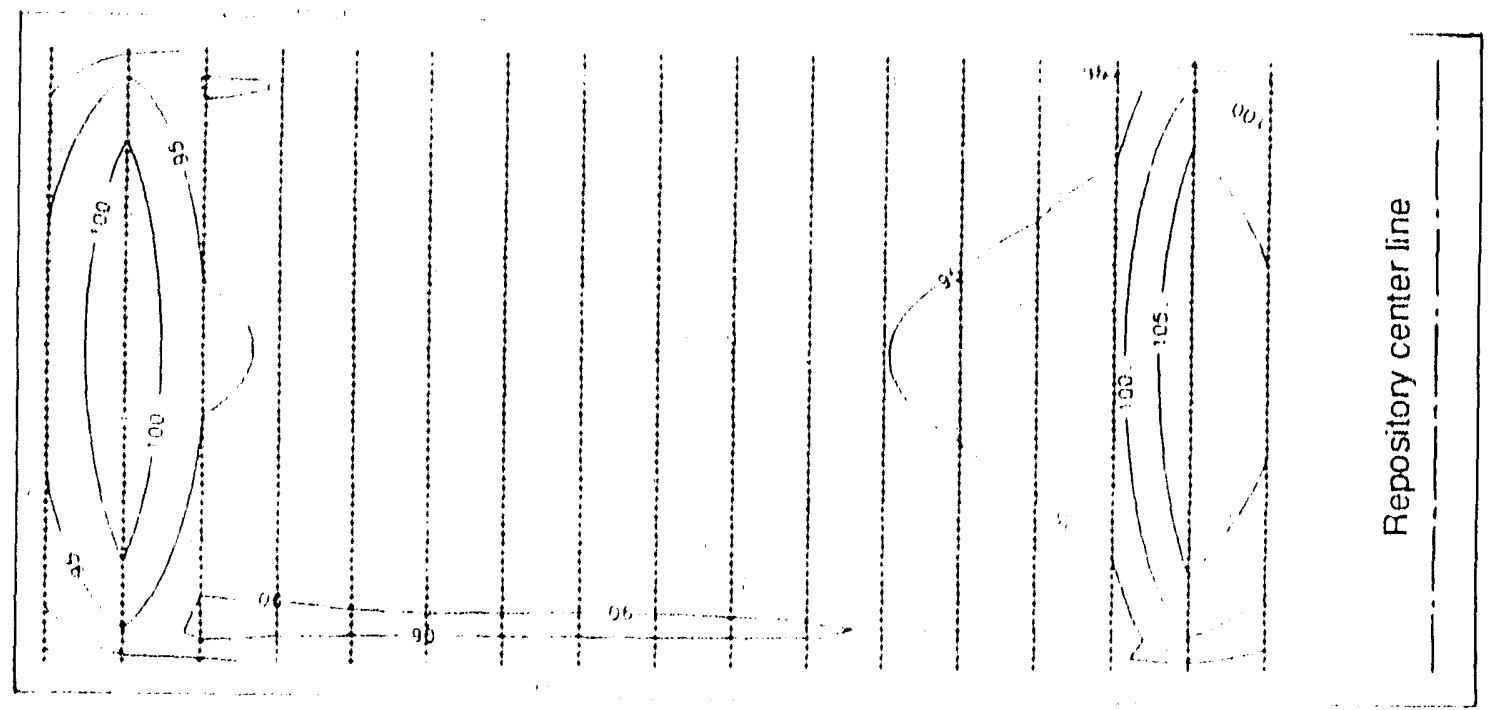

(A)

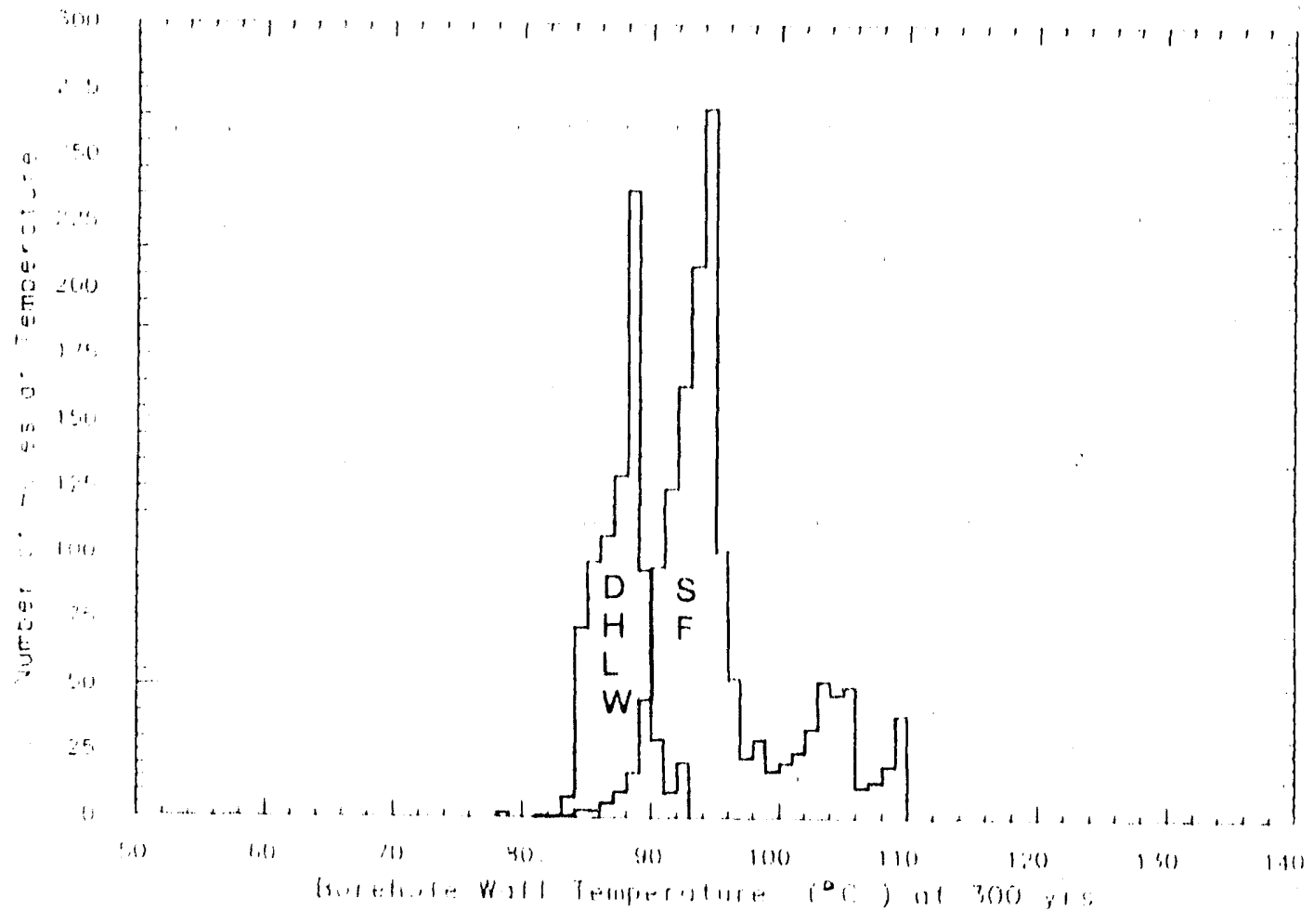

(B)

Figure 15. Panel $\mathrm{H}$ borehole wall temperature isotherms $(A)$ and histograms (B) at about 300 years after closure for the Oldest Fuel First, Commingled Waste case 


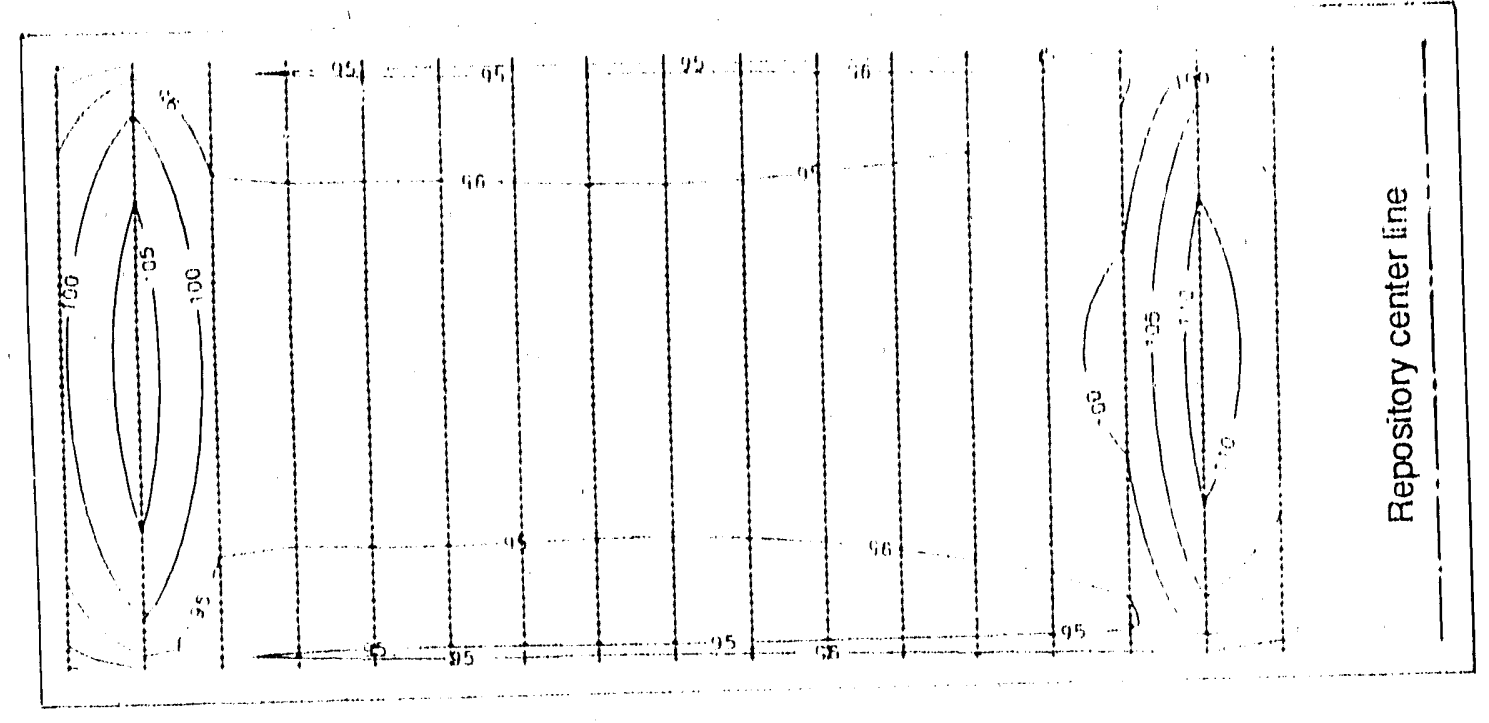

(A)

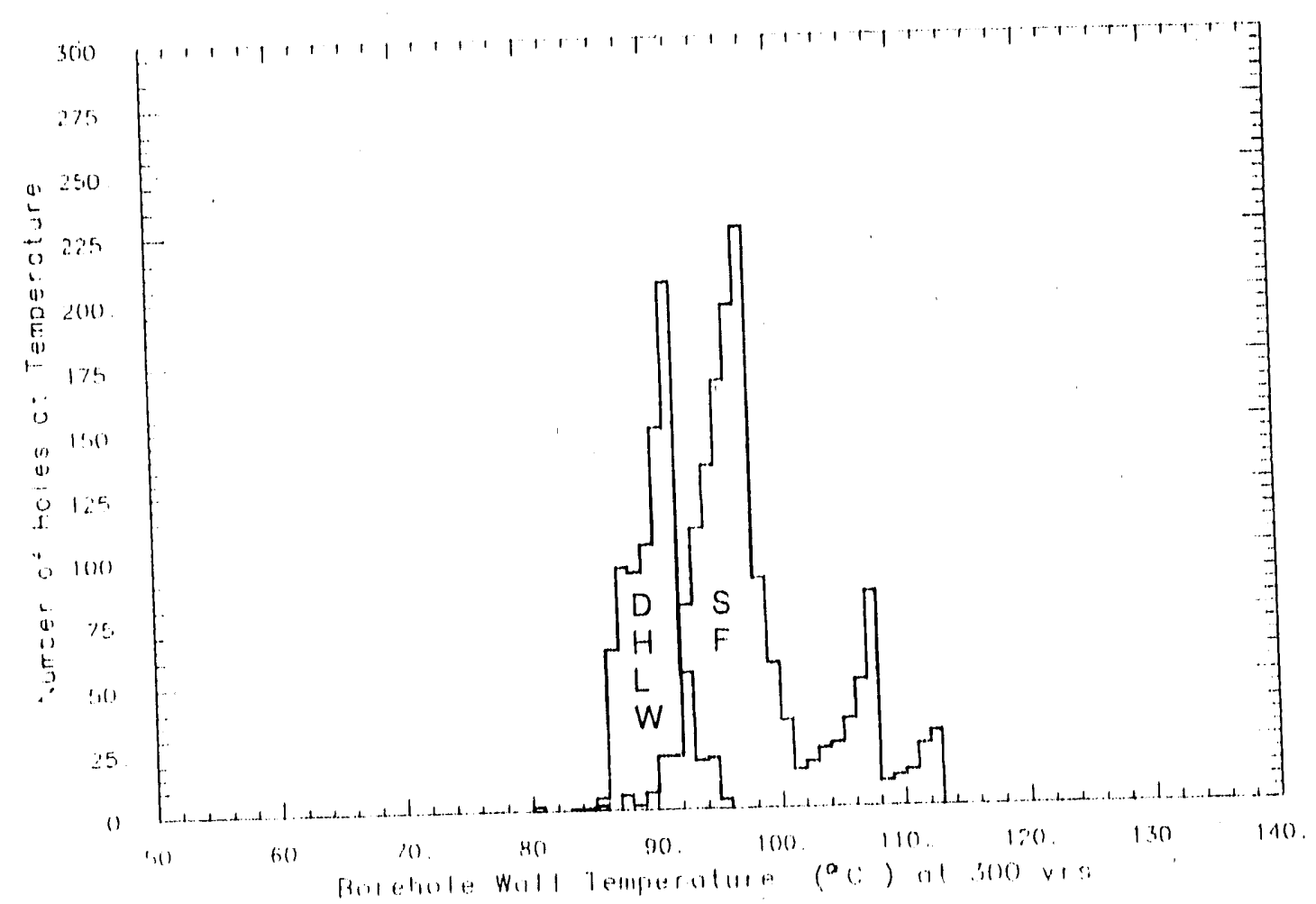

(B)

Figure 16. Panel $\mathrm{H}$ borehole wall temperature isotherms $(\mathrm{A})$ and histograms (B) at about 300 years after closure for the Levelized Energy - Oldest Inventory, Commingled Waste case 


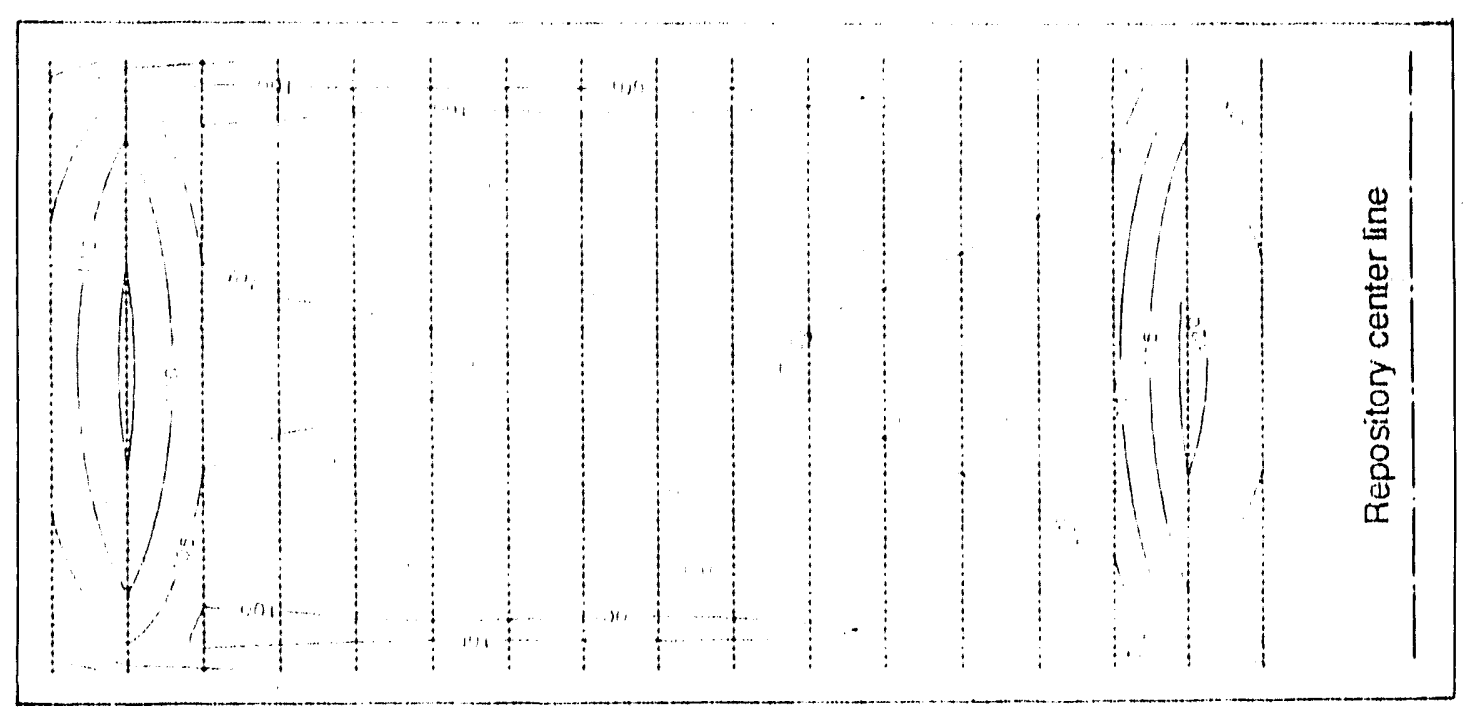

(A)

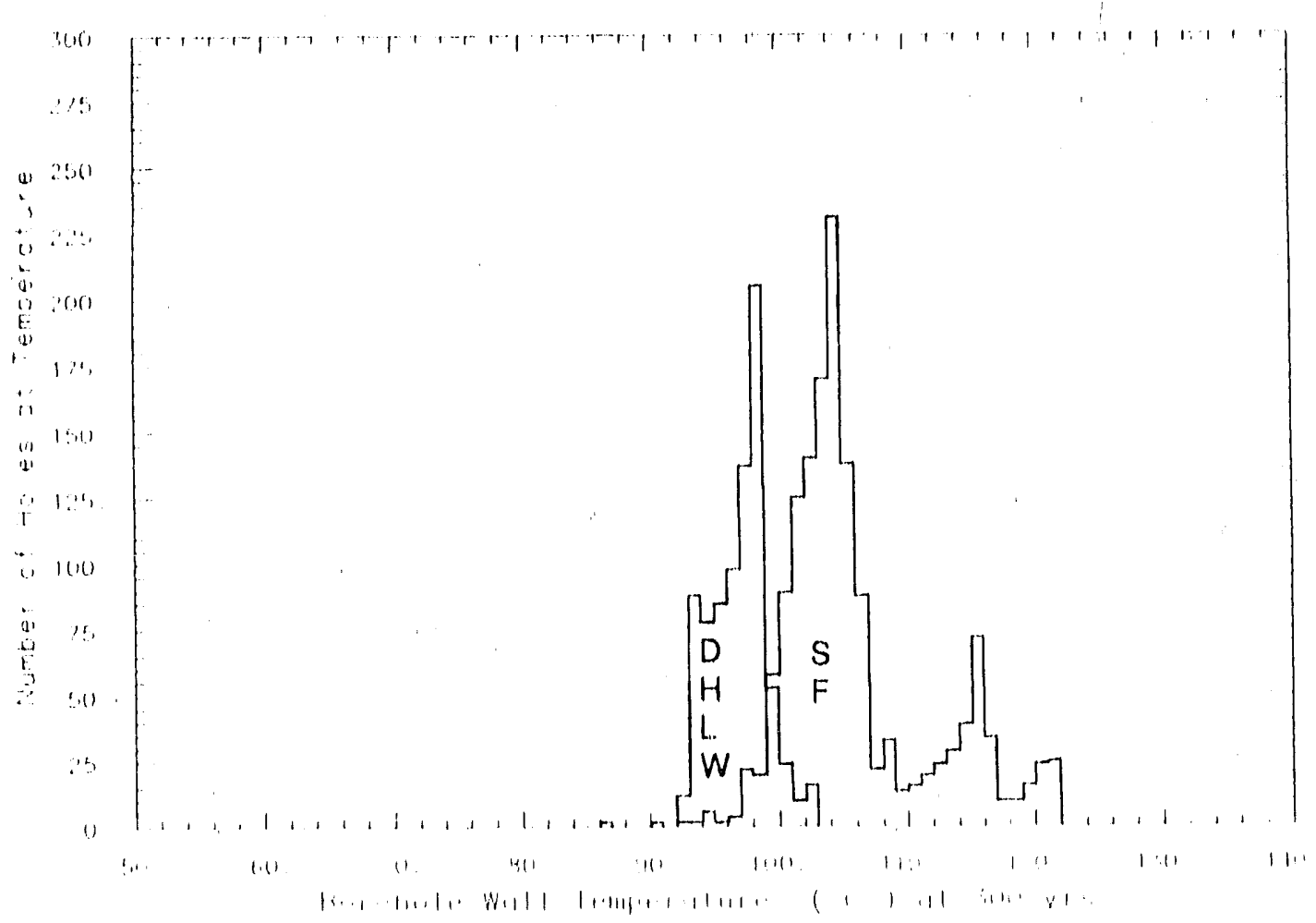

(B)

Figure 17. Panel $\mathrm{H}$ borehole wall temperature isotherms $(A)$ and histograms $(B)$ at about 300 years after closure for the Levelized Energy - "Hi-Graded" Inventory, Commingled Waste case 


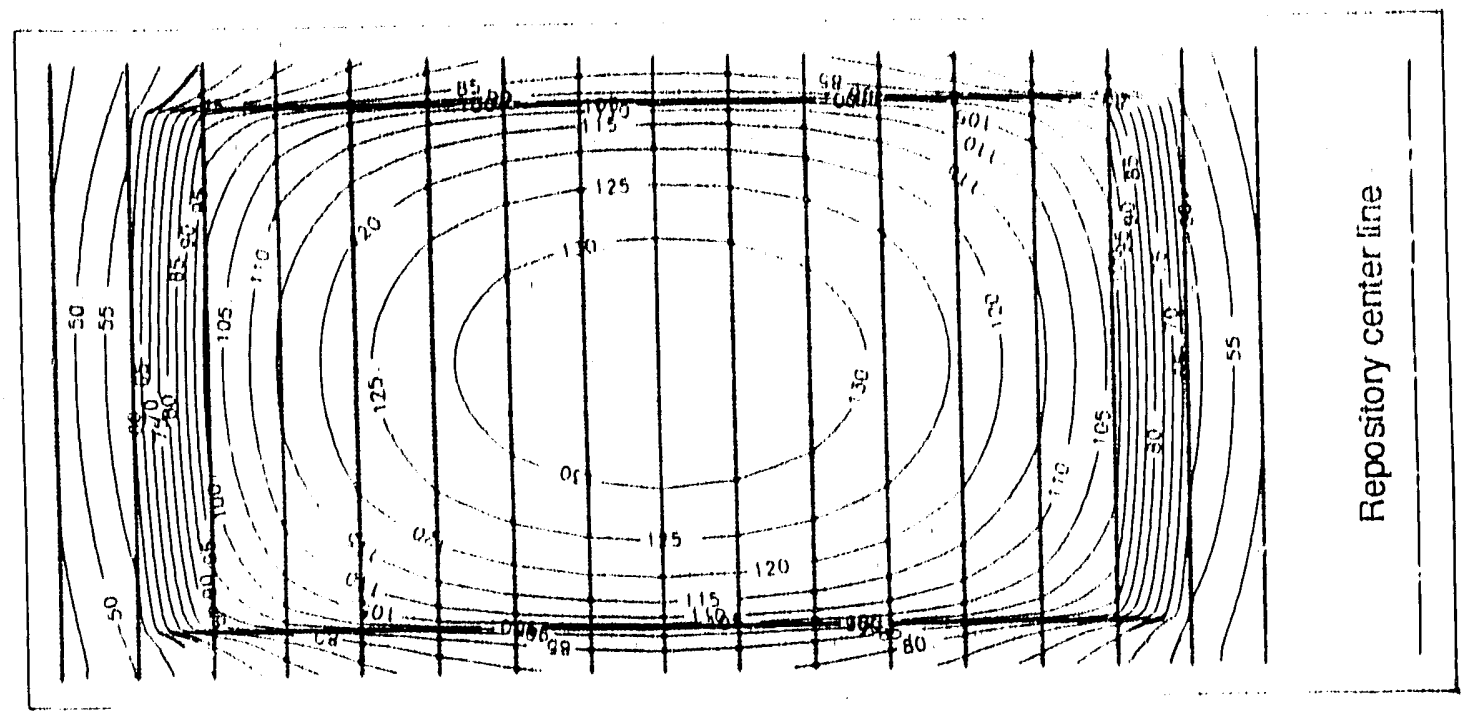

(A)

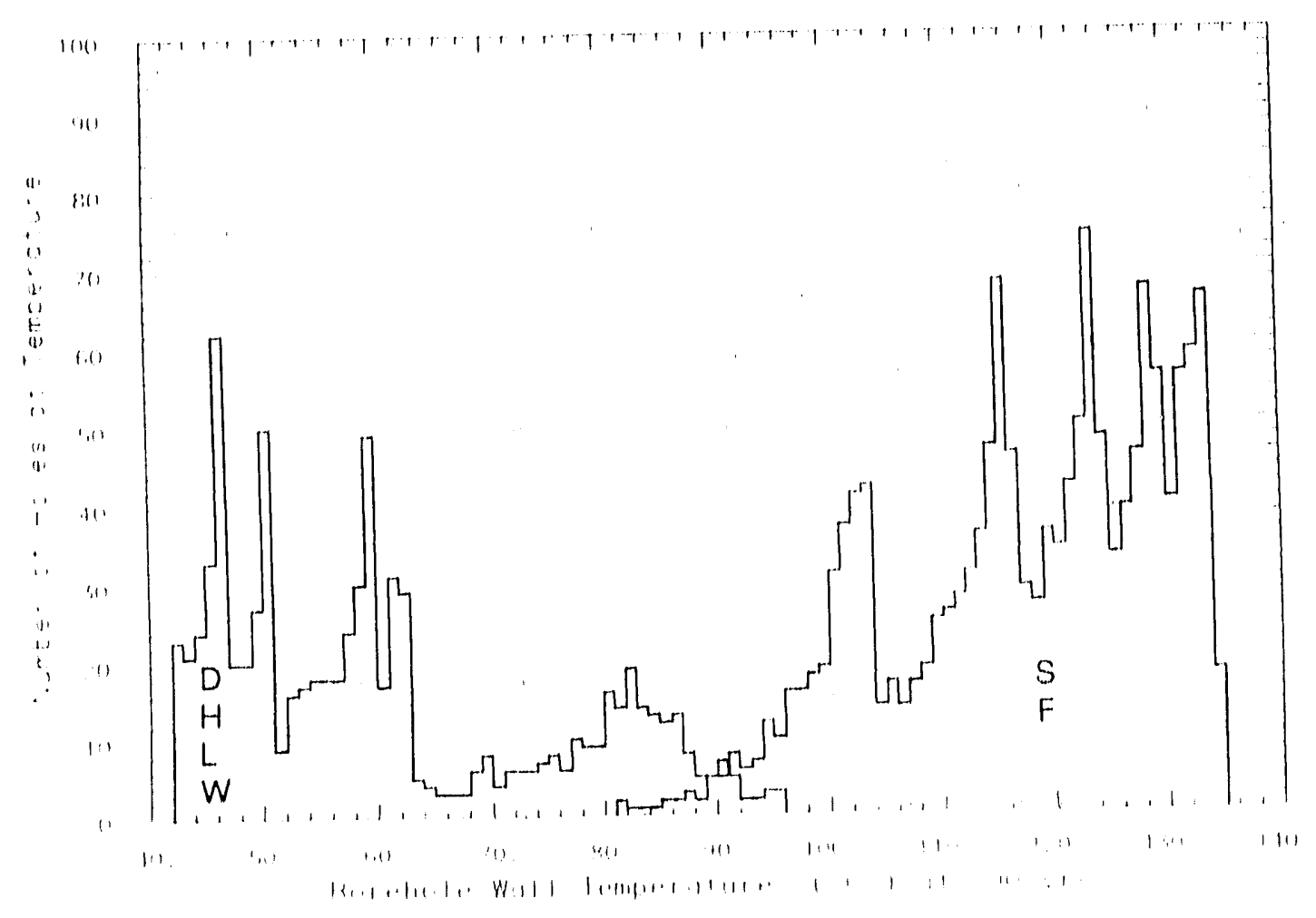

(B)

Figure 18. Panel $H$ borehole wall temperature isotherms $(A)$ and histograms $(B)$ at about 300 years after closure for the Oldest Fuel First, Non-Comrningled Waste case 

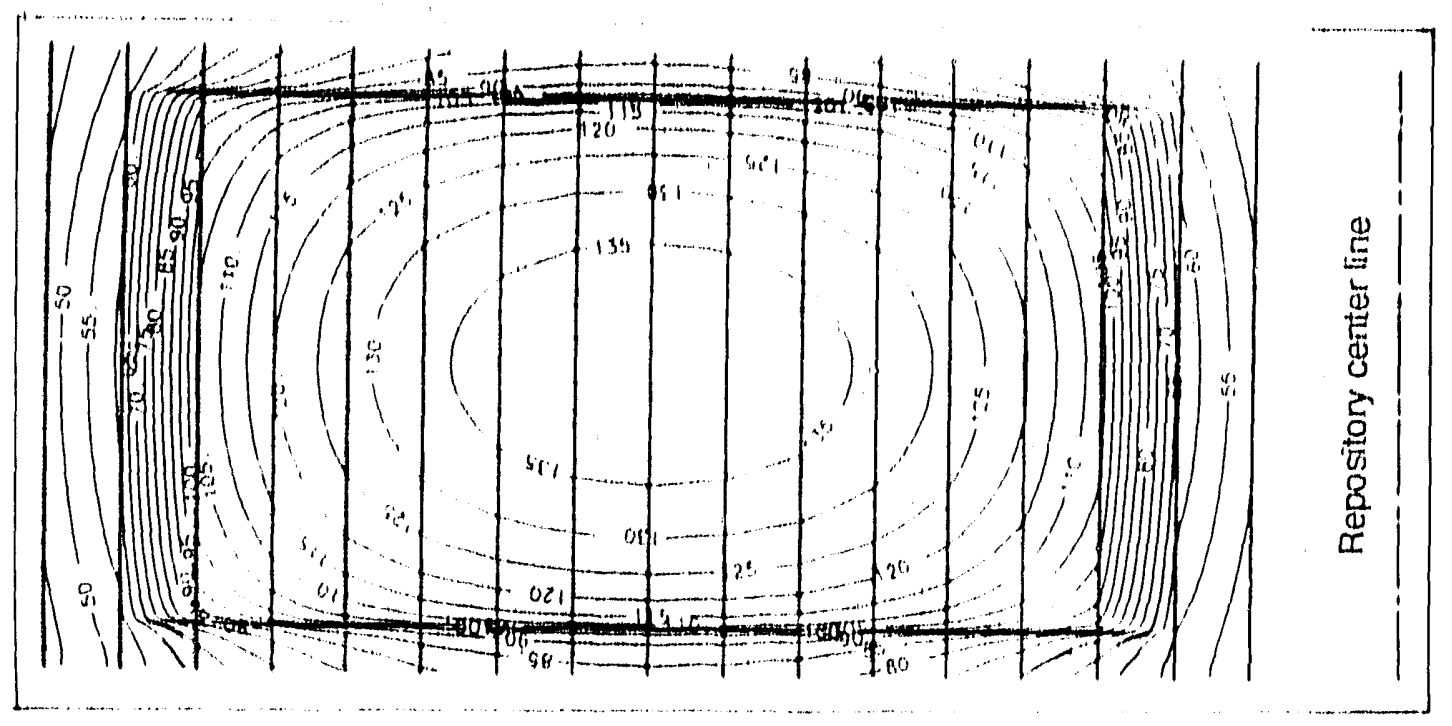

(A)

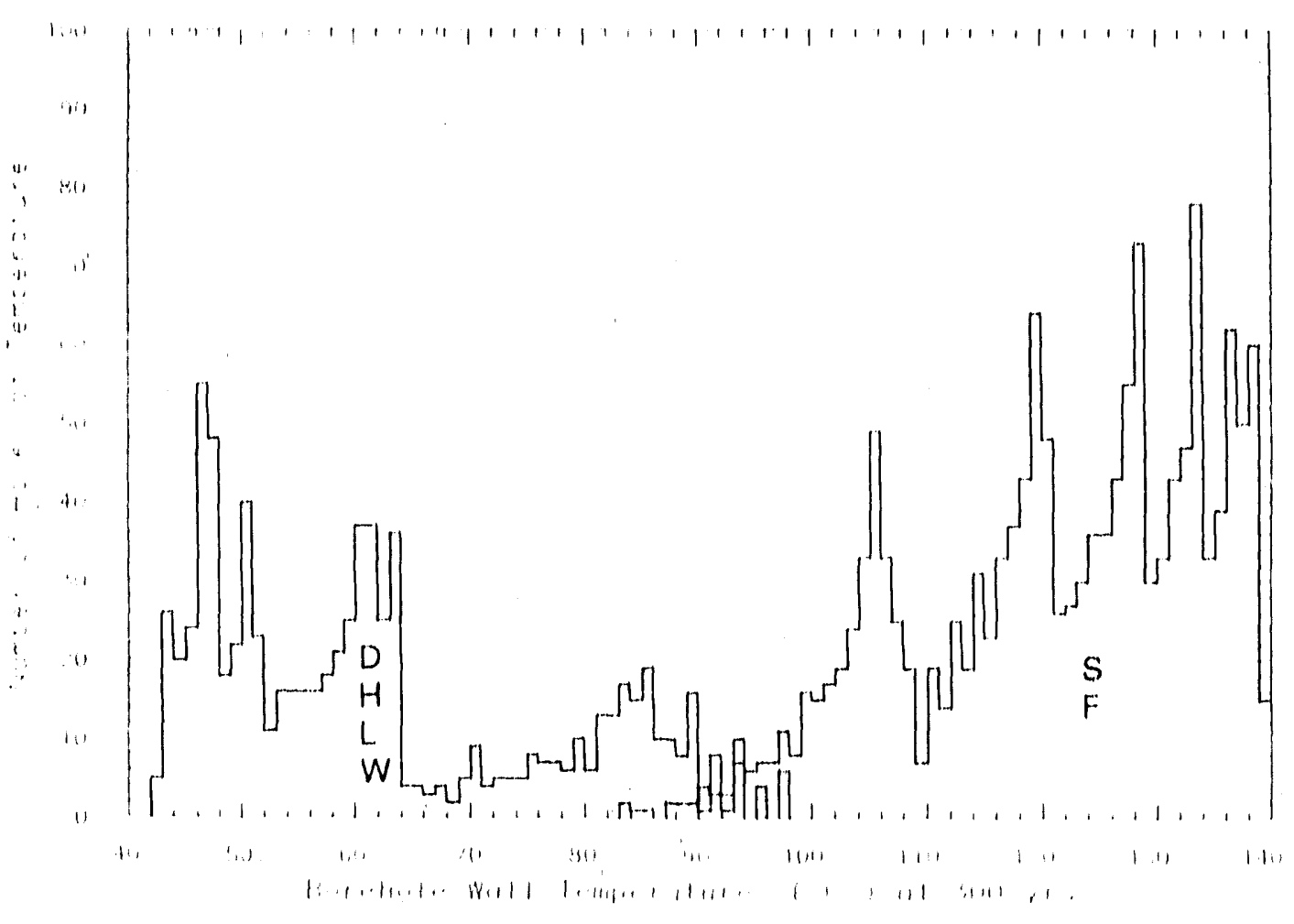

(B)

Figure 19. Panel $H$ borehole wall temperature isotherms $(A)$ and histograms $(B)$ at about 300 years after closure for the Levelized Energy - Oldest Inventory, Non-Commingled Waste case 


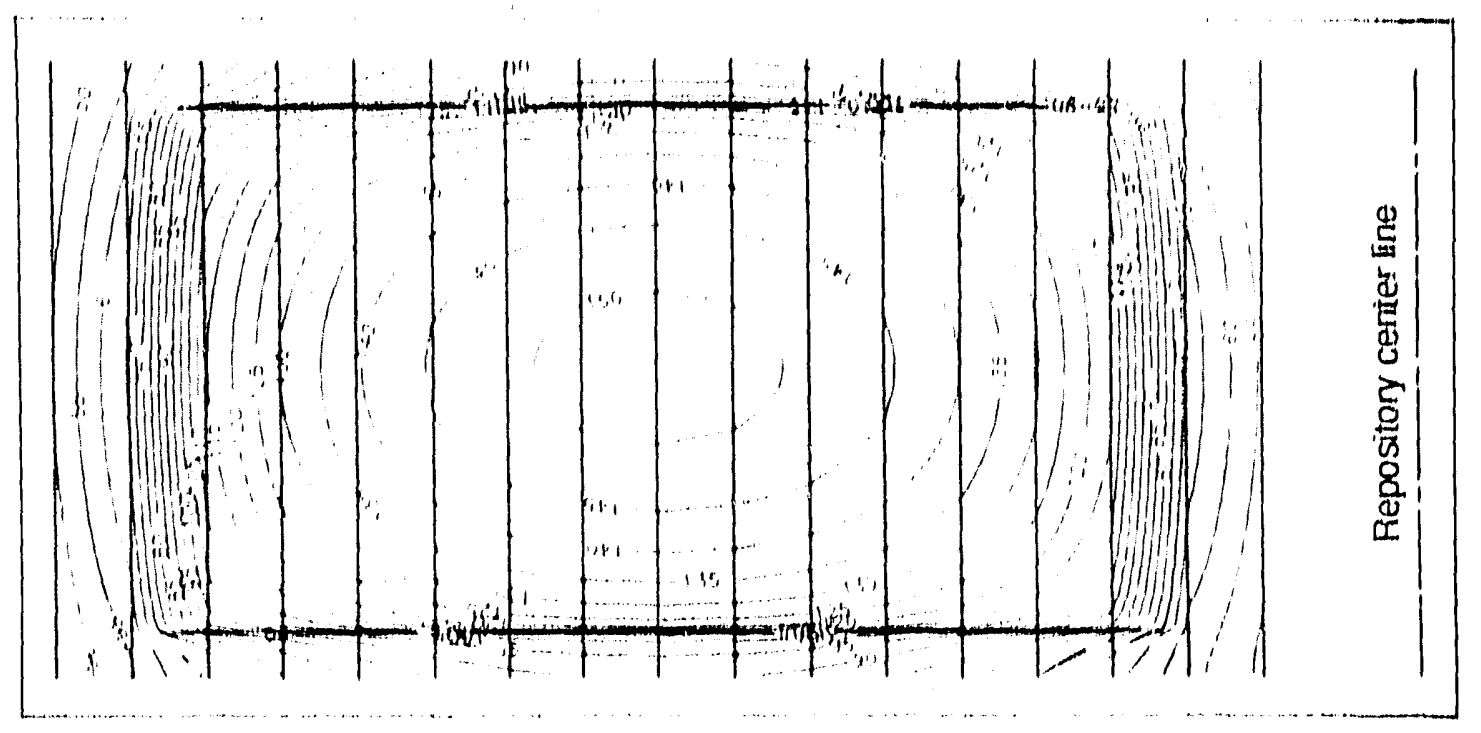

(A)

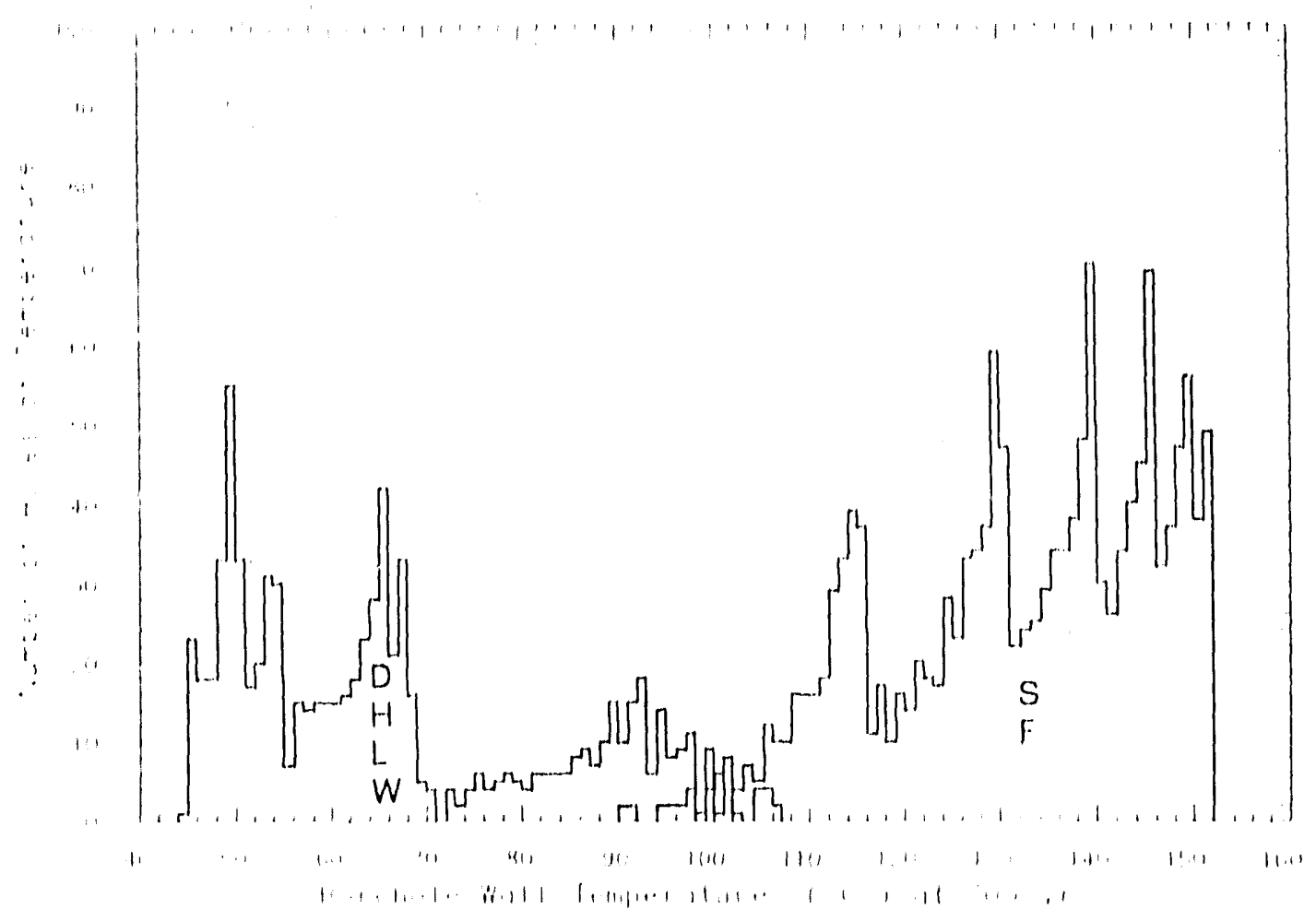

(B)

Figure 20. Panel $\mathrm{H}$ borehole wall temperature isotherms $(\mathrm{A})$ and histograms $(B)$ at about 300 years after closure for the Levelized Energy - "Hi-Graded" Inventory, Non-Commingled Waste case 


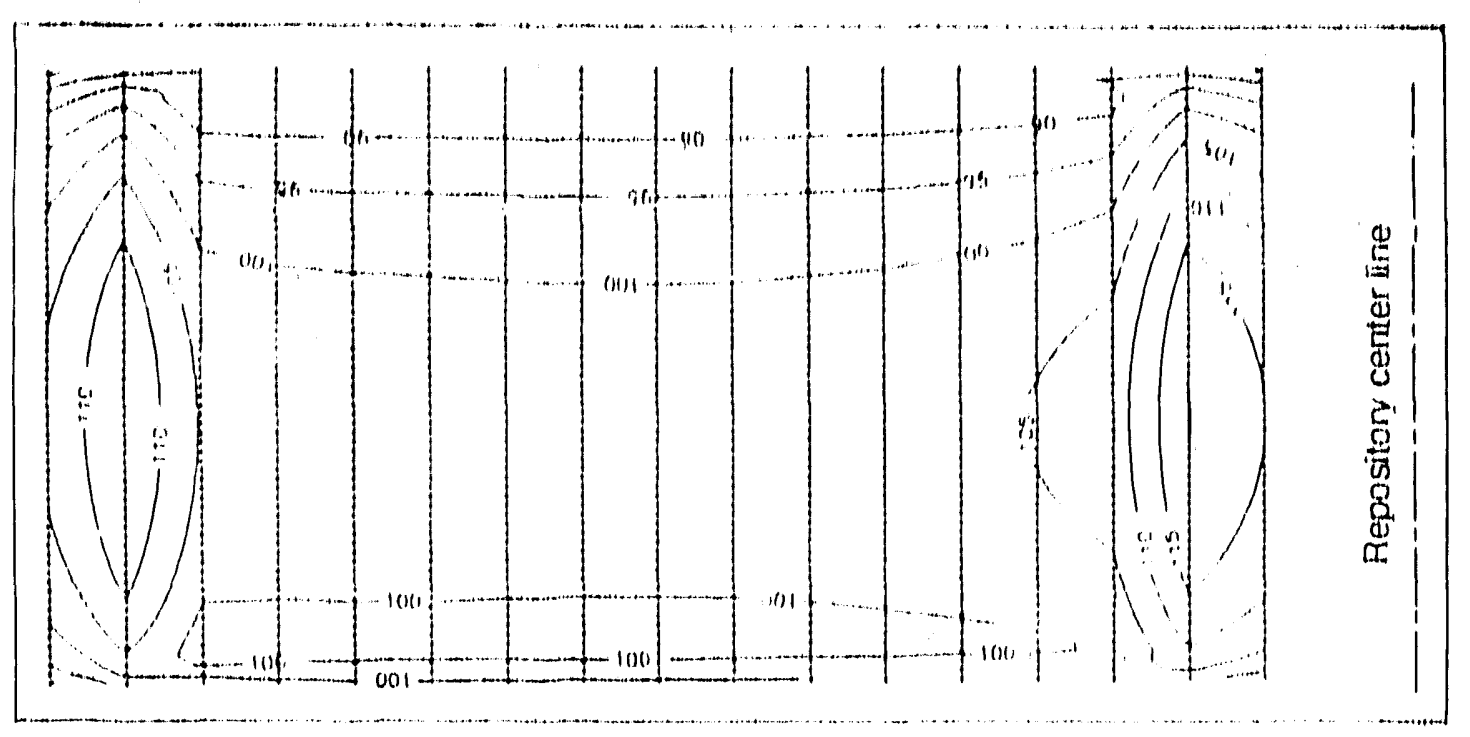

(A)

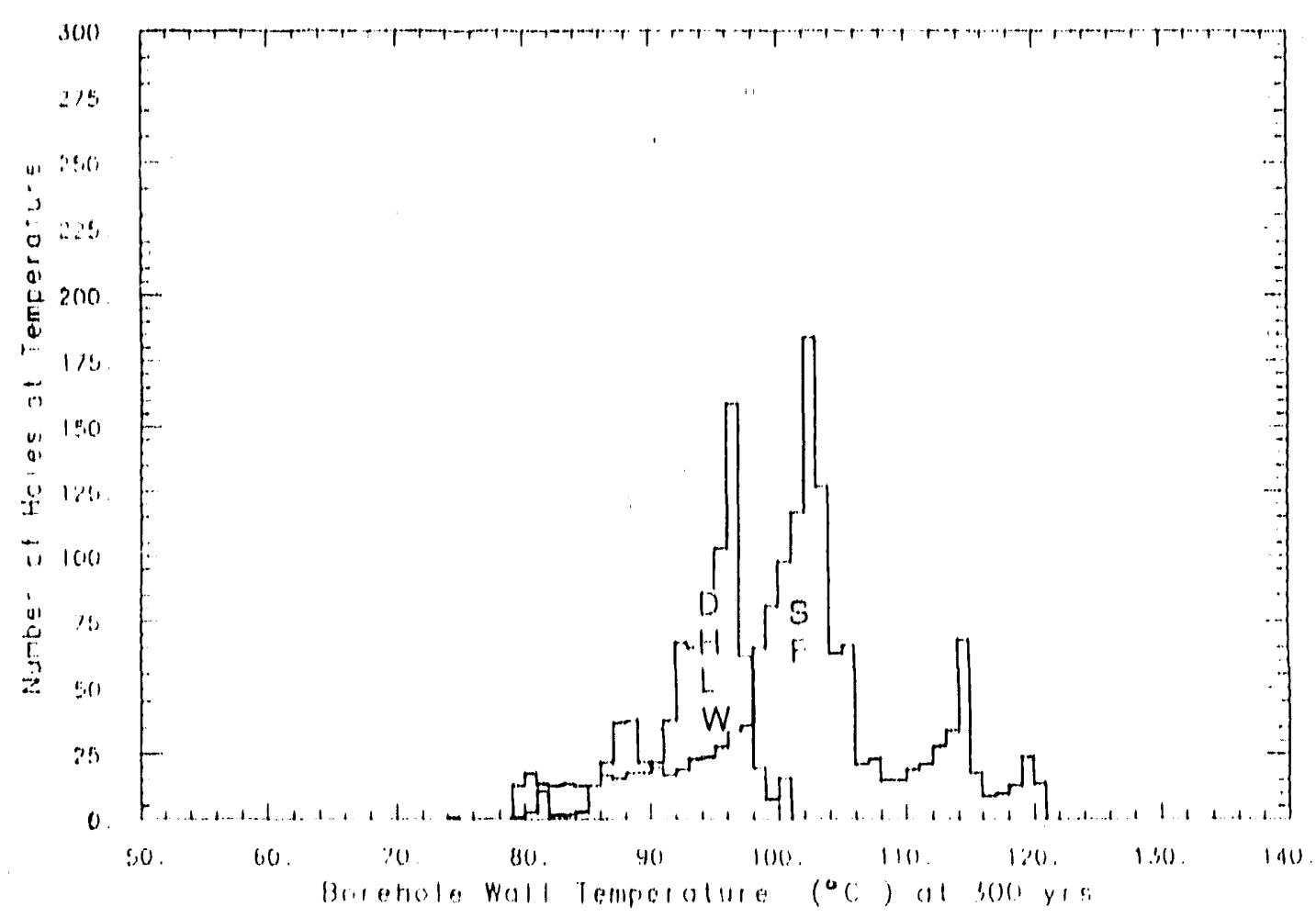

(B)

Figure 21. Panel $J$ borehole wall temperature isotherms (A) and histograms (B) at about 300 years after closure for the Oldest Fuel First, Commingled Waste case 


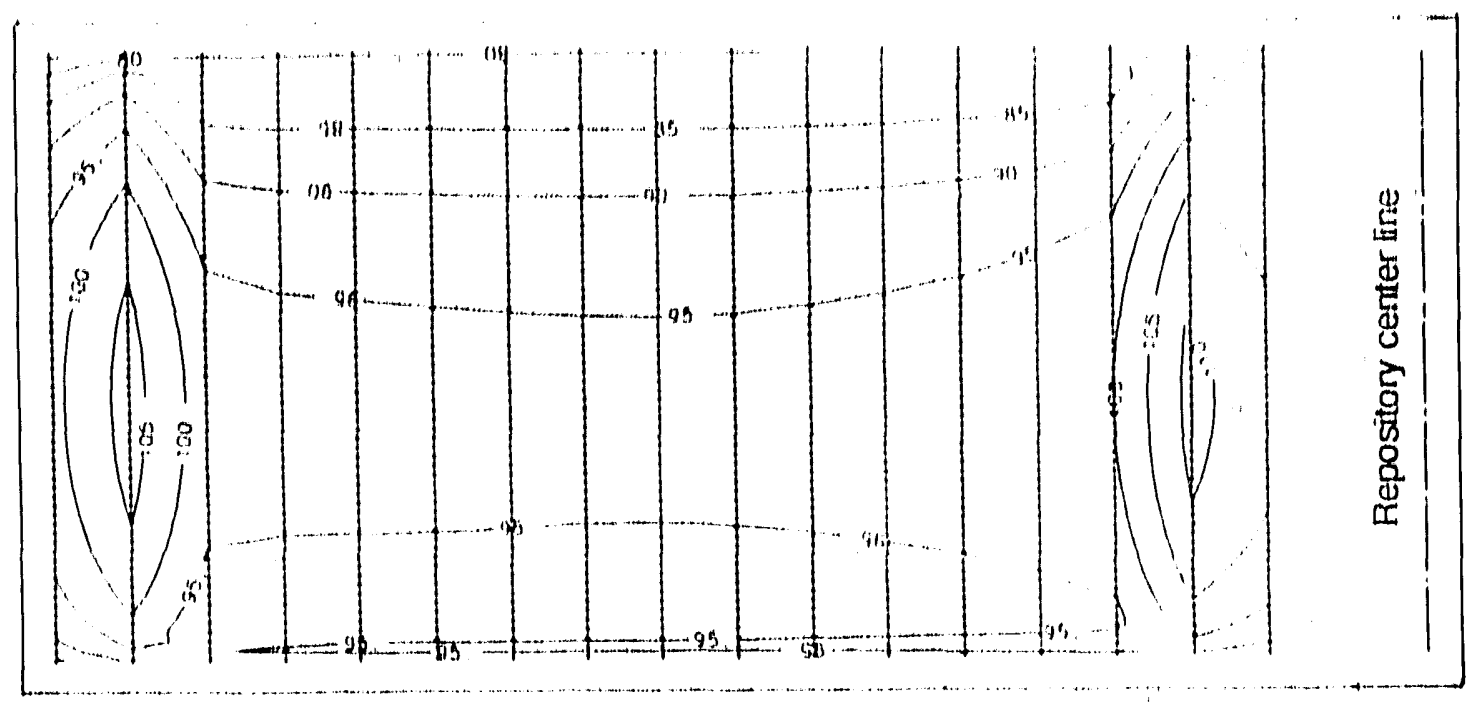

(A)

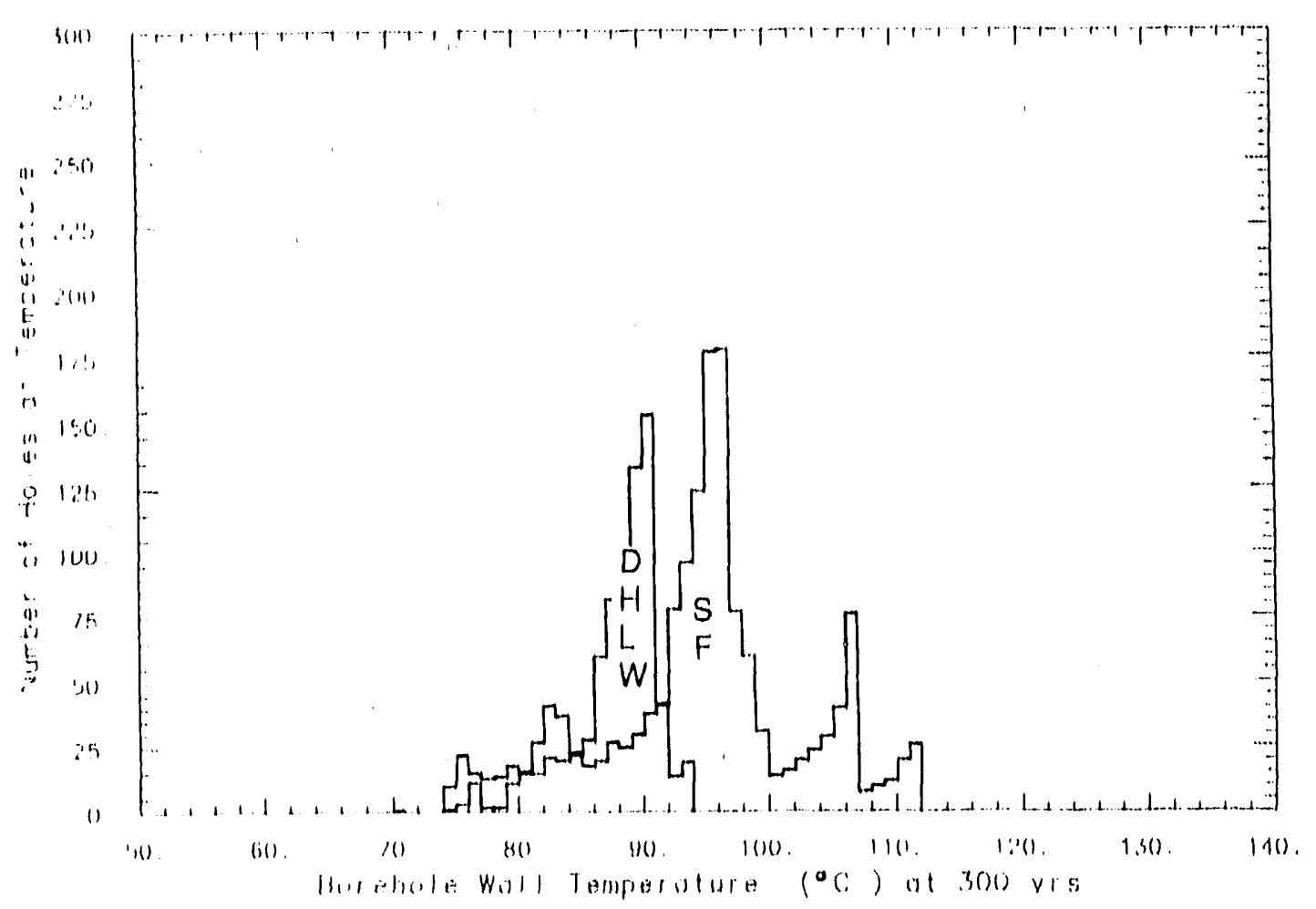

(B)

Figure 22. Panel $J$ borehoie wall temperature isotherms $(A)$ and histograms $(B)$ at about 300 years after closure for the Levellzed Energy Oldest Inventory, Commingled Waste case 


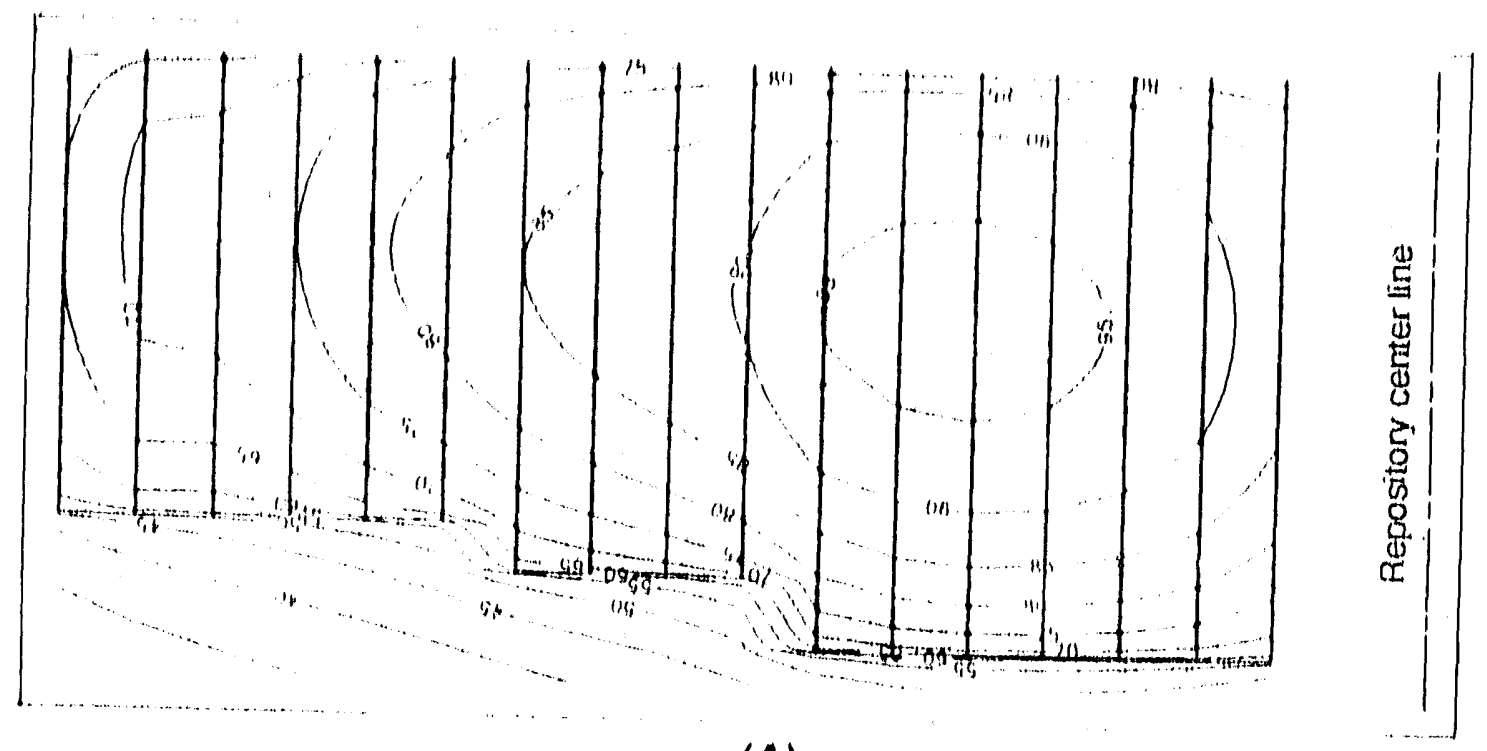

(A)

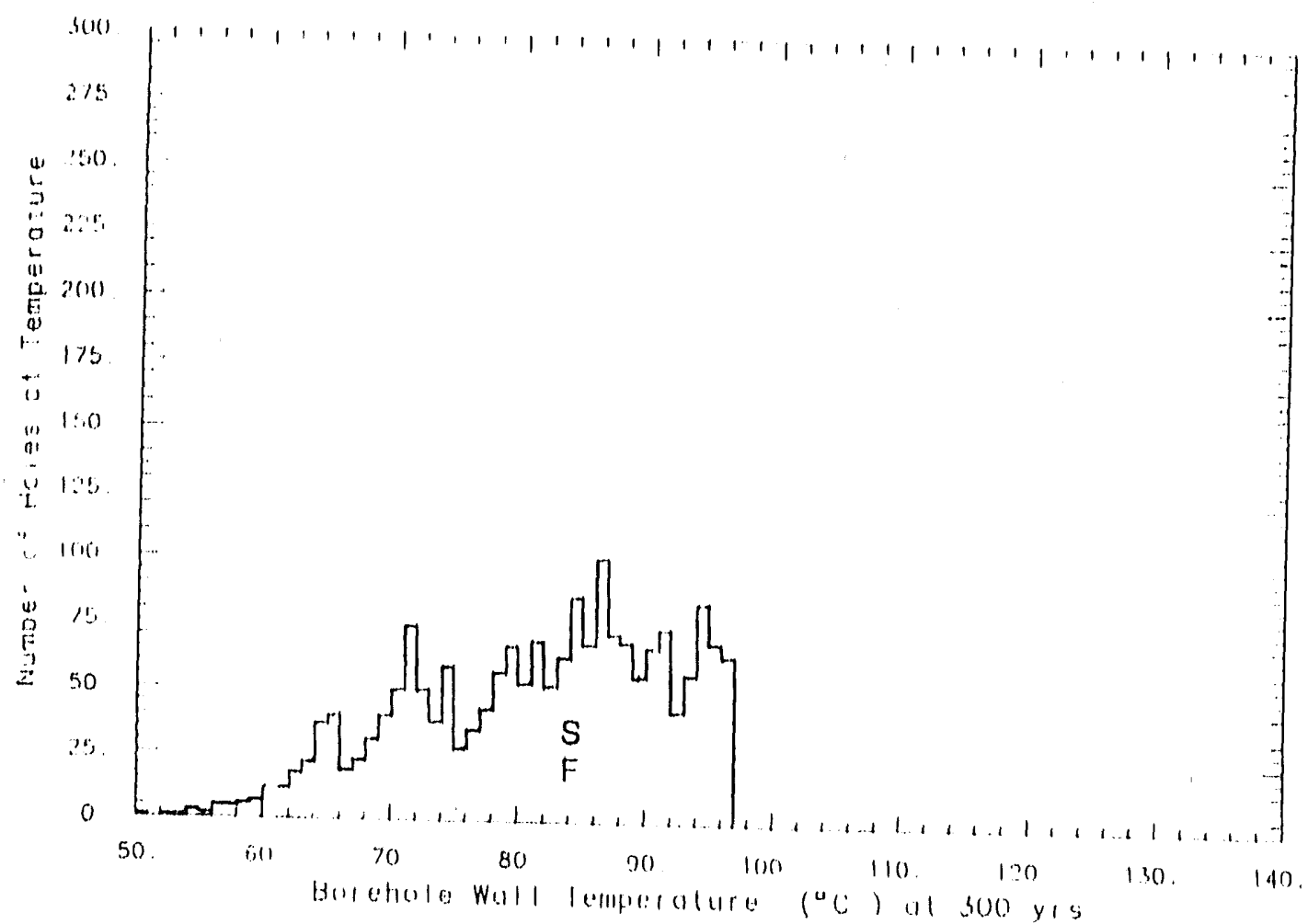

(B)

Figure 23. Panel A borehole wall temperature isotherms (A) and histograms (B) at about 300 years after closure for the Oidest Fuel First, All Spent Fuel case 


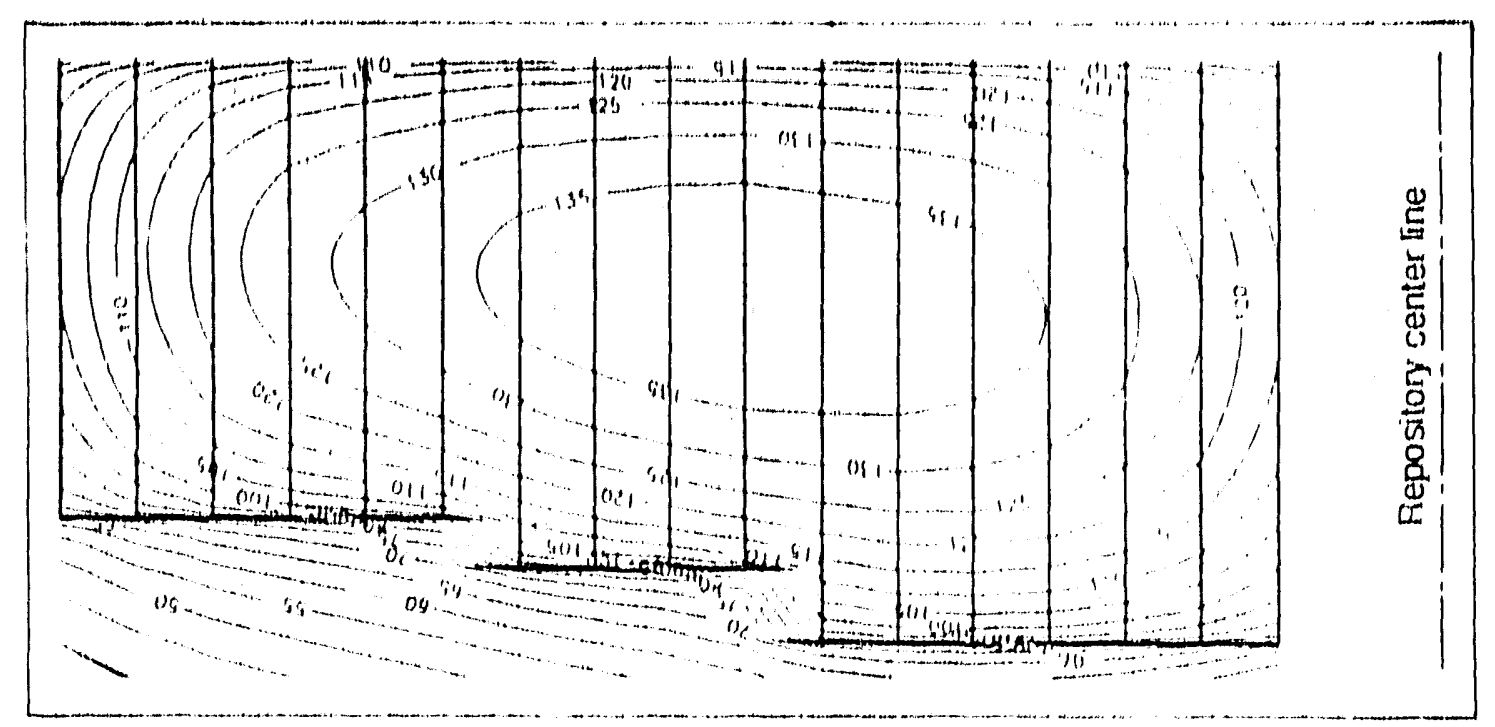

(A)

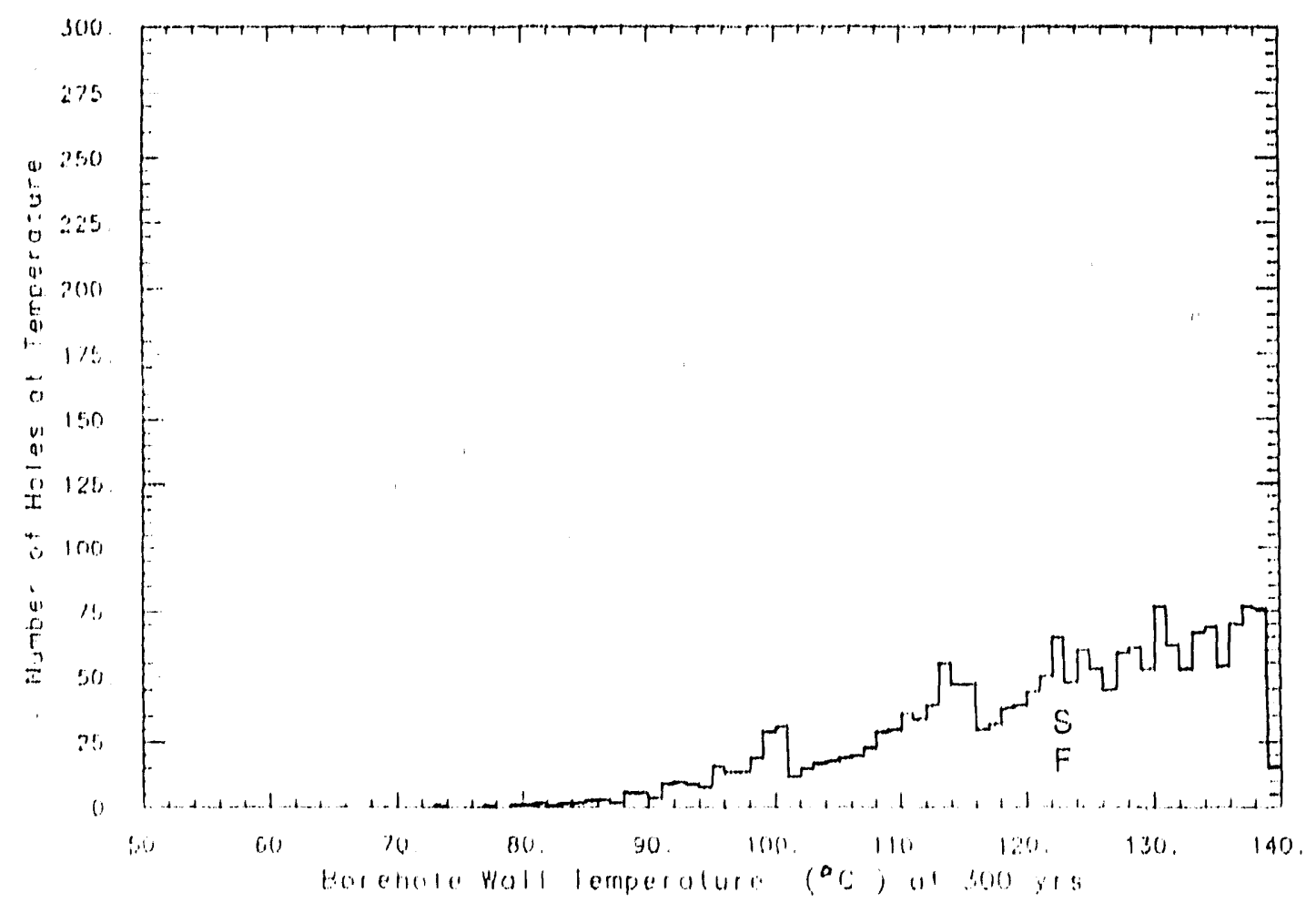

(B)

Figure 24. Panel A borehole wall temperature isotherms (A) and histograms (B) at about 300 years after closure for the Levelized Energy Oldest Inventory, All Spent Fuel case 


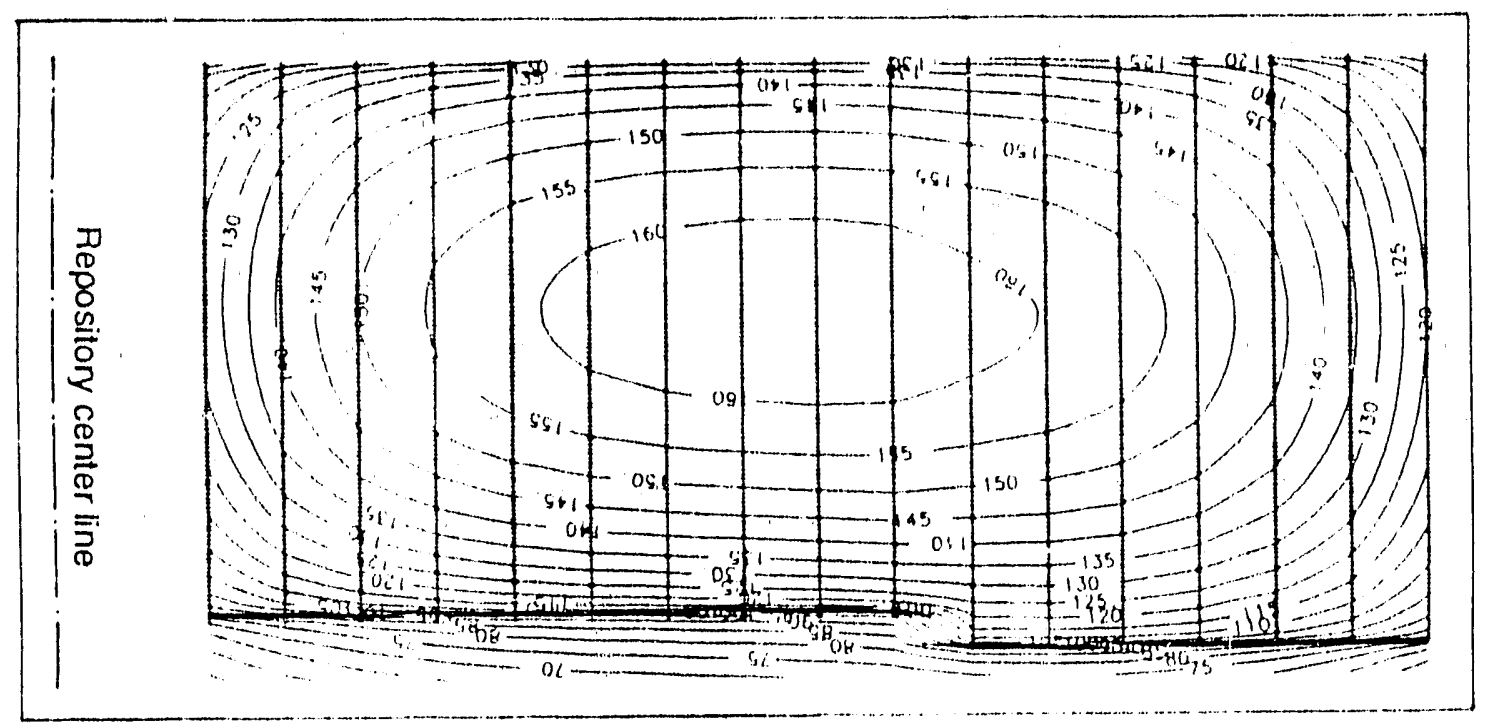

(A)

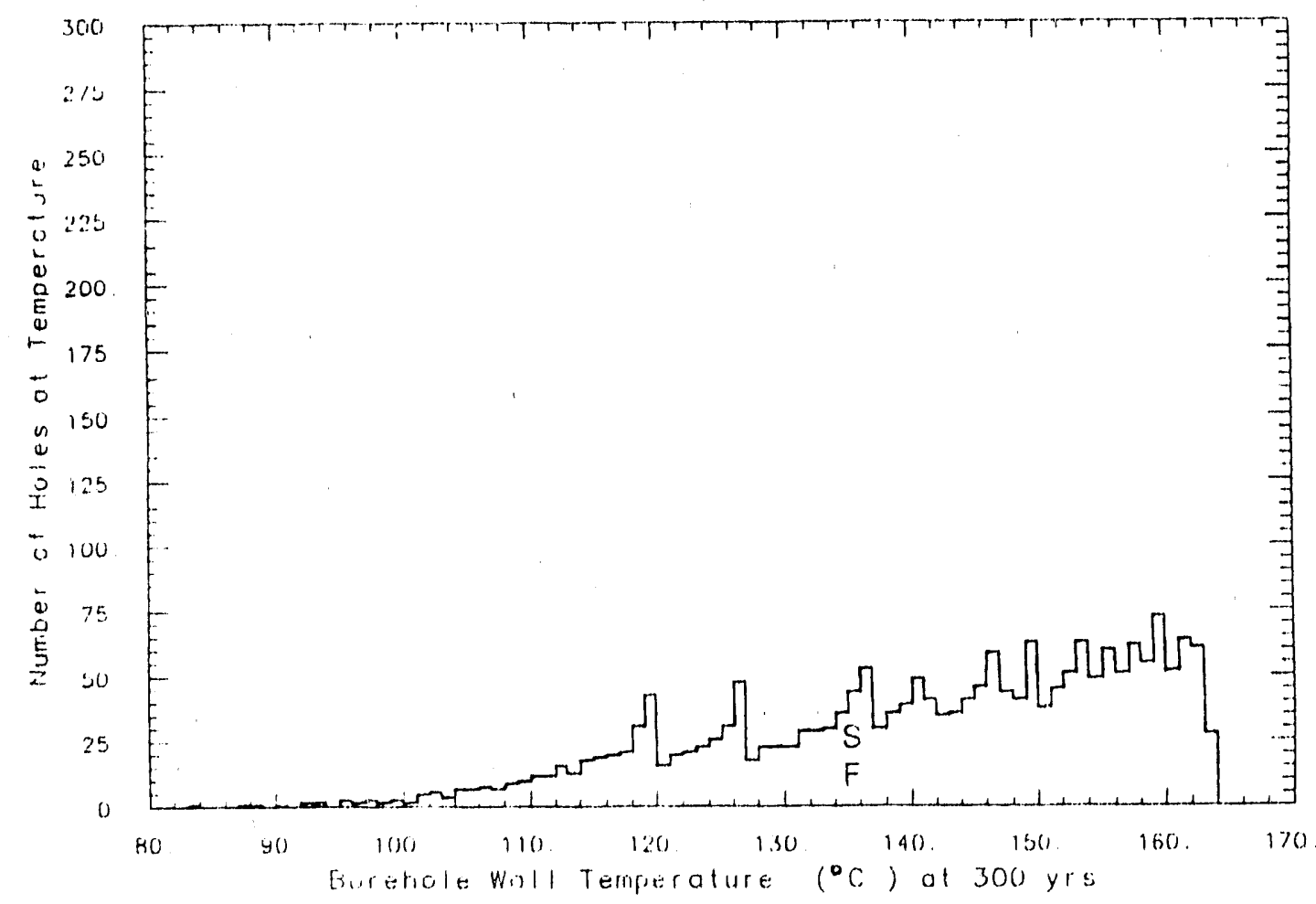

(B)

Figure 25. Panel T borehole wall temperature isotherms (A) and histograms (B) at about 300 years after closure for the Oldest Fulel First, All Spent Fuei case 


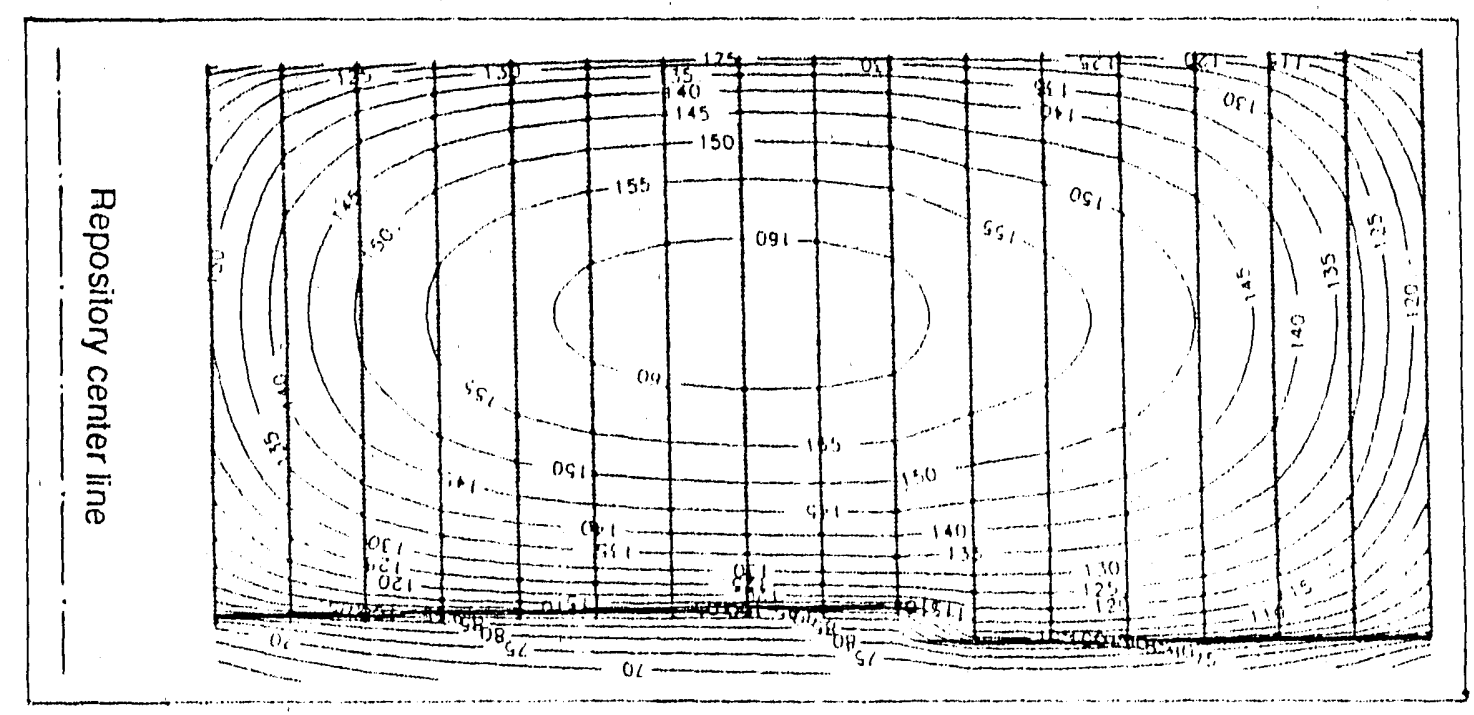

(A)

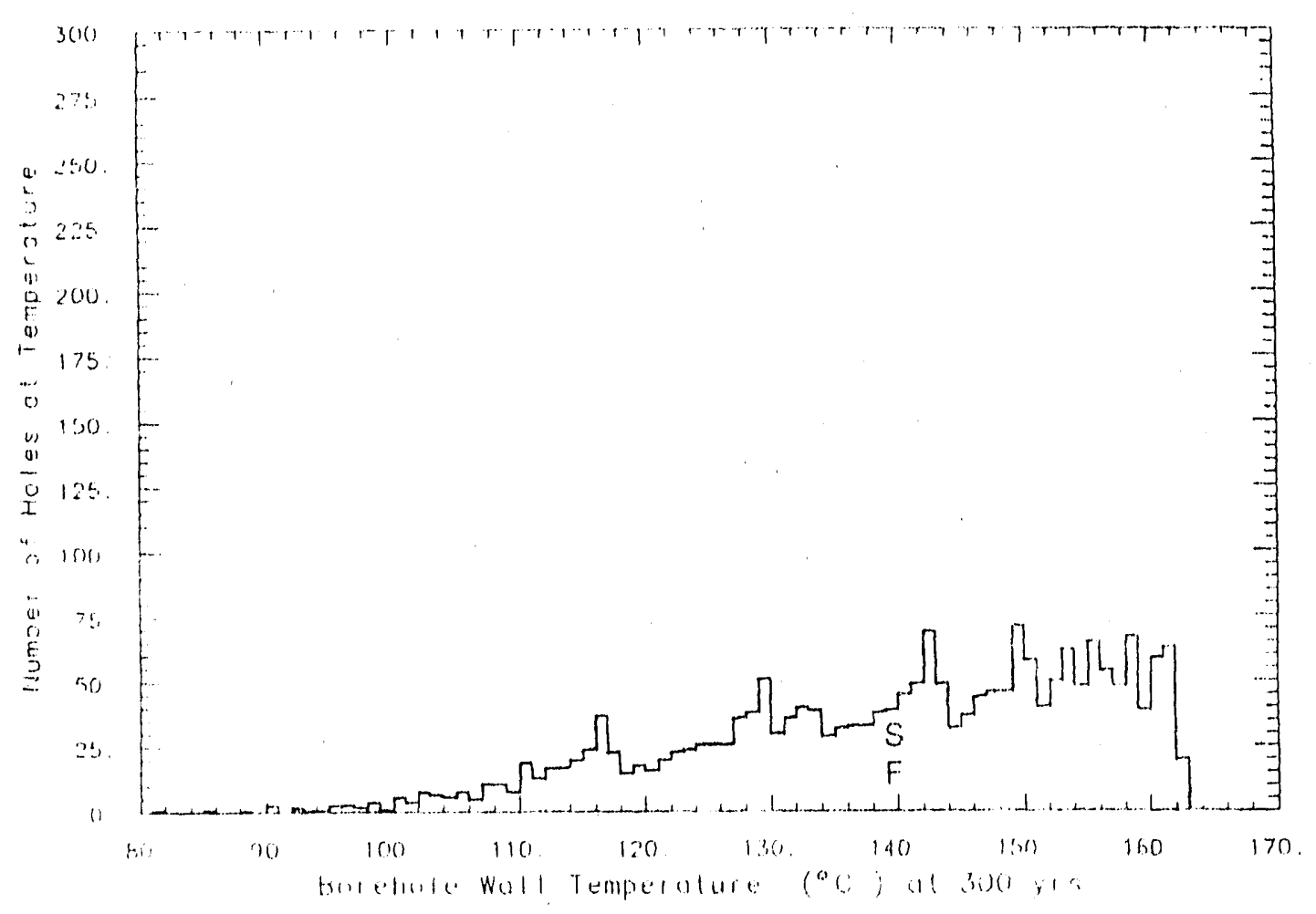

(B)

Figure 26. Panel $T$ borehole wall temperature isotherms $(A)$ and histograms (B) at about 300 years after closure for the Levelized Energy Cldest Inventory, Al! Spent Fue! case 


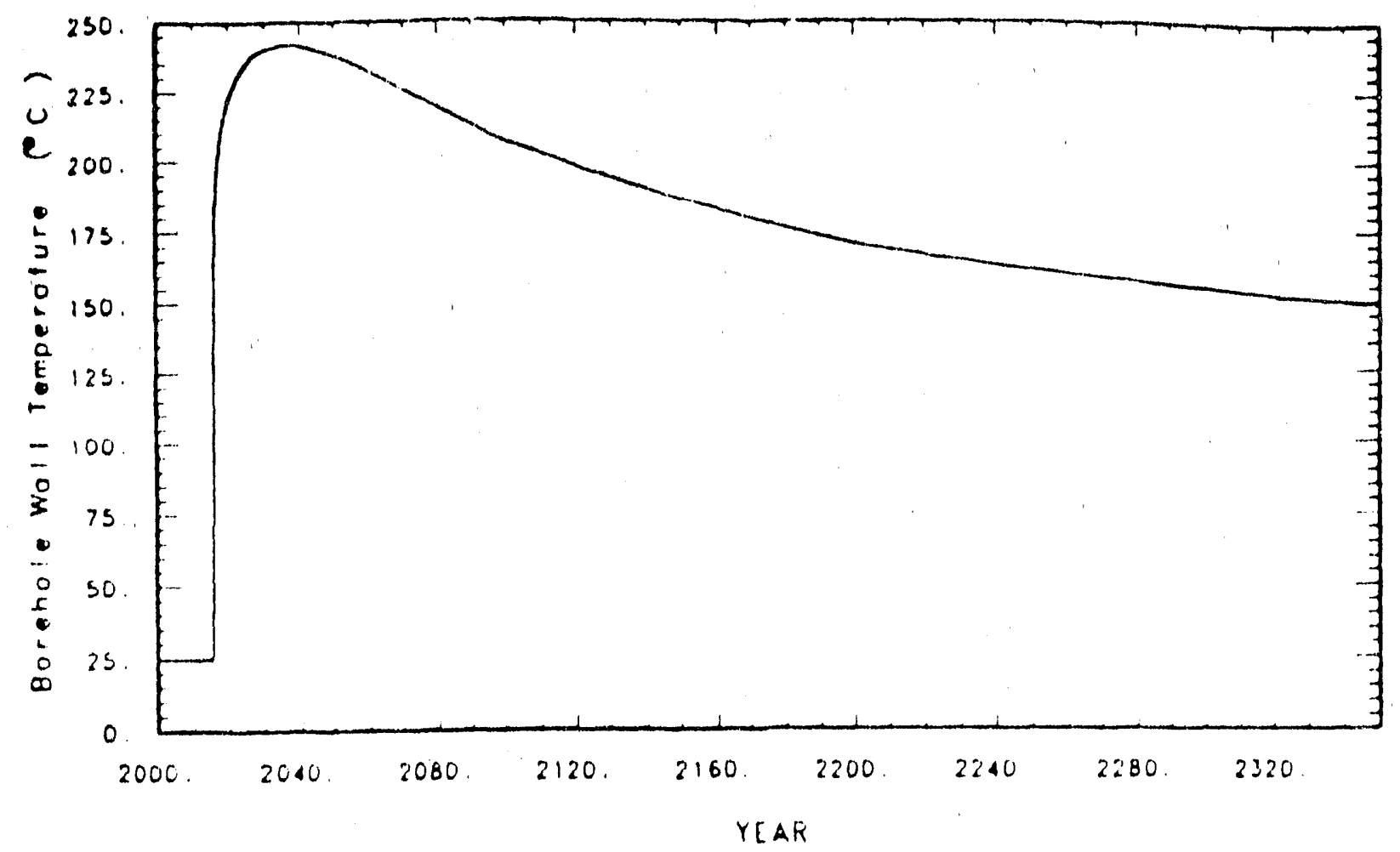

(A)

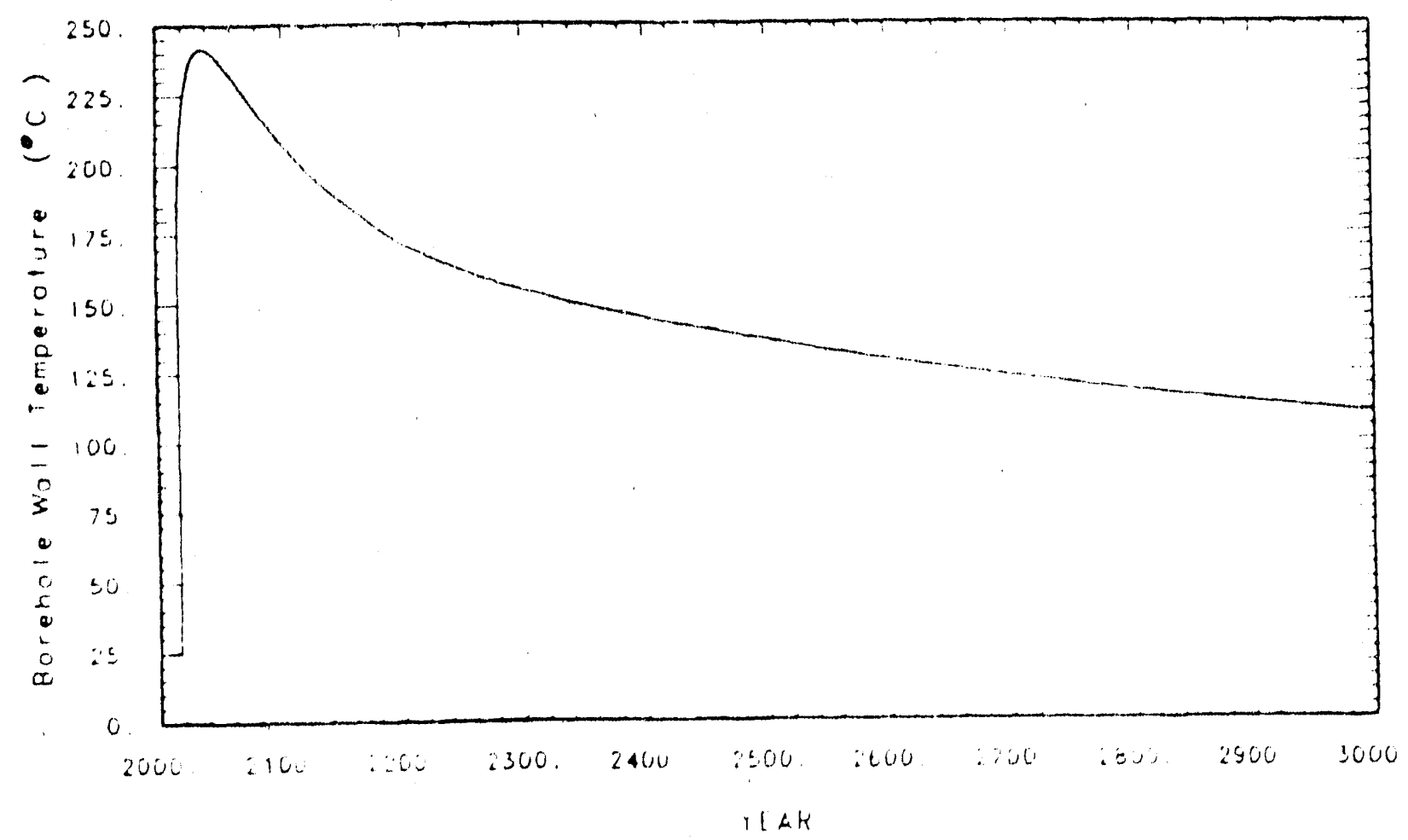

(B)

Figure 27. Temperature history for the hottest emplacement hole in the "Hi-Graded" Inventory case analysis of Panel $\mathrm{H}$ : (A) for 300 years, (B) tor 1 , ono years 
Appendix $A$

Waste Acceptance Schedule 


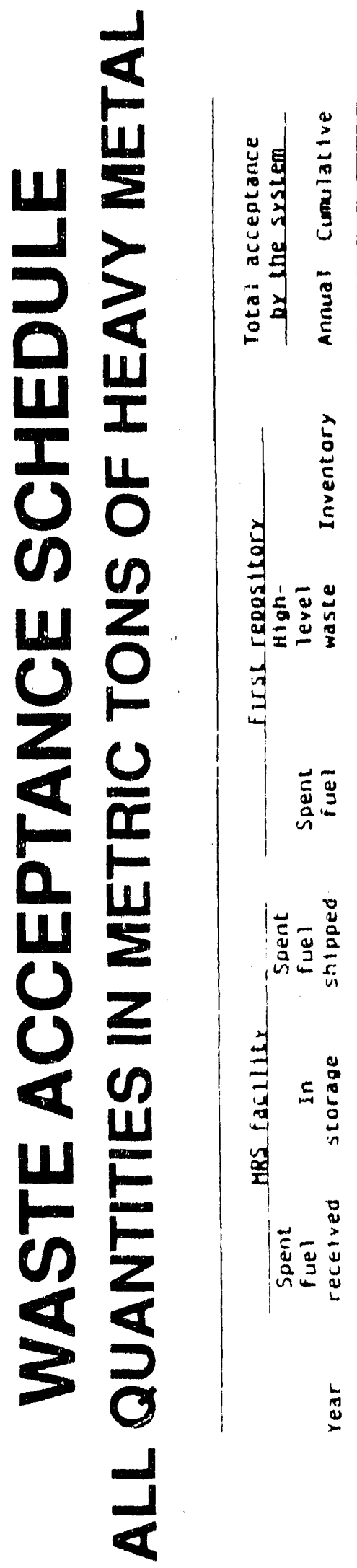

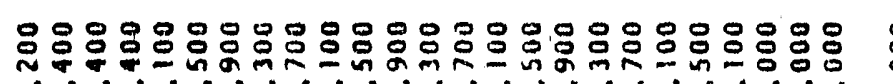

-

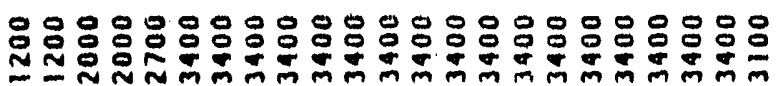

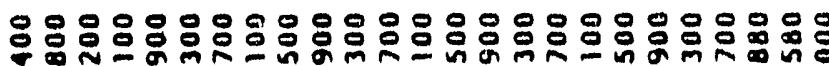

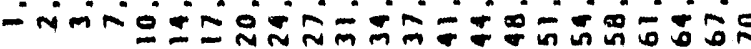

$\because$

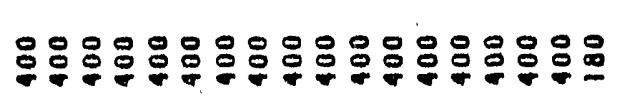

:

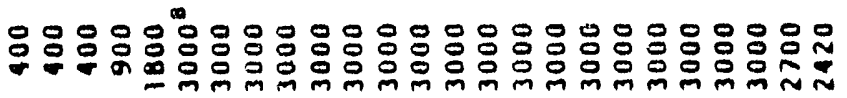

:

은

în

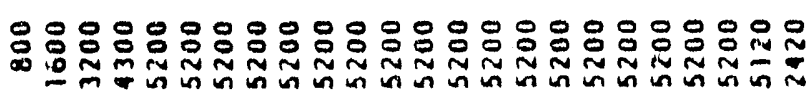

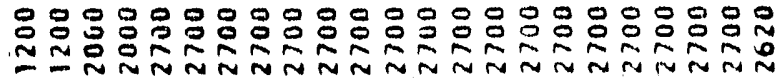

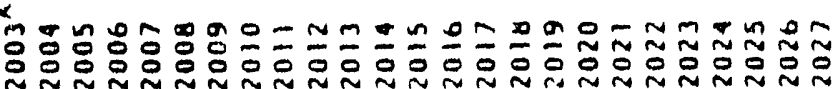

:

$\stackrel{g}{\Xi}$

京

要要

कृ

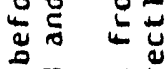

范

产

$\frac{a}{n} \frac{1}{5}$

ณ

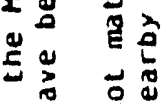

$\ddot{\circ} \stackrel{̊}{=}$

पू

要

急

a

岂

的薜

范

i.

एह

三

E

的总

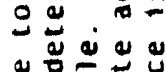

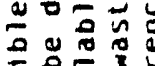

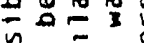

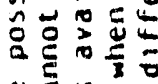

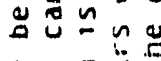

$\lambda \sim c_{0}$

है

开是玉

是至 
Appendix B

Historical and Projected Inventory Tables 
荌 苦

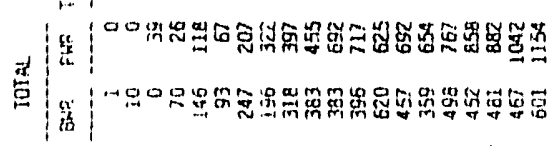
(a) 第 染 出 留 家 只语

䍃

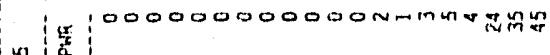
9 篦

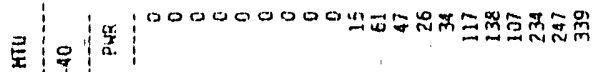
琶

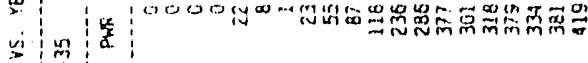
舟 焦 喜 员

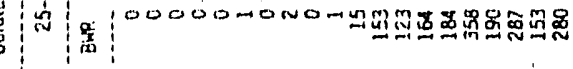

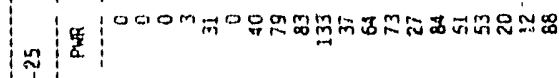
N

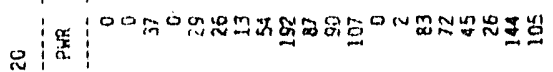
i y y y

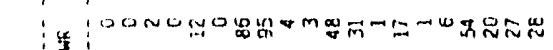

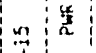
(3)

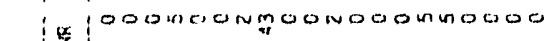
0

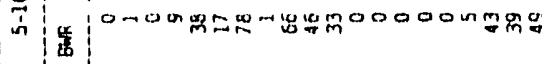
4)

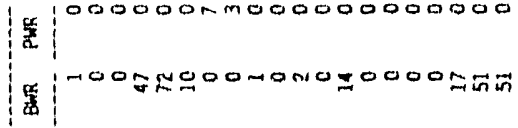

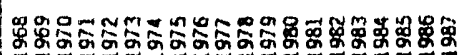




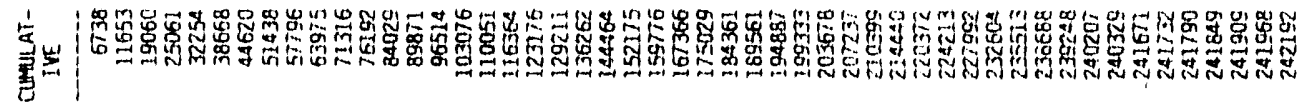

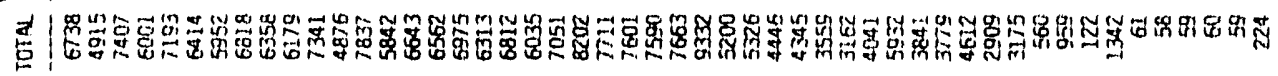

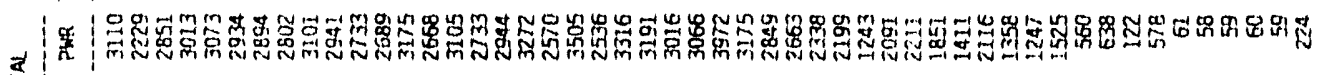

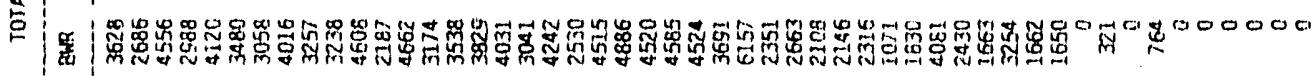
190000000000000000000000000000000000000000010000000 㟯

等 点:

| 管 :

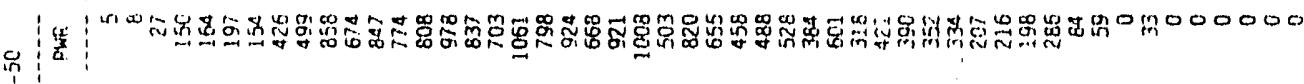

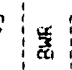

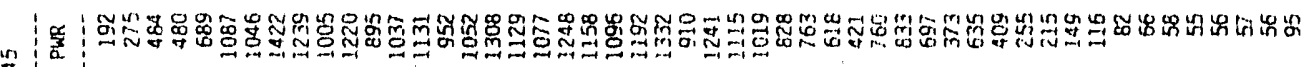

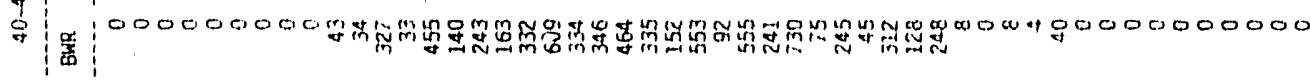

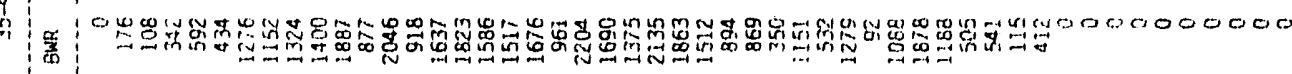

尊 等

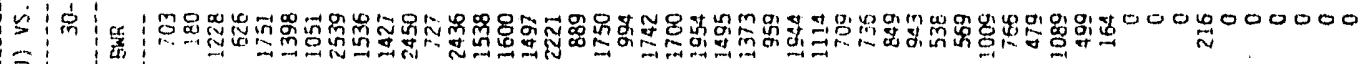

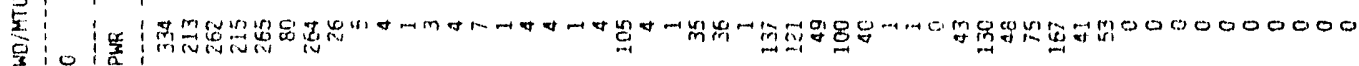
等

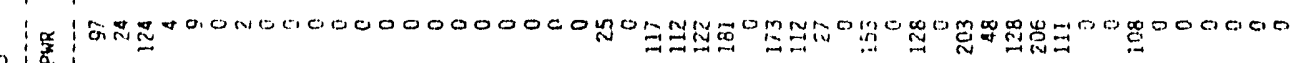

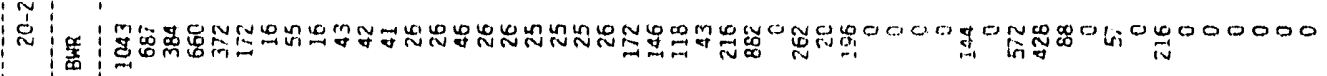

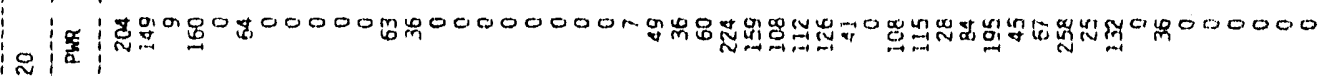

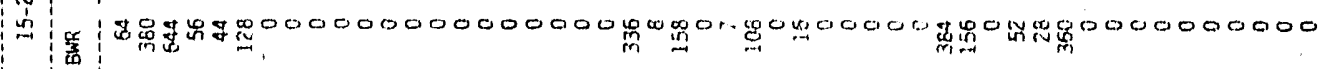
留

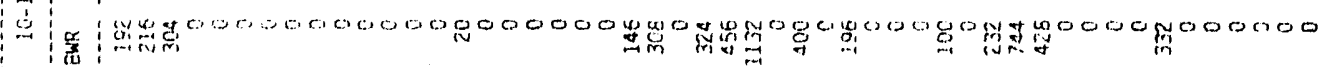

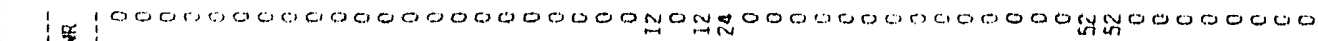
c: w (ii

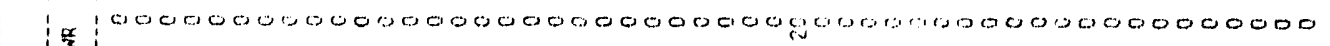
: r.s:

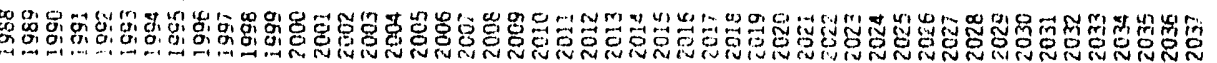




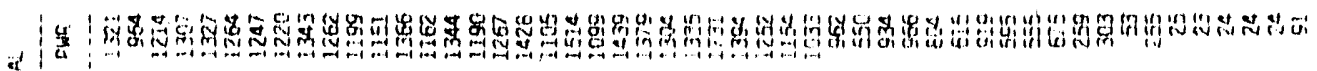

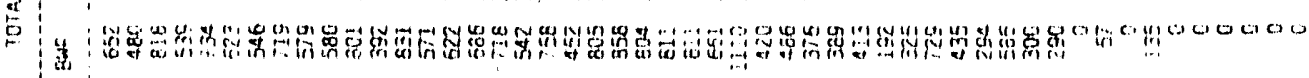
出 (5: 然 箘

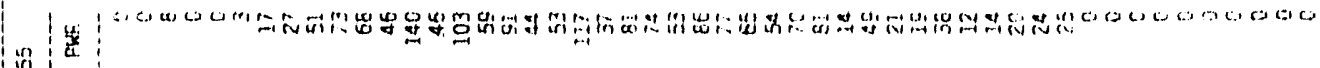
家 :

管 篦

年 焉

9 空

\begin{tabular}{|l|l|l|l}
4 &
\end{tabular}

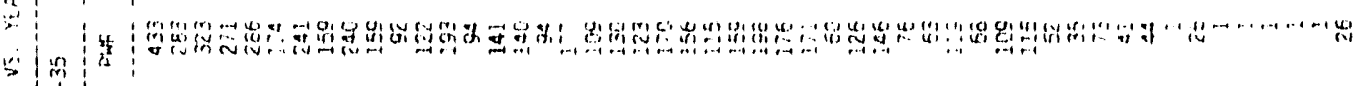

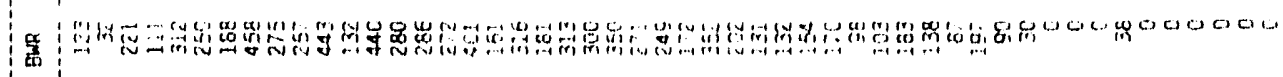
委

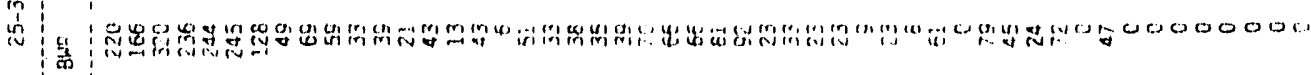

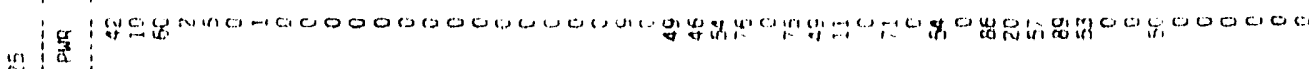
D D

舀

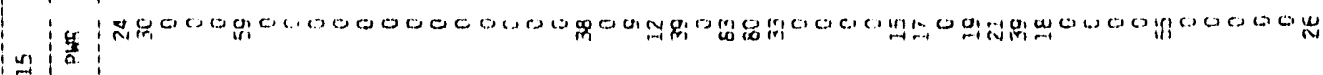

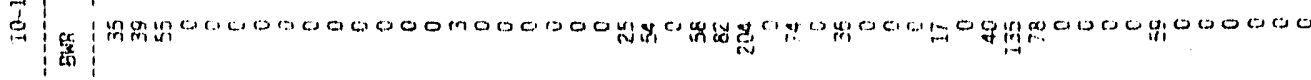

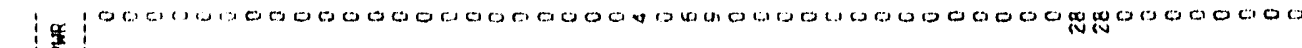

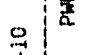
(1) 10100000000000000000040000000010000000000000000000100000000 蕰 F

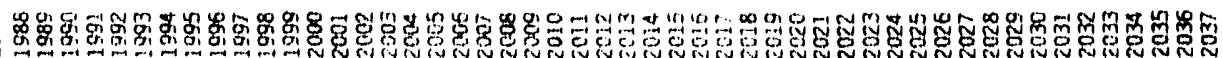


Appendix $\quad$ :

Flowchart and Listing of Scheduling Program 


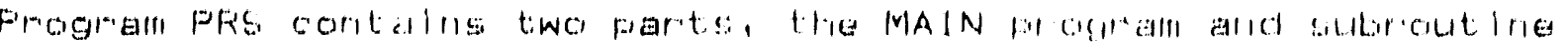

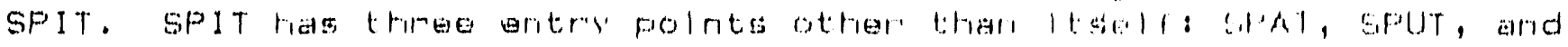
SPOT. In the description that follows, theses foll entry points ares addressed Individual I $y$.

\section{Inltal lindt comas from threge flas:}

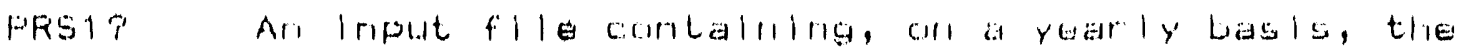

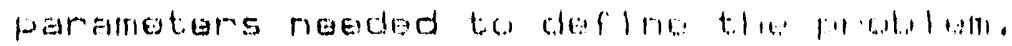

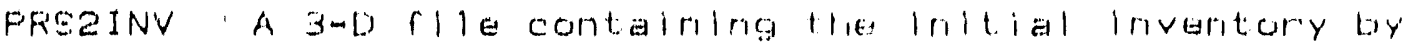
AGE, BURINUP aInd TYPE:

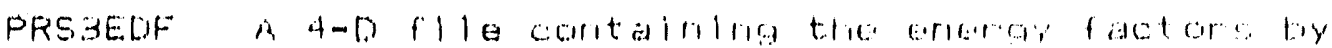

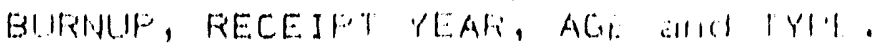

cutput is written to $\$ 1 \%$ files:

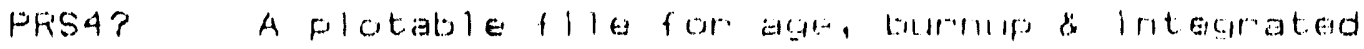
energy.

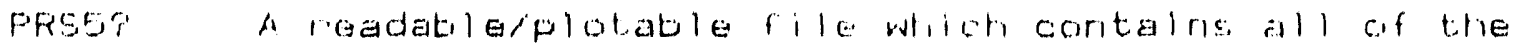

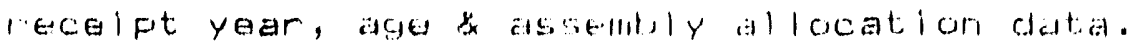

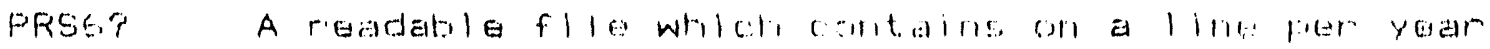
basls sorieduled al locat ichs alld average

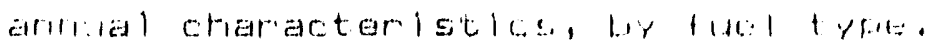

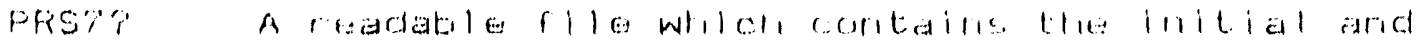
firal turalloogted inverilcory.

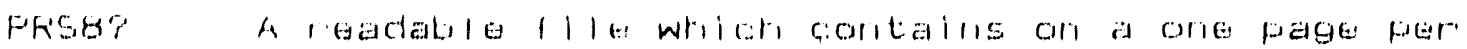
year liagis vilut was tiaker from Iriventory.

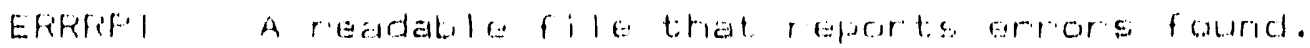




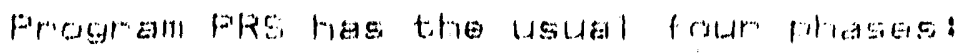

Conception, Birtin, LI fe \& batil.

\section{CONCEIVE}

At compl te tIme, PRS Is concelved witil il sat cI PARAMETER'G, to estatal sh the slze of varlous arrays, ia cillmoN block for access by the subroutine SFJ' and l te ontry polnte, arid a llata statement derinlrog some varlablas.
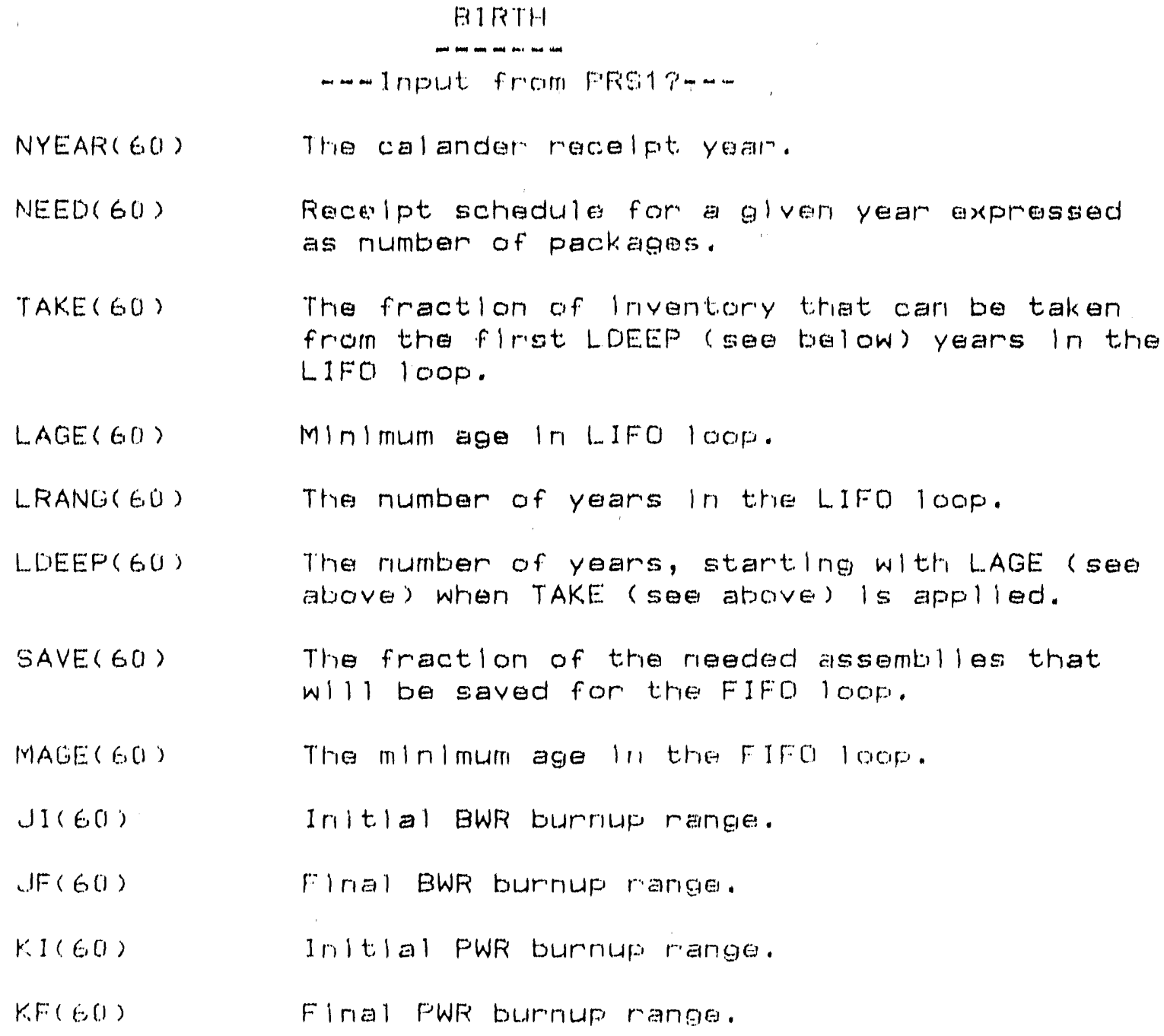


\author{
-.- Input from file FRS 3 EDF-.. \\ year and alot. \\ year and alge. \\ After Infut is completead, a CAl.L. is made lo Gly: \\ -.. SPIT wrltes to Frs? \\ IYRE, MEW, MPW (seg above) InItlal J riventory
}

EEB(12,60,60) BWR engrey depositilar factors by burnup,recelpt

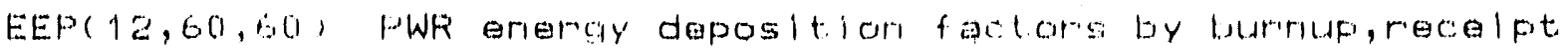

In its operatianal I fe, PRS ras flve lo loops. The outer loop (Index $N$ ) is over the years aval latele. liside trils loop are two palrs of doubly-nested DO loops, ore for LIFO and one for FIFO. In each pair, with the recelft year Index. (N) avallables, trie auter loop of the pair (Index LI) loops aver the Inventory, and the irirer loops (Indloes $J$ or $K$ ) loop over the burnup.

At the end of each l teration of the outer look, if recelpts are a) located, a CALL is made to SFAT.

- - SPAT WR I tES LO PFSB

\begin{tabular}{|c|c|c|c|}
\hline NYEAF' (NAP) & Recel & Pt $y \in a r$. & \\
\hline$N A G$ & $A \subseteq G$ e & $r \in c \in \mid p t$. & \\
\hline NBW( 61,13 ) & BWFi & linventory & a $1 /$ ocat $E d$. \\
\hline NFW 61,13$)$ & FWh & iriventen $y^{\prime}$ & al 10 atead. \\
\hline ITA & Total & inventiory & al I coated \\
\hline
\end{tabular}

NYEAR, NEED, LAGE, LRLING, LDEEP, TAKE, SAVE (se日 aboVe) for trils year.

IBN

AGEB

BURG

C.Fi. I.
BWF assemtal les reguested.

BWR averages age.

BWR average tur.tur.

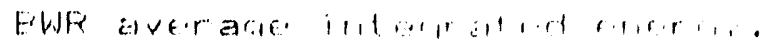




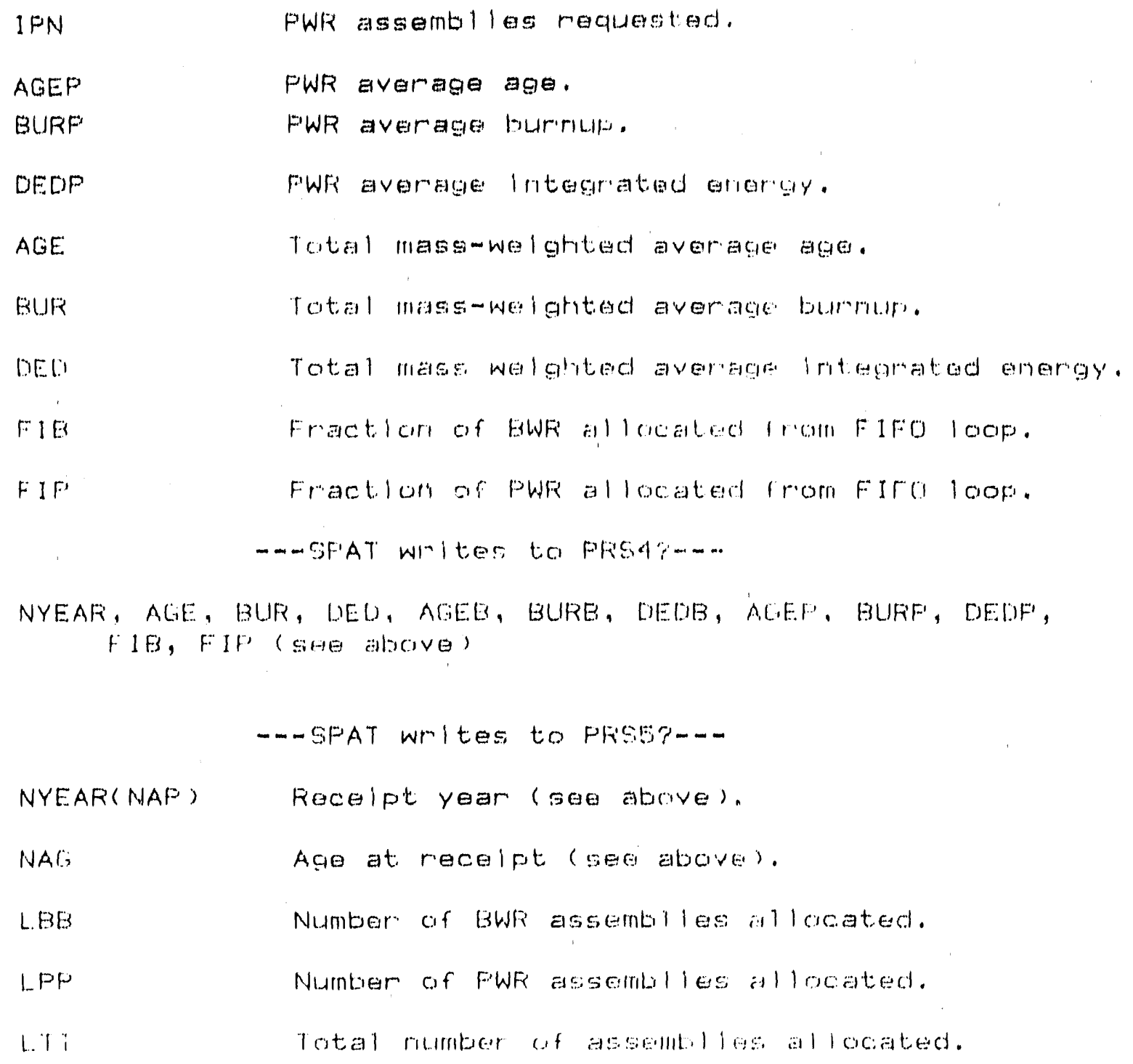

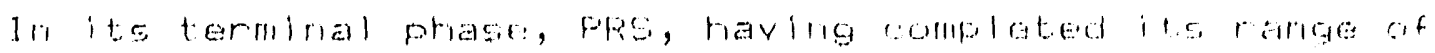
Echedul ing actiors, CALL'S SPIT, SPUI, SFOT, and [.17.

- - SpIT writes to prot?-n

NYEAF, MBW, MFW (see above) IJIal locatid I nvertory.

- SPUT wr. t tes to F'RSE'

INEER Trat number of packaces.

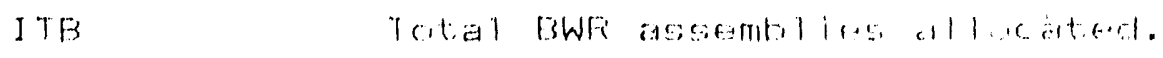

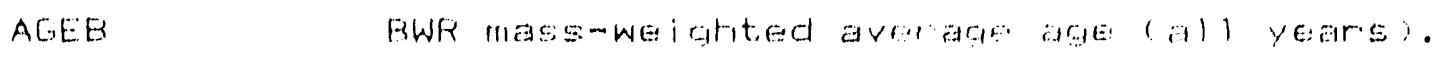


BURB

$D E D B$

I TP

AGEP

BURP

DEDP

$A G E$

BUR

DED

ITT

IC

IO

IS

ERRSUM
BWR mass-we ighted avemage burnup (a) 1 years).

BWR mass-weighted average integrated energy (a) 1 'years).

Total PWR assemblies allocaced.

PWR mass-weighted average age (all years).

PWR mass-weighted average burriup (a) 1 years).

PWR mass-weighted average integrated energy (a) 1 years).

Overall mass-weighted average age (a) l years).

Overall mass-weighted average burriup (a) years).

Overall mass-weighted average integrated energy (a) l years).

Total of all assemblies allocated.

CPU time used (us).

Input-output time used (1.15).

Operating system time used (US).

-.-SPOT writes to ERRRPT.--

Number of errors found

NOTE

The "?" used in cutput file names may be chariged to a symbol as the run designator.

The files PRS6?, PRS7?, PRS8?, and ERRRPT contain an entry on I ine 1 of some or all pages that contains:

$T D(3)$

$A A$
Clock time, Date, Computer used.

PRSXIII? The program version and run designator. 


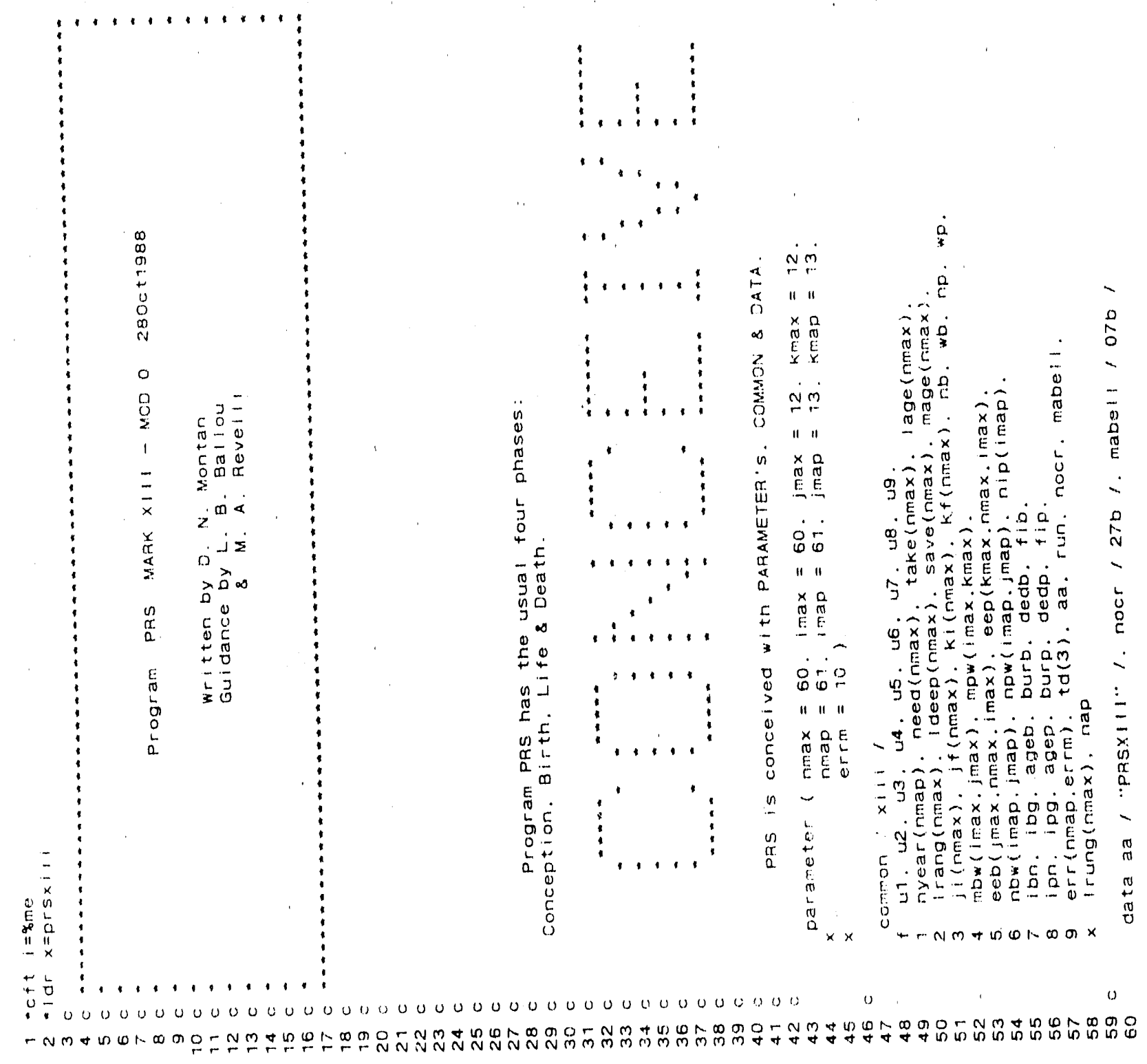




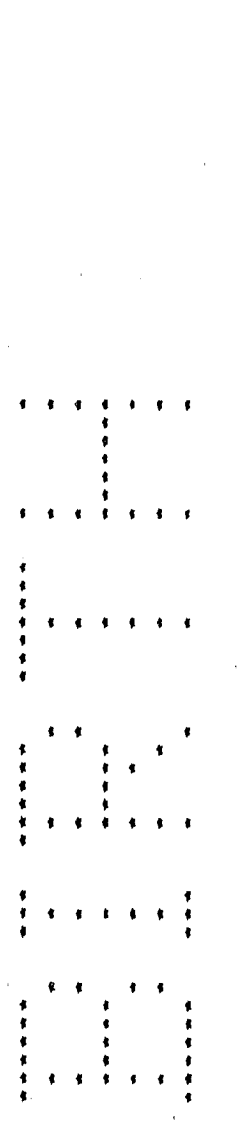

$\therefore+20$

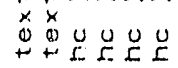
$\therefore-10900$

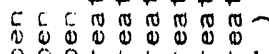

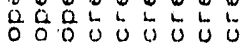

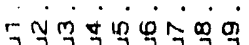

(a)

" | " | | | | | | |

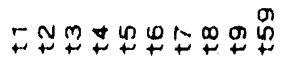

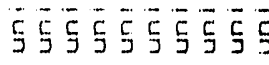
至荡

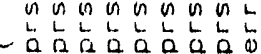
"

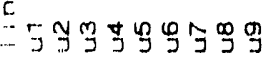
U.

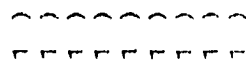
$\therefore \dot{x} \cdot \dot{0}$

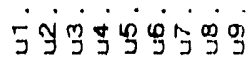

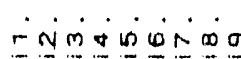
...... m ㄴ.. 0000090000

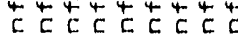

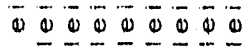
$4+454+4$

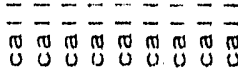

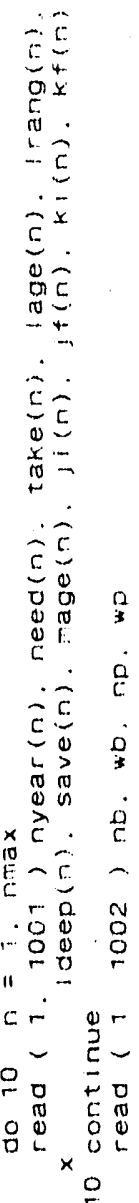

O 0
0
0

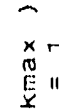
$\cdot \hat{N}$ $"=$

í 20 $\pi=0 \quad x-2 \quad 0$ E一⿻

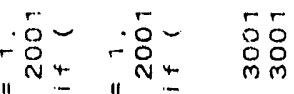
$-\therefore$ 勿

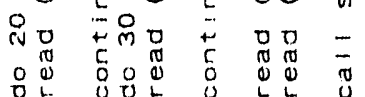
용

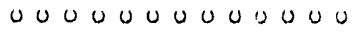

$u$ $u$

u u O O O O

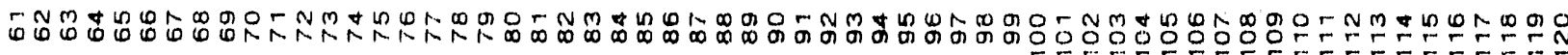




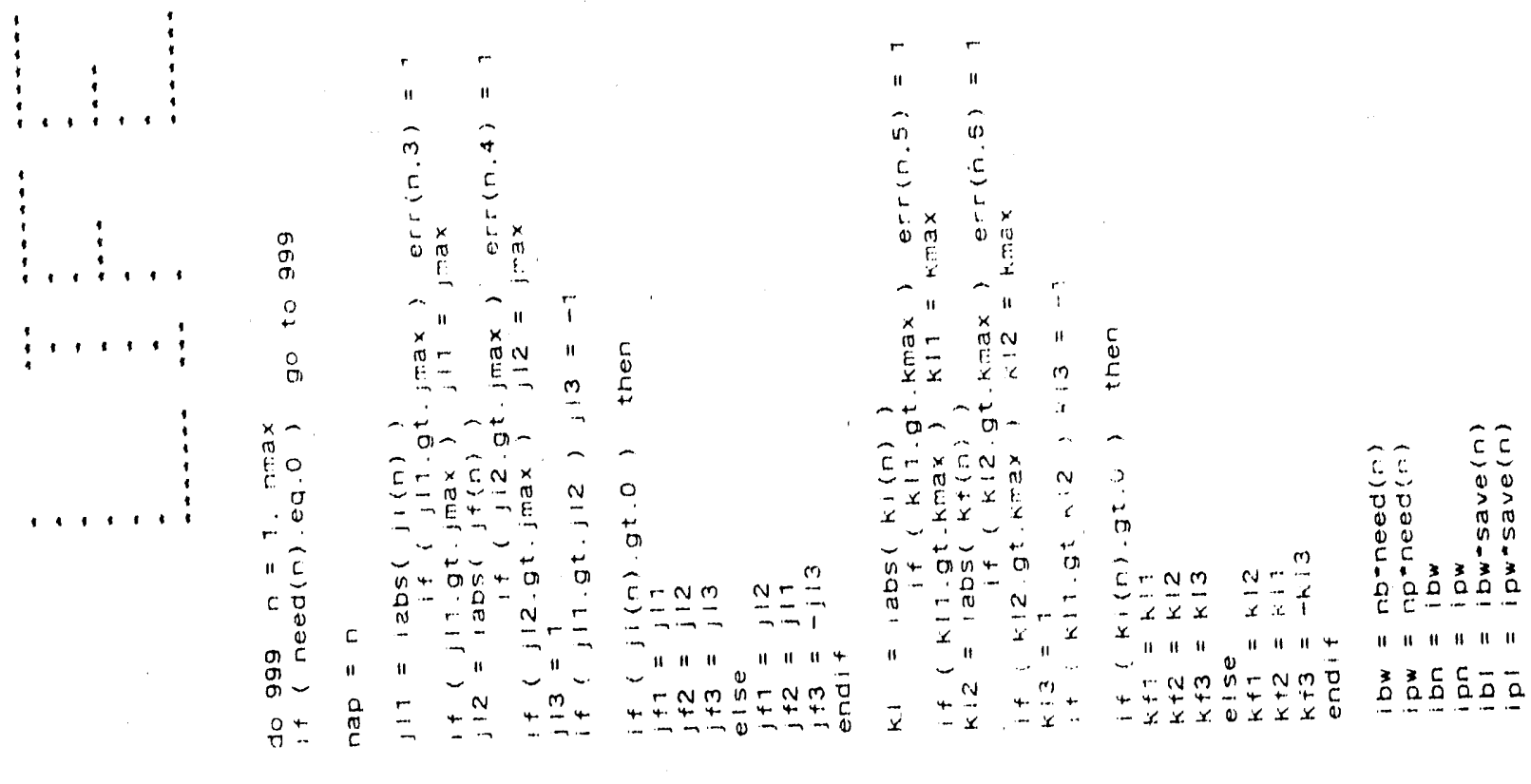

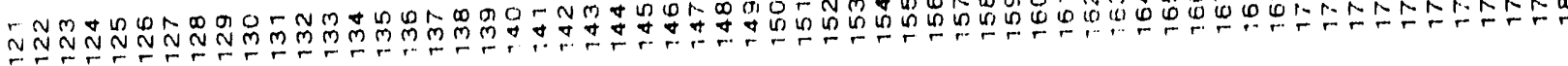




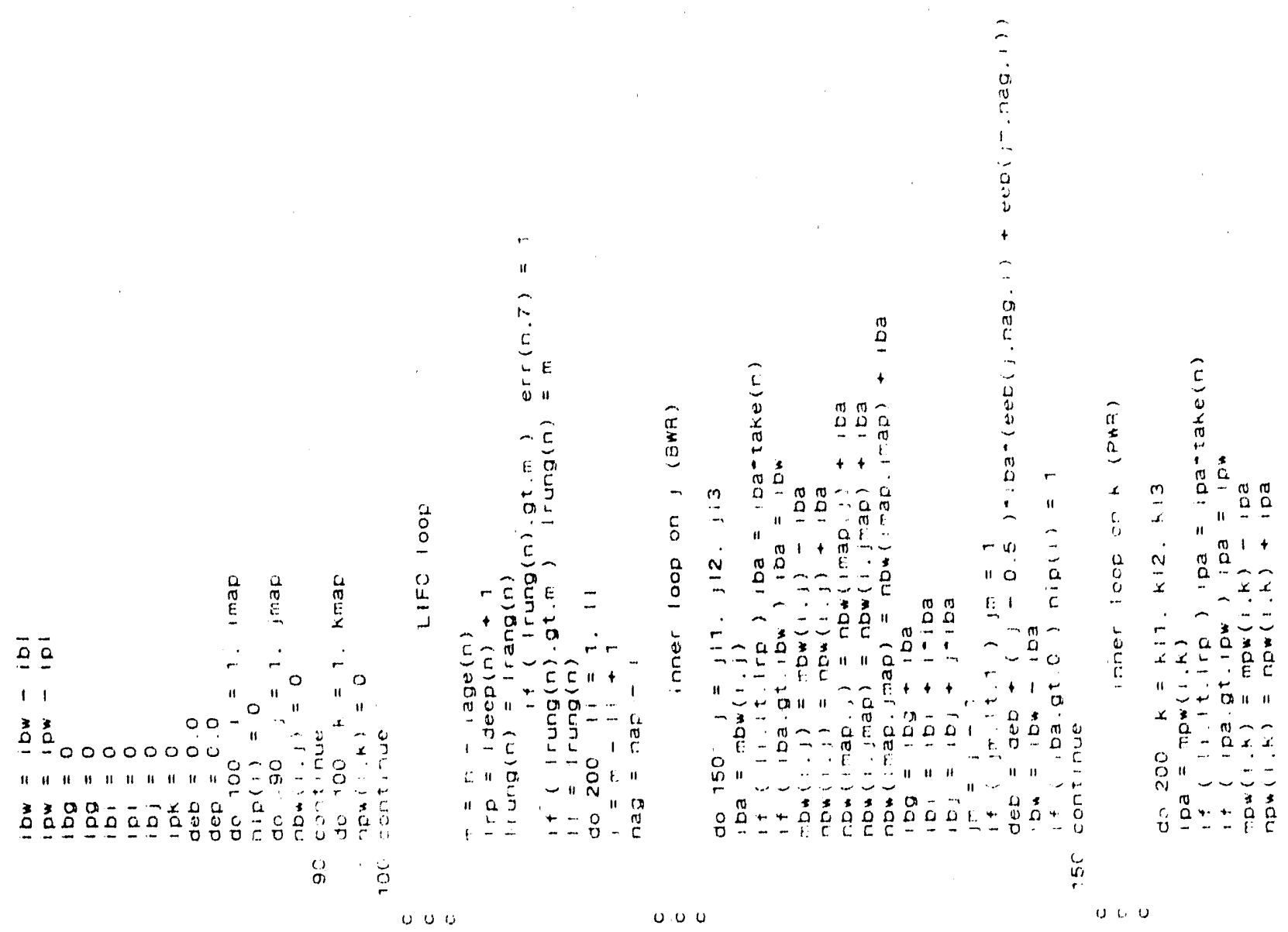

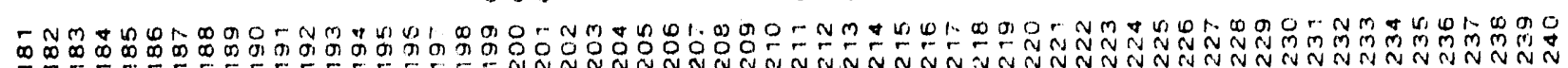




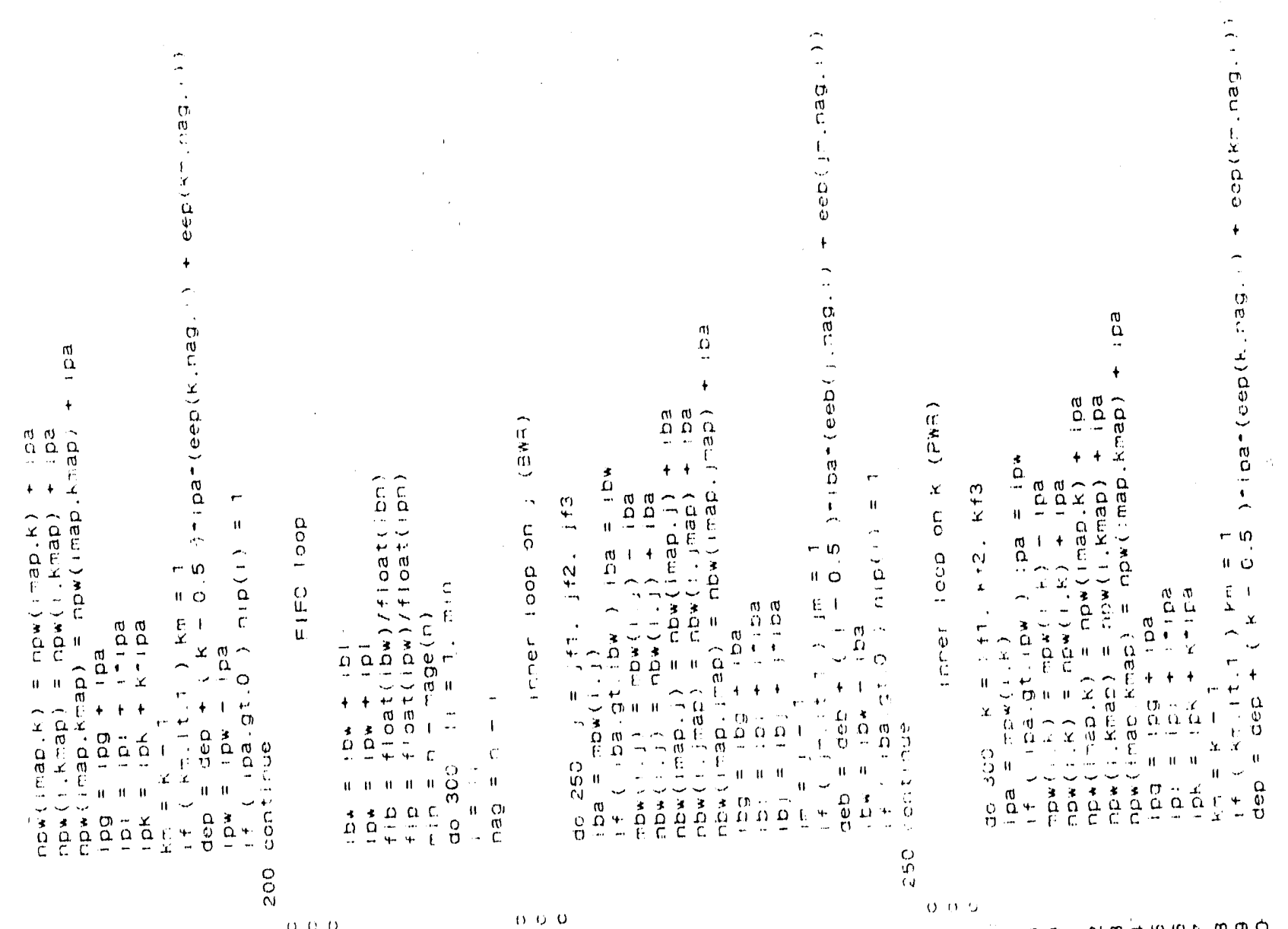

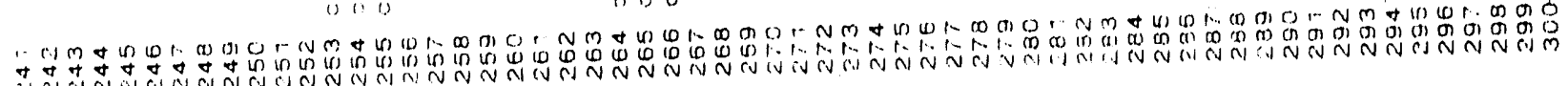




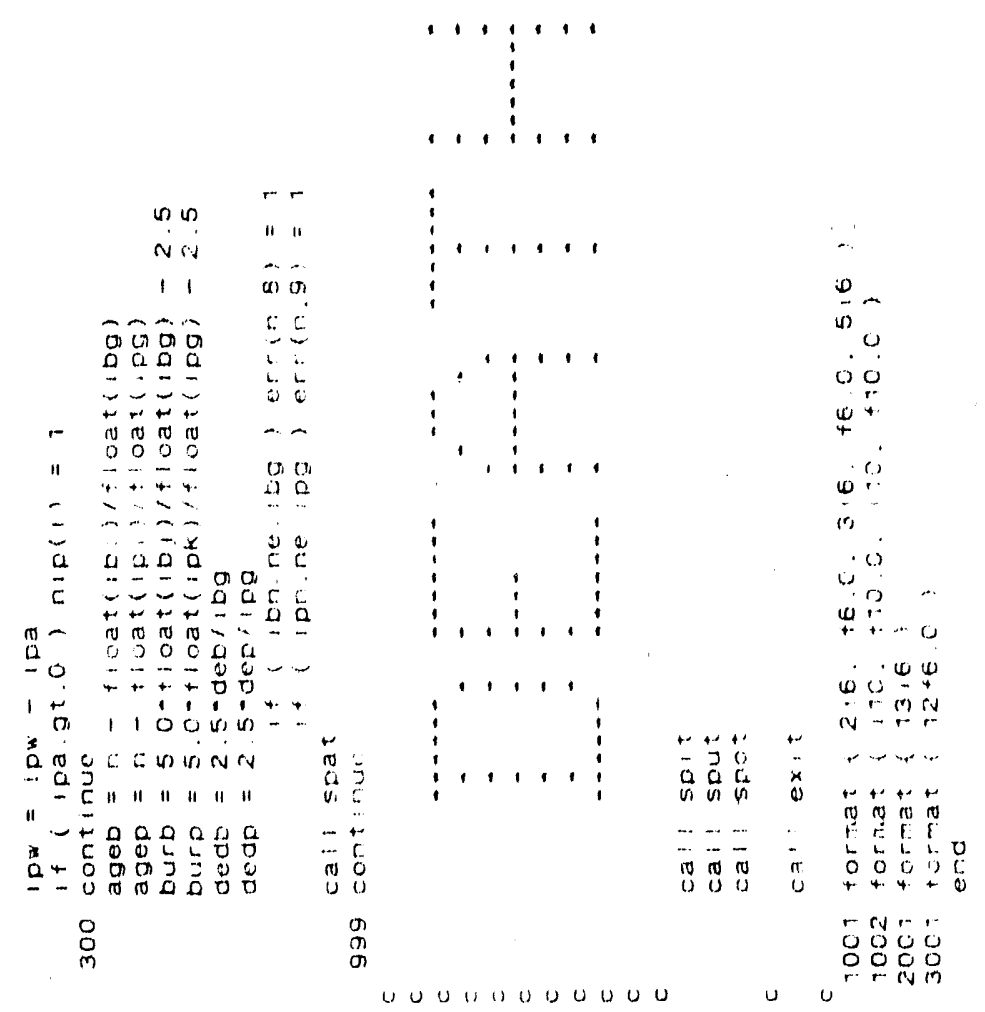

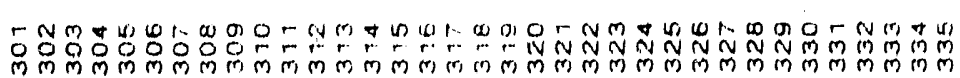




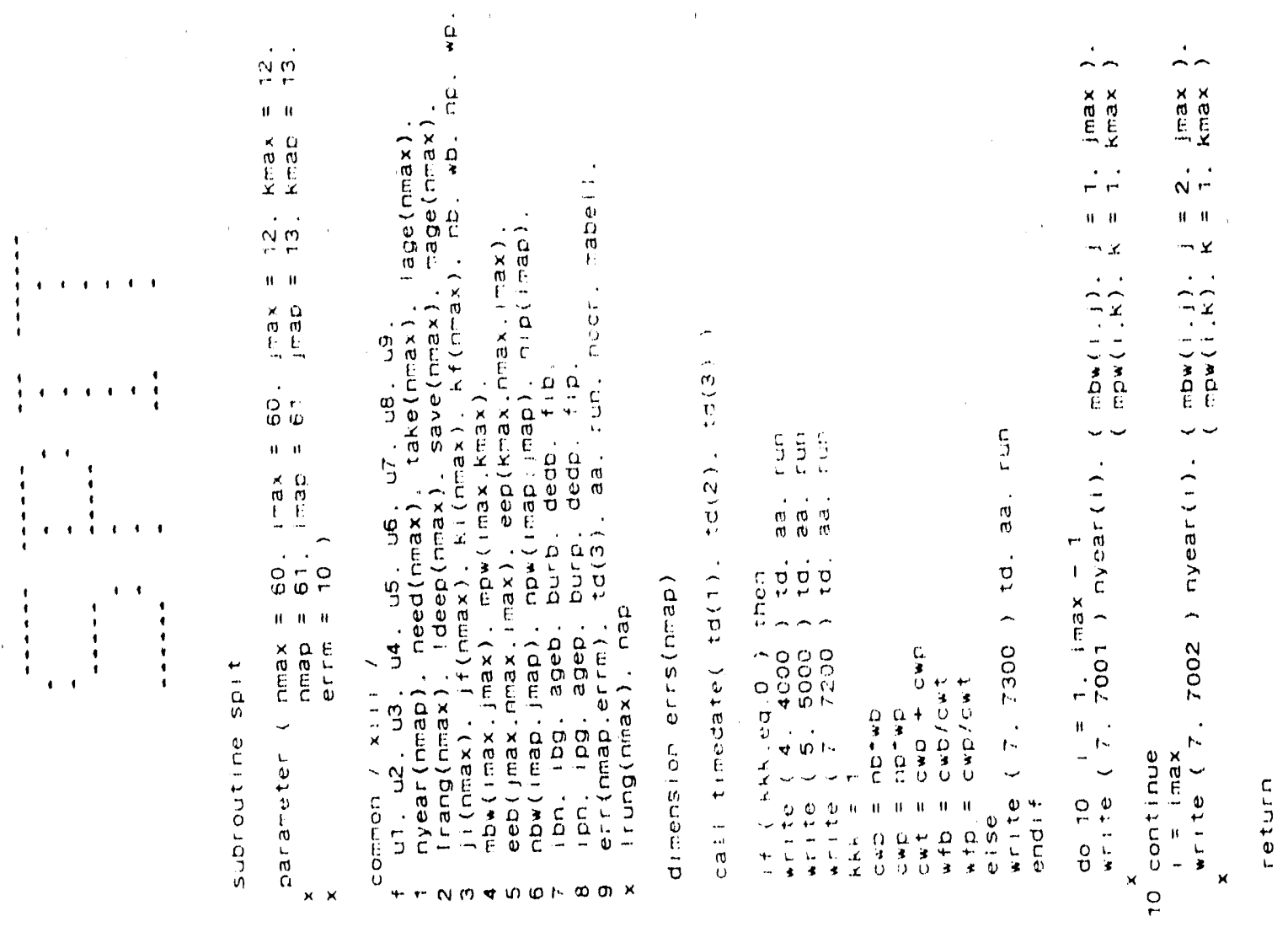

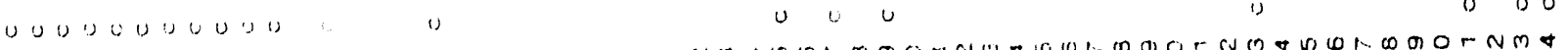

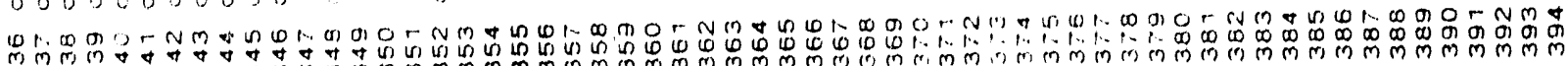



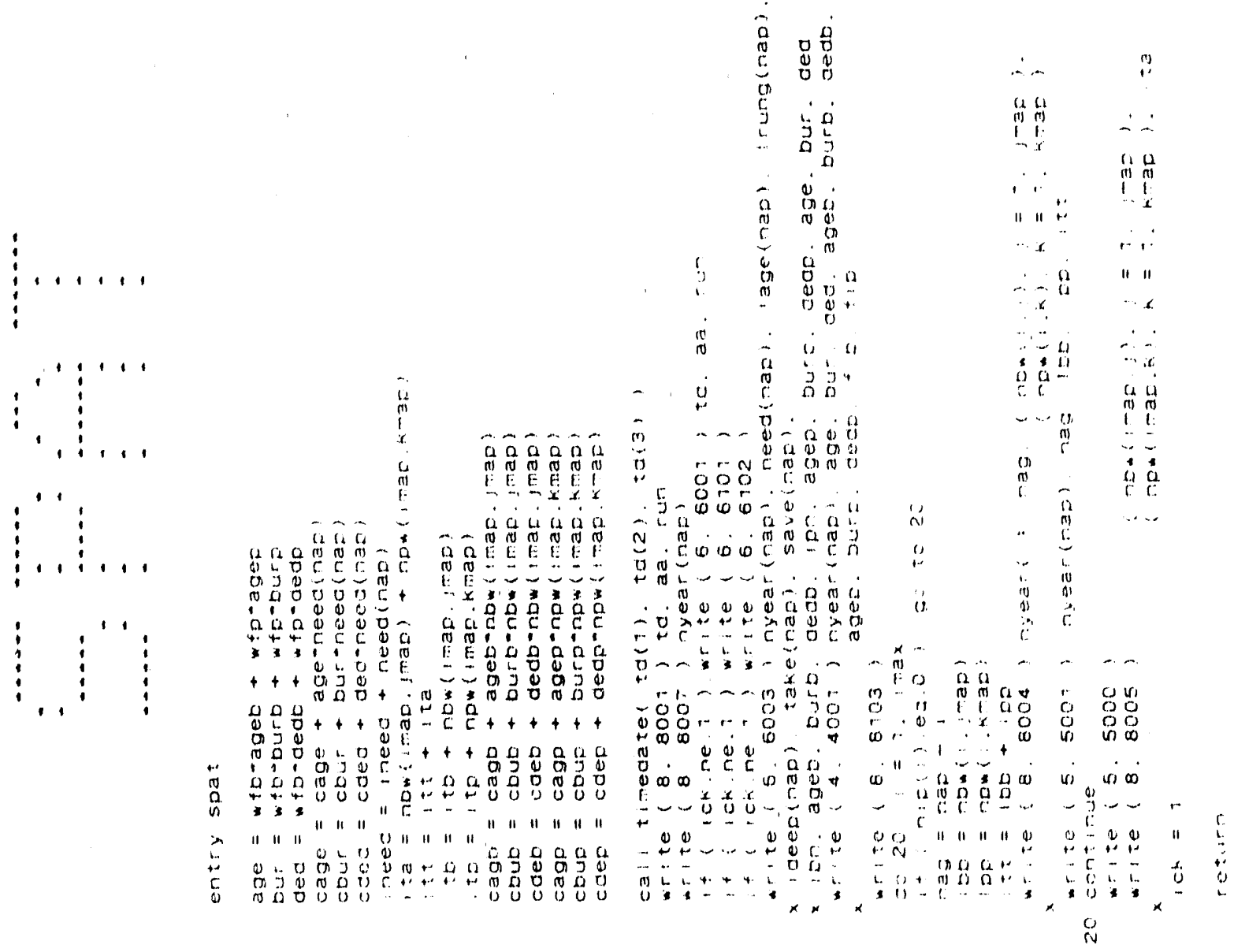

u vu u u u u u

i)

4.140

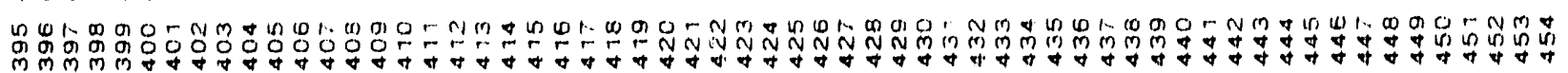



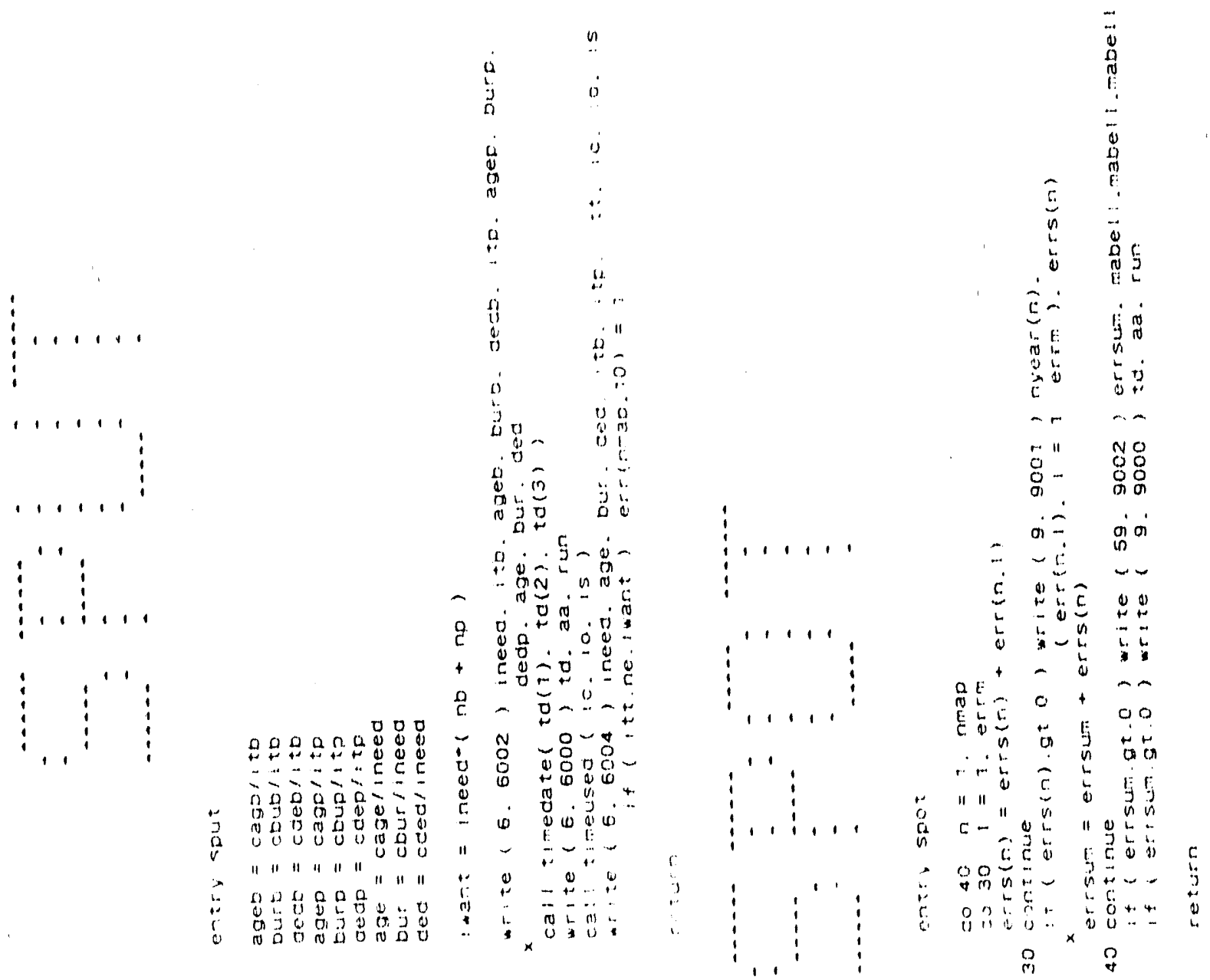

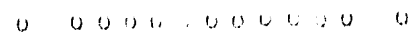

u O OUT

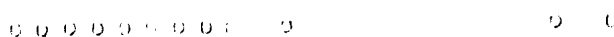
n 4) 


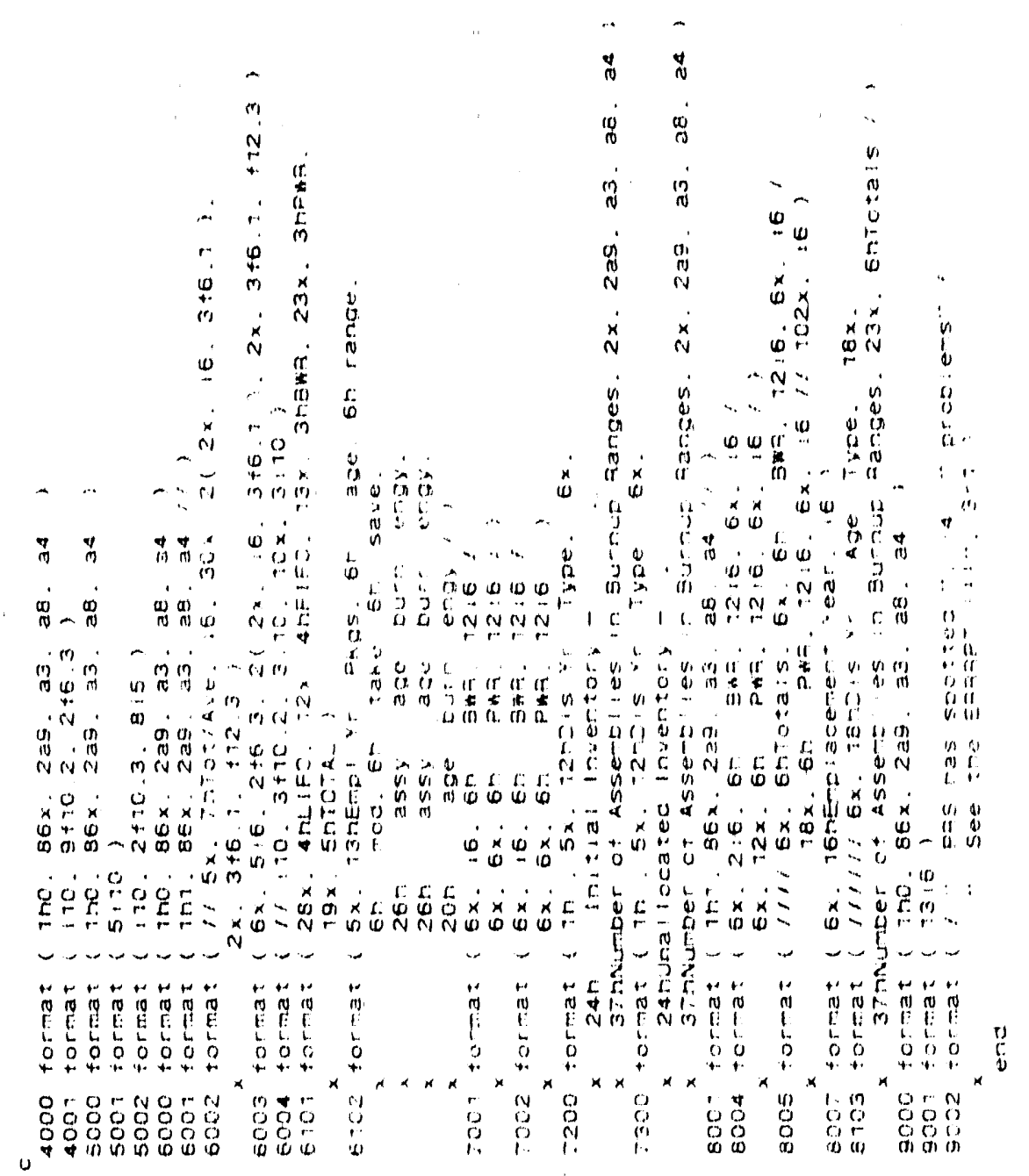

幽

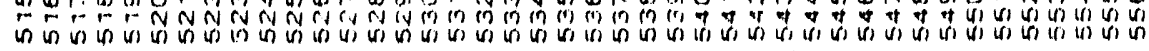




\section{Appendix D}

\section{Oldest Fuel First Receipt Schedule \\ From}

Oldest Fuel Inventory 
m m rOm

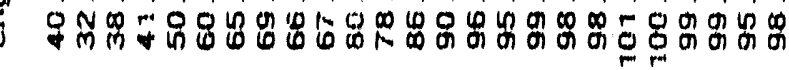

J

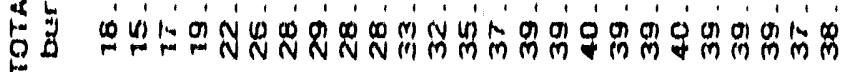

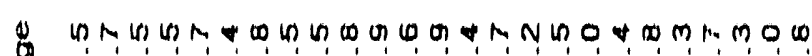

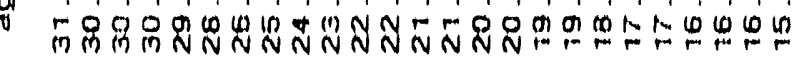

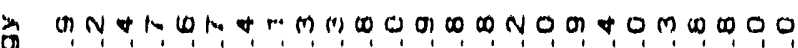

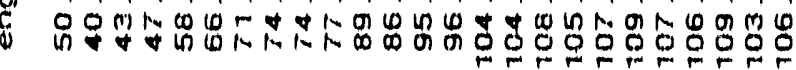

E

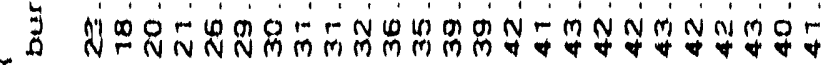

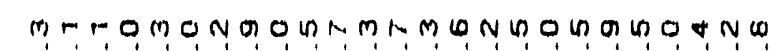

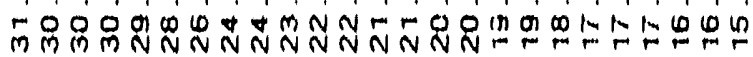

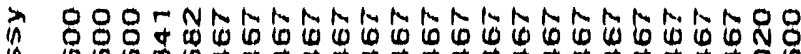
岱

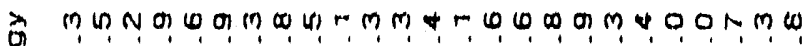
\& N

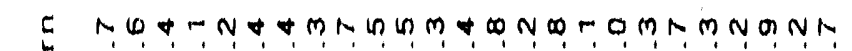

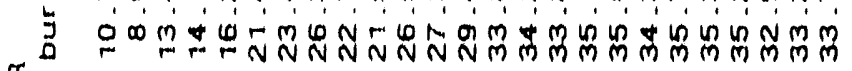

$\varphi$ in

1. $=$

m

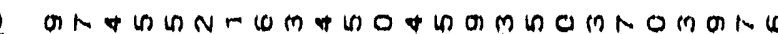
(1) Mm M

ไ

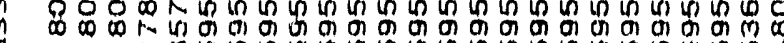
त

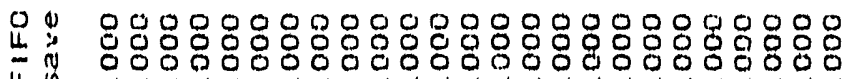

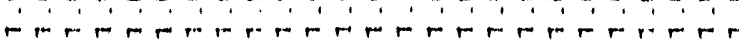

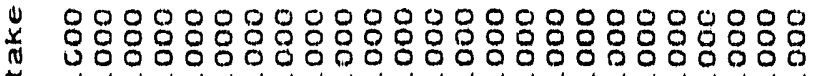
0000000000000000000000000

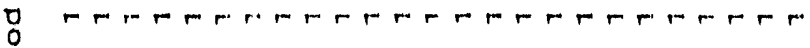

0000000000000000000000000

운

in

$\stackrel{\text { on }}{N}$

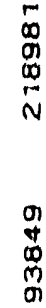

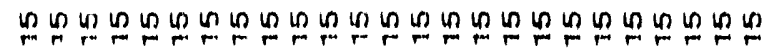

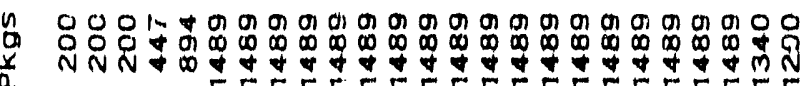




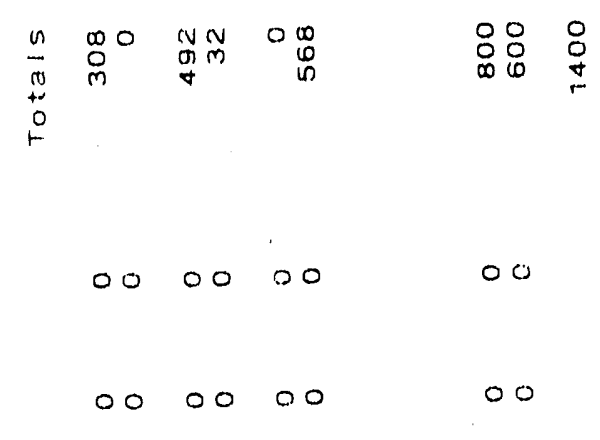

00000000

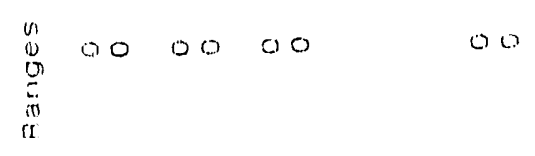

$\begin{array}{llll}0 & 000000 & 00 \\ \frac{7}{2} & & & \end{array}$

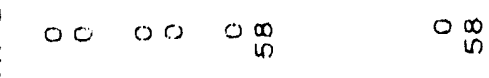

$\frac{y}{y} 00+0 \quad 0 \underset{\infty}{N}+\underset{\infty}{N}$

$00 m_{m}^{0} \underset{\infty}{\infty} \quad m_{\infty}^{\infty}$

$+$

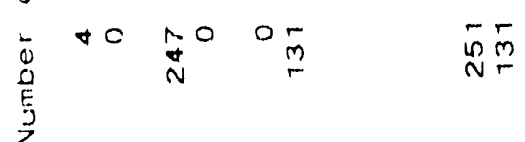

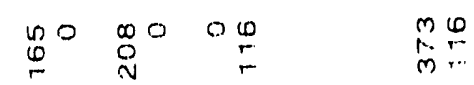

$\infty_{\infty}^{\infty} 00000 \quad \infty_{0}^{\infty}$

is 00 m 00 in

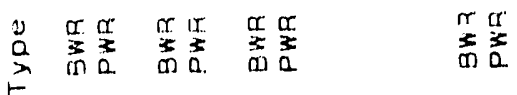

崩 $\stackrel{N}{m} \stackrel{m}{m}$

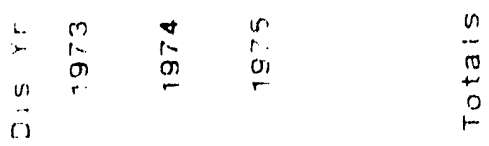




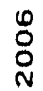

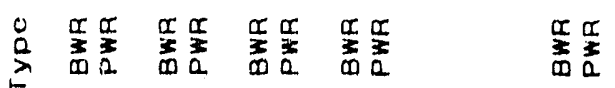

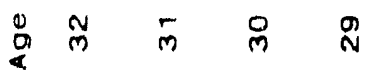

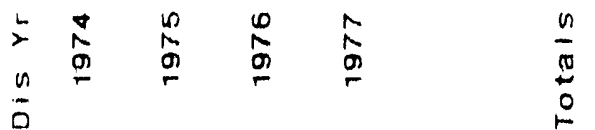



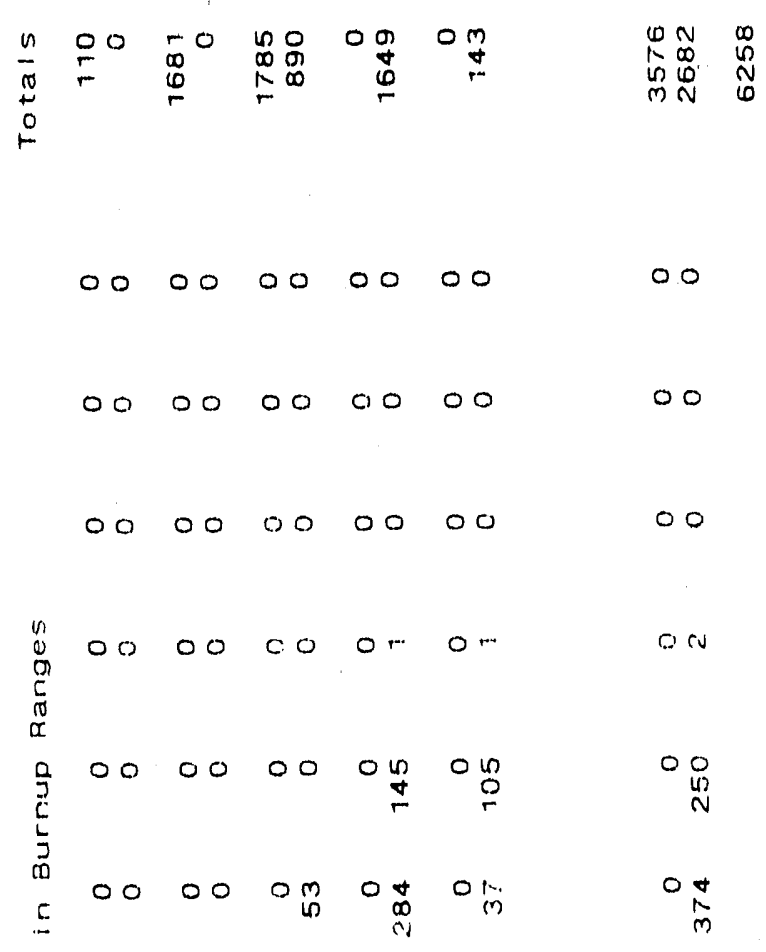

$0000+\underset{m}{0} \underset{m}{\infty} 00 \quad \stackrel{m}{N}$

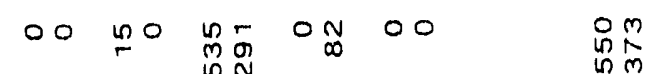

4

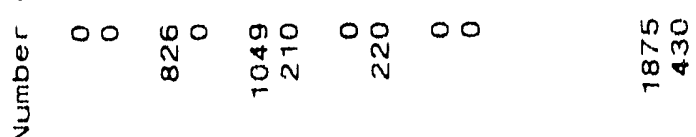

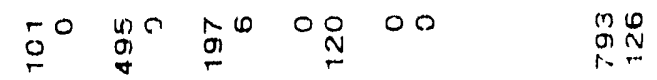

No $\begin{gathered}m^{+} \\ 0\end{gathered}$

No DO 00 DO 00 no

$\hat{o}$

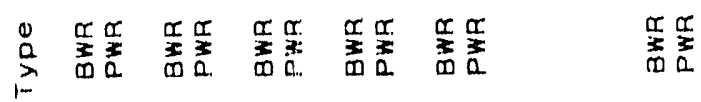

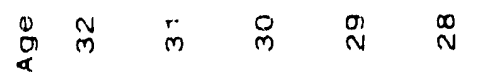

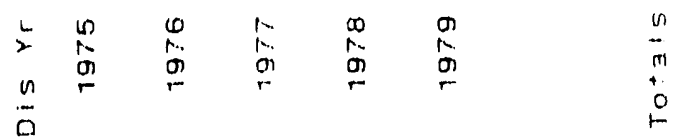


$\infty$
$\stackrel{0}{N}$
$\stackrel{D}{N}$

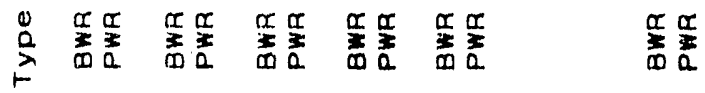

$\stackrel{0}{a} \bar{m} \stackrel{\circ}{M} \stackrel{\infty}{N} \hat{N}$

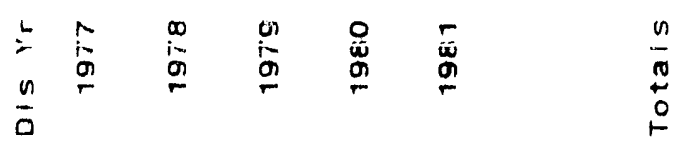




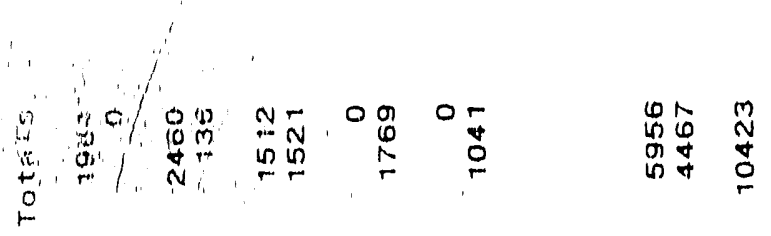




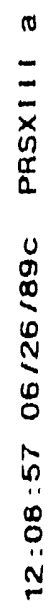

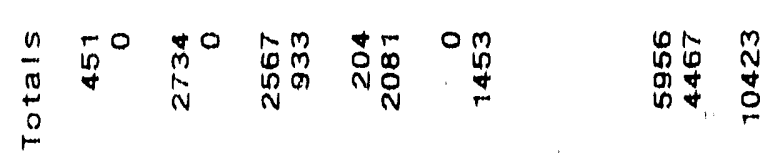



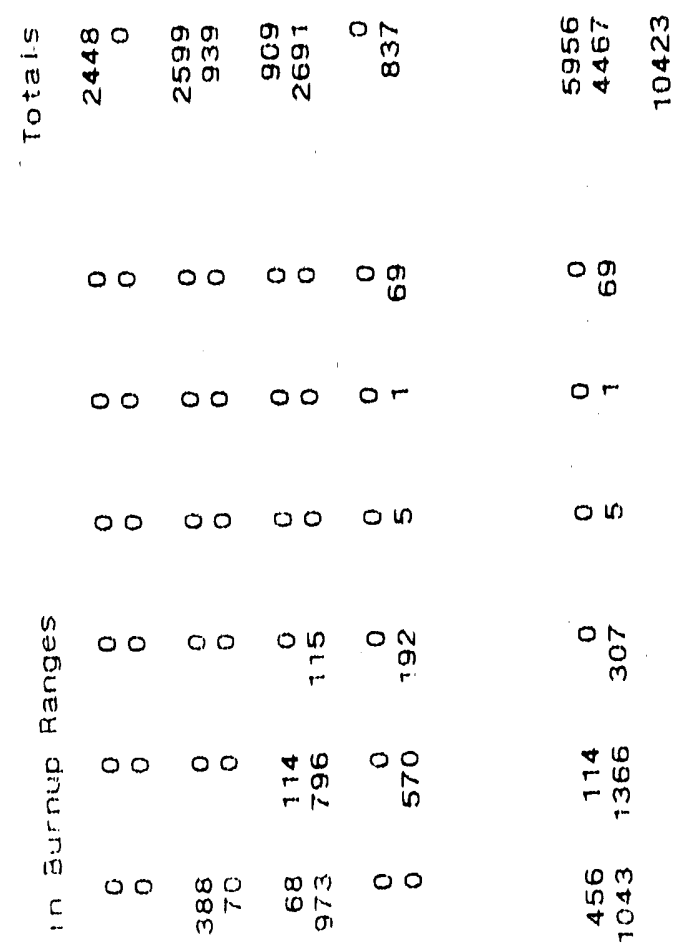

ז

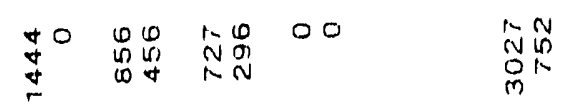

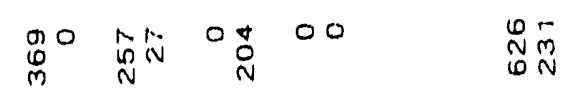
$+$

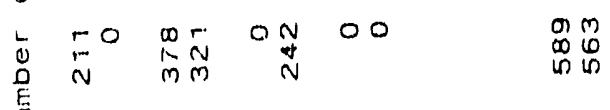
OO $\stackrel{M}{N}_{0}^{+}$O $\stackrel{N}{N}_{N}^{N} \frac{N}{N}$

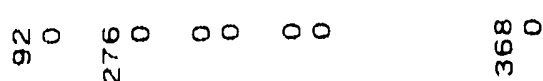

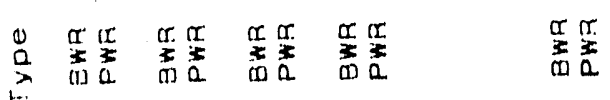

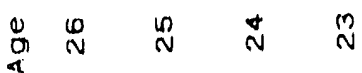

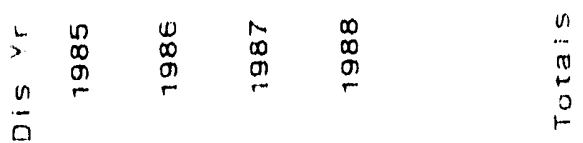


ב.

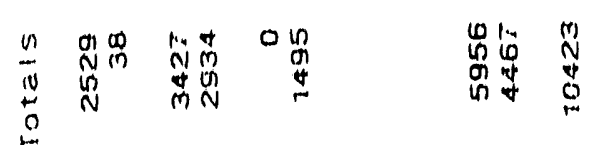

oo or oo or

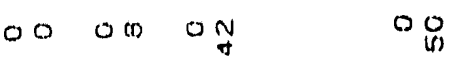

$000 \underset{\sigma}{\stackrel{0}{0}}$

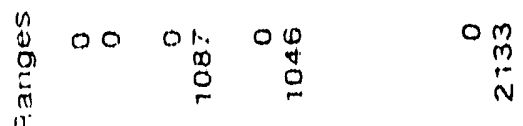

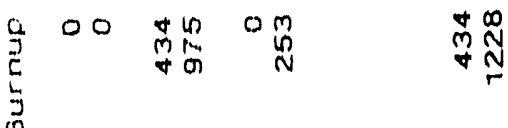

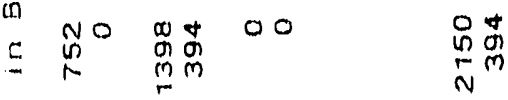

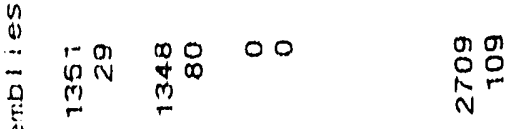

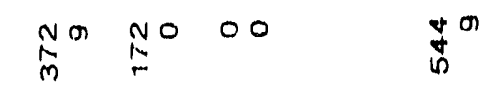

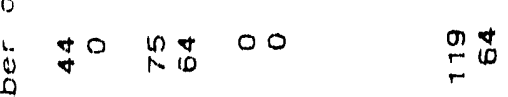

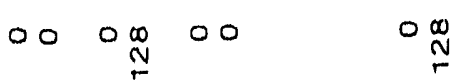

$000000 \quad 00$

$000000 \quad 00$

$\stackrel{n}{\stackrel{n}{N}}$

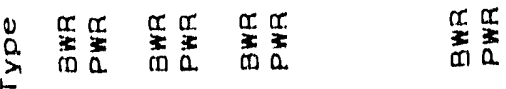

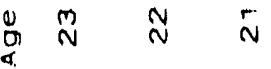

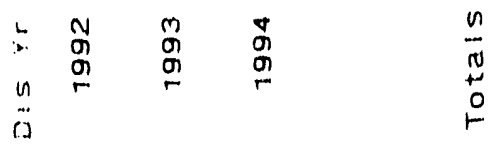




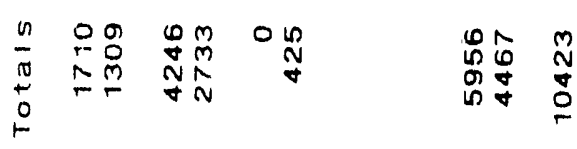

OO ON ON On

$000 \underset{0}{0} 0 \stackrel{0}{0}$ 年

$00 \quad \underset{0}{0} 0 \frac{0}{m} \quad 0 \underset{\infty}{0}$

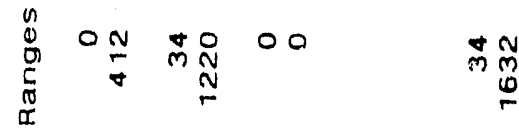

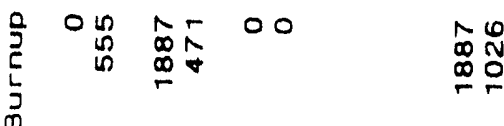

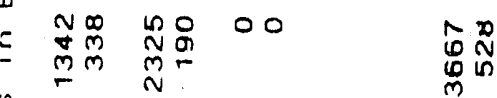

$\stackrel{N}{n} \stackrel{m}{D}_{0}^{n} 0-00 \quad \mathbb{N}^{n}$

mo $0000 \quad$ mo

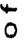

500000000

z

$000000 \quad 00$

00000000

$000000 \quad 00$

$\stackrel{\infty}{\stackrel{\infty}{N}}$

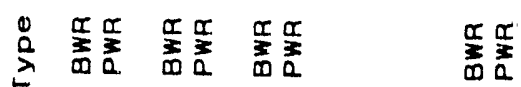

$\stackrel{0}{\infty} \stackrel{\text { N }}{\leftarrow}$

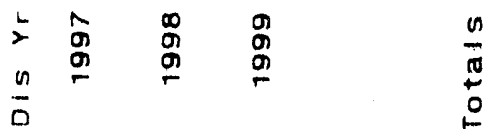


000000

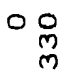

00 总

$0 \underset{\frac{1}{2}}{\frac{1}{2}}$

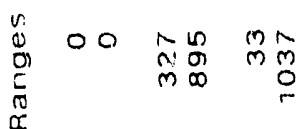

을

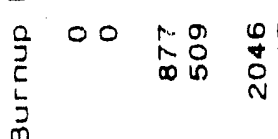

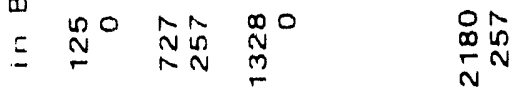

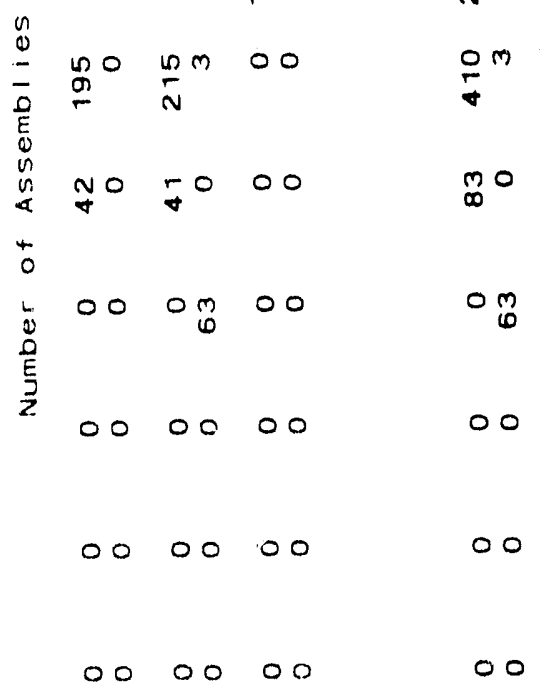

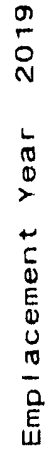

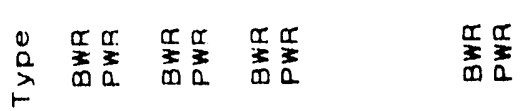

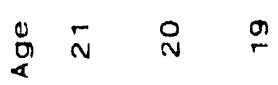

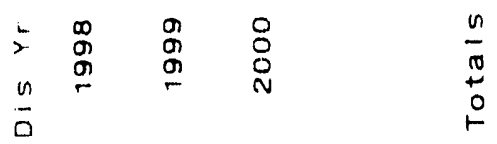




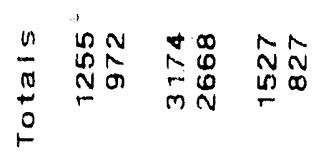

OO ON OD

o o

O 0 OD

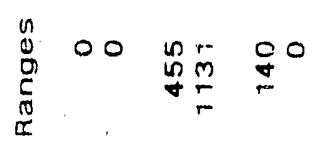

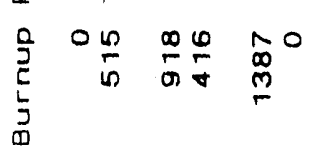

$\begin{array}{lll}\infty & \infty \\ 0 & m & 0 \\ 0 & 0 & 0 \\ n & \end{array}$

in $r$

$\frac{n}{0} \tilde{n}^{*} \hat{m}^{N} 00$

$\overline{0}$

in w N

$+$

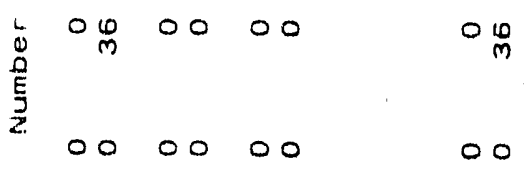

000000

000000

in

$\frac{2}{8}$

号

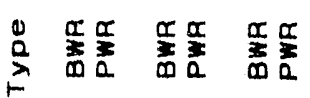

010

$0 \underset{n}{n}$

O

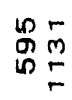

象学

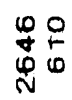

$\mathfrak{n}_{n}^{\infty}$

No

00

00

ฉำ 용

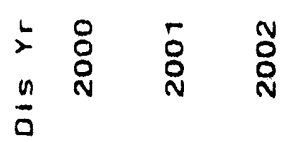

善爱

$\underset{10}{\frac{n}{6}}$

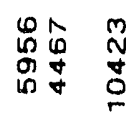


$\underset{N}{N}$

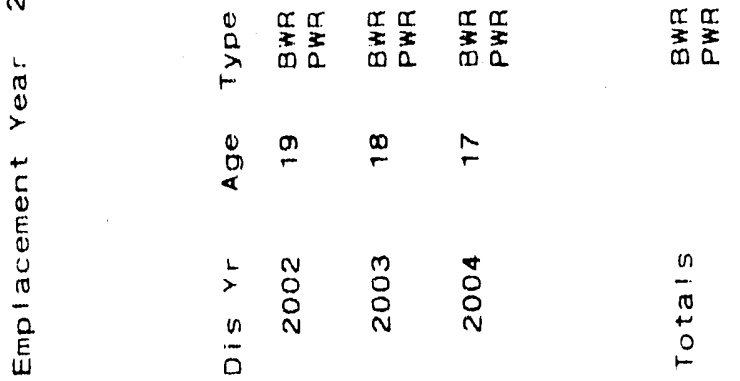


0
$\vdots$
$\bar{x}$
0
0
0
0
0
0
0
0
0
0
0
0
0
0
0
0

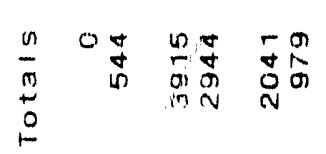

00 on

$000 \frac{2}{2} \stackrel{m}{\frac{m}{2}}$

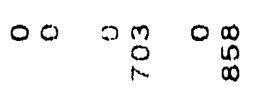

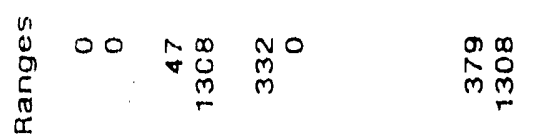

苛

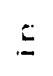

n

$\overline{0}$$$
\text { 足 }
$$$$
\text { in } 00 \stackrel{0}{\infty} 00 \quad \stackrel{\infty}{\circ}
$$

$\stackrel{4}{0}$

它

\begin{tabular}{lllll}
\hline & 00 & 00 & 00 & 00 \\
\hline \multirow{Z}{Z}{} & 00 & 00 & 00 & 00 \\
00 & 00 & 00 & 00 \\
00 & 00 & 00 & 00
\end{tabular}

$\stackrel{\text { N }}{\text { N }}$

$\infty_{0}^{\infty}$

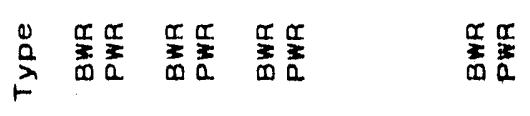

$\stackrel{\infty}{\circ} \stackrel{\infty}{\rightleftharpoons}=$

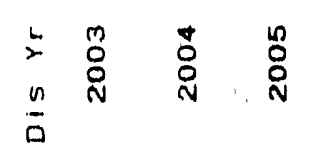

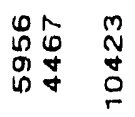

$\stackrel{n}{N}$

on

○.

$\stackrel{m}{\stackrel{m}{n} \underset{n}{R}}$

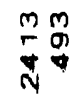

$m_{m}^{\infty}$

$\stackrel{\infty}{N} O$

$\frac{n}{\pi}$ 


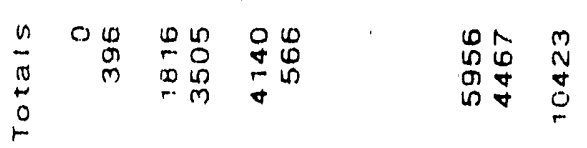

OO Om ON O

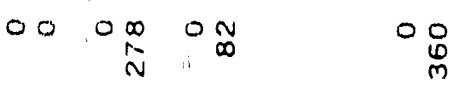

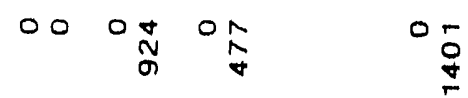

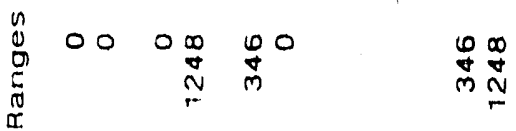

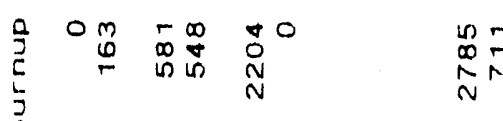

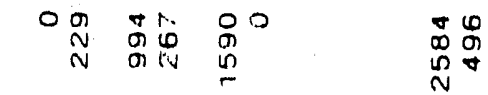

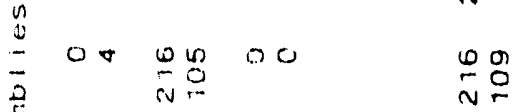

OO N N $N^{n}$

$000000 \quad 00$

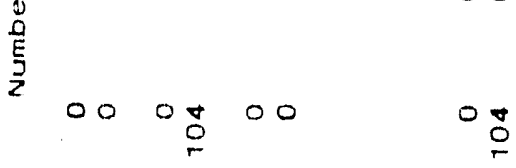

00000000

$000000 \quad 00$

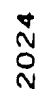

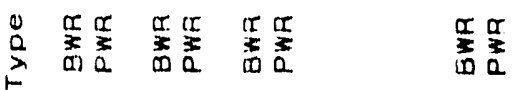

$\stackrel{\infty}{\mathscr{\infty}} \stackrel{\oplus}{\leftarrow}$

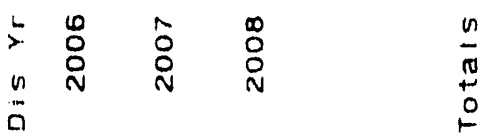


$0 \ln$

$\begin{array}{lll}0 & 0 \\ 0 & 00 & 0 \\ 0\end{array}$

a

\begin{tabular}{|c|c|c|}
\hline $\begin{array}{c}0 \infty \\
0 \\
{[} \\
r\end{array}$ & 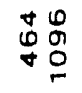 & $\mathbb{m}_{m}^{n}$ \\
\hline
\end{tabular}

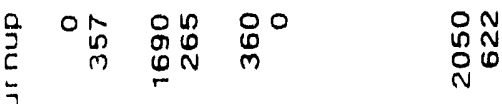

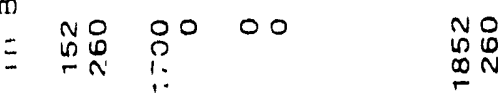

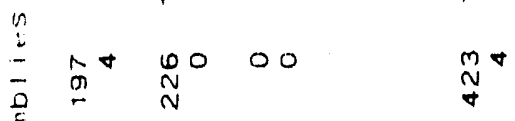$$
\text { ij }
$$

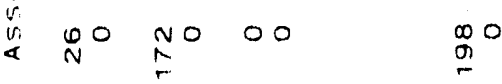

5

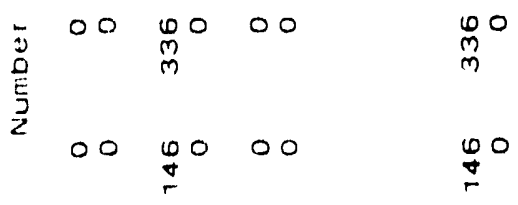

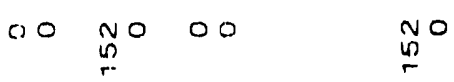

00000000

$\stackrel{n}{N}$

$\stackrel{2}{2}$

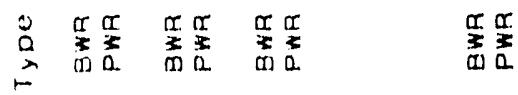

r $\quad \begin{array}{llll}0 & 0 & 10 & n\end{array}$

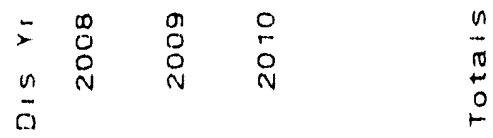




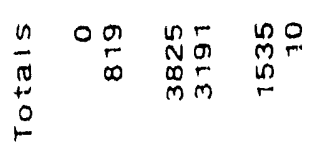

OO ON OD O

OO $0 \underset{\mathscr{D}}{\infty}$ ON

Oก OD 00

榇

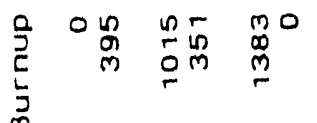

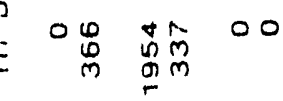

$\stackrel{n}{0}$ or on 00

䓠

in $0 \stackrel{2}{2} 0000$

4

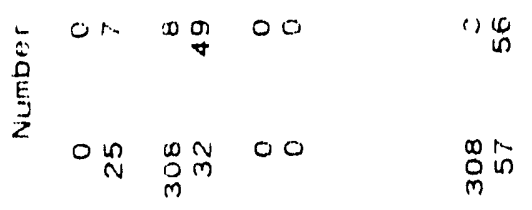

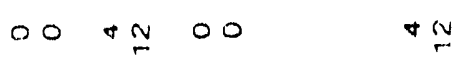

00000000

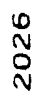

告

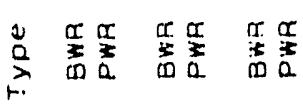

$\begin{array}{lll}O & 0 \\ 0 & 0 \\ 0 & 0 \\ 01 & 0 & 0 \\ 0 & 0\end{array}$

员

요욤

$\stackrel{N}{\sim} \frac{N}{\leftarrow}$

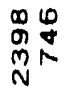

药

品

$\underset{\sim}{0}$

$\underset{8}{0} \stackrel{0}{=}$

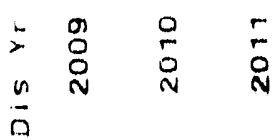

$\frac{n}{n}$ 
0
$=$
$\vdots$
$x$
0
0
0
0
0
0
0
0
0
0
0
0
0
0
0
0
0
0
0
$N$
-

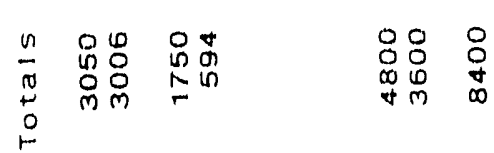

OO ON ON

ON $\stackrel{0}{m}$ O

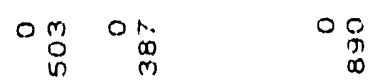

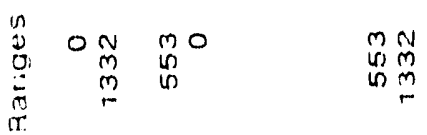

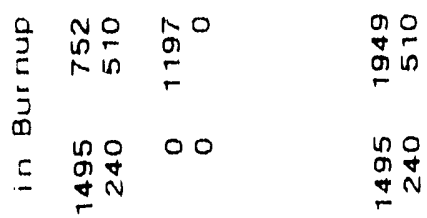

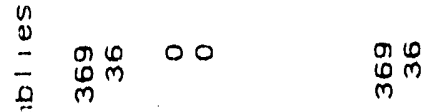

$\stackrel{\infty}{=}=00 \quad \frac{\infty}{=}=$

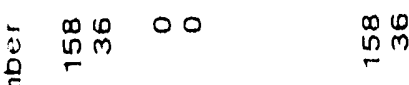

0000

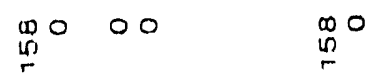

$0000 \quad 00$

$\stackrel{i}{i}$

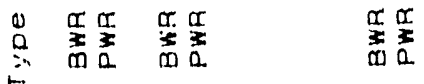

$\stackrel{\oplus}{\infty} \stackrel{\varphi}{r} \stackrel{n}{r}$

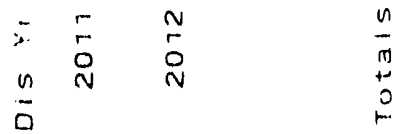




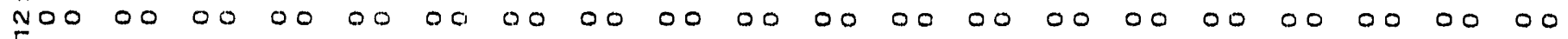

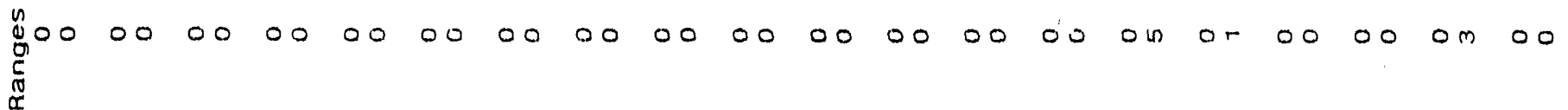

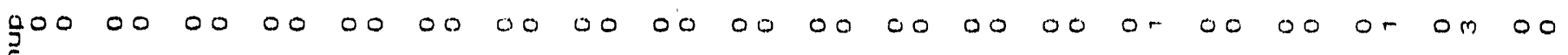
ติ

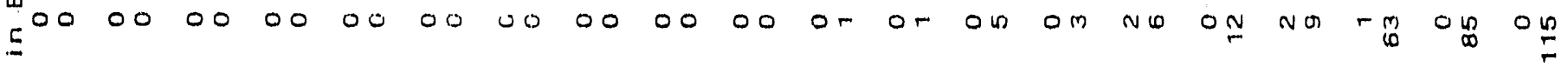

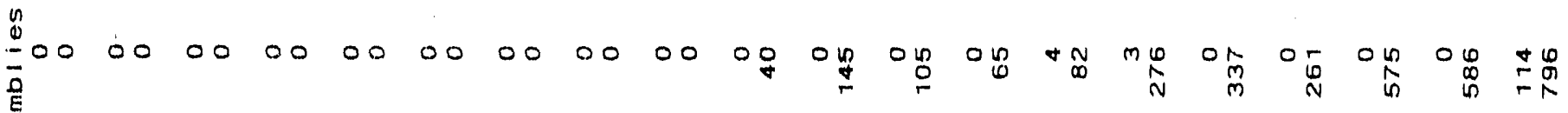
至O $\stackrel{4}{\circ}$

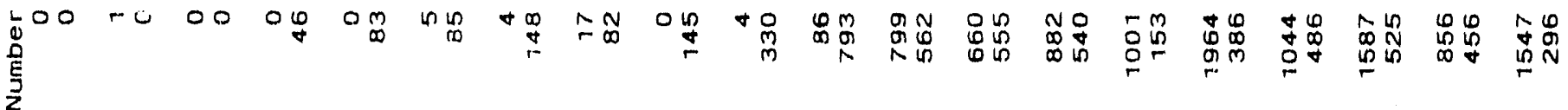

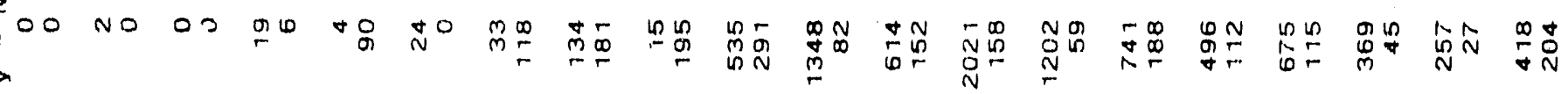

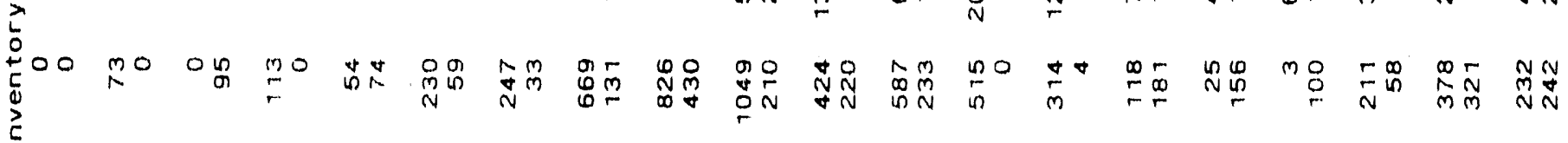
-

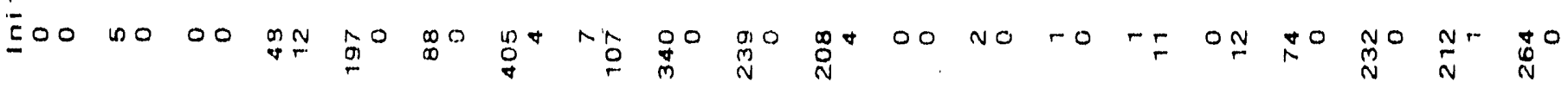

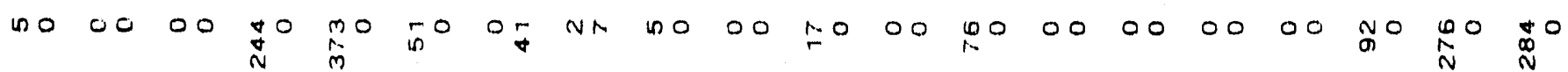

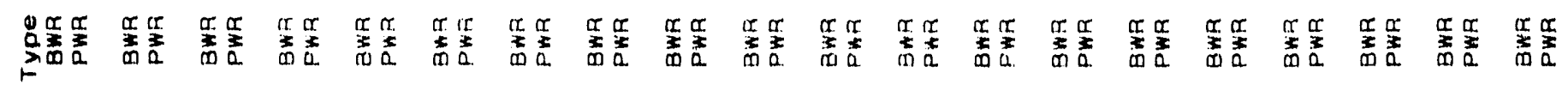

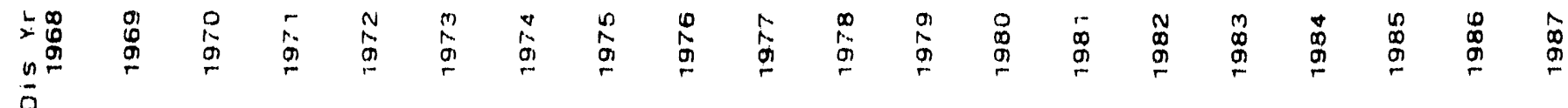




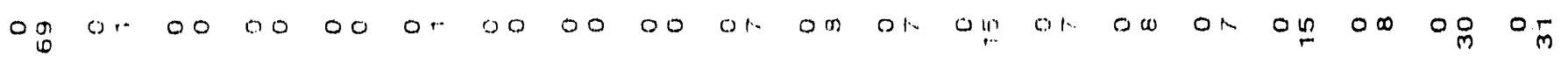

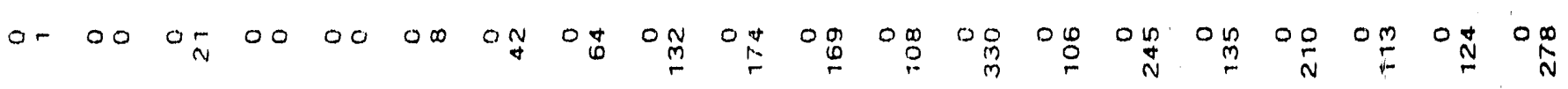

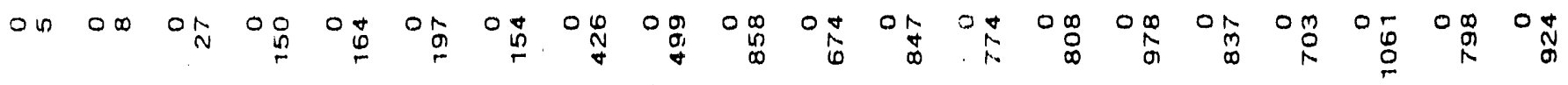

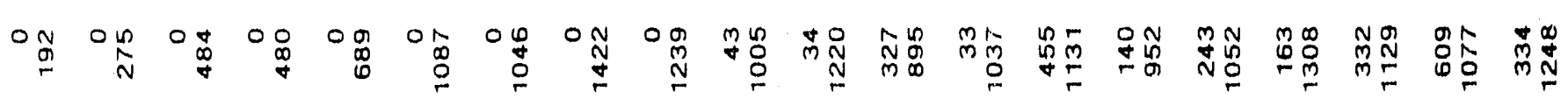

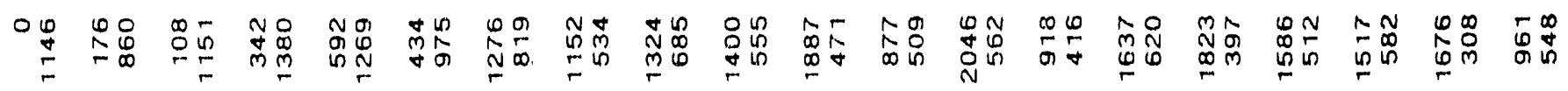

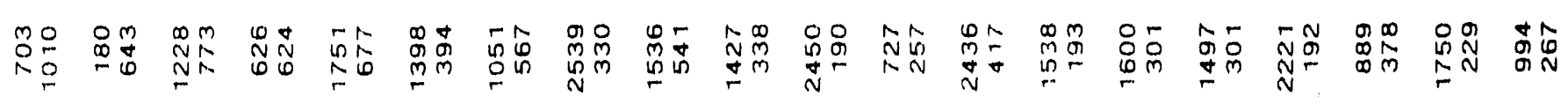

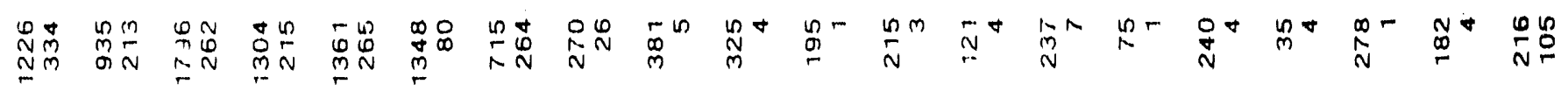

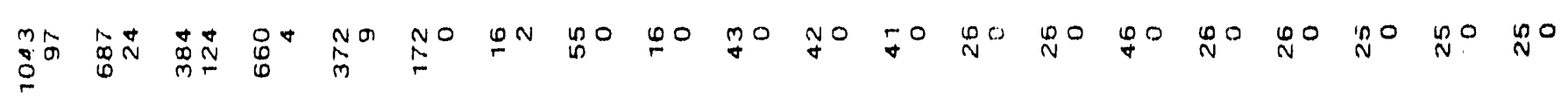

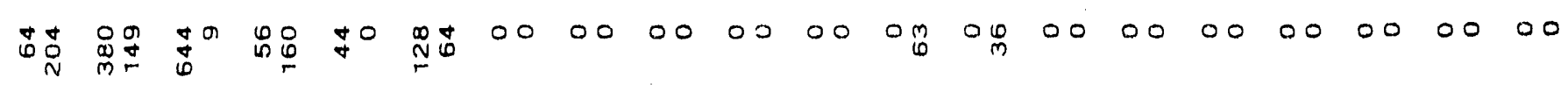

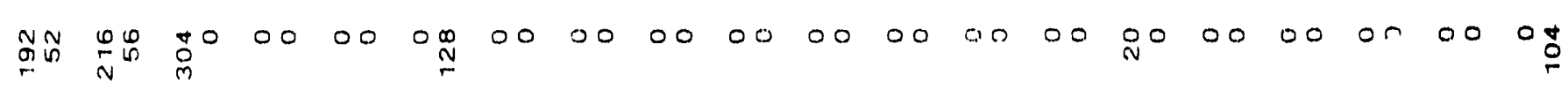
$00 \stackrel{N}{0} 000000000000000000000000900000000000$ \&o No No 0000000000000000000000000000000000

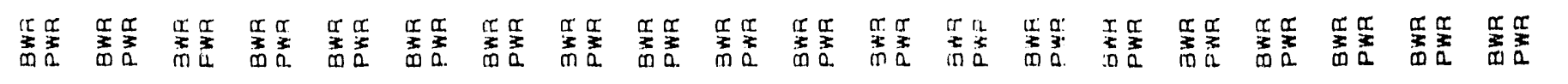

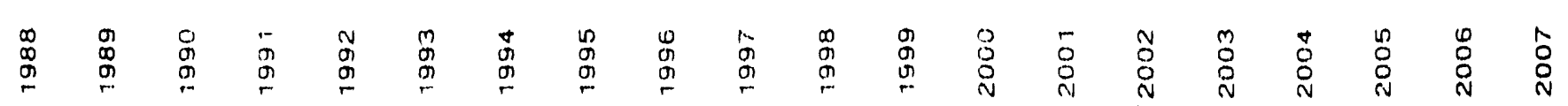




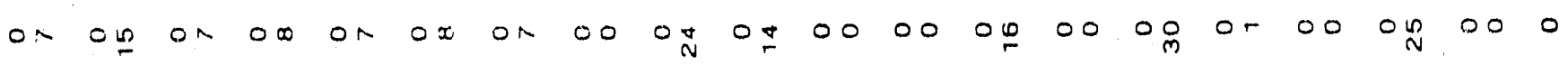

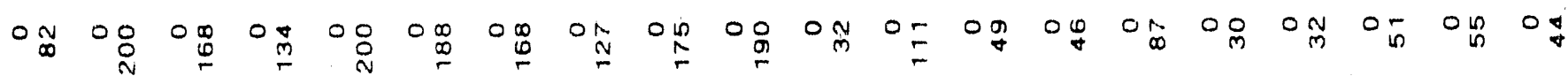

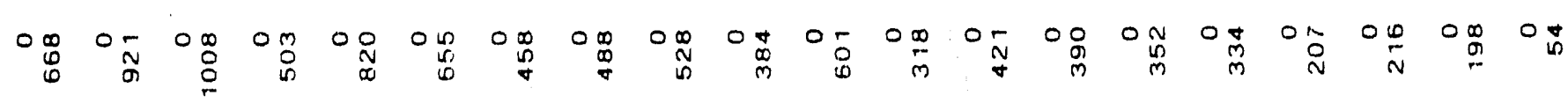

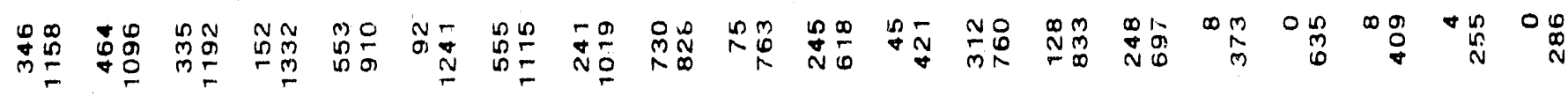
总岱

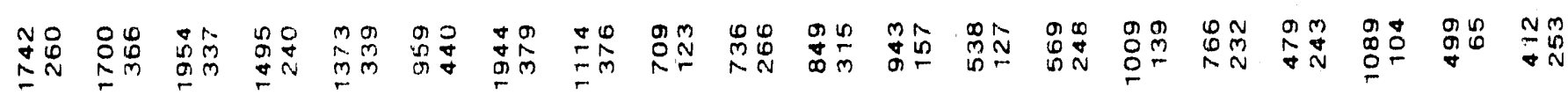

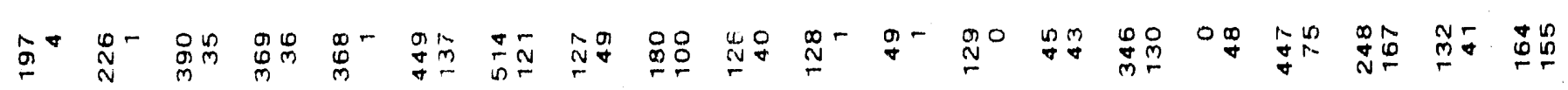

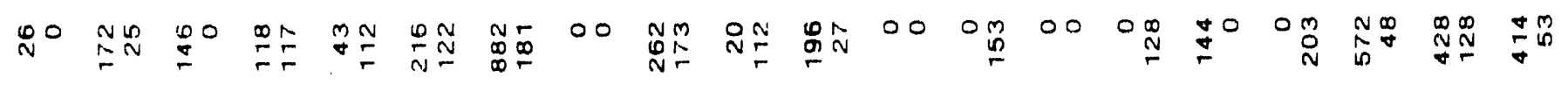

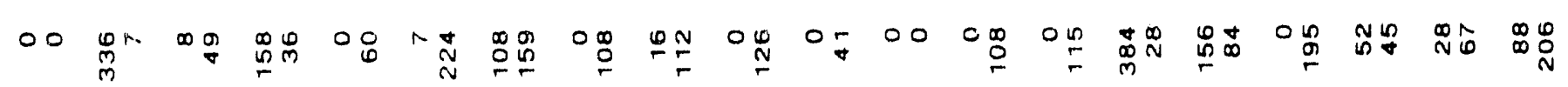

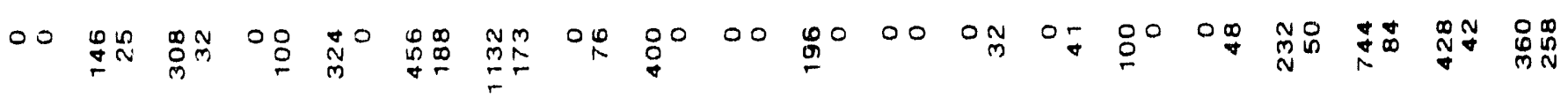

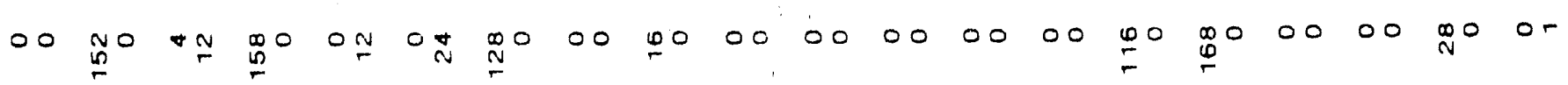

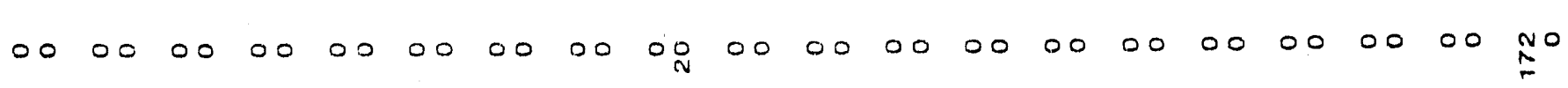

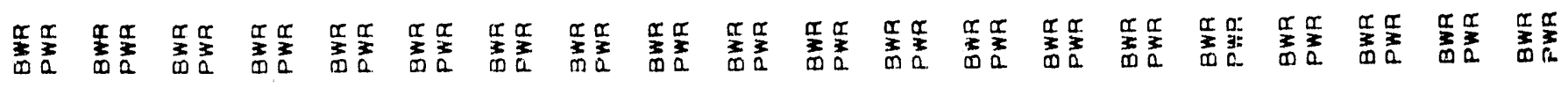

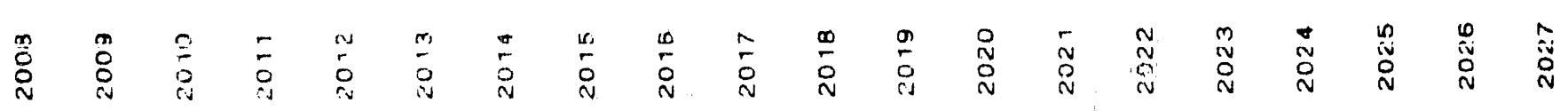


$\stackrel{N}{\sim} 0000000000000000000000000000000000000000$

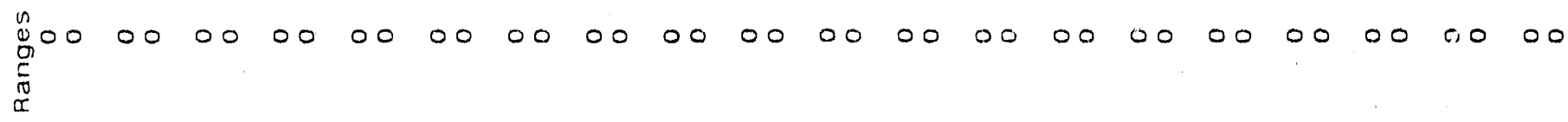
20000000000000000000000000000000000000000 ఏ) $[0000000000000000000000000000000000000000$ ,

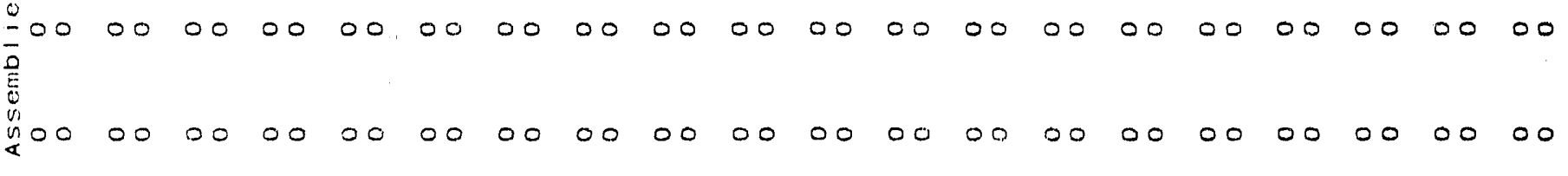
$+$

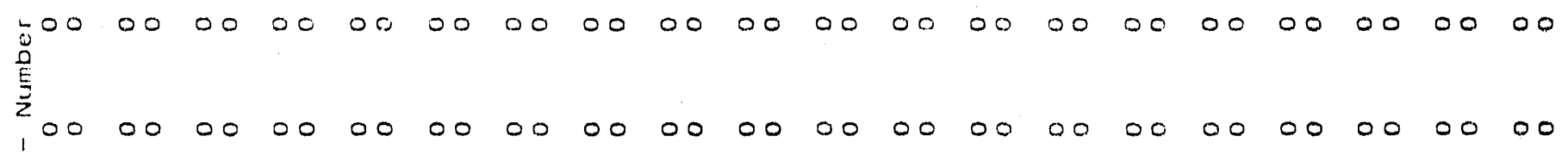

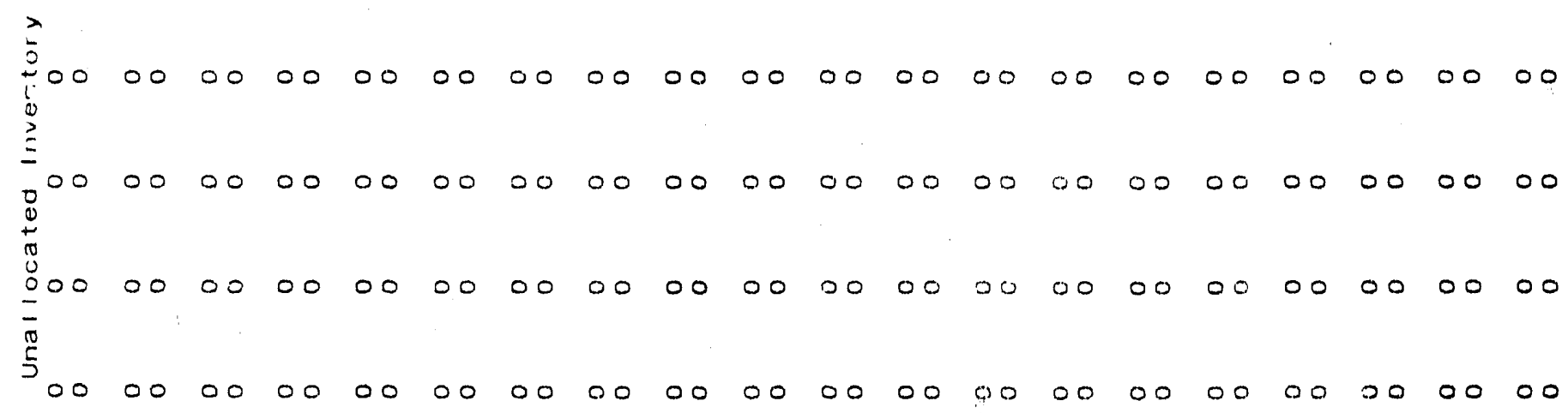

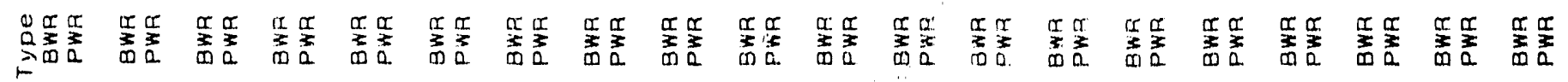

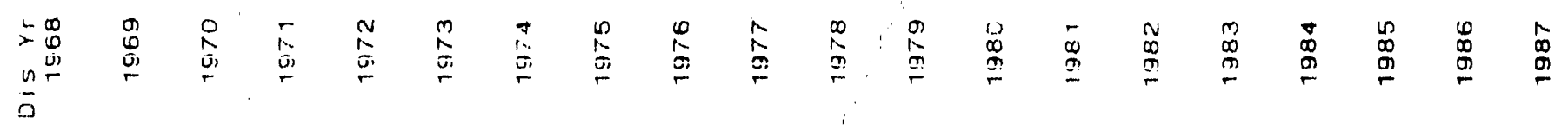


0000000000000000000000000000000000000000 0000000000000000000000000000000000000000 0000000000000000000000000000000000000000 0000000000000000000000000000000000000000 0000000000000000000000000000000000000000 0000000000000000000000000000000000000000 0000000000000000000000000000000000000000 0000000000000000000000000000000000000000 $00000000=0000000000000000000000000000000$ 0000000000000000000000000000000000000000 0000000000000000000000000000000000000000 0000000000000000000000000000000000000000

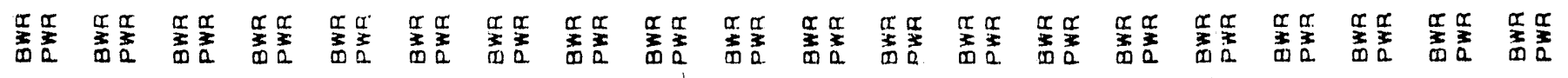

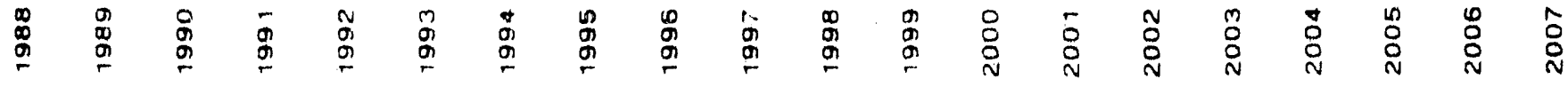




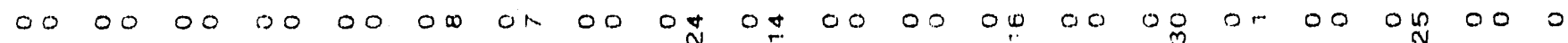

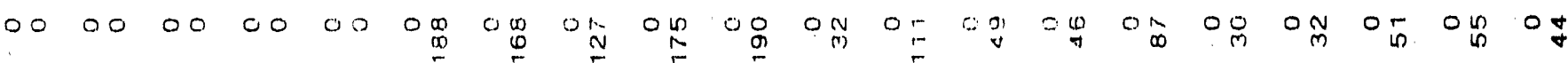

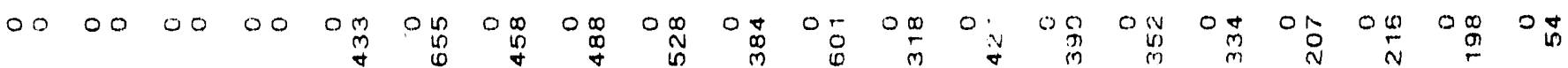

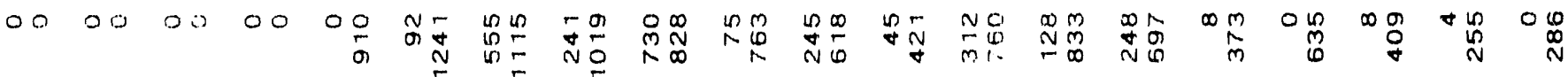

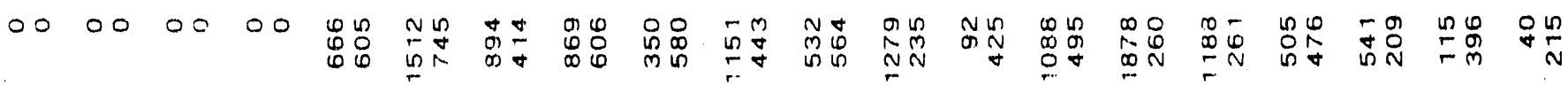

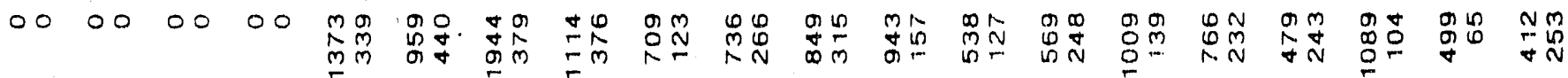

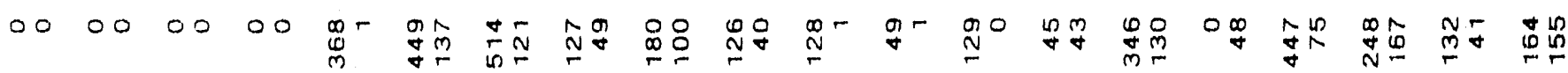

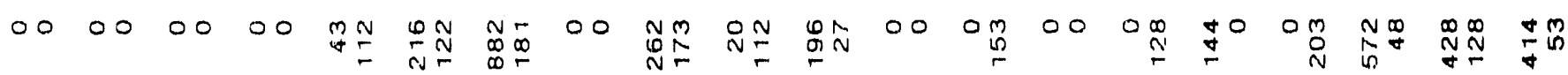

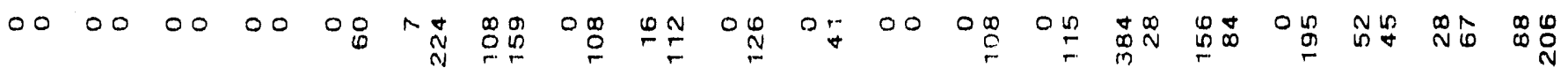

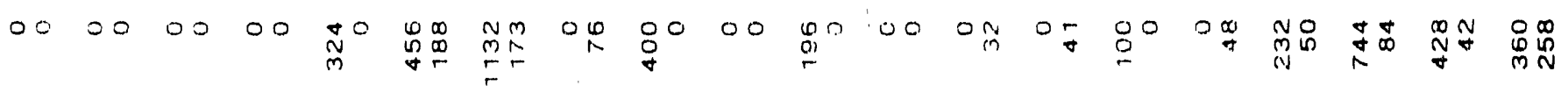

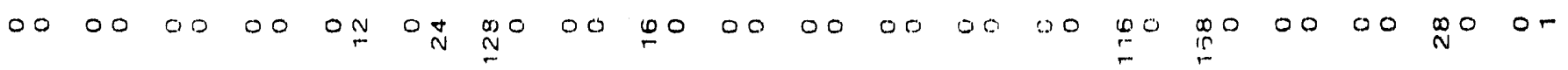

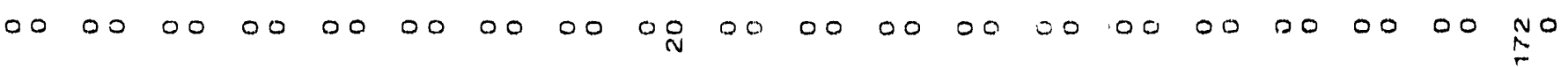

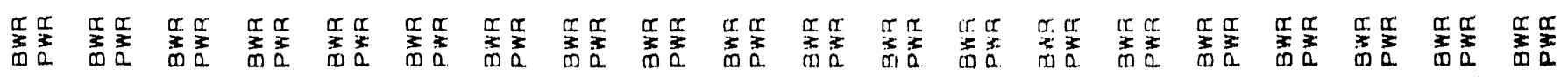

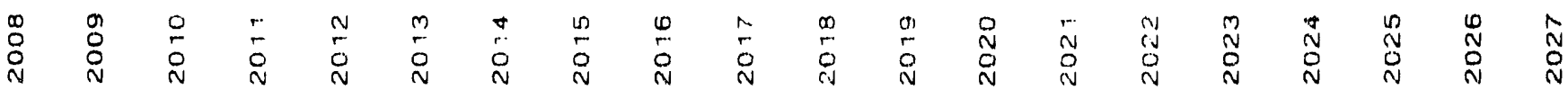


Appendix E

Levelized Energy Receipt Schedule

$$
\text { From }
$$

Oldest Fuel Inventory 


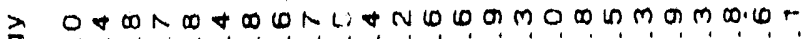

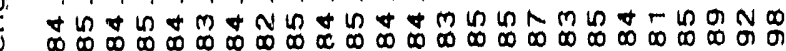

JE NO-

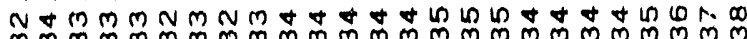

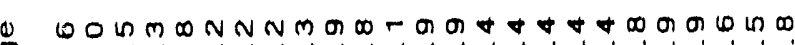
O

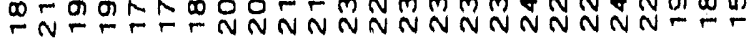

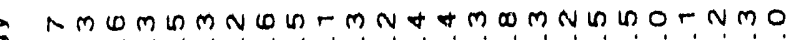

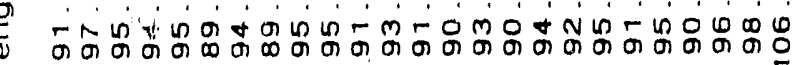

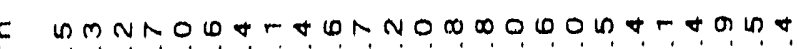

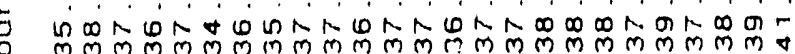

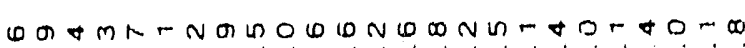
कO

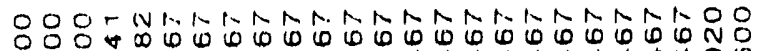

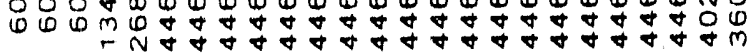

NGNNND

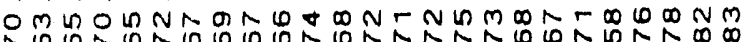

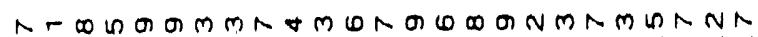

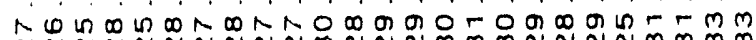
NNNNNNNNNNMNNNMMMNNNNMMMM

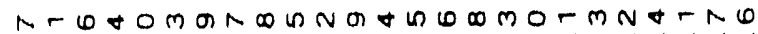
क

> О О О

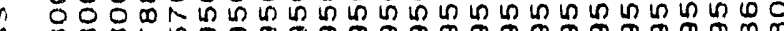
舟

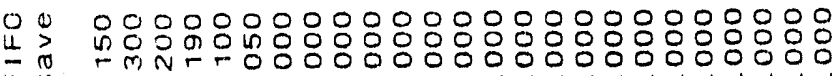
Ln o00000000000000000000000

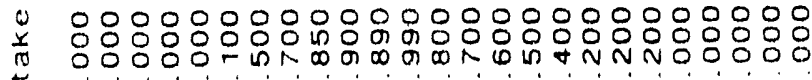
- o00000000000000000000000

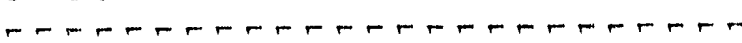

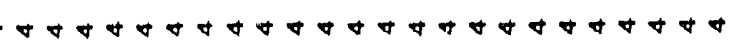

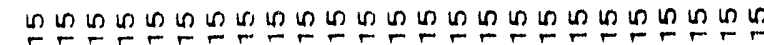

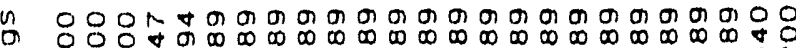
a $\quad$ a N

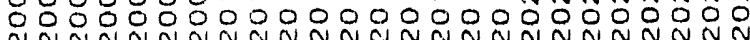


$\stackrel{n}{\stackrel{0}{\circ}}$

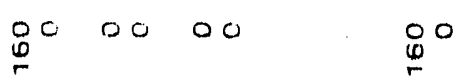

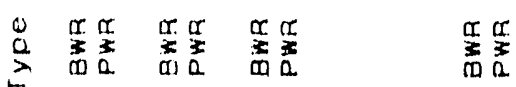

$\stackrel{\sharp}{\&} \stackrel{m}{m} \stackrel{0}{r}$

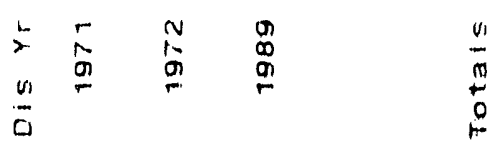




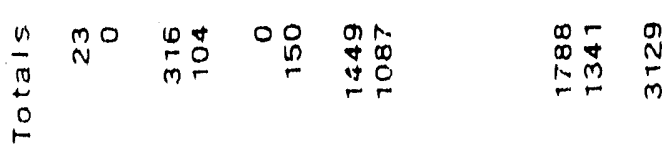

0000000000

$0000000 \frac{n}{n}$

$0000000 \frac{n}{N}$

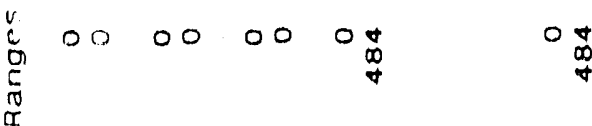

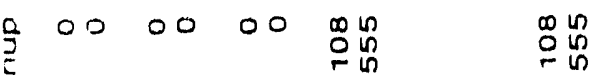

0000 or $\stackrel{N}{N}_{N}^{\infty} \stackrel{N}{N}_{N}$

$\stackrel{n}{n} 0000 \quad 0 \prod_{\infty}^{n} \frac{m}{r} \quad \frac{m}{m}$

$00+00000+0$

$+$

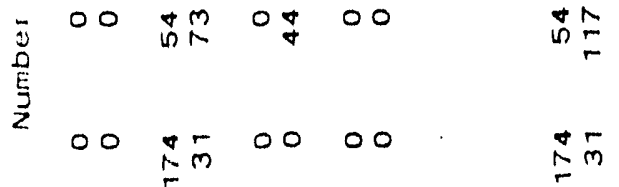

$00 \quad 0_{0}^{\circ} 0000 \quad \$^{\circ}$

$\stackrel{M}{N}^{0} 00000 \quad M^{0}$

$\stackrel{0}{\circ}$

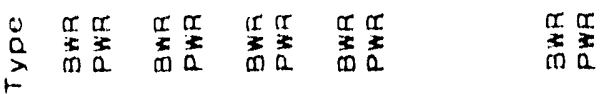

$\stackrel{1}{0}$

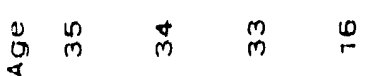

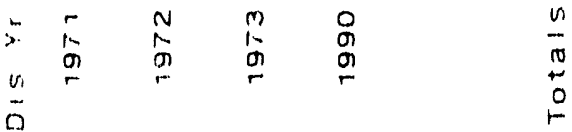



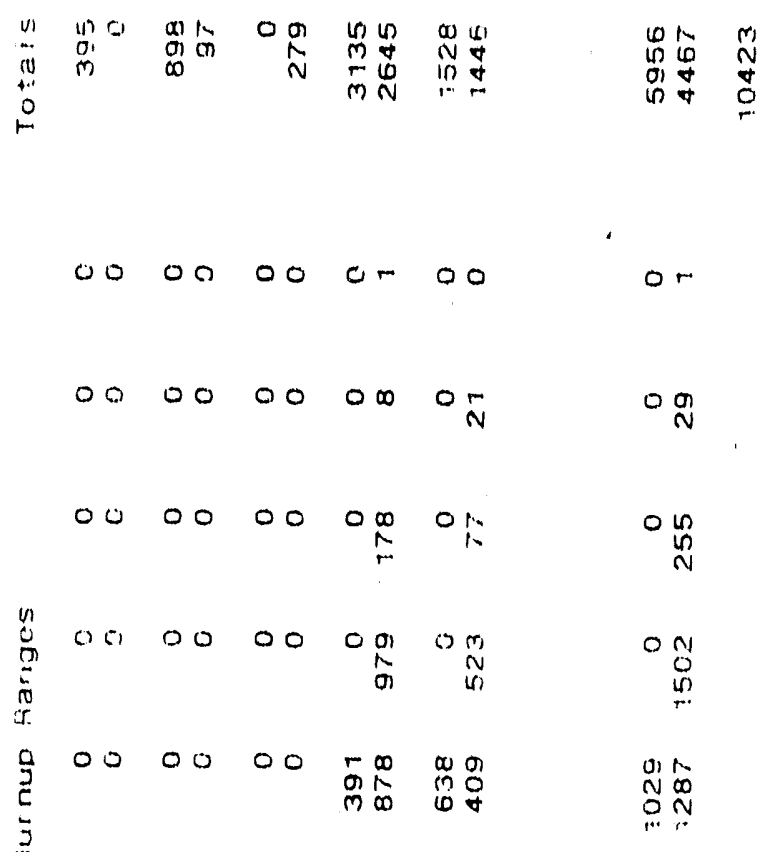

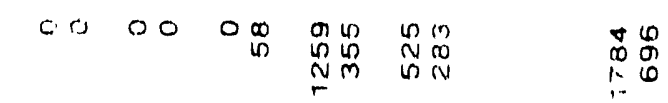

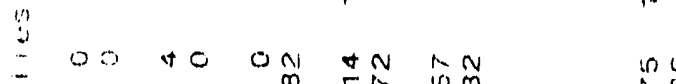

包

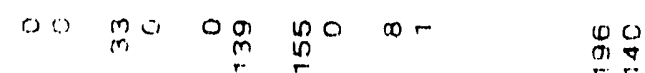

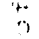

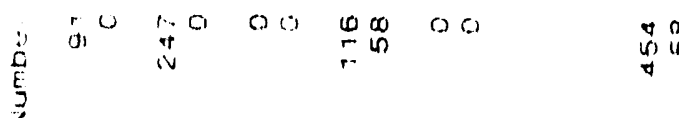

$\begin{array}{llllllll}0 & 0 & 0 & 0 & 00 & 0 & 0 & 0\end{array}$

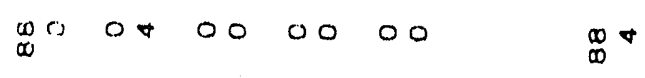

in or 0000 o0 in

O

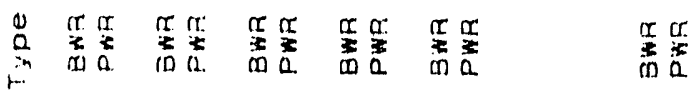

$\stackrel{2}{2}$

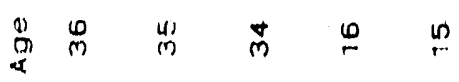

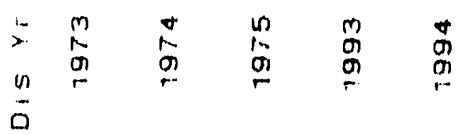

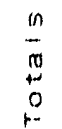




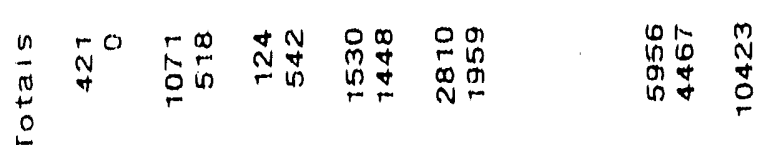

$0000000000 \quad 00$

$0000000 \frac{n}{4}$

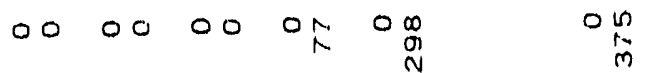

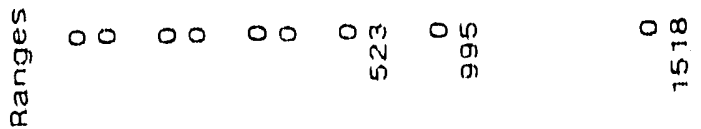

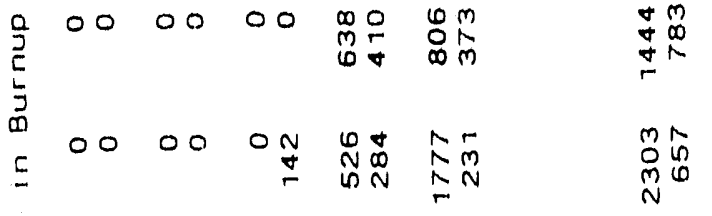

$\stackrel{n}{0} 00 \cong 0$ 㝵

○一 崖

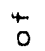

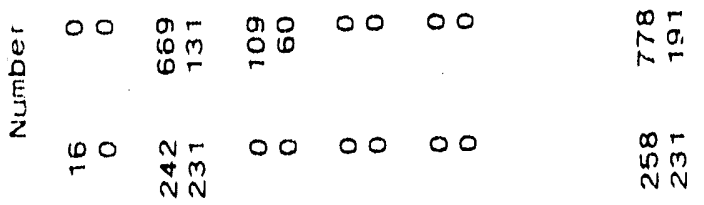

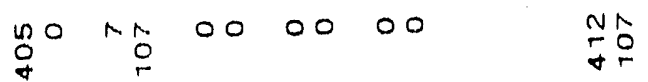

00 NN 000000 NN

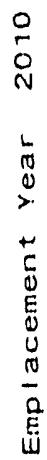

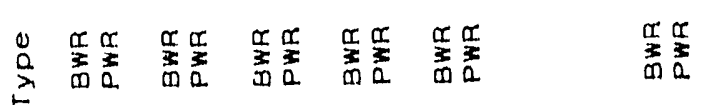

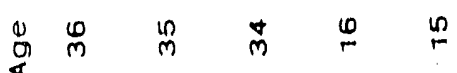

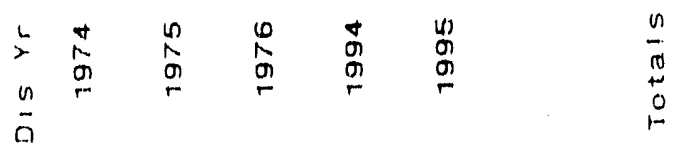


¿ 


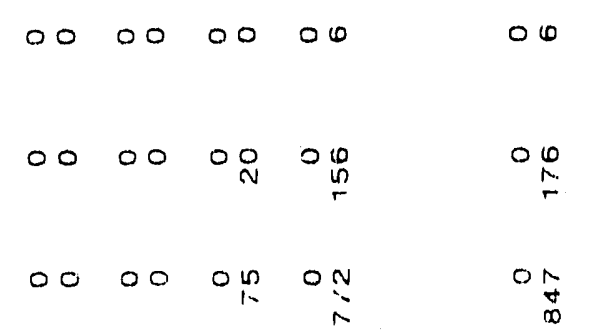

$\stackrel{n}{\stackrel{N}{*}}$

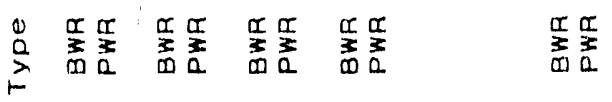

2

品

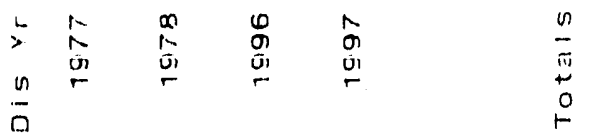




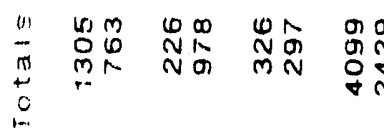

Do 00 Or On

$00000 \% 0 \frac{0}{n}$

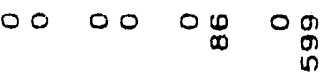

$\sum_{\substack{n \\ 0}}^{10}$

20000000

$\bar{Z}$

00 iv $\underset{m}{m} m_{m}^{m} \frac{\infty}{N}$

$\circ \stackrel{m}{m} \underset{N}{\stackrel{m}{m}} \stackrel{m}{m} \stackrel{m}{N}$

एक 00 no mo

$+$

$\therefore \quad \nabla 00000$

E

wis 000000

$\stackrel{N}{0}^{w} 000000$

$1=0000000$

$\stackrel{m}{o}$

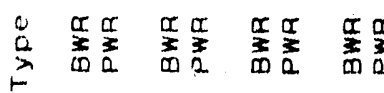

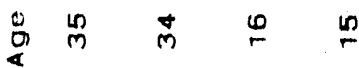

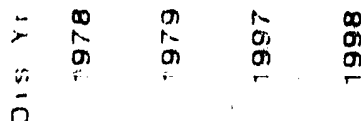

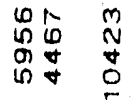

$0 \infty$

○思

0
0
0
0

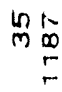

$\begin{array}{ll}9 & 0 \\ r & \infty \\ 0 & 0 \\ 0\end{array}$

$\mathfrak{m}_{\substack{n \\ m}}$

$\begin{array}{ll}0 & 0 \\ 0 & 0\end{array}$

(i)
0
(5)

$\forall 0$
iv

00
$5 N$

$\stackrel{\infty}{0}_{0}^{\circ}$

1.0

$\frac{a}{\frac{a}{3}}$

$\frac{n}{5}$ 


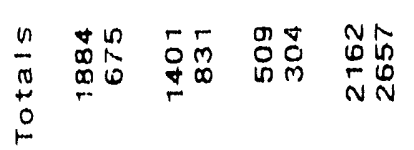

$$
00000.00
$$$$
\begin{aligned}
& n \\
& 0 \\
& 0 \\
& 0 \\
& 0 \\
& 0 \\
& 0 \\
& 0 \\
& 3 \\
& 0 \\
& 0 \\
& 0
\end{aligned}
$$

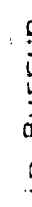

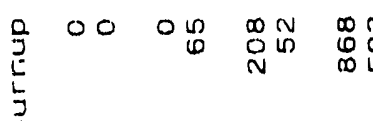$$
\text { n }
$$$$
\text { 岁 }
$$

$\frac{\vec{N}}{\mathrm{D}}$

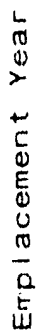$$
0000 \quad 0 \%
$$$$
0000 \quad 0 \stackrel{n}{\wedge} \underset{\substack{\infty \\ \infty}}{\infty}
$$

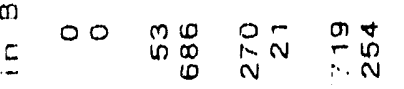$$
\frac{0}{0} \quad \text { in }
$$

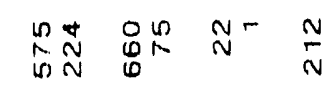$$
\frac{1}{0 N} \mathbb{D}_{\infty}^{\infty} 0 \text { no }
$$

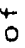$$
\text { 舟是 } 000000
$$$$
00000000
$$$$
00000000
$$

总是

or

$\circ \stackrel{n}{N}$

00
0
0
0

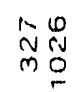

나용

인

$N$
$\forall$
0
0

$\begin{array}{ll}2 & \\ 0 & N \\ 0 & 0 \\ 0 & 0\end{array}$

点

กั

\begin{tabular}{ll}
$\infty$ & 0 \\
\hdashline & 0
\end{tabular}

00

00

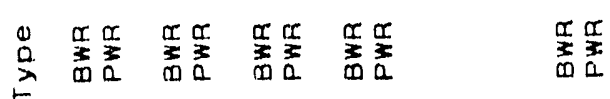

量

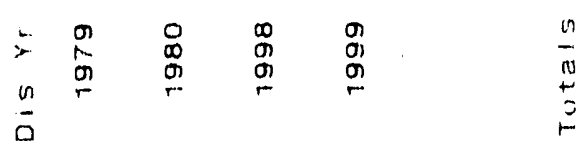


$\stackrel{4}{\stackrel{2}{2}}$

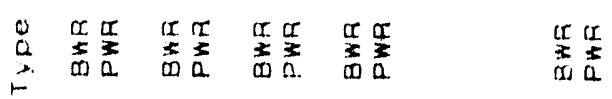

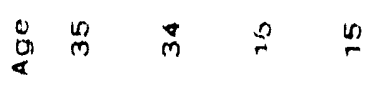

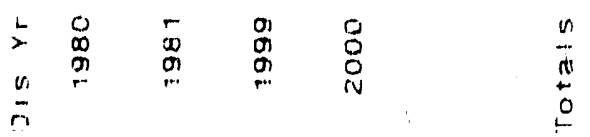




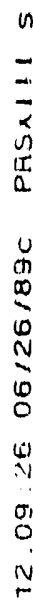

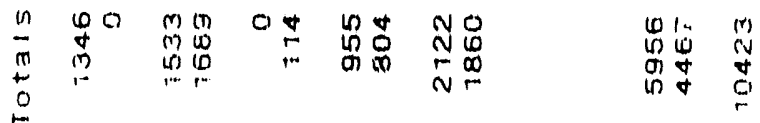

$000000000 \%$ 0.

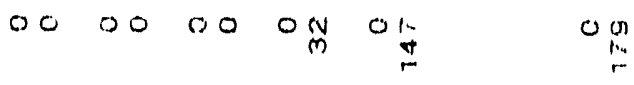

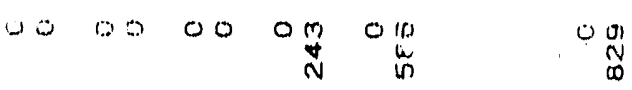

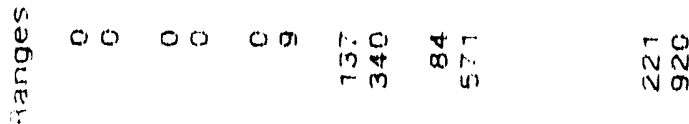

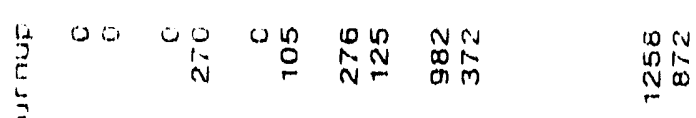

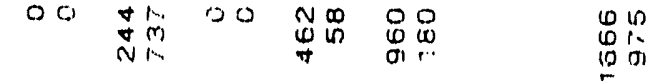

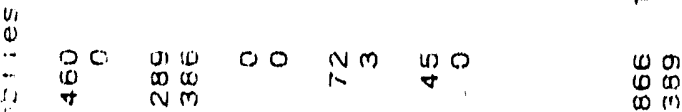

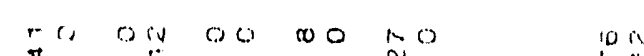

.

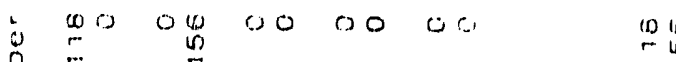

$\varphi_{V} 0 \%$ OD OC NO

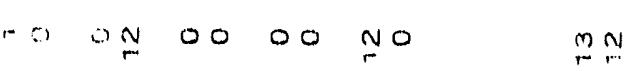

000000000000

$\stackrel{N}{\stackrel{N}{N}}$

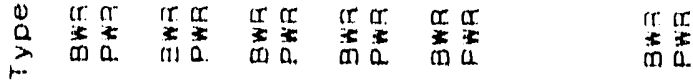

㟧

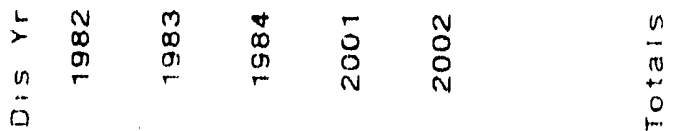




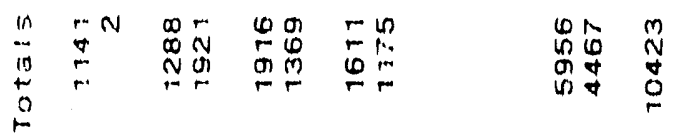

00000000,00

$0000 \quad 000000$

oc or og or or

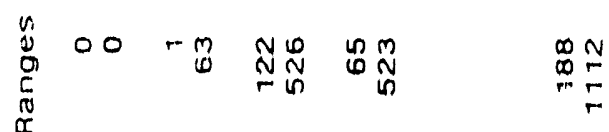

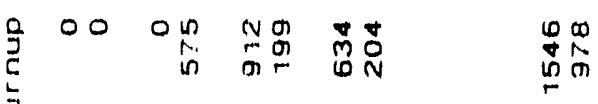

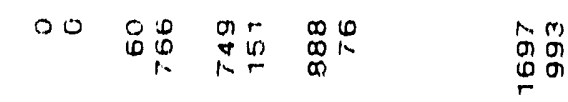

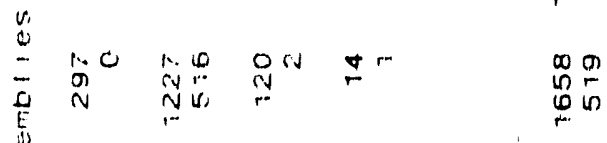

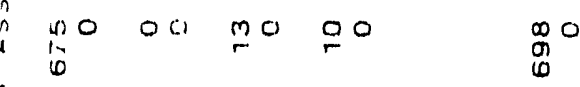

$\because$

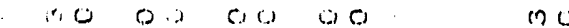

总

NM 00 DO 00 nूल

\$0 $000000 \quad+0$

$00000000 \quad 00$

$\stackrel{n}{\stackrel{n}{N}}$

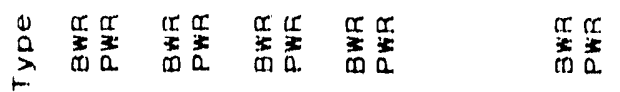

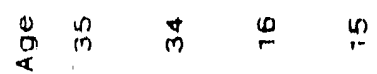

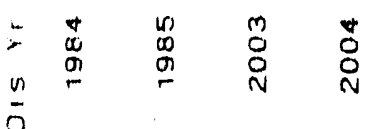




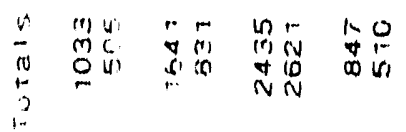

$20 \quad 00 \quad 0 \% \quad 0 \%$

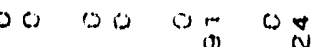

$010000 \begin{array}{ll}0 \\ 0 \\ 0\end{array}$

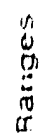

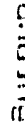

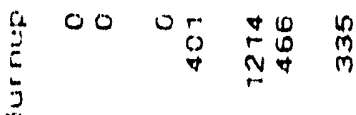

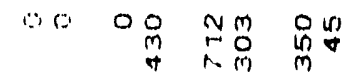$$
\text { क ओ }
$$$$
\text { ग1. }
$$

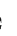$$
\text { (") "y a) } 0000
$$$$
\text { ? }
$$

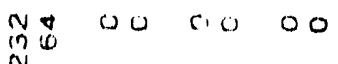$$
\text { iv wo }
$$

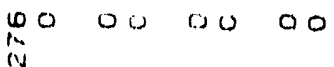

$\underset{N}{N}$

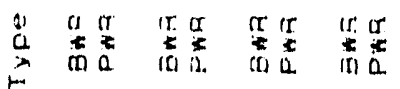

$\stackrel{4}{n} \stackrel{n}{n} \stackrel{0}{n}$

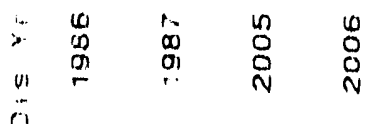

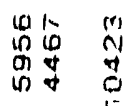

$D \stackrel{(1)}{m}$

$\frac{015}{5}$

○

$\stackrel{n}{\infty} \underset{\sim}{m}$

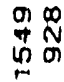

$N$
0
0
0

$\bigcup_{\substack{n \\ n}}^{\infty} a$

01
$y$
$y$

$\operatorname{lom}_{0} \underset{n}{m}$

$\stackrel{N}{M} \mathbb{W}$

$\stackrel{N}{N}$

no

$\begin{array}{ll}\text { Ir } & \text { ir } \\ \text { iII } & 0 \\ \text { in } & 0\end{array}$ 


\begin{tabular}{|c|c|c|c|c|c|}
\hline & & $8^{\circ}$ & 00 & 00 & $0^{0}$ \\
\hline $\begin{array}{l}\pi \\
0 \\
\nu\end{array}$ & 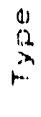 & 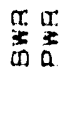 & 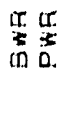 & 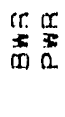 & $\begin{array}{ll}\mathfrak{a} \\
\vdots \\
\mathfrak{a}\end{array}$ \\
\hline & ถั & $\stackrel{n}{m}$ & m & $\underset{r}{\mathscr{\sigma}}$ & \\
\hline$\frac{u}{\text { UI }}$ & $\begin{array}{l}3 \\
n \\
n\end{array}$ & $\begin{array}{l}\infty \\
\infty \\
\infty \\
\sigma \\
r\end{array}$ & $\begin{array}{l}a_{1} \\
a_{0} \\
\sigma_{1} \\
r\end{array}$ & $\begin{array}{l}\text { L } \\
\text { O } \\
\text { N }\end{array}$ & $\frac{n}{\pi}$ \\
\hline
\end{tabular}



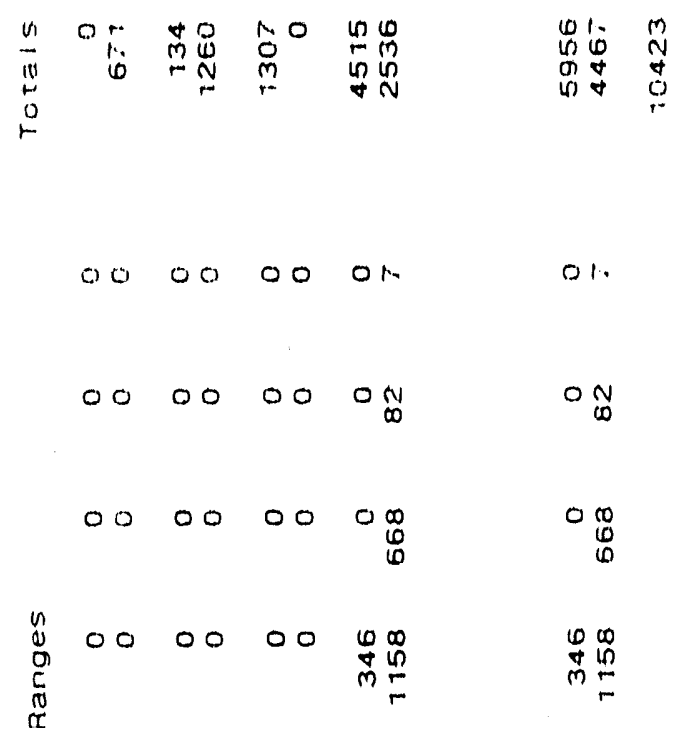

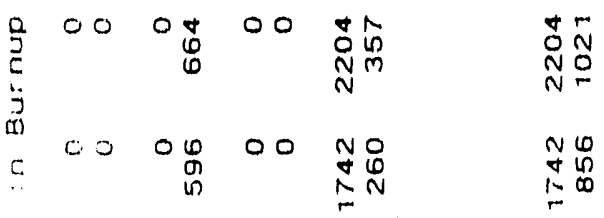

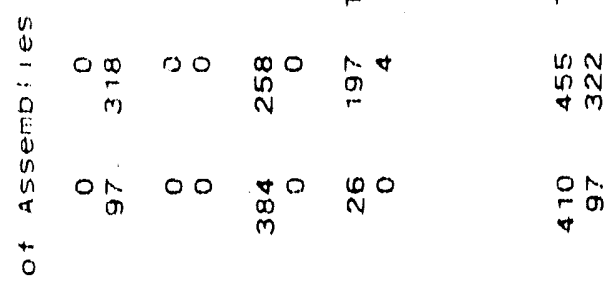

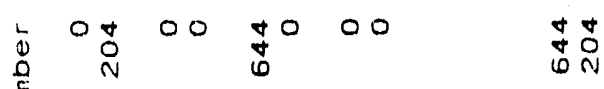

ON NO NO NOD

$00 \operatorname{din}^{0} 0000 \quad \operatorname{in}^{\circ}$

$00 \operatorname{NO}_{0} 0000$ N

$\stackrel{\mathbb{N}}{\stackrel{N}{N}}$

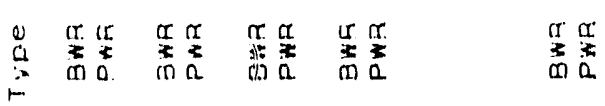

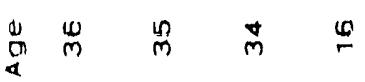

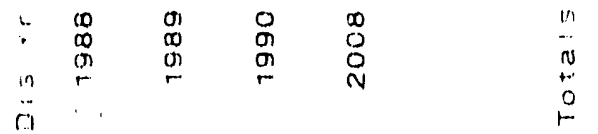




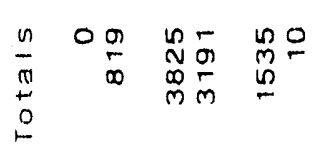$$
00 \text { or. } 00
$$$$
000 \underset{n}{\infty} 00
$$$$
000000
$$$$
\begin{aligned}
& n \\
& 0 \\
& 0 \\
& 0 \\
& 0 \\
& 0 \\
& 0 \\
& 0
\end{aligned}
$$$$
\stackrel{\varrho}{\vdots}
$$$$
\equiv
$$$$
\text { OA in } 00
$$$$
\rightarrow \text { or }
$$$$
\text { ०ृ कू }
$$$$
\text { - } \mathrm{N} M
$$

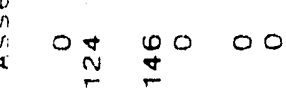$$
5
$$

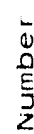$$
\stackrel{5}{0} 0
$$

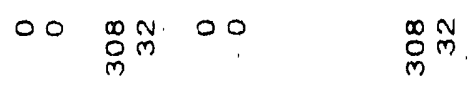$$
0,+n g 0
$$$$
000000
$$

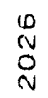

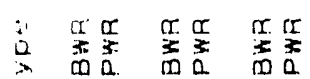

$\frac{1}{9}$

$\begin{array}{llll}0 & 0 & 0 & 0 \\ \square & m & r\end{array}$

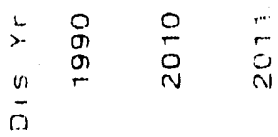$$
00
$$

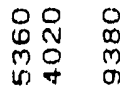

010

08

010
0
0
0

$N \mathcal{N}$
$\sim \sigma$
$\sim$

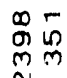

范员

के

$\stackrel{\oplus}{\forall}$

$\infty \underset{n}{\infty}$

$\mathbb{p}_{m}^{\infty}$ m.

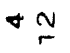

00

$\frac{\alpha}{\underline{m}}$ 
$\because \begin{array}{lll}0 & \ldots & 0 \\ 0 & 0 & 0 \\ 0 & m & \infty\end{array}$

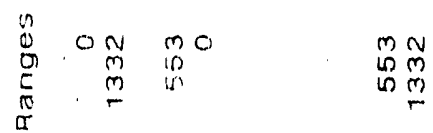

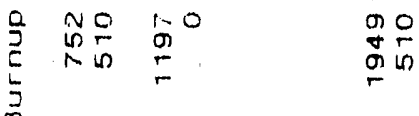

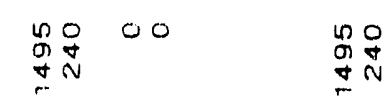

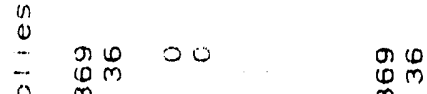

$0 m^{0}$

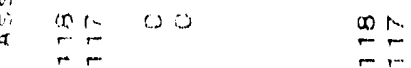

to

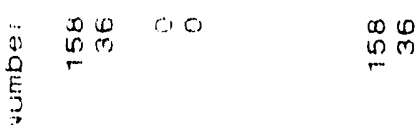

$0000 \quad 00$

$\begin{array}{llll}\infty & 0 & 0 & \infty \\ \infty & \infty\end{array}$

000000

$\stackrel{N}{N}$

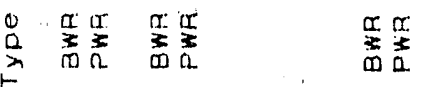

$\stackrel{0}{a} \stackrel{0}{\infty} \stackrel{n}{2}$

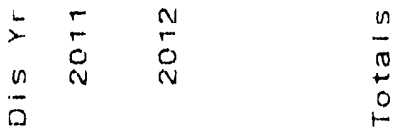


NoO 00000000000000000000000000000000000000

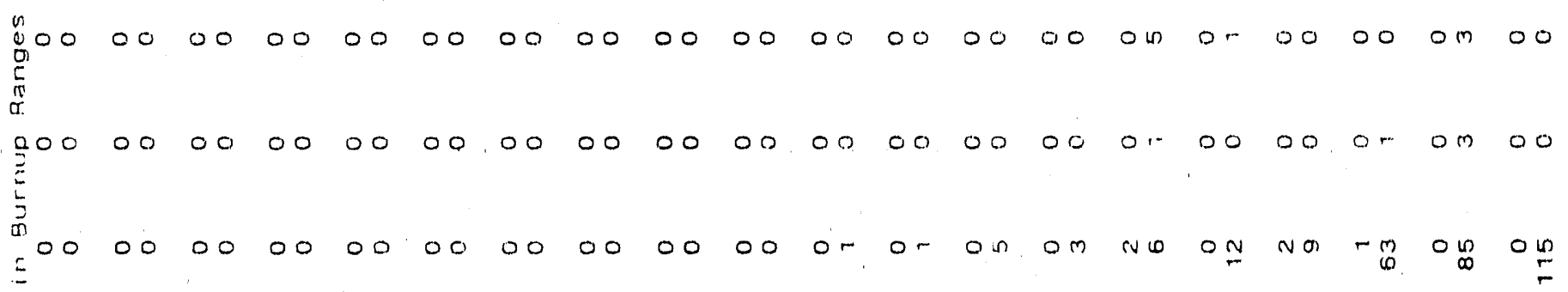

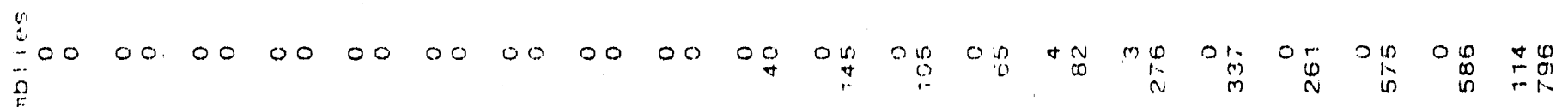

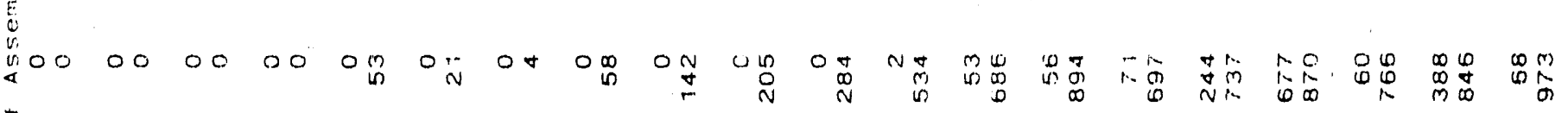
$\overleftarrow{0}$

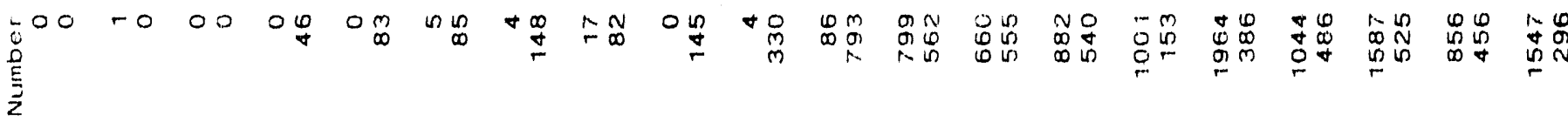

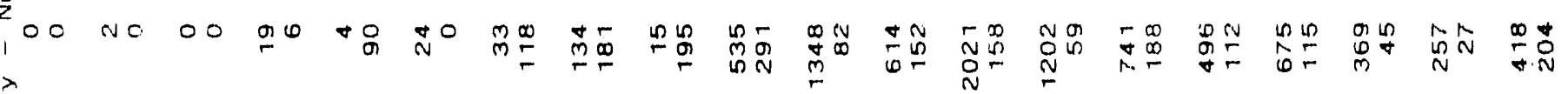

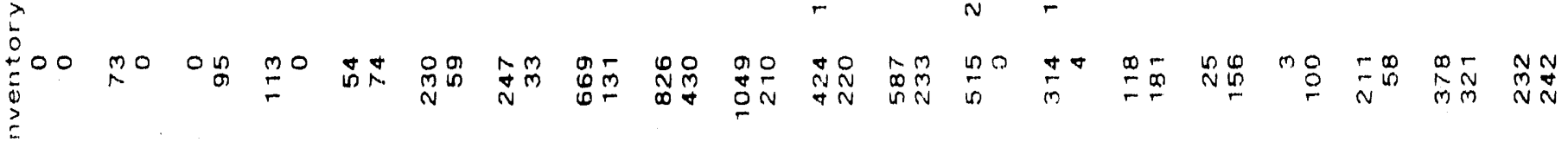
-

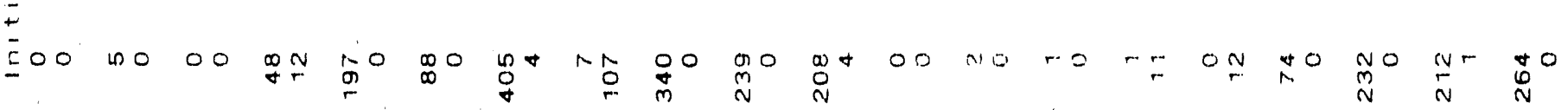

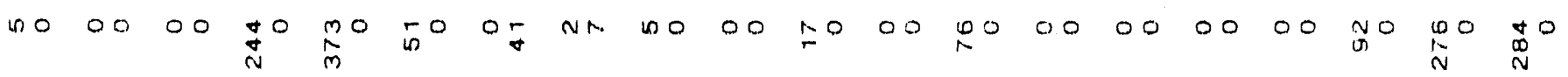

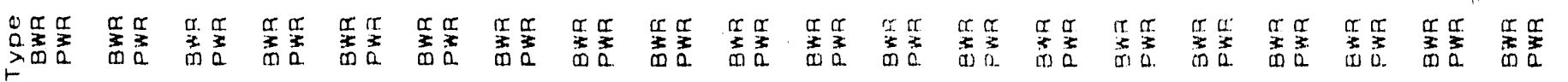

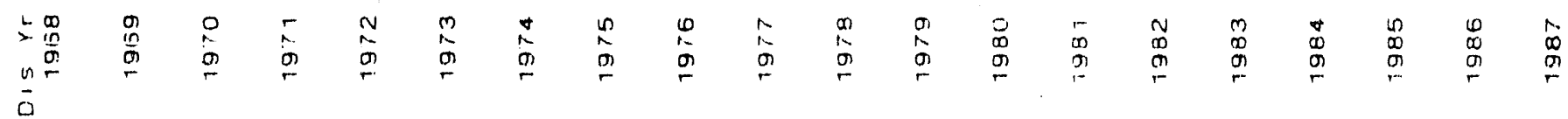




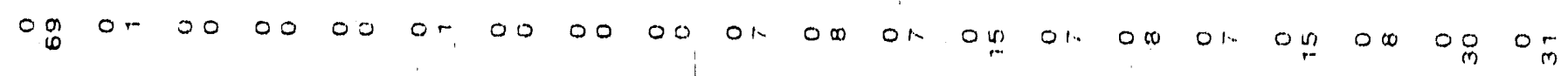

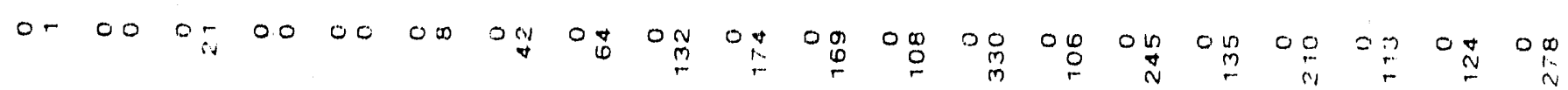

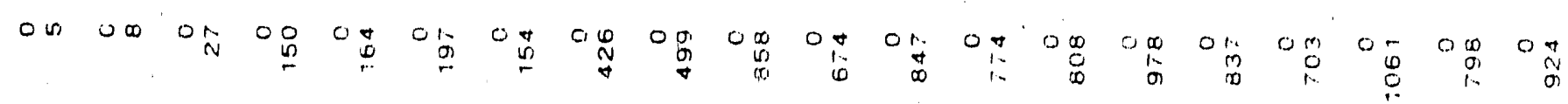

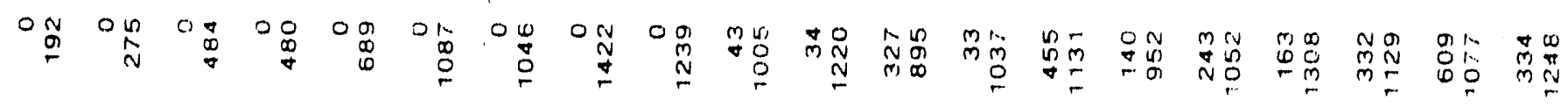

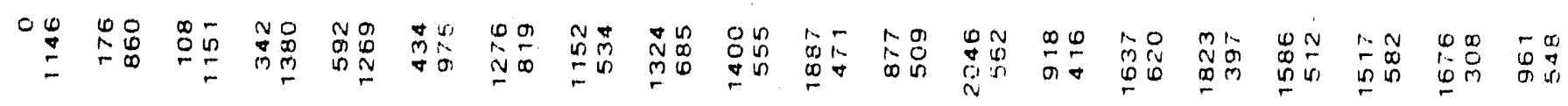
음

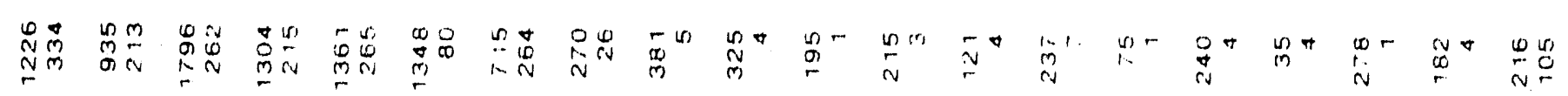

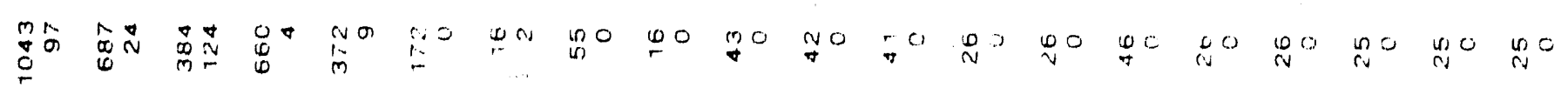

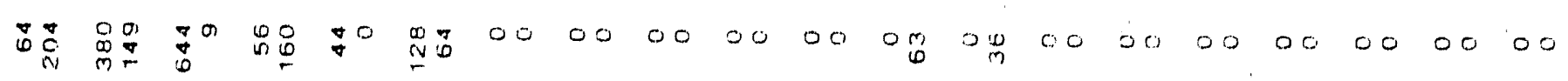

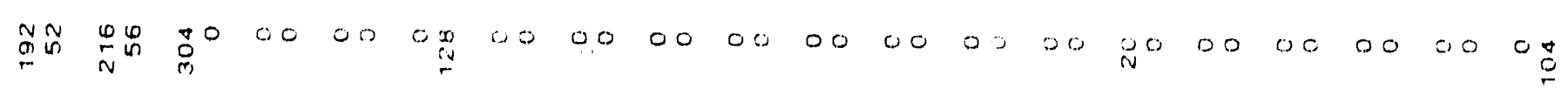

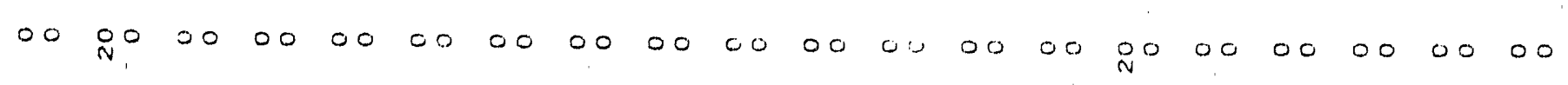

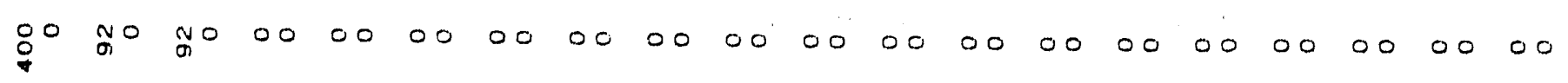

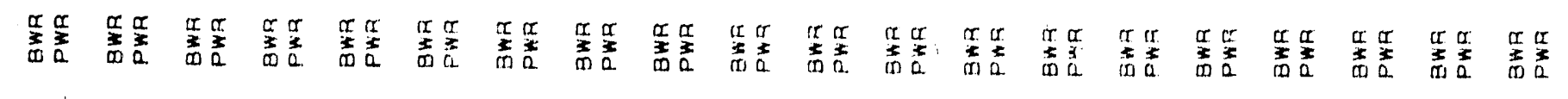

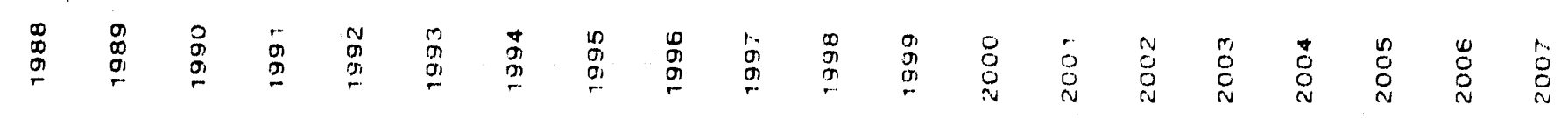




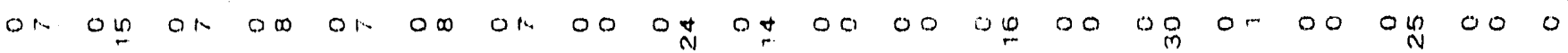

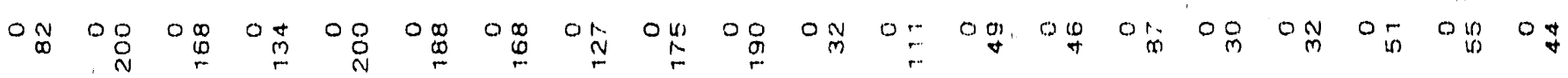

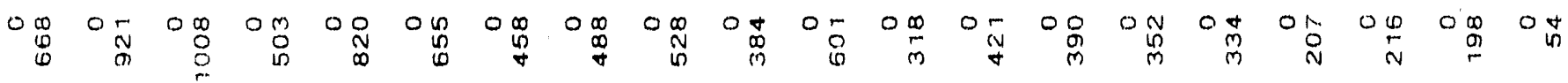

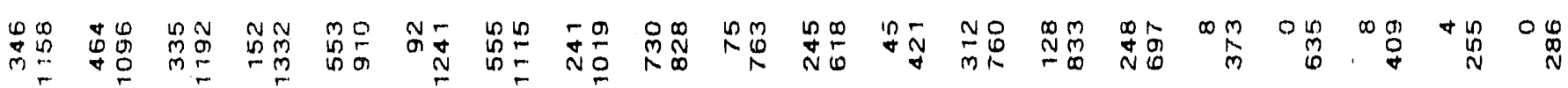

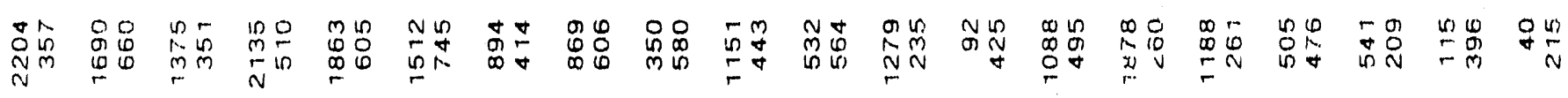

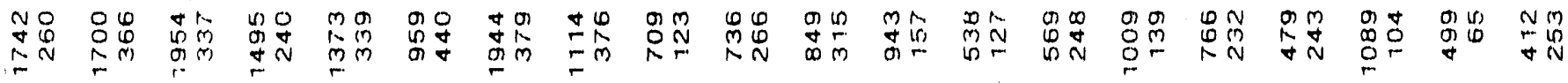

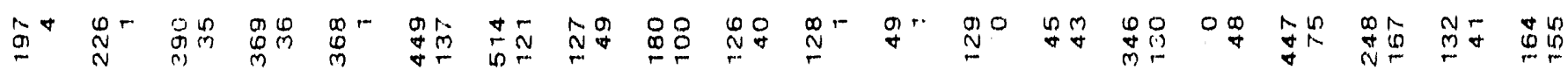

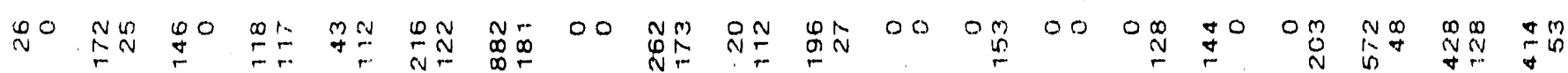
○

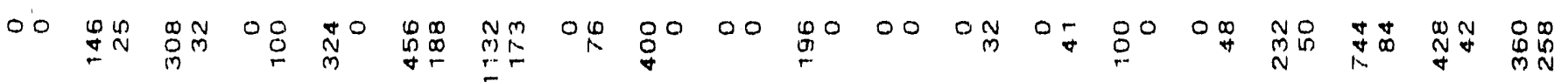

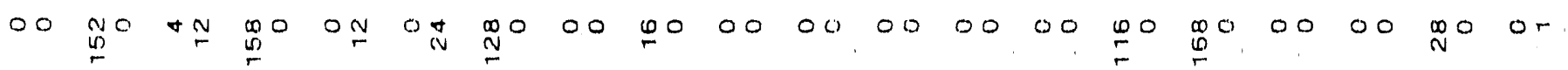

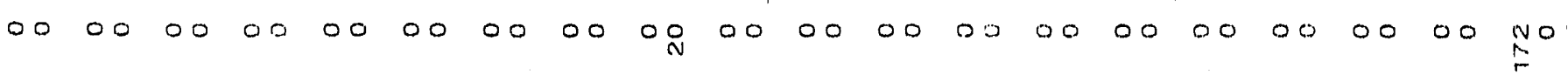

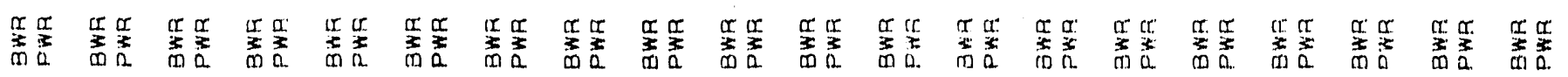

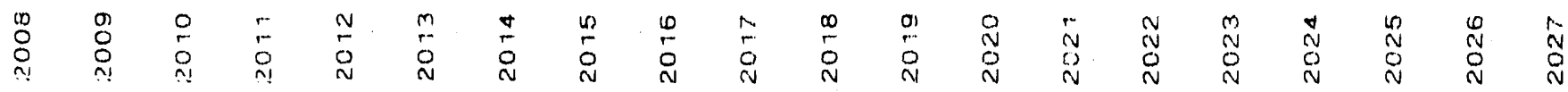




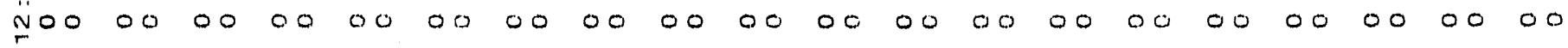

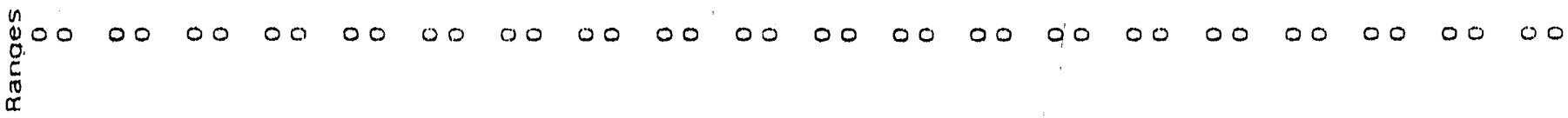

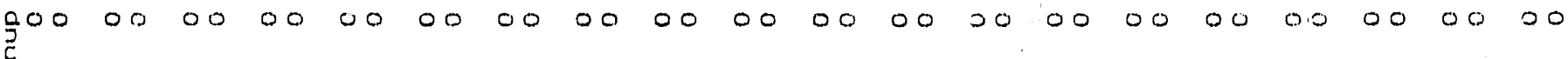
藏 $E^{0000000000000000000000000000000000000000}$ n $\$ 0000000000000000000000000000000000000000$ $\stackrel{\circ}{\mathrm{E}}$ ñ 4

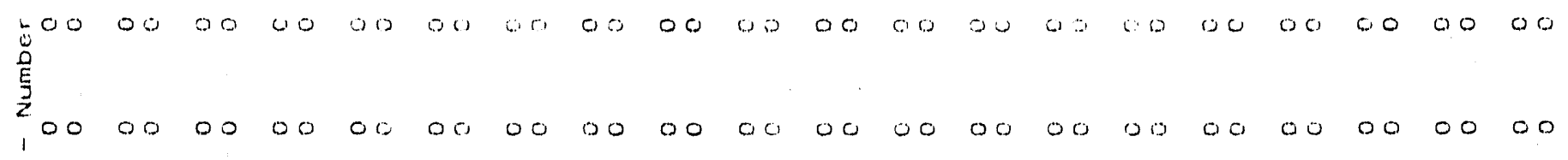

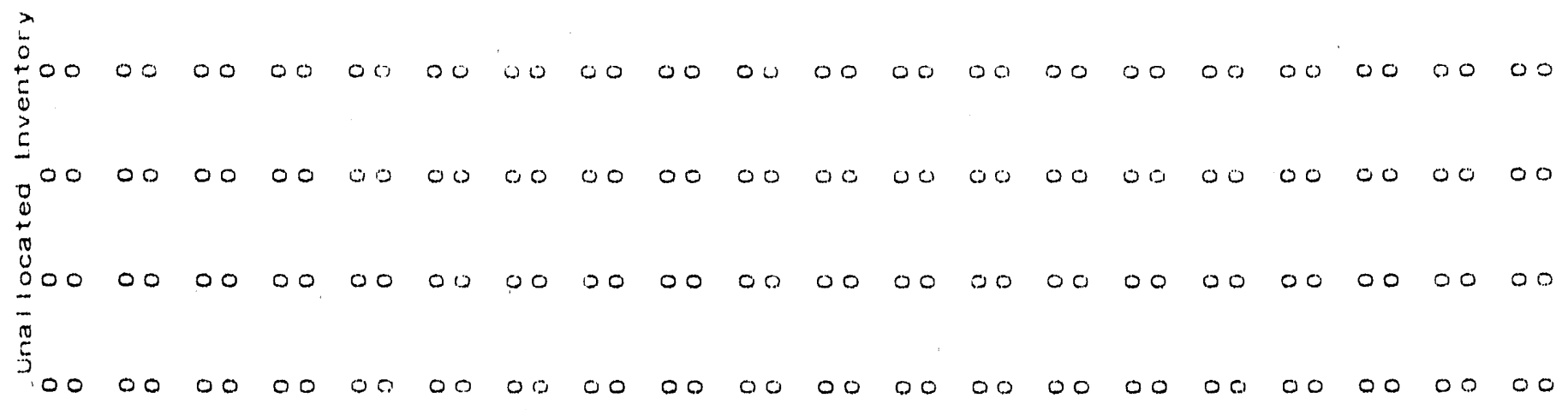

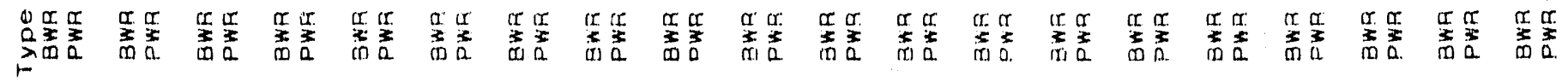

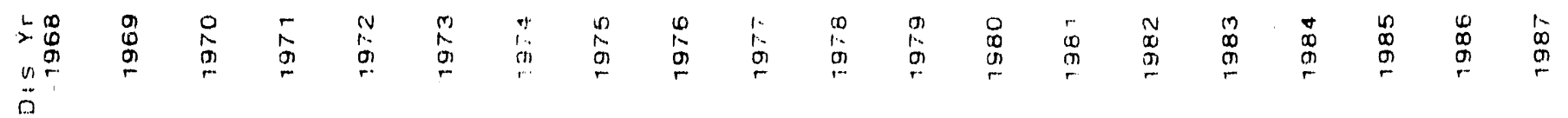




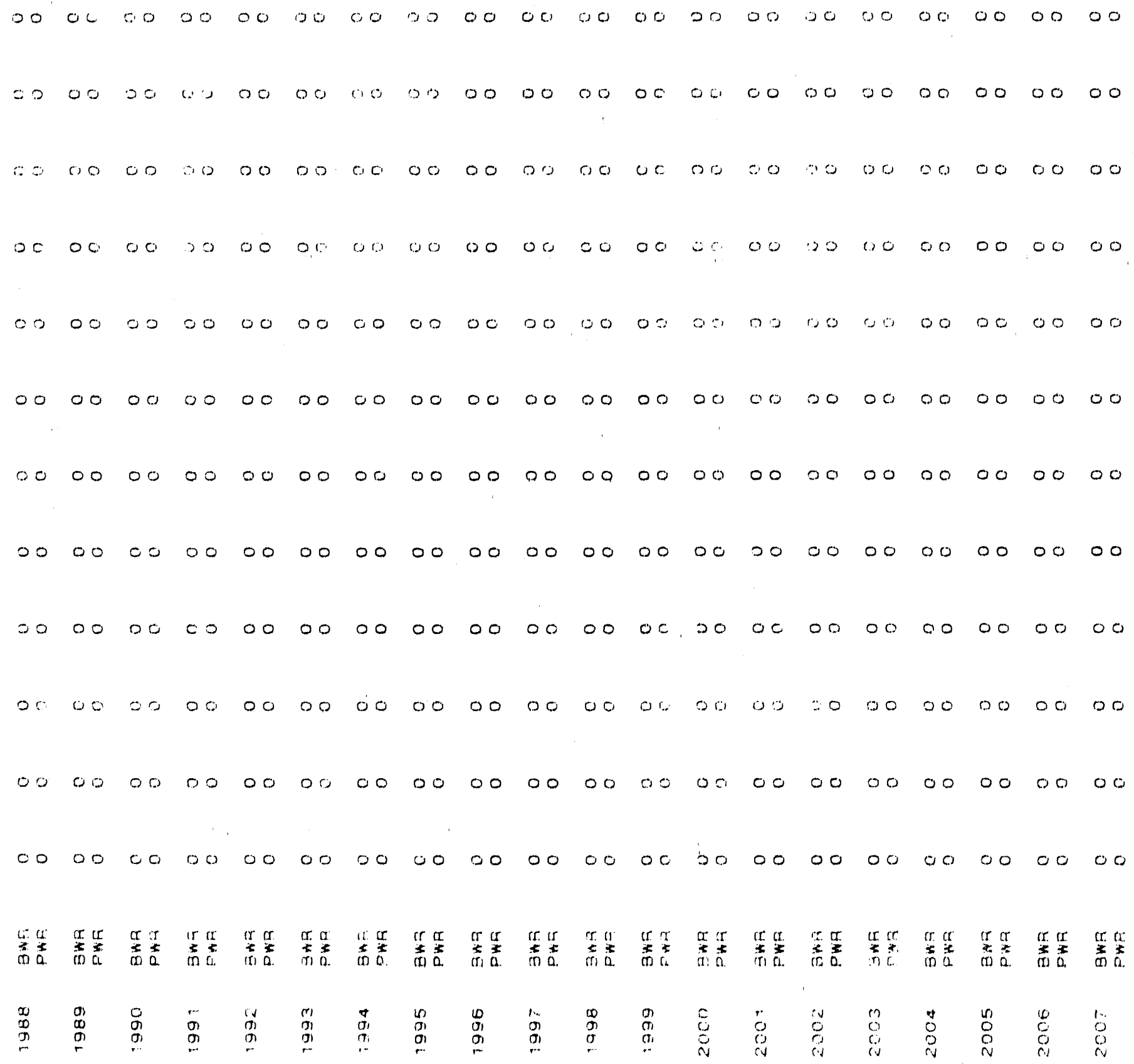




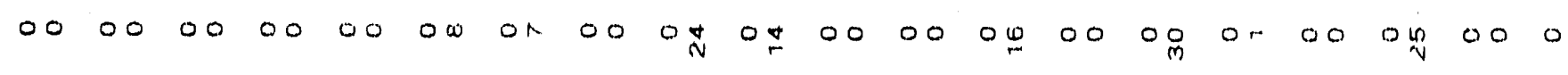

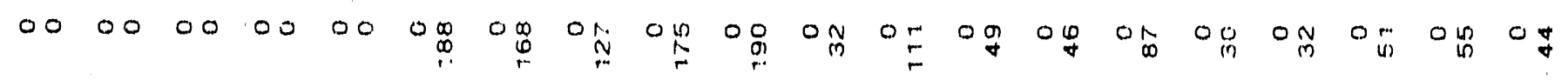

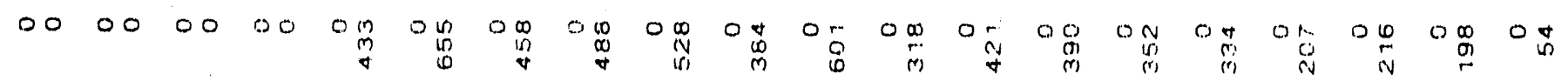

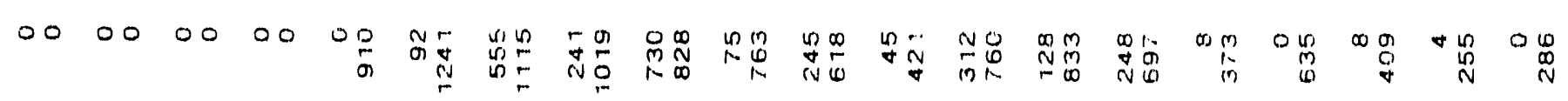

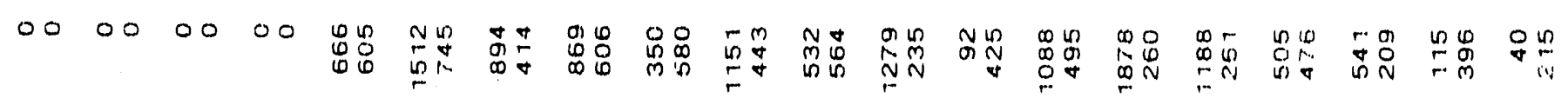

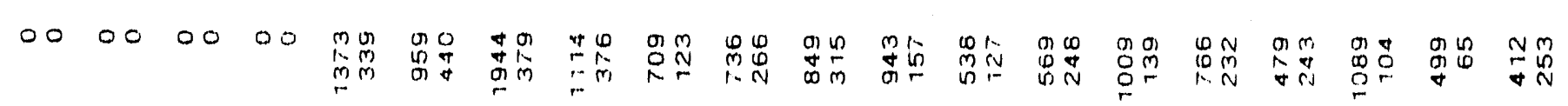

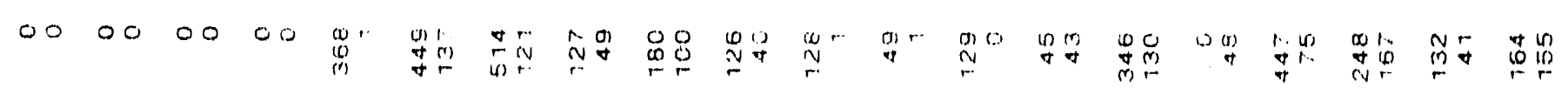

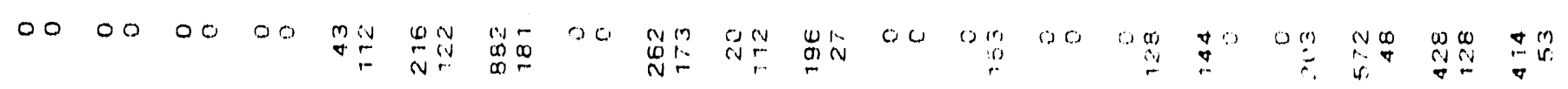

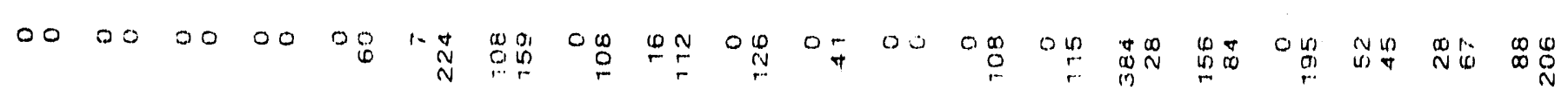

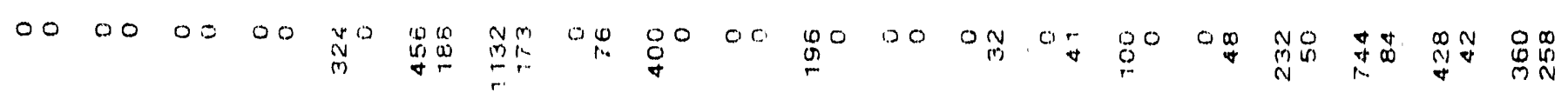

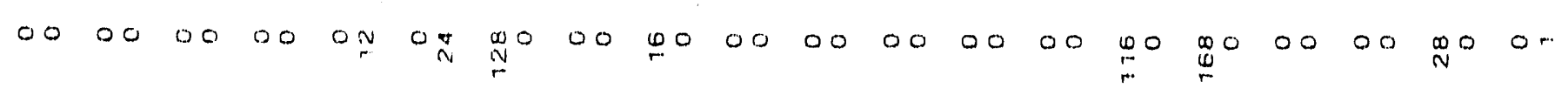

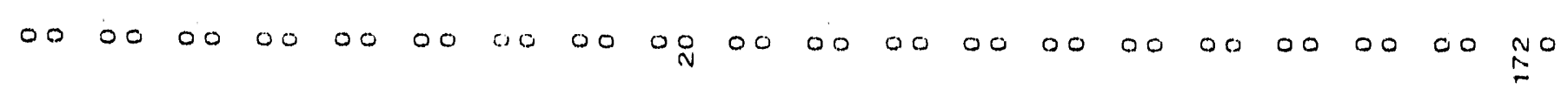

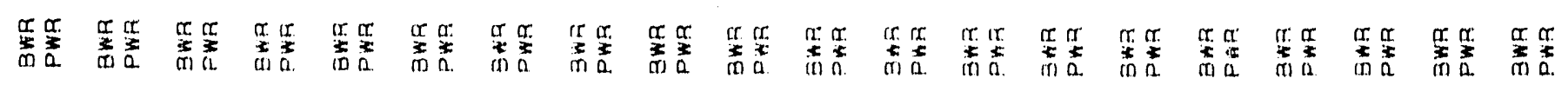

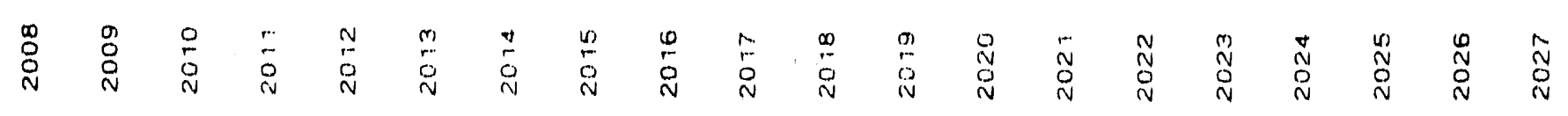


Appendix 1

levelized finergy Receipt Sichodeice

From

"HimGraded" Inventory 


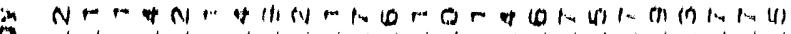

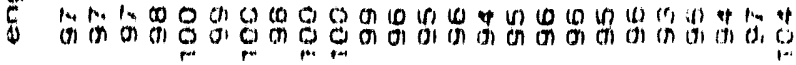

a 0 O

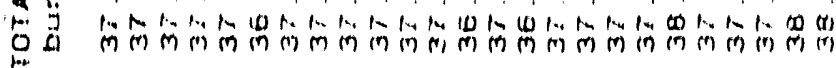

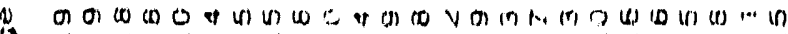
F.

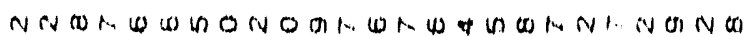

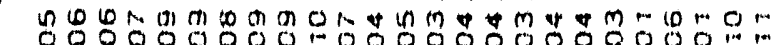

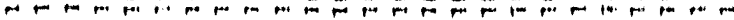

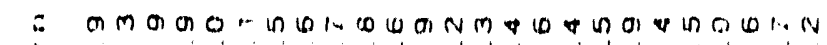
可 :

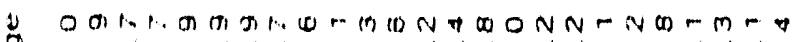

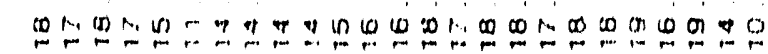

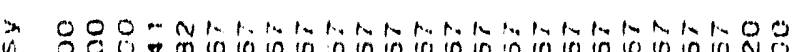
ज.

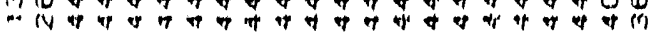

it

l.

(1)

it.

(r)

1.

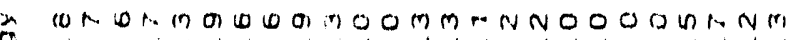

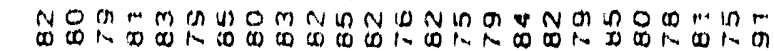

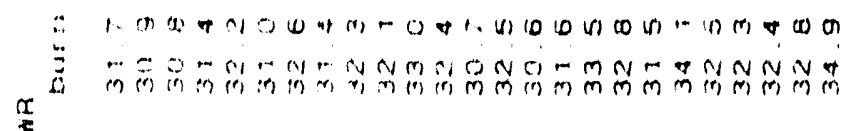
7

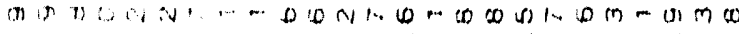

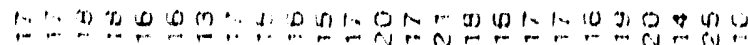

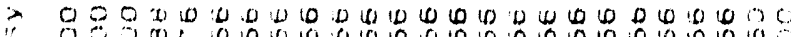
a

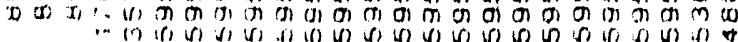

औ क

×

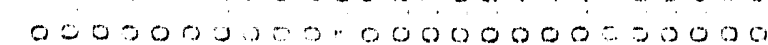

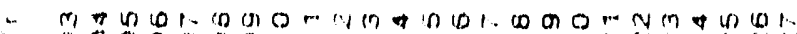

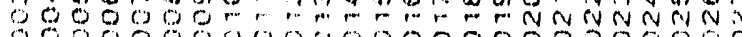
a

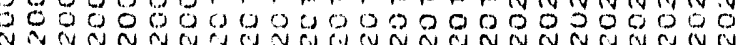



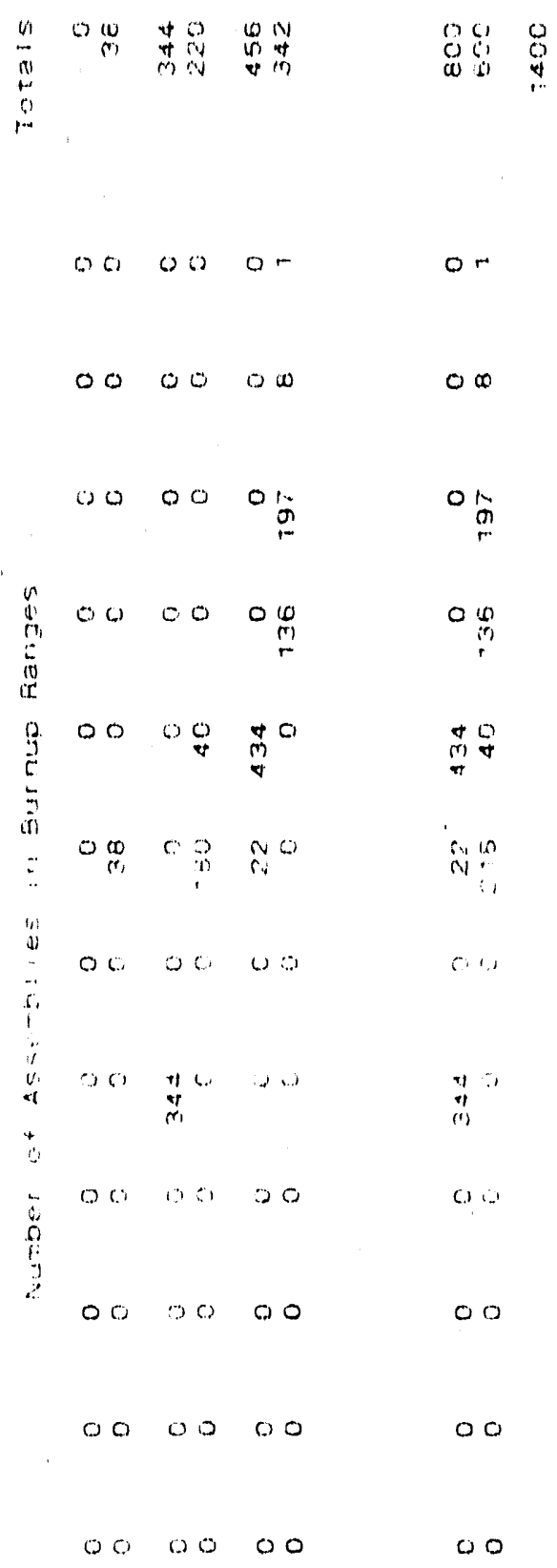

号

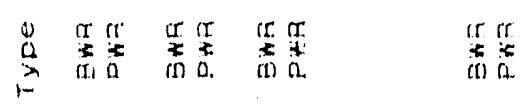

$\stackrel{4}{a} \stackrel{\infty}{d} \quad \stackrel{m}{a j}$

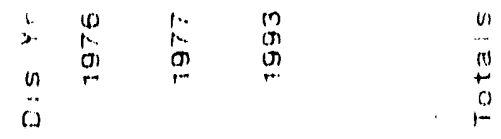




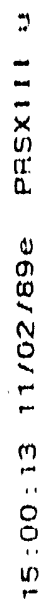

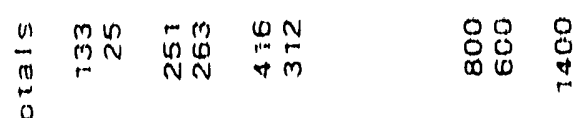

$000000 \quad 00$

$00000 \%$

00000 盟

i⿱

量 00 O

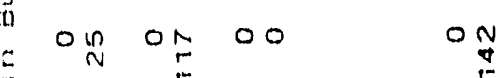

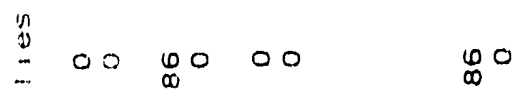

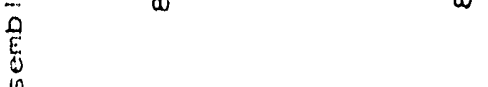

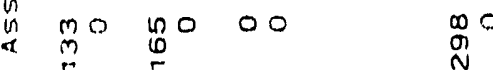

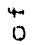

$-00000000$$$
\stackrel{0}{3}
$$

量

00000000

000000.00

00000000

$n$
$\stackrel{2}{0}$
0

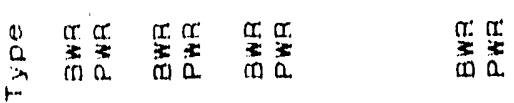

$\underset{\substack{1 \\ 0}}{\infty}$

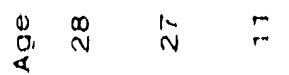

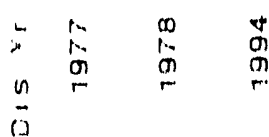

$\underset{n}{\frac{n}{n}}$ 


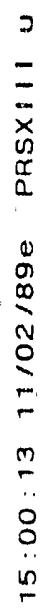

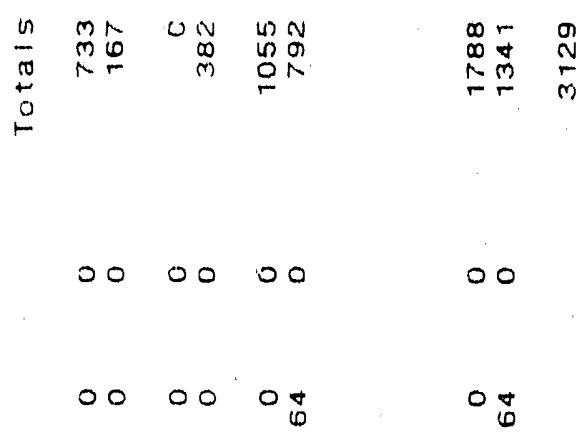

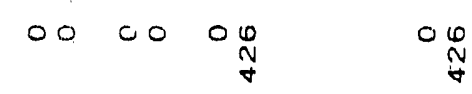

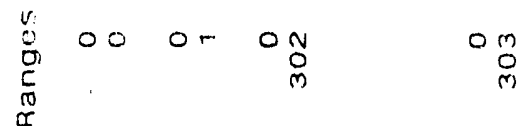

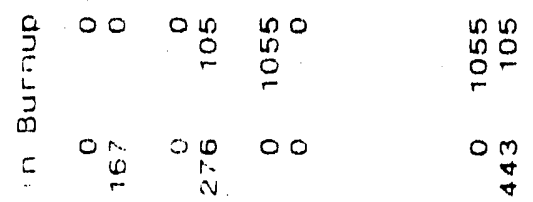

$\begin{array}{lllll}n & n & 00 & 00\end{array}$

$\overline{0}$
E
on
0

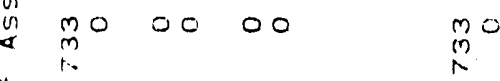

5

- 00000000

$\begin{array}{lllll}\frac{O}{E} & & & & \\ \sum & 00 & 00 & 0 & 0\end{array}$

00000000

00000000

$\stackrel{\bullet}{\circ}$

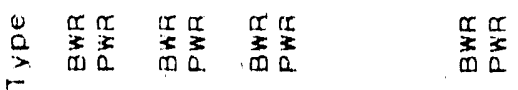

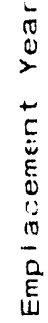

$\stackrel{\infty}{0} \stackrel{\infty}{\sim} \stackrel{N}{\infty}=$

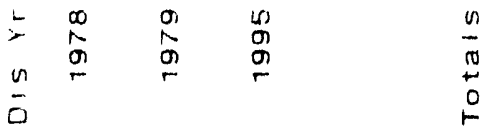



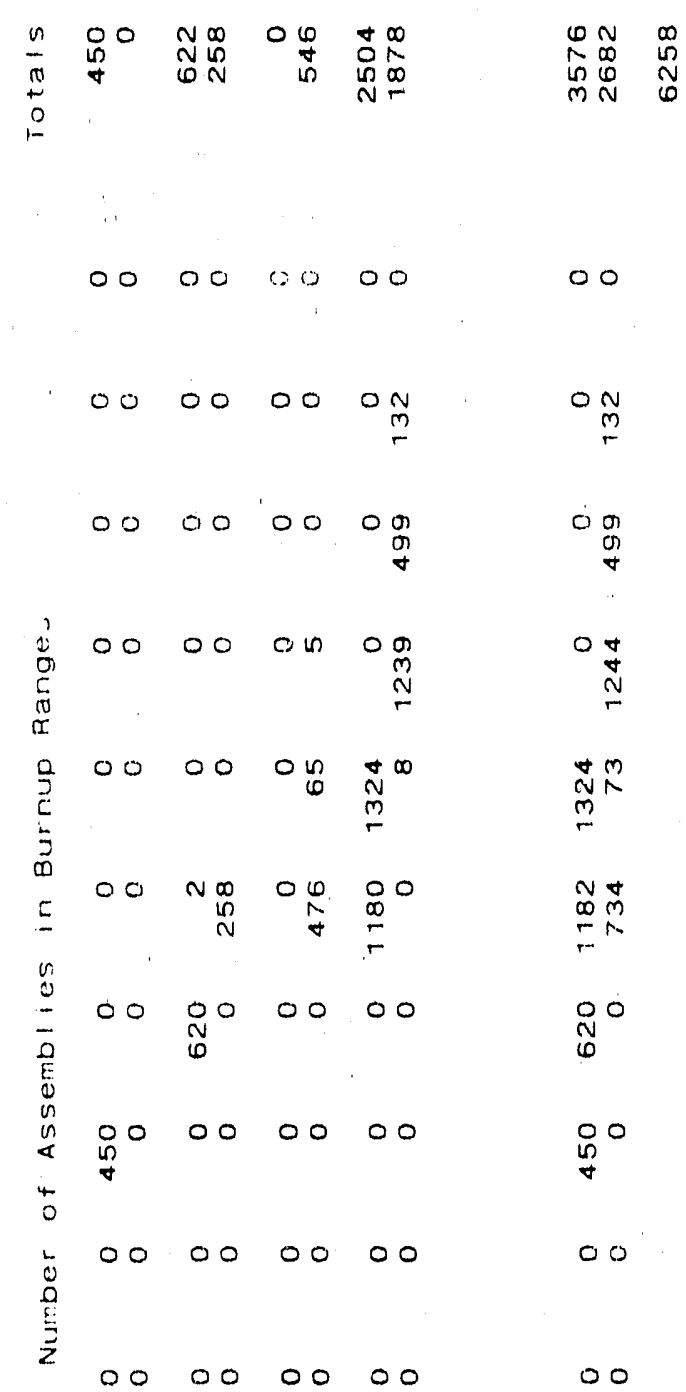

0000000000

$00000000 \quad 00$

$\hat{O}$
$\stackrel{N}{0}$

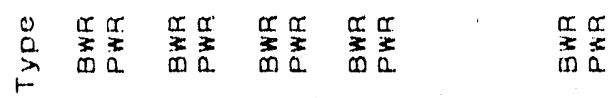

$\stackrel{\otimes}{\square} \stackrel{\infty}{\sim} \quad \stackrel{N}{N}$

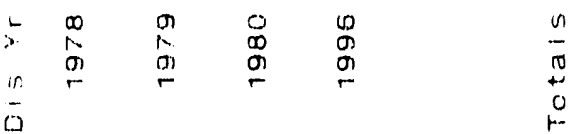


$\infty$
0
0
$i v$ 
0
0
0
0 


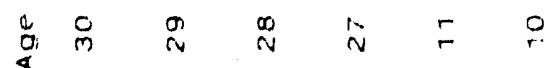

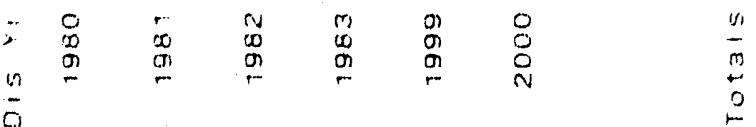




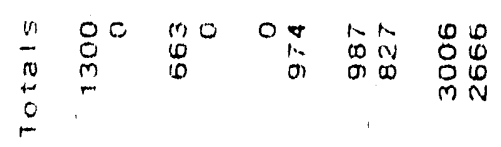

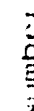

$\frac{N}{2}$$$
0000000 m 06
$$$$
0000000 \frac{m}{N}
$$$$
00.00000 \frac{N}{n}{ }_{\infty}^{-}
$$

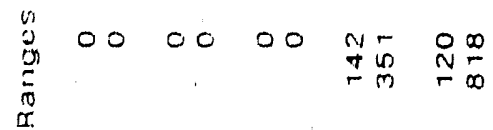$$
\frac{2}{3}
$$$$
5
$$$$
\stackrel{-}{a}
$$$$
\frac{1}{b} d
$$

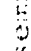$$
\text { a }
$$

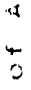$$
=0000000000
$$

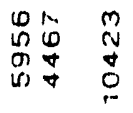

On:

om

ON

\begin{tabular}{ll}
$N$ & 9 \\
0 & 0 \\
$\sim$ & 0 \\
\hdashline
\end{tabular}

$N$
0
0
0
$\infty$

ô

on:

100

F

$\underset{\infty}{\infty} \infty$

00

00

00

00

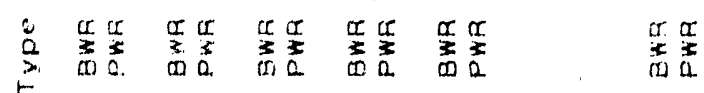

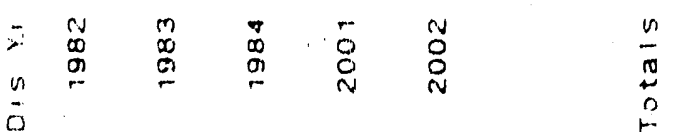




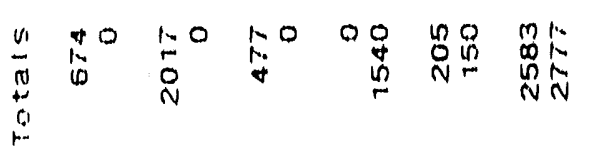$$
000000000100
$$$$
000000000 \% 00
$$$$
000000000 \frac{m}{0}
$$$$
\begin{aligned}
& n \\
& 0 \\
& 0 \\
& 0 \\
& 0 \\
& 0
\end{aligned}
$$$$
\frac{0}{3}
$$

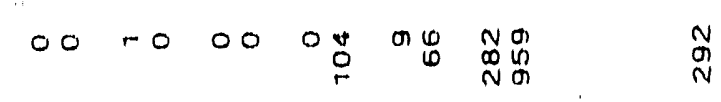$$
\text { 00 } 00 \text { O } 0 \text { O }
$$

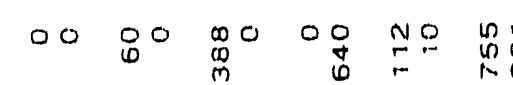$$
\text { DO } \mathbb{\infty}_{\infty} \operatorname{mol}_{\infty} 00 \text { NO }
$$

$$
\mathbb{L}_{0}^{+}
$$

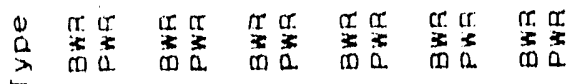

$\stackrel{0}{a} \stackrel{0}{m} \stackrel{\infty}{\sim} \stackrel{\infty}{N} \quad r$

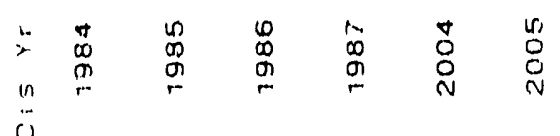

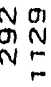

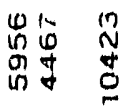

(2) 10

0

$\underset{m}{m}$

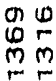

$\underset{m i n}{n}$

+0
an

$\underset{⿱}{0} 0$

00

00

00

芯乐

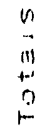


OO 00 OO ON ON ON

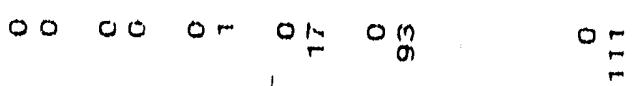

00 O0 On OO

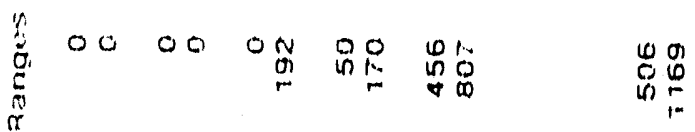

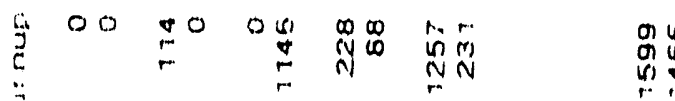

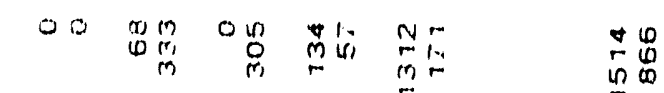

li $u$ mo oo

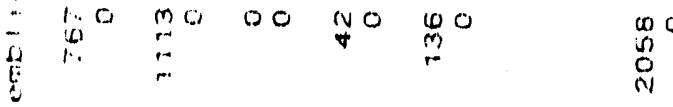

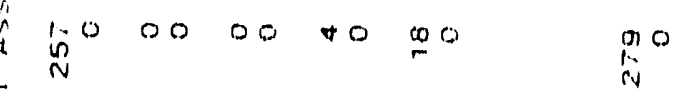

- 0000000000 00

空

000000000000

000000000000

000000000000

$\stackrel{\varphi}{\stackrel{0}{N}}$

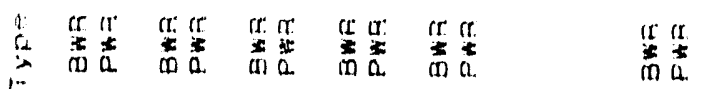

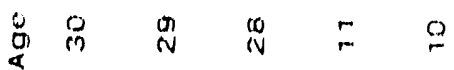

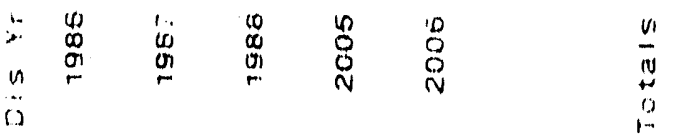




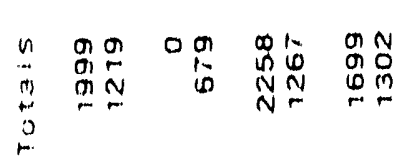

00000000

$00000 \% 00$

$00 \quad 000 \% 0 \begin{aligned} & 0 \\ & m\end{aligned}$

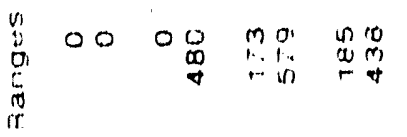

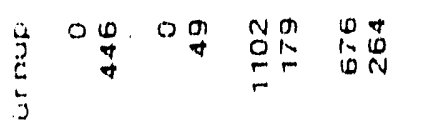

-

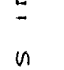

mo 00 go

要

n 0000 mo $\mathbb{0}_{0}^{\infty}$

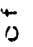

嫣

- 0000000

量

00000000

00000000

00000000

$n$
$i$
$i$
$i$

$\frac{1}{2}$

ن

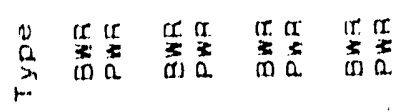

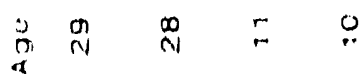

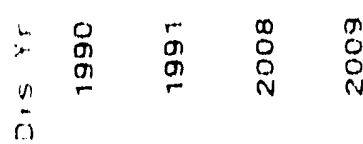

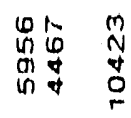

00

$0 \stackrel{N}{N}$

O

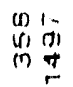

心

少学

wa
No
0
0

NO

r

$\Gamma_{\infty}^{\circ}$

00

00

00

$\frac{n}{n}$ 


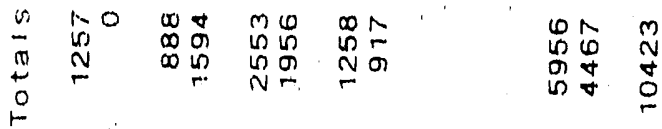

Do DO OR ON ON

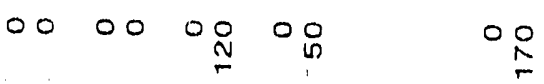

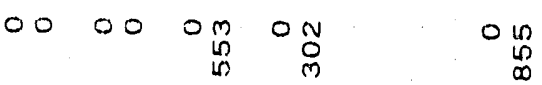

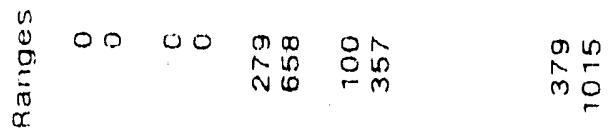

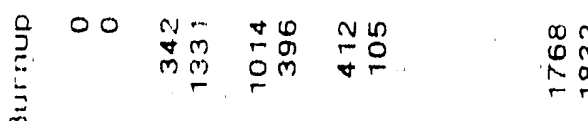

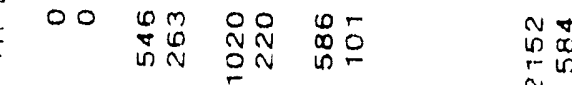

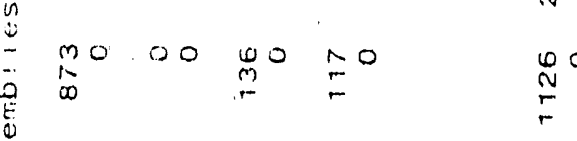

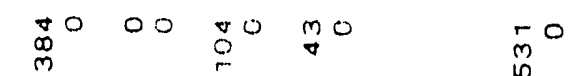

0

$00000000 \quad 00$

$00000000 \quad 00$

$00000000 \quad 00$

$00000000 \quad 00$

î

Dू

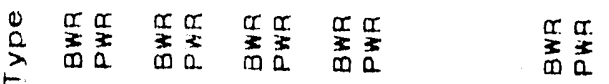

$\underset{i}{0} \stackrel{0}{i}=0$

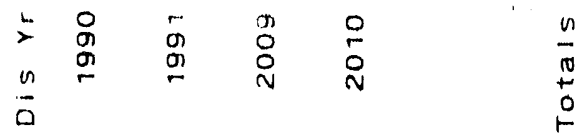




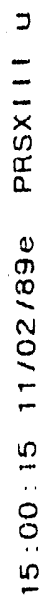

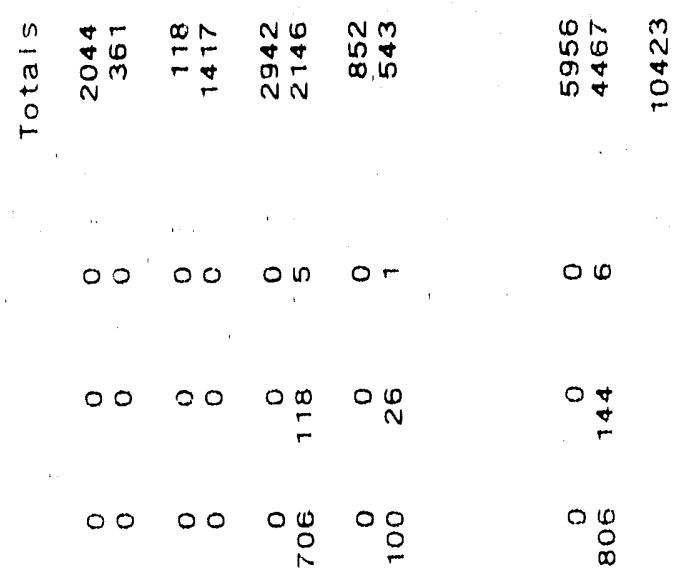

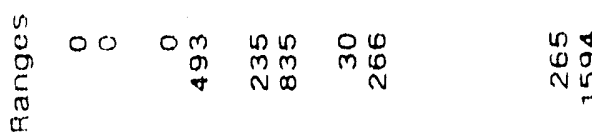

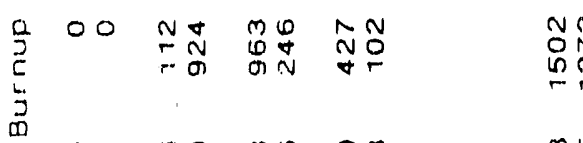

E

兽

i. 00 mo $^{\text {mo }} \mathbb{\infty}^{0}$

+0 r

500000000.00

है

$00000000 \quad 00$

$00000000 \quad 00$

$00000000 \quad 00$

$\stackrel{\bar{N}}{\stackrel{N}{N}}$

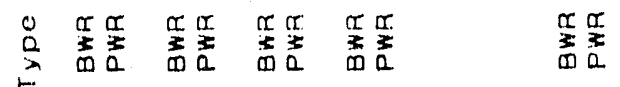

वृ $\stackrel{2}{\text { i }}=\stackrel{\square}{=}$

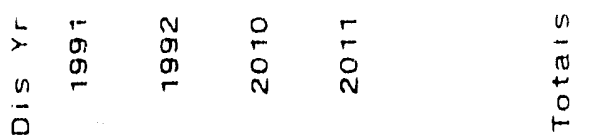




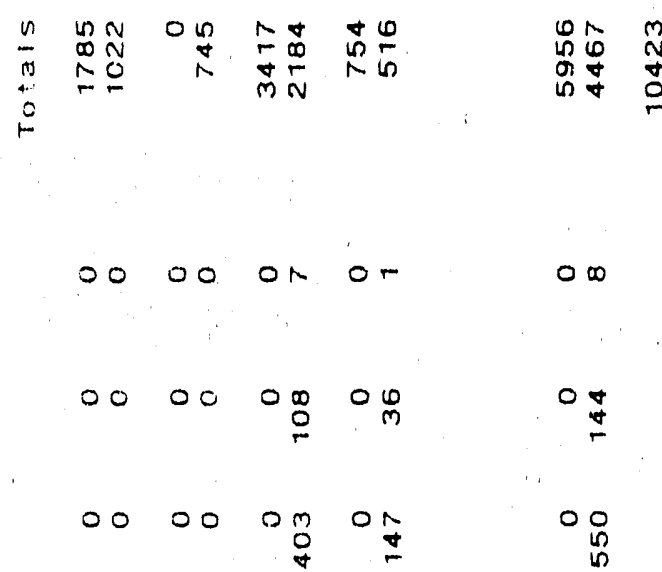

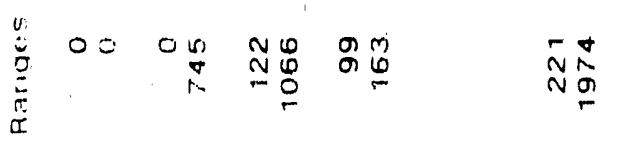

\begin{tabular}{|c|c|c|c|c|}
\hline O & 00 & 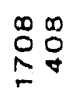 & $\begin{array}{l}n \\
\tilde{n}_{n}^{\infty}\end{array}$ & $\begin{array}{l}M \\
\dot{D} \\
\dot{N} \\
\stackrel{\infty}{\infty}\end{array}$ \\
\hline $\begin{array}{l}n \vec{R} \\
\stackrel{\sim}{N} 0\end{array}$ & 00 & 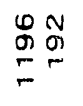 & 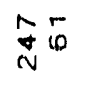 & $\begin{array}{l}\infty \\
\infty \\
\infty \\
m \\
m \\
m\end{array}$ \\
\hline o & 00 & $\begin{array}{l}\mathscr{D}^{\circ} \\
\stackrel{N}{N}\end{array}$ & $\mathscr{0}^{\circ}$ & $\begin{array}{l}\text { No } \\
\stackrel{+}{O}\end{array}$ \\
\hline 00 & 00 & Un & 1.0 & $\begin{array}{l}\text { No } \\
\stackrel{\circ}{ }\end{array}$ \\
\hline 00 & 00 & 00 & 00 & 00 \\
\hline & 00 & 00 & 00 & \\
\hline
\end{tabular}

$00 \mathrm{CJ0000} 00$

0000000000

$\stackrel{N}{N}$

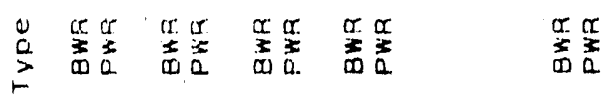

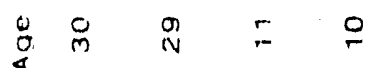

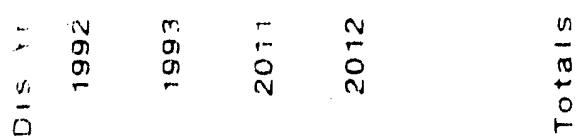




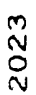

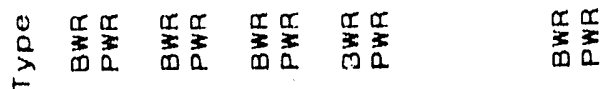

$\stackrel{0}{a} \stackrel{m}{m} \stackrel{0}{N}=$

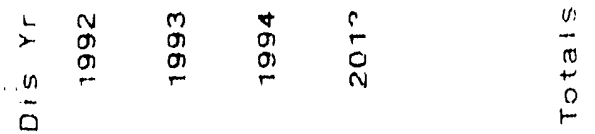


$J$
$=$
$\bar{x}$
0
0
0
0
0
0
0
0
0
$\vdots$
$\vdots$
0
0
0
0
0
0

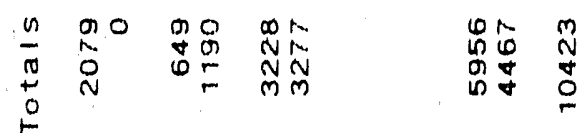

00000000

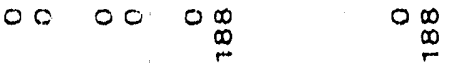

$00000 \prod_{0}^{10} \quad 0.00$

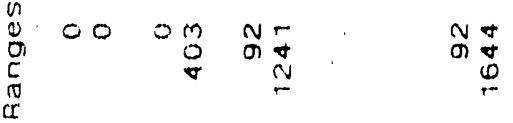

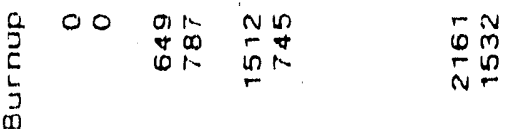

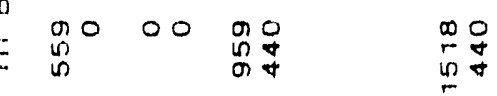

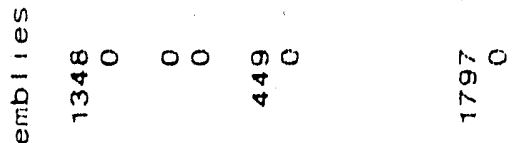

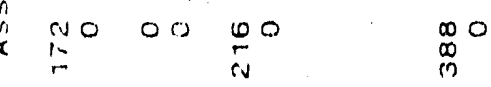

- 00000000

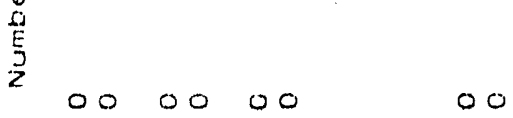

00000000

$000000, \quad 00$

$\dot{4}$
0
0

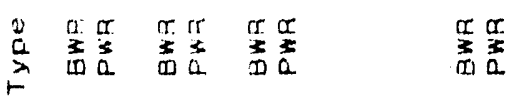

$\stackrel{2}{2} \stackrel{2}{m}:$

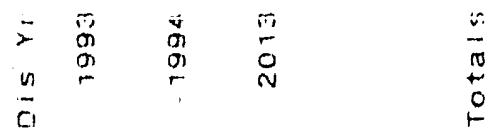




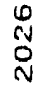


$\ddot{n} 0000000000000000000000000000000000000000$

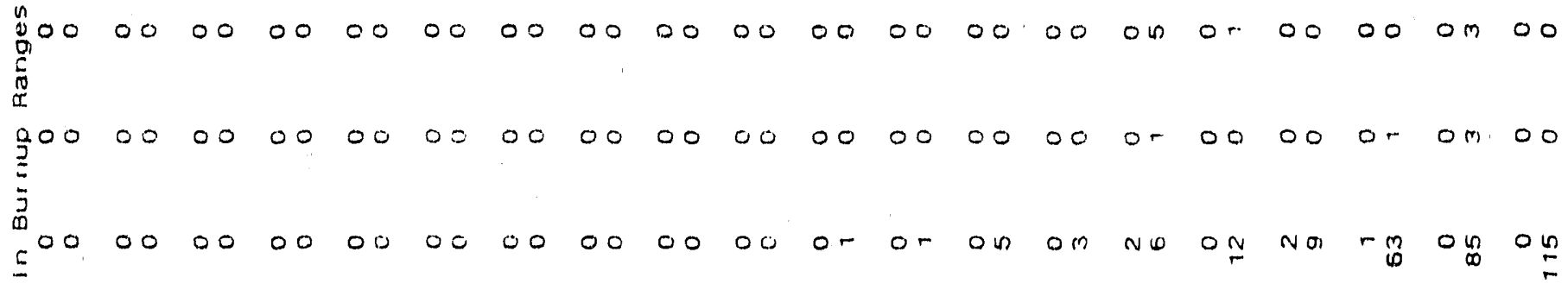

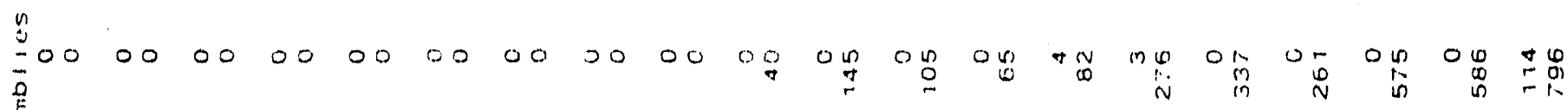

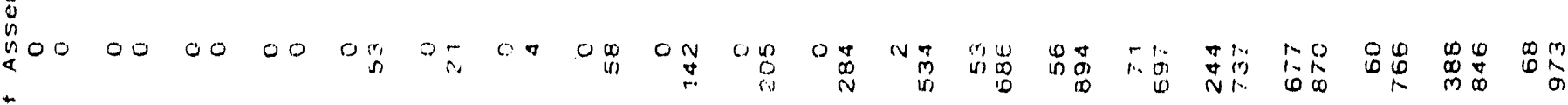

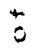

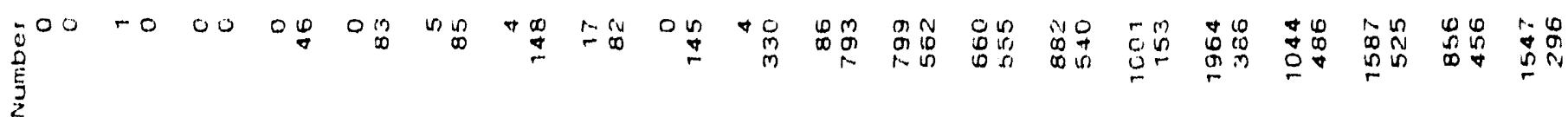

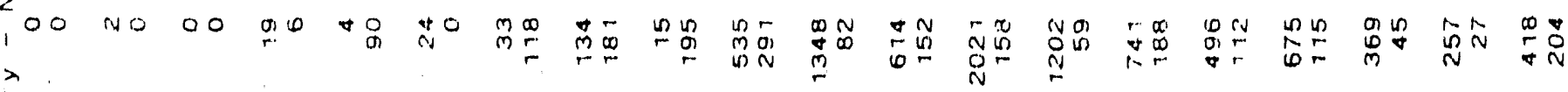

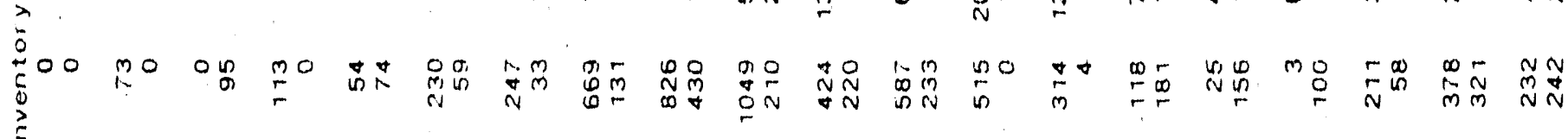
EO

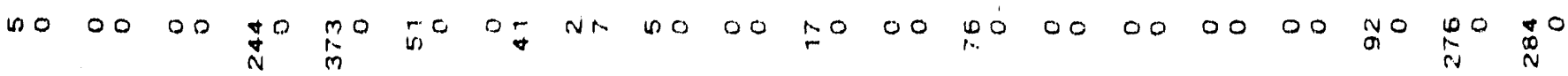

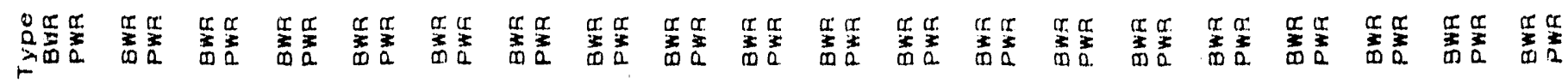

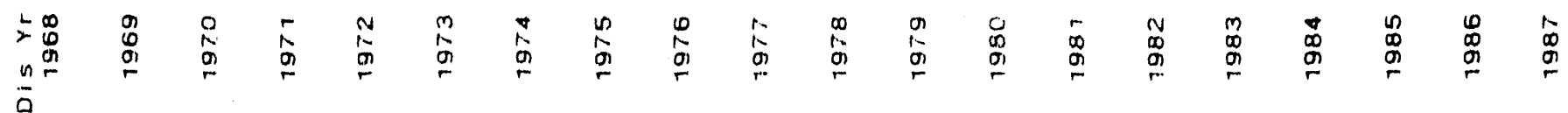




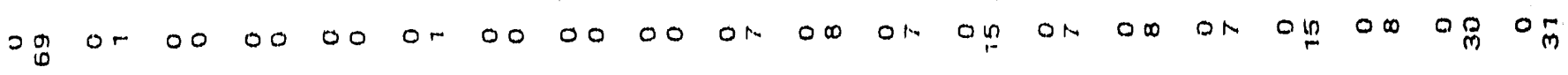

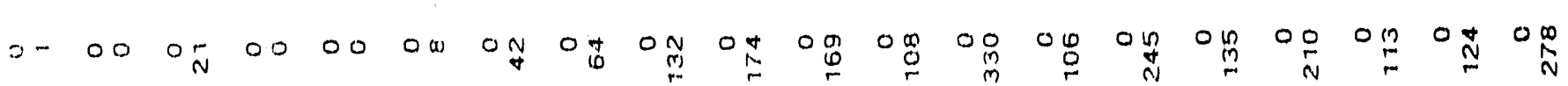

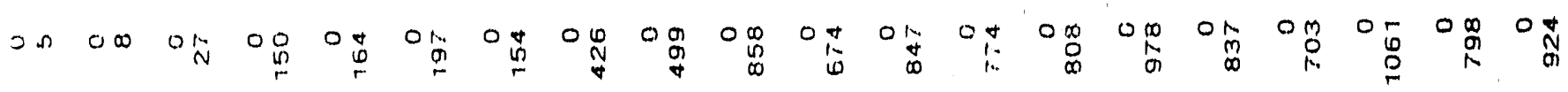

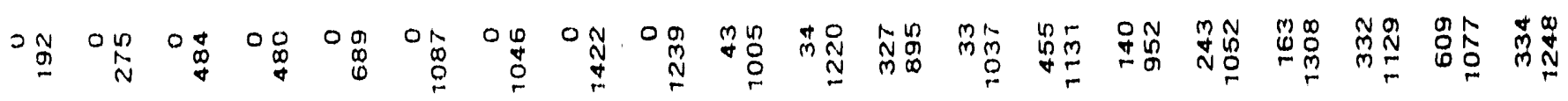
ว

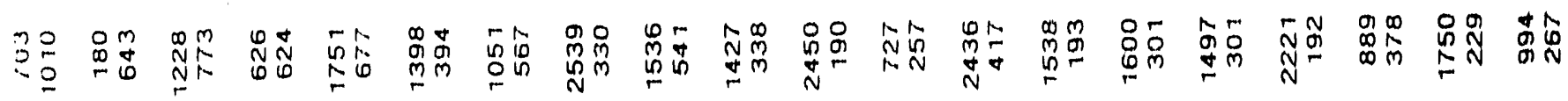

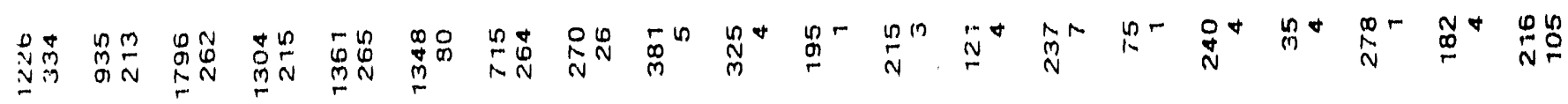
产公

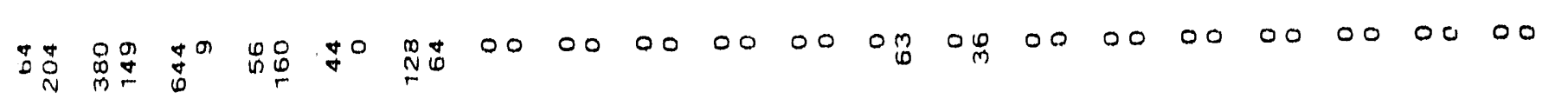

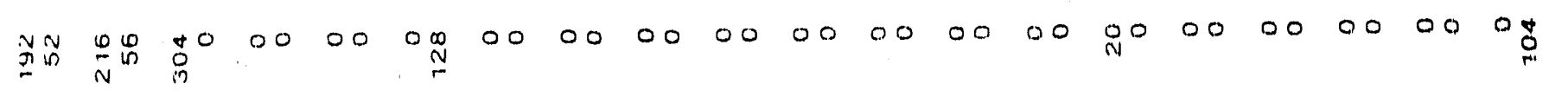
$00 \mathrm{~N}^{0} 000000000000000000000000900000000000$

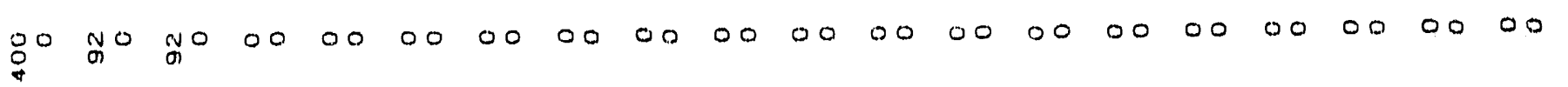

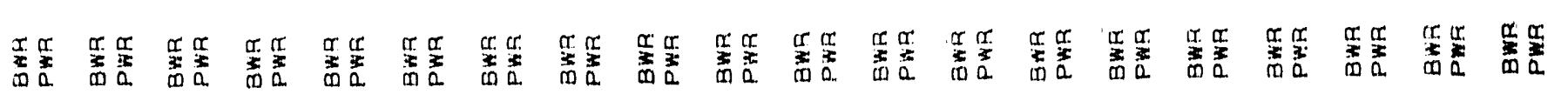

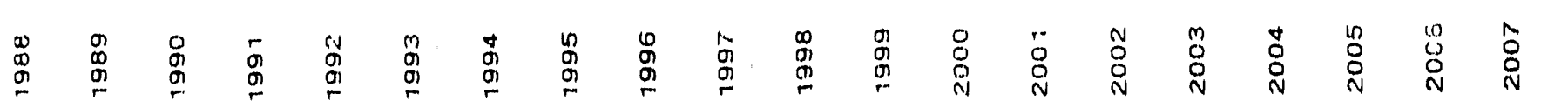




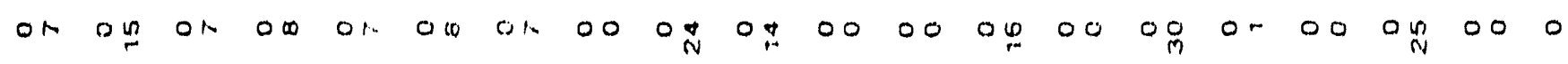

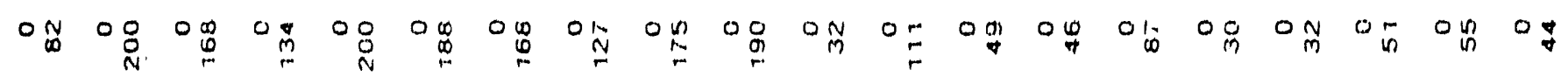

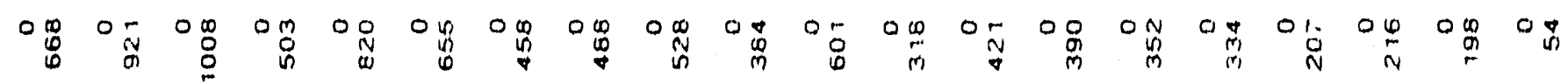
品点

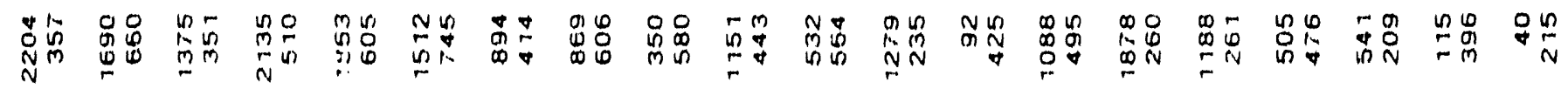

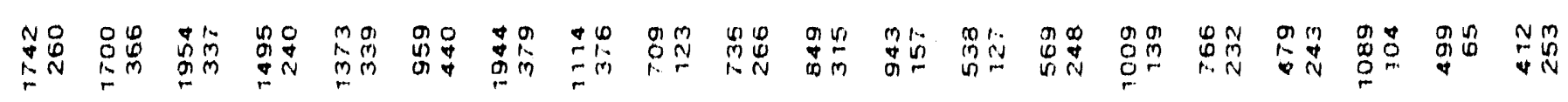

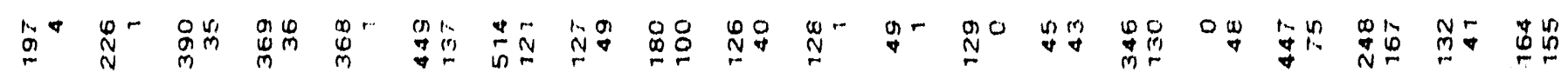

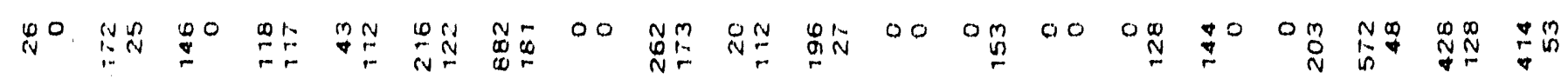

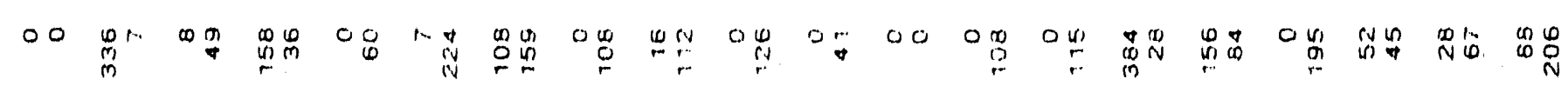

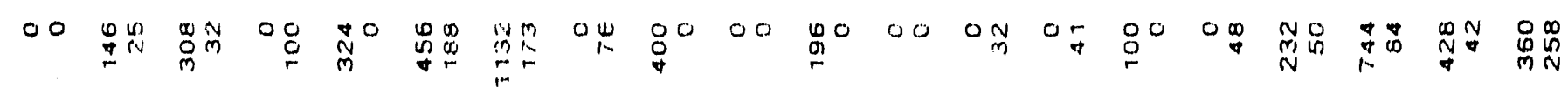

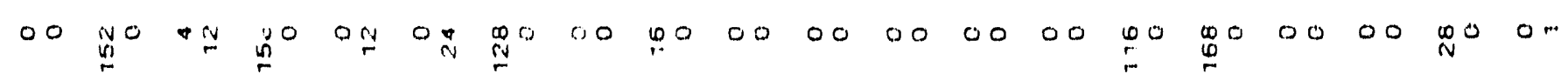
00000000000000000000000000000000000000 NO

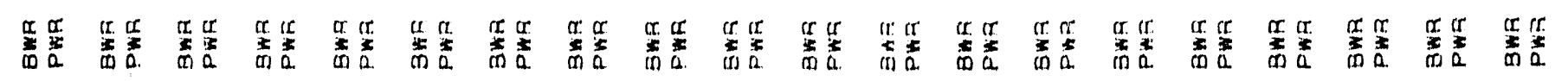

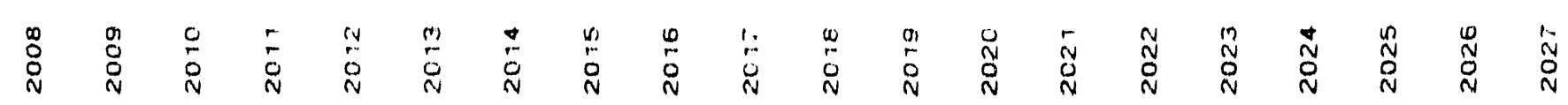


in 0000000000000000000000000000000000000000 $\mathscr{H}_{0} 00000000000000,00000000000000000000000000$ 0000000000000000000000000000000000000000 c0000000000000000000000000000000000000000 20000000000000000000000000000000000000000 D

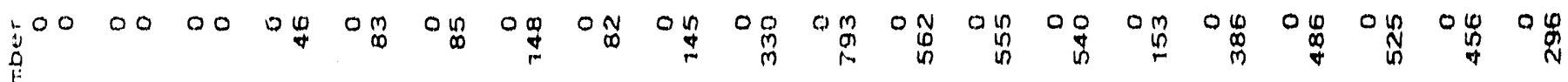
10000 00 00 00 00 0

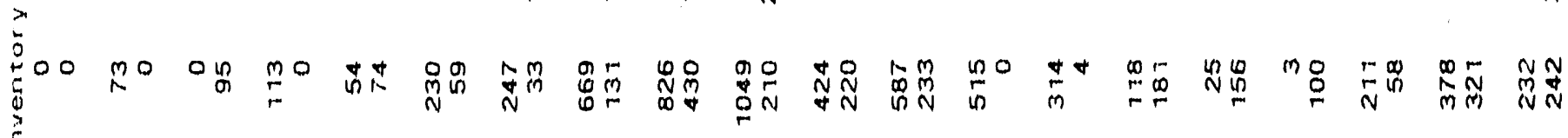

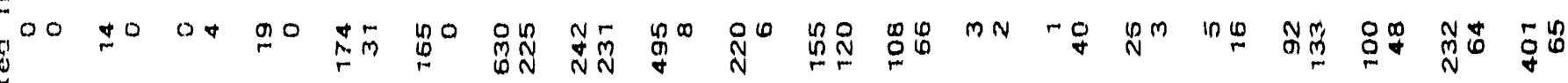

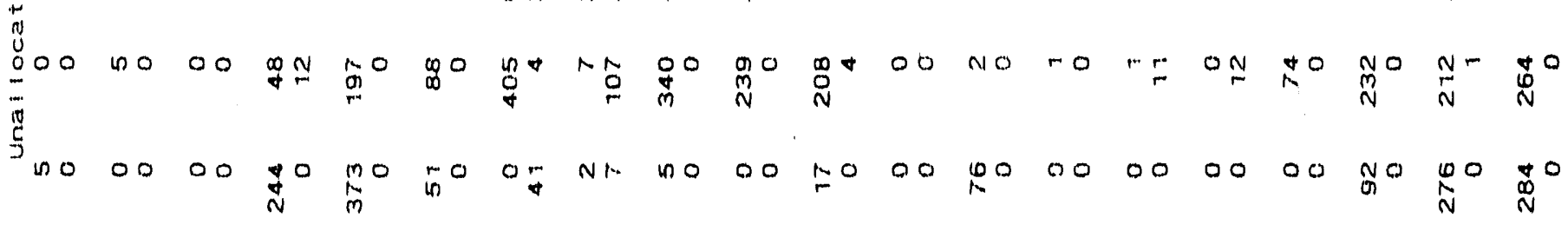

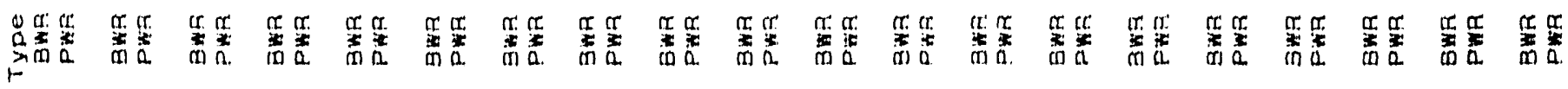

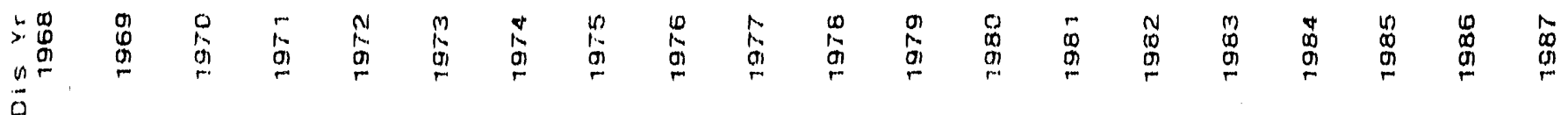


0000000000000000000000000000000000000000 0000000000000000000000000000000000000000 00000000000000000000000000000000000000000 0000000000000000000000000000000000000000 0000000000000000000000000000000000000000 0000000000000000000000000000000000000000

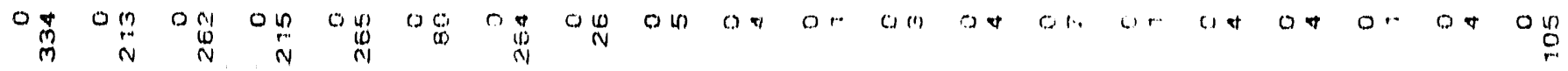
0 a 0 \% 范

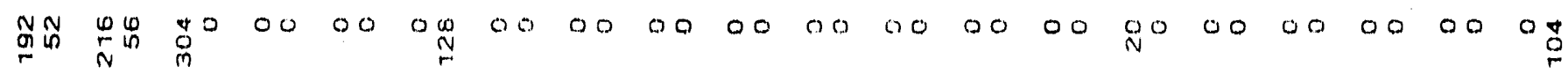

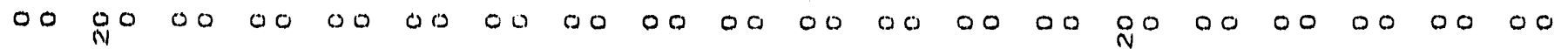

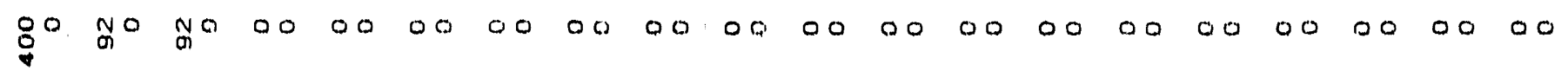

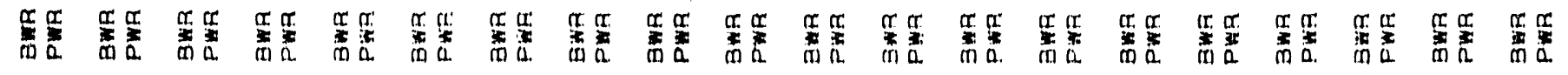

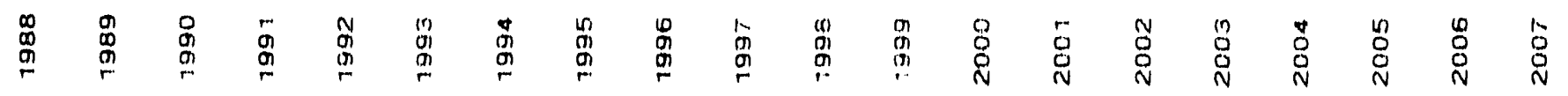




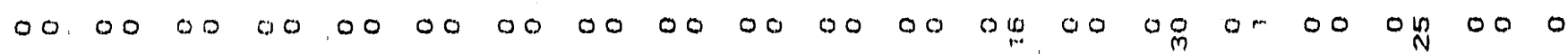

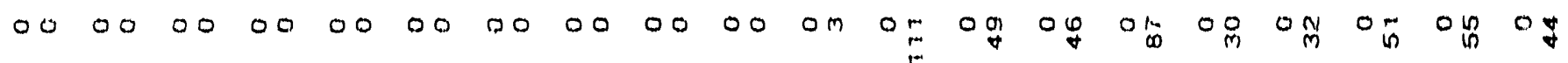

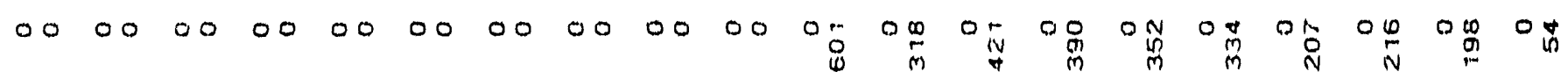

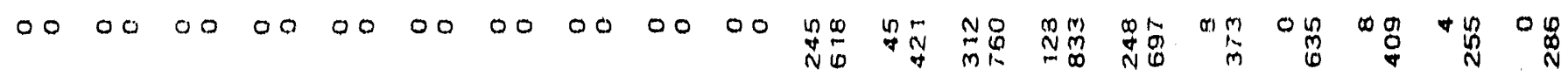

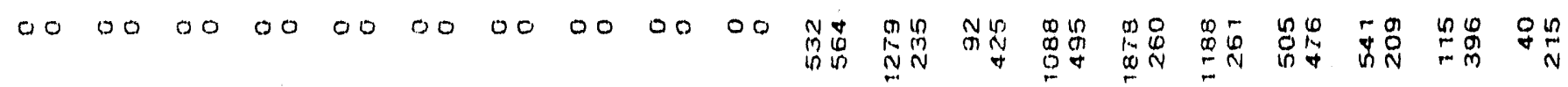

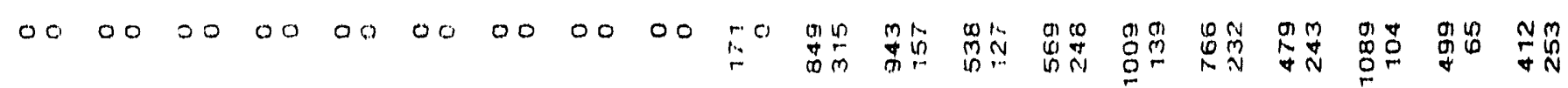

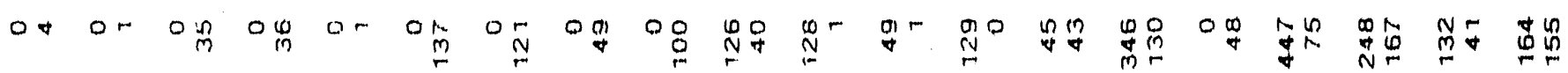
OO ON N 00 ON ON $\underset{\sim}{N} \underset{\sim}{N}$ O

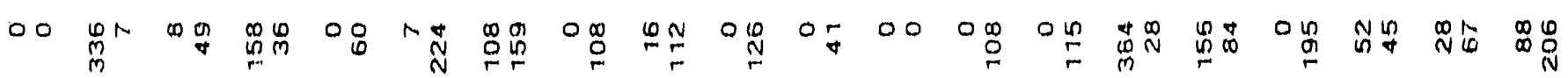

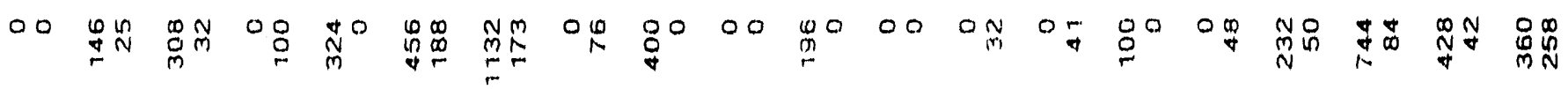

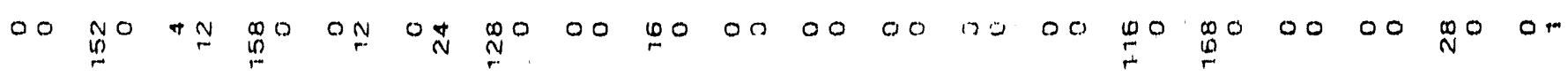

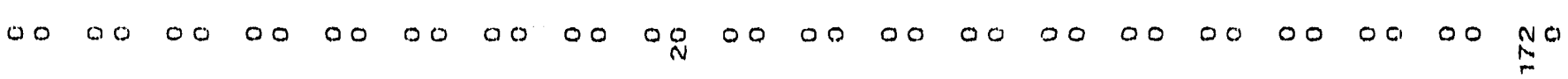

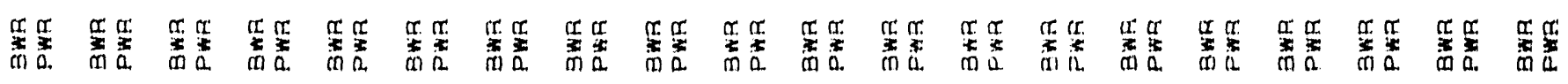

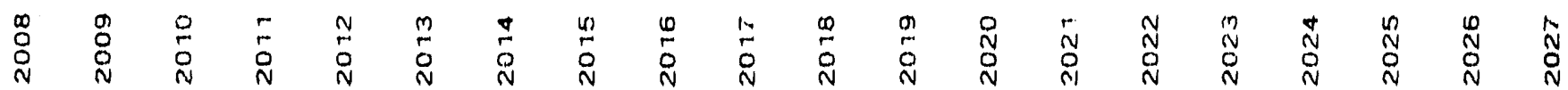


APPENDIX G

Reference Information and Technical Data Base Summary

Values for the conductivity, density and heat capacity of Topopah Spring welded tuff, as discussed in Section 1.2.3, were taken from the YMP Reference Information Base, Version 3.001. This report contains neither candidate information for the YMP Reference Information Base nor candidate data for the YMP Site and Engineering Properties Data Base. 

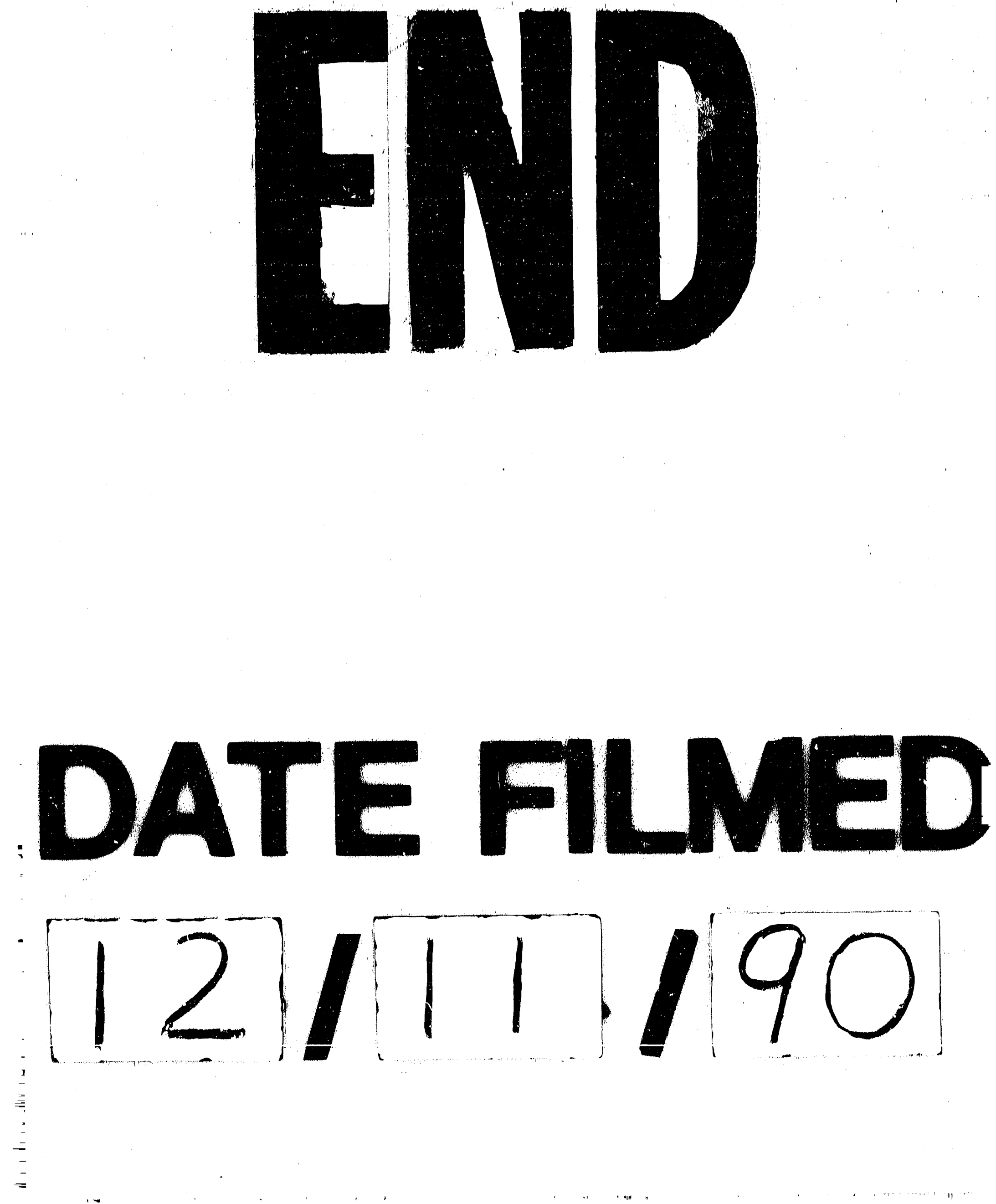
